\title{
IntechOpen
}

\section{Power Quality Issues in Distributed Generation}

Edited by Jaroslaw Luszcz
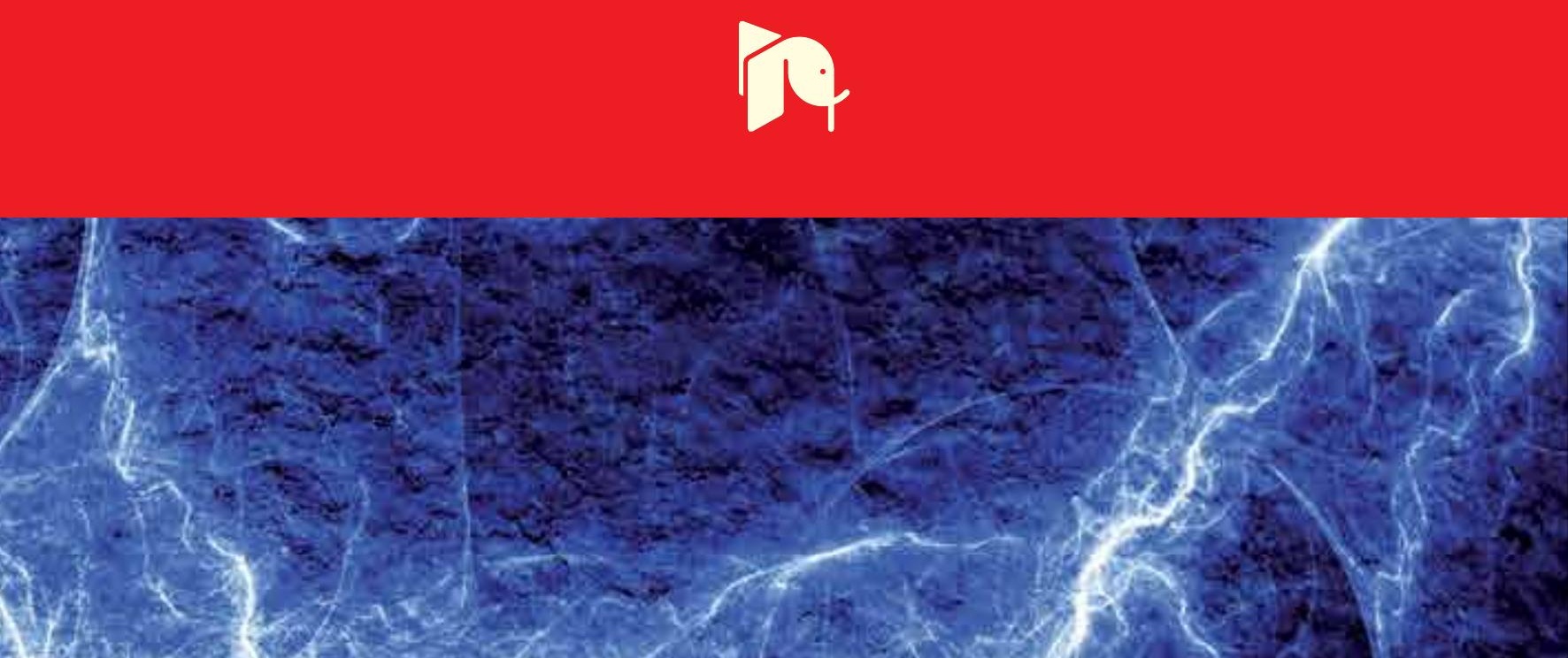



\section{POWER QUALITY ISSUES \\ IN DISTRIBUTED GENERATION}

Edited by Jaroslaw Luszcz 


\section{Power Quality Issues in Distributed Generation}

http://dx.doi.org/10.5772/59895

Edited by Jaroslaw Luszcz

\section{Contributors}

Jacek Rezmer, Tomasz Sikorski, Ricardo de Andrade Lira Rabêlo, Vigna Ramachandaramurthy, Rodney H.G. Tan, Fabio Leccese, Chang-Ming Liaw

\section{(c) The Editor(s) and the Author(s) 2015}

The moral rights of the and the author(s) have been asserted.

All rights to the book as a whole are reserved by INTECH. The book as a whole (compilation) cannot be reproduced, distributed or used for commercial or non-commercial purposes without INTECH's written permission.

Enquiries concerning the use of the book should be directed to INTECH rights and permissions department (permissions@intechopen.com).

Violations are liable to prosecution under the governing Copyright Law.

\section{(cc) BY}

Individual chapters of this publication are distributed under the terms of the Creative Commons Attribution 3.0 Unported License which permits commercial use, distribution and reproduction of the individual chapters, provided the original author(s) and source publication are appropriately acknowledged. If so indicated, certain images may not be included under the Creative Commons license. In such cases users will need to obtain permission from the license holder to reproduce the material. More details and guidelines concerning content reuse and adaptation can be foundat http://www.intechopen.com/copyright-policy.html.

\section{Notice}

Statements and opinions expressed in the chapters are these of the individual contributors and not necessarily those of the editors or publisher. No responsibility is accepted for the accuracy of information contained in the published chapters. The publisher assumes no responsibility for any damage or injury to persons or property arising out of the use of any materials, instructions, methods or ideas contained in the book.

First published in Croatia, 2015 by INTECH d.o.o.

eBook (PDF) Published by IN TECH d.o.o.

Place and year of publication of eBook (PDF): Rijeka, 2019.

IntechOpen is the global imprint of IN TECH d.o.o.

Printed in Croatia

Legal deposit, Croatia: National and University Library in Zagreb

Additional hard and PDF copies can be obtained from orders@intechopen.com

Power Quality Issues in Distributed Generation

Edited by Jaroslaw Luszcz

p. cm.

ISBN 978-953-51-2187-9

eBook (PDF) ISBN 978-953-51-6392-3 


\section{We are IntechOpen, the first native scientific \\ publisher of Open Access books}

$3,350+$

Open access books available

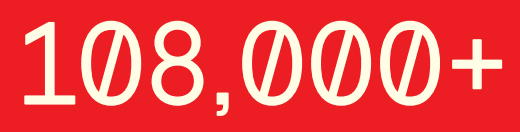

International authors and editors

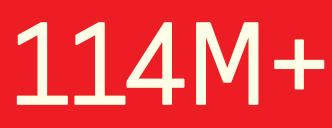

Downloads

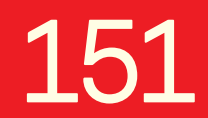

Countries delivered to

Our authors are among the

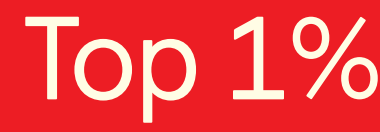

most cited scientists

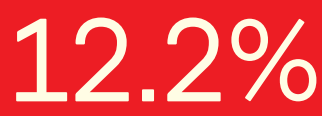

Contributors from top 500 universities

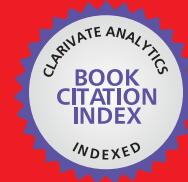

WEB OF SCIENCE ${ }^{\text {TM }}$

Selection of our books indexed in the Book Citation Index in Web of Science ${ }^{\mathrm{TM}}$ Core Collection (BKCI)

Interested in publishing with us?

Contact book.department@intechopen.com

Numbers displayed above are based on latest data collected.

For more information visit www.intechopen.com 



\section{Meet the editor}

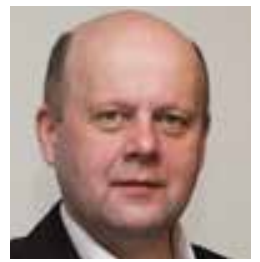

Jaroslaw Luszcz received his M.Sc. and Ph.D. degrees from Gdansk University of Technology in Poland. Currently, he is at the Electrical and Control Engineering Faculty, Gdansk University of Technology. During fifteen years of professional experience in the area of power quality and electromagnetic compatibility, he has been involved in and led a number of grant-funded fundamental research projects and actively cooperated with power electronics industry as an EMC consultant for R\&D projects. Mr. Luszcz has published over 50 scientific papers at international conferences and in journals, as well as three book chapters. His current research activities focus on EMC and power quality issues related to the integration of high power static converters with the power grid. Mr. Luszcz is a member of the IEEE EMC Society and Technical Committee 7 - Low Frequency EMC. 



\section{Contents}

Preface XI

Chapter 1 Distributed Generation and Its Impact on Power Quality in Low-Voltage Distribution Networks 1

Tomasz Sikorski and Jacek Rezmer

Chapter 2 Applications of Switch-Mode Rectifiers on Micro-grid Incorporating with EV and BESS 41

K. W. Hu and C. M. Liaw

Chapter 3 A Comprehensive Modeling and Simulation of Power Quality Disturbances Using MATLAB/SIMULINK 83

Rodney H.G. Tan and Vigna K. Ramachandaramurthy

Chapter 4 An Application of Simple and Compact Genetic Algorithms for Estimating Harmonic Components 109

Andre L. S. Pessoa, Pedro H. C. Ulisses, Hermes M. G. C. Branco and Ricardo de Andrade Lira Rabêlo

Chapter 5 A Distributed Web-Based System for Temporal and Spatial Power Quality Analysis 127

Stefano Di Pasquale, Sabino Giarnetti, Fabio Leccese, Daniele

Trinca, Marco Cagnetti and Maurizio Caciotta 



\section{Preface}

Distributed generation of electrical energy harvested from renewable sources is expected to continue to grow in the coming years. On the other hand, in recent decades the quality of delivery of electric power has become one of the important measures of effectiveness of electric power system. Therefore, significant improvements in the security, reliability, efficiency of electric power delivery systems and in limitations of electromagnetic disturbances are needed.

Those changes require multiple developments and upgrading the existing electromechanically controlled system to an electronically controlled grid by implementation of many power electronic converters. Electric power conversion methods that use switch-mode technology are already widely used and known as very efficient. However, it is also known that they are very polluting in terms of electromagnetic emission. These unique features of power electronic converters are closely related to power quality improvement as well as its degradation.

This book deals with several selected aspects of electric power quality issues typically faced during grid integration processes of contemporary renewable energy sources. In subsequent chapters of this book the reader will be familiarized with the issues related to voltage and current harmonics and inter-harmonics generation and elimination, harmonic emission of switch-mode rectifiers, reactive power flow control in power system with non-linear loads, modeling and simulation of power quality issues in power grid, advanced algorithms used for estimating harmonic components, and new methods of measurement and analysis of real time accessible power quality related data.

Jaroslaw Luszcz

Gdansk University of Technology

Poland 



\title{
Distributed Generation and Its Impact on Power Quality in Low-Voltage Distribution Networks
}

\author{
Tomasz Sikorski and Jacek Rezmer \\ Additional information is available at the end of the chapter
}

http://dx.doi.org/10.5772/61172

\begin{abstract}
This chapter is dedicated to review and investigate present approaches to power quality assessment in low-voltage (LV) networks with distributed generation (DG). Two complementary approaches are considered: firstly, origin of the emission limits requirement for the DG is searched in general electromagnetic compatibility (EMC) conditions used for the equipment and adopted to DG; secondly, rules and regulation of integration with a power system network is used in order to estimate the possible influence of DG on power quality in point of common coupling (PCC). An example of the regulation is control of reactive power consumption in function of active power generation known as $\cos \varphi(\mathrm{P})$ characteristic. This chapter constitutes the attitude that complementary approach brings improvement to the decision about the possible impact of DG in a power system network. It was shown that a combined approach allows to define a proposition of the limits of particular power quality parameters associated with the investigated node of LV network characterized by apparent short circuit power in the PCC $\left(S_{\mathrm{kPCC}}\right)$. This combination brings desirable effect of criterion, making for integration of DG with LV networks. Mentioned attitude was investigated using a real case study of a photovoltaic (PV) system consisting of three independent one-phase subsystems. Estimated influence of the investigated PV on power quality parameters in the PCC was verified using real measurement. The measurement procedure allows to verify the real influence of the investigate DG on power quality in the PCC, however, the task in not easy due to problems of separation of the searched influence from the measurement background. One of the proposed approach is to affiliate changes of investigated power quality parameters with activities of the investigated DG, e.g., energy production. As it was presented in the case of influence of the investigated PV static voltage changes or total harmonic distortion in current in the PCC, a correlation index can be also implemented in order to classify the force of the common influence.
\end{abstract}

Keywords: Power quality, distributed generation, distribution network, connection criteria 


\section{Introduction}

Distributed generation (DG, dispersed generation, distributed resources or DR, embedded generation or EG) is currently one of the most actively-developed energy sector, mainly for the reason of environmental energy technologies and the idea of smart power grids. While this is not a new concept, there is still a lack of unified definition that explicitly allows the classification of DG $[1,11,13,14,16,22,42]$. The main issue is the acceptance criterion, which can be both the capacity of the installed power, the point of connection to the transmission or distribution system or subject to the disposal of the central power regulations, and finally the type of technology. One of the most frequently quoted definition is based on the report of the Working Group 37.23 CIGRE (Council on Large Electric Systems) [14], at present the committee SC C6, which suggests to treat as distributed generation all generation units independent from central regulation and to introduce a capacity of power limit of 50-100 MW. For comparison, the limit in the power of distributed generation in the United Kingdom is set at $100 \mathrm{MW}$, in the United States $50 \mathrm{MW}$, New Zealand $5 \mathrm{MW}$, and 1.5 MW in Sweden. Recent work on distributed generation CIGRE run by the Study Committee SC6 Distribution Systems \& Dispersed Generation proposed to minimize the definition of DG to a connection to the distribution network without central regulation. Additionally, some subdivisions of DG related to power capacity can be also found in the literature including: microgeneation $(1 \mathrm{~W} \div 5$ $\mathrm{kW})$, small generation ( $5 \mathrm{~kW} \div 5 \mathrm{MW})$, medium generation (5 MW $\div 50 \mathrm{MW})$, and large generation (50 MW $\div 150 \mathrm{MW})$.

Since the last quarter century a significant growth of DG, also recognized as dispersed generation or distributed energy resources (DER), was indicated in electrical power systems (EPS). The mentioned process is strongly supported by global convention of pollution reduction and promotion of environment-friendly technologies. The natural consequence is an increasing contribution of renewable energy sources (RES) and combined heat and power (CHP) systems. Additionally, special mechanisms concerning deregulations in energy markets and purchase tariffs were developed in many countries. In parallel to the mentioned convention, a progress in generation technologies is observed that indicates economic benefit in distributed generation investments.

Such convention has given rise to new challenging concepts for future power system architectures, giving a significant position to smart power grids (SPG). Here, ideas are revealed for using DG in islanding scenarios, fault-ride-through (FRT) concepts, voltage stability, and virtual power plants (VPP). DG is also inseparably linked with interoperability concepts, communication protocols, and control and regulation procedures. These mentioned concepts becomes significant when the scale of DG contribution is expanded and when location of the DG is related to parts of power systems characterized by a weak level of reliability. Such scenario can be especially used for ideas for many prosumers connected to LV distribution networks.

Besides the global growth of DG in power systems and new smart grids concepts, several issues have been consequently discussed and investigated for years. These issues do not stay in opposition to the common concepts but try to reveal answers for crucial techical problems 
about the integration of DG with EPS. One of the issues raised is the impact of DG on power quality (PQ). A wide discussion can be found in $[2,7,10,11,14,15,17,19,20,21,22,24]$.

In the general discussion of PQ and DG in distribution networks, we can distinguish two approaches:

a. "pro-prosumer", which can be represented by the discussable convention "feed and forget";

b. "pro-operator", which is associated with responsibility for control, regulation, stability, and maintenance of grid codes standards.

The aim of this work is to compare the mentioned approaches and reveal significant relations between regulations applied in LV DG systems and its effect on power quality. One of the crucial examples is the standard characteristics $\cos \varphi(\mathrm{P})$ of power factor in relation to the levels of generated active power. Another example is the effect of rapid switching operation executed in DG or the contribution of DG in waveform distortion.

In order to reveal the aim of the work, a case study of power quality investigation in real photovoltaic (PV) system, connected to LV power systems is presented.

Contents of the work is based on:

a. introduction of power quality as a part of electromagnetic compatibility (EMC)

b. actual discussion about EMC standards related to LV DG, including classical EMC IEC 61000 standard family [31] $\div 34]$ consisting of emission limits for LV equipment, technical report IEC/TR 61000-3-15 [35] considering assessment of low frequency electromagnetic immunity and emission requirements for dispersed generation systems in LV network,

c. actual discussion about connection criteria related to LV DG represented by VDE-AR-N 4105 [43], IEEE Std. 929 [40] and 1547 [42], CIGRE criterion rapport [13, 14], which represents technical requirements for the connection and parallel operation with LV distribution networks,

d. description of regulations of LV DG based on predefined curve exhibits relation between active power $(\mathrm{P})$ and reactive power $(\mathrm{Q})$, which is also known as $\cos \varphi(\mathrm{P})$ characteristic,

e. association of power quality indices with connection criteria of DG used by distribution system operators (DSO),

f. definitions of statistics and correlation tools proposed as supporting tools in the assessment of the influence of DG on power quality,

g. real case study of power quality measurement and assessment in LV PVs with special consideration to reveal the effect of DG on power quality,

h. summary concerning the contrast between present power quality requirements used for DG systems and the possible real contributions of DG in power quality issues,

i. summary concerning statistics and correlation tools as supporting indices applied in the assessment of the influence of DG on power quality, 
j. discussion about the possible effect of the scale of DG contribution in LV networks in relation to the present connection criteria.

\section{Power quality issues in the integration process of distributed generation with electrical networks}

At present, there is a broad discussion on the development of regulatory provisions in relation to the connection criteria and terms of cooperation of LV DGs with distribution electrical networks. An example of the efforts is the intensive work on the draft standards including the methodology for evaluating the possibility of connecting small generations to LV system. Existing projects of VDE-AR-N-4105 [43] or IEC/TR 61000-3-15 [35], as well as IEEE Standards 929 [40] and 1547 [42] are worth mentioning.

The influence of the source on the power grid depends on several elements:

a. conditions at the connection point defined by the short-circuit power at the PCC $\left(S_{\mathrm{kPCC}}\right)$,

b. nominal parameters and regulation characteristics of the DG source,

c. compatibility features of the DG.

The influence of the connection of the source on LV power system may be assessed on the basis of the known power quality indicators. The list of considered parameters followed by their definitions $[4,5,8,9,12,18,23,26,28,38]$ :

1. Power frequency, frequency variations $(\mathrm{f})$

2. Voltage magnitude variation, slow voltage changes, level of voltage $\left(\Delta \mathrm{u}_{\mathrm{a}}\right)$

3. Rapid voltage changes $\left(\Delta \mathrm{u}_{\max }\right)$

4. Voltage fluctuation, flicker severity $\left(\mathrm{P}_{\mathrm{st}}, \mathrm{P}_{1 \mathrm{t}}\right)$

5. Voltage unbalanced (asymmetry) $\left(\mathrm{k}_{\mathrm{u} 2}\right)$

6. Voltage harmonics, interhamonics, subharmonics, DC injection

7. Current harmonics, interhamonics, subharmonics, DC injection

8. Events

8a. Voltge dips

$8 b$. Short interruptions

8c. Long interruptions

8d. Temporary overvoltages (swells)

8e. Transient overvoltages, oscillatory, impulsive

8f. Commutation notches $\left(\mathrm{d}_{\mathrm{kom}}\right)$ 
9. Mains signaling, audio-frequency centralized ripple-control

\section{1. "Pro-prosumer" approach" - Feed and forget, unconditional connection}

The "pro-prosumer" approach is related to unconditional connection criteria used in the electromagnetic compatibility emission limit references. Generally, the idea is to connect smalland microgeneration to LV distribution networks on the condition that the classical definition of IEC EMC emission limits is passed during standard laboratory tests and the generation equipment have obtained specific certifications. That means that selected emission limits, as well as methods of measurement for particular power quality parameters, should be defined also for LV DG technologies. In practice, the mentioned approach expresses the direction that LV DG equipment should be treated the same as LV load. Then, classical relation between emission limits, system disturbances level, compatibility level, and equipment immunity levels known from the IEC EMC approach [30] is adapted to the LV DG equipment (Figure 1).

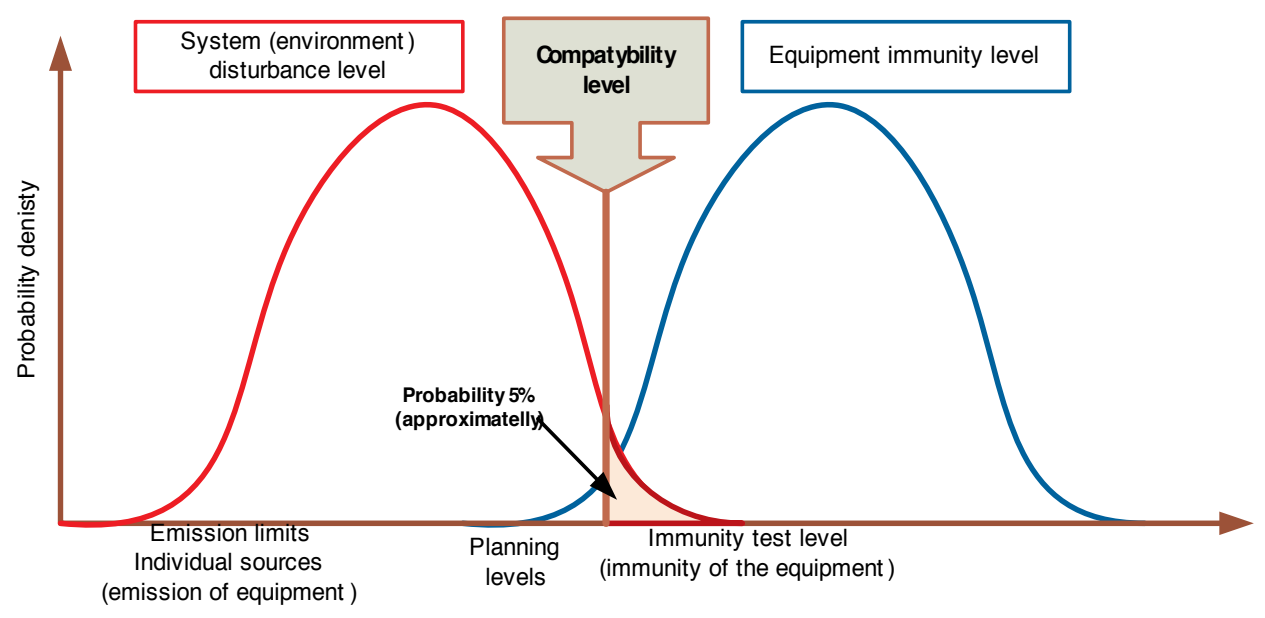

Figure 1. General relations between emission limits, system disturbances level, compatibility level, and equipment immunity level [30].

Following this approach, new draft standards or technical reports are created in order to define a standardized laboratory setup and test procedures for LV DG. Examples are EN: 50438 [29], IEC / TR 61000-3-15 [35], and VDE-AR-4105 [43]. In order to emphasize the mentioned idea, a laboratory setup for emission and immunity tests for DC-supplied inverters proposed in IEC/ TR 61000-3-15 [35] is illustrated in Figure 2.

After defining the laboratory setup, the next issue is to define the emission limits for the LV DG. Reviewing the proposition of standards [29, 35, 42, 43] allows us to conclude that aroup of standards dedicated to emission limits for the equipment is adapted to LV DG. Thus, permissible emission limits of particular power quality disturbances of LV DG are proposed to be the same as for the LV load. An example can be emission limits for harmonic current emissions IEC 61000-3-2 [31] and 3-12 [32], limitation of voltage changes, voltage fluctuations, 


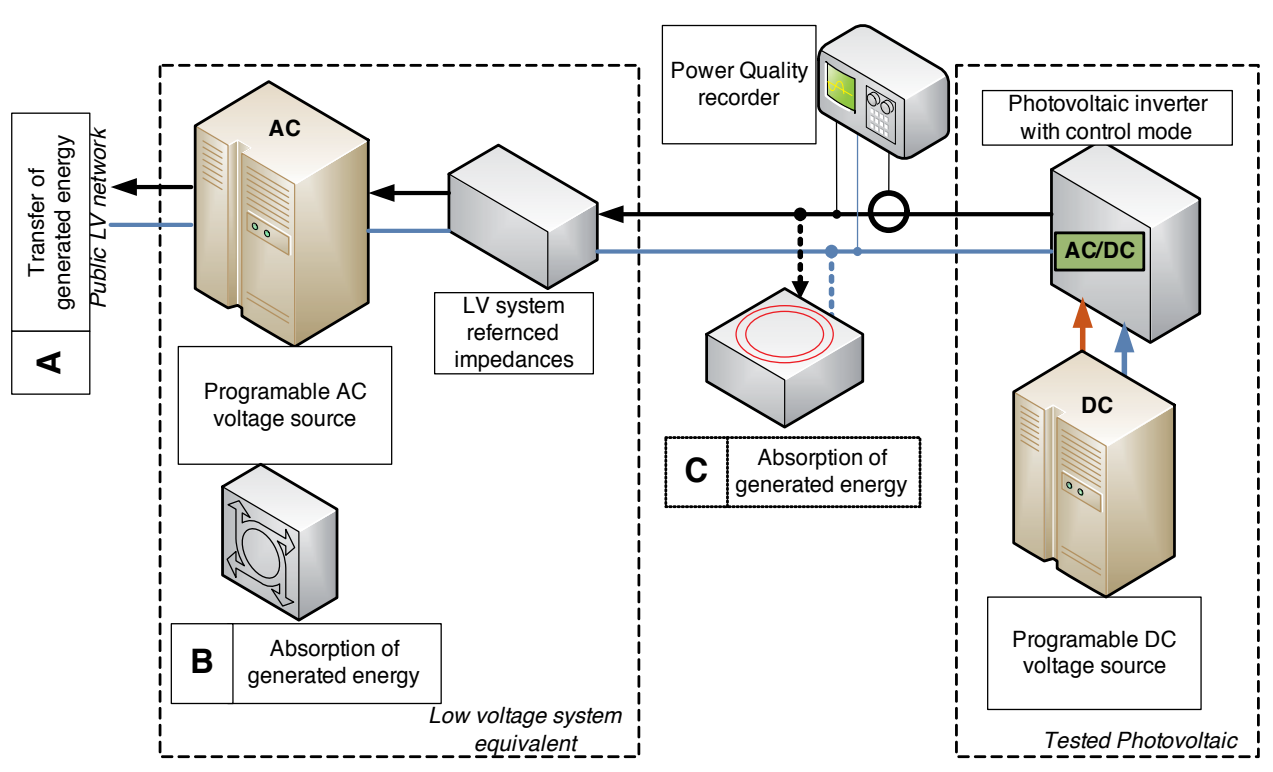

Figure 2. Laboratory setup for emission and immunity tests for DC-supplied inverters IEC/TR 61000-3-15 [35].

and flicker IEC 61000-3-3 [33] and 3-11 [34]. An example of the certification procedure for the DG directly associated with standards dedicated to load in the range of emission limits for voltage changes, voltage fluctuations, and flicker is presented in Figure 3.

Referring to the mentioned EMC approach illustrated in Figure 1, a LV public distribution network constitutes the environment for the load and LV DG. Thus, an LV network is characterized by higher levels of disturbances.

\section{2. "Pro-operator approach" - Network support and connection criteria}

Distribution system operators (DSOs) are responsible for the reliability of the power system. In case of crucial issues for distributed generation, the role of the DSO is to control the generation unit. During disturbances in the power system, as well as during normal operating conditions, selected issues of regulation are necessary to consider. Particularly, in the steady state condition where the regulation is dedicated to active and reactive power that has a prominent effect on voltage regulation. In transient state, under or overvoltage, as well as under and over frequency regulation is necessary in order to preserve network security management.

\subsubsection{Static voltage stability}

Due to popular inverter-based methods of integration with power systems, LV DG are able to contribute to static voltage stability using two modes of active $(\mathrm{P})$ and reactive $(\mathrm{Q})$ power control:

a. work with a fixed power factor $\cos \varphi$, 


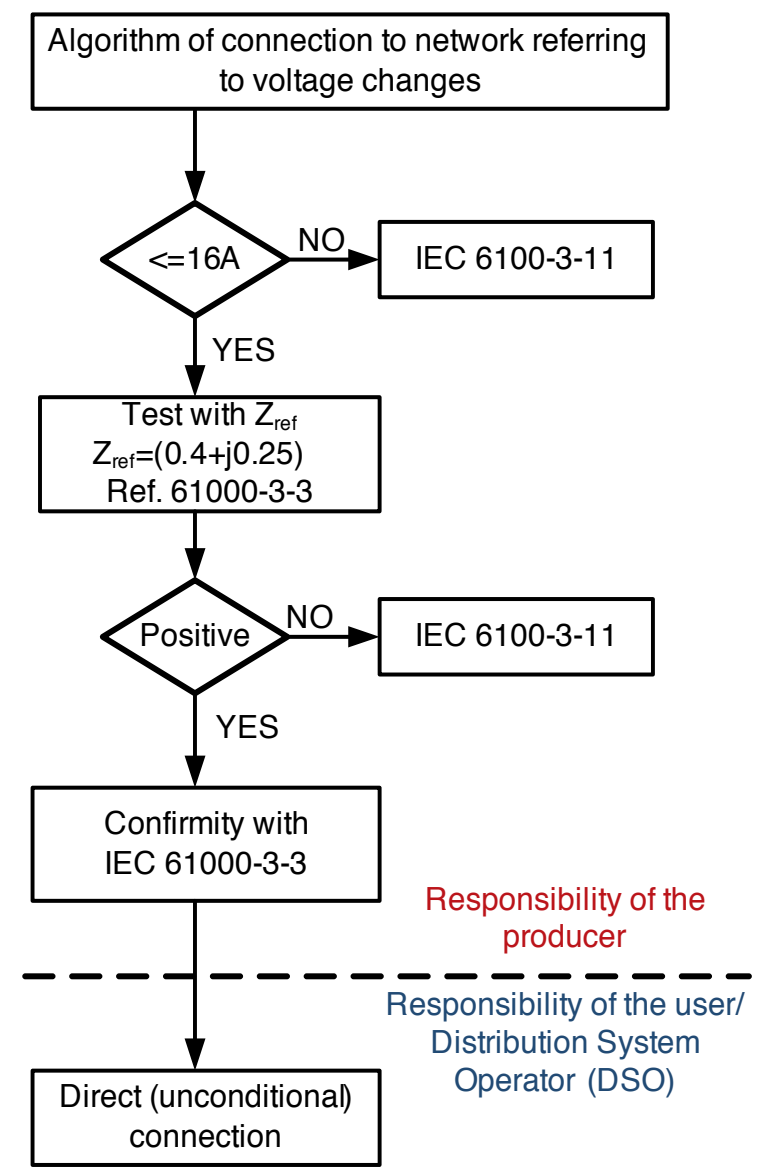

Figure 3. Example of an algorithm for assessment of possible voltage fluctuation and flicker severity applied for the device and LV DG in PCC [33].

b. work with variable power factors depending on the level of generated active power that in practice is realized by the application of defined by the operator characteristics $\cos \varphi(\mathrm{P})$.

In the regime of constant power factor, it is determined that depending on the maximum apparent power of the generation unit $\left(S_{E \max }\right)$, power factor cannot be less than 0.9 or 0.95 . An example can be the approach to force the photovoltaic systems to work with power factor $\cos \varphi$ equals 1. Constant power factor is also used in the case of asynchronous generators directly connected to low voltage using capacitor banks as reactive power control. Synchronous and double-fed asynchronous generators might be involved in the regulation of reactive power in LV distribution networks. Inverterbased power generation units are predisposed for implementation of the characteristics of power factor depending on the active power production $\cos \varphi(\mathbf{P})[10,43]$. It has to be emphasized that the shape of the characteristic and its crucial coordinates can be defined by DSOs on the basis of power system conditions in the 
area of PCC with respect to the maximum apparent power of the generation unit. However, in practice, a standard characteristic $\cos \varphi(\mathrm{P})$ is implemented. The standard $\cos \varphi(\mathrm{P})$ characteristic depends on the maximum apparent of the generation unit $\left(\mathrm{S}_{\mathrm{Emax}}\right)$. Examples of the characteristic are presented in Figure 4 for units with $S_{\mathrm{Emax}}<13,8 \mathrm{kVA}$ and Figure 5 for units with $S_{\text {EMAX }}>13,8 \mathrm{kVA}$. Describing the regulation, it can be seen that in up to $20 \%$ of the maximum active power generation of the generation unit $\mathbf{P}_{\mathrm{EMAX}}$, both generation and consumption of reactive power is allowed. In many cases of this range, the generation of active power is realized simultaneously with the generation of reactive power. This mode of work can be treated as work with induction power factor $\cos \varphi_{\text {ind }}$. In the range of $20 \%$ to $50 \%$ of $\mathrm{P}_{\text {EMAX }}$, only active power generation is recommended. Operating above $50 \%$ of $\mathrm{P}_{\text {EMAX }}$ generation of active power is accompanied by a reactive power consumption that can be treated as a mode with capacitive power factor $\cos \varphi_{\text {cap }}$. The level of reactive power consumption depends on the size of the generation unit. For units with $S_{\text {Emax }}<13,8 \mathrm{kVA}$ the desirable coordinate is $\cos \varphi_{\text {ap }}=0.95$ and for units of $S_{\text {Emax }}>13,8 \mathrm{kVA}$ it is $\cos \varphi_{\text {cap }}=0.9$. The aim of implementation of reactive power consumption has a significant meaning in the reduction of voltage increase due to high levels of active power generation.

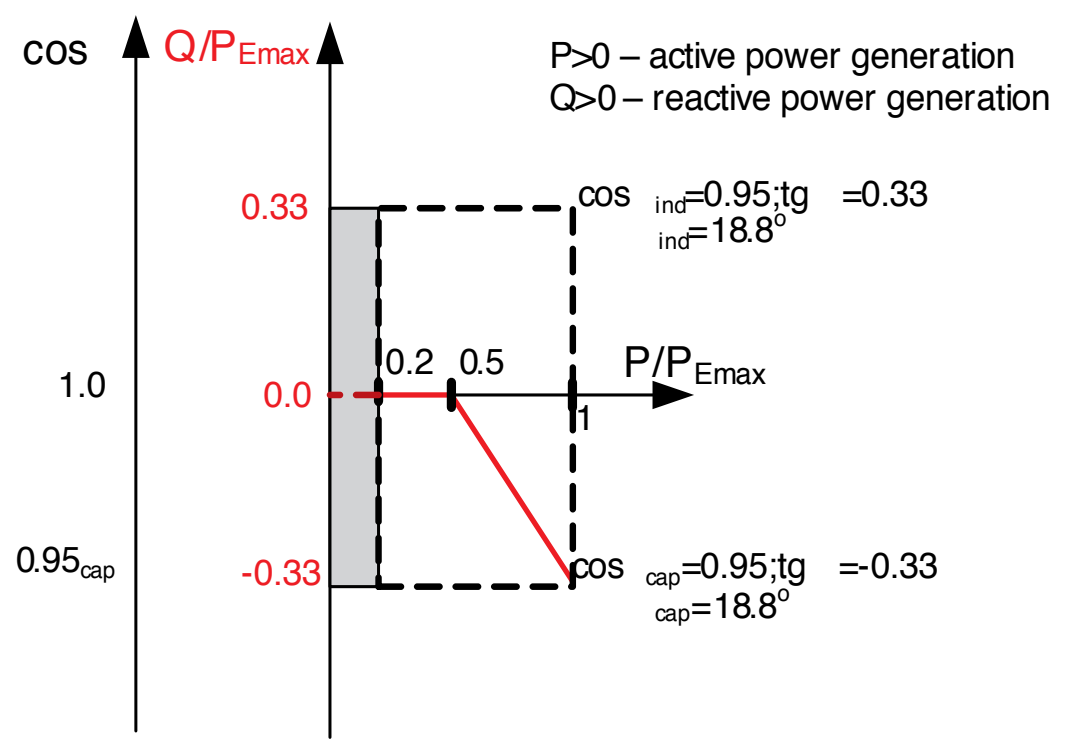

Figure 4. Standard characteristic $\cos \varphi(\mathrm{P})$ for the generation unit within the range of maximum apparent power $\mathrm{S}_{\mathrm{Emax}}$ from $3,68 \mathrm{kVA}$ to $13,8 \mathrm{kVA}$.

\subsubsection{Active power feed-in at under and over frequency}

When studying network security management, few other limitations of power generation units can be introduced. One of the limitations is the reduction of active power generation in selected ranges of over frequency condition known as frequency regulation characteristic $\mathbf{P}(\mathbf{f})[10,43]$. 


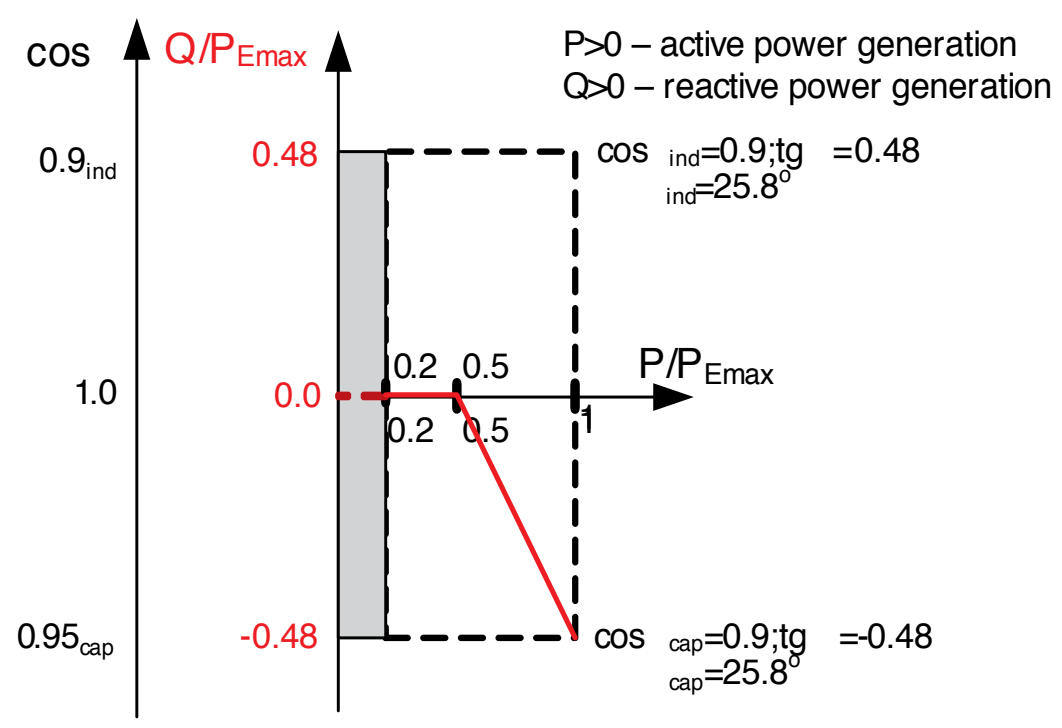

Figure 5. Standard characteristic $\cos \varphi(\mathrm{P})$ for the generation unit within the range of maximum apparent power $\mathrm{S}_{\mathrm{Emax}}$ of more than $13,8 \mathrm{kVA}$.

Figure 6 exhibits the idea of the regulation. It is visible that for power system frequency in the range of $50.2 \mathrm{~Hz}$ to $51.5 \mathrm{~Hz}$ it is recommended to reduce active power generation from the instantaneous level $\mathrm{P}_{\mathrm{M}}$ generated at the time of over frequency detection with gradient $40 \%$ of $\mathrm{P}_{\mathrm{M}}$ per Herz. At system frequencies higher than $51.5 \mathrm{~Hz}$, the power generation unit shall be disconnected immediately.

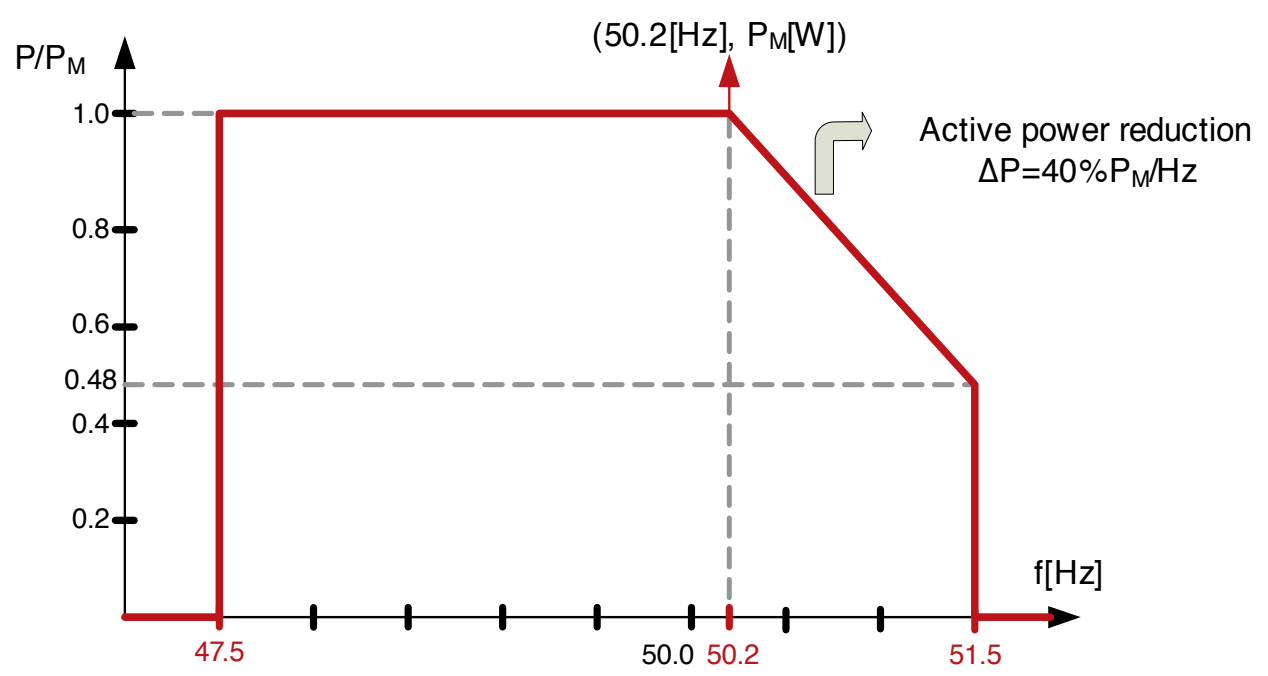

Figure 6. Standard characteristic $\mathrm{P}(\mathrm{f})$ for the generation unit. 


\subsubsection{Disconnection by network protection}

The present approach to the disconnection of the DG due to power system protection is dictated by a few selected cases: risk of islanding, risk of overload on the power system network, risk of steady-state and dynamic network stability, rise in mains frequency, and resynchronization of sub-systems. These mentioned aims are realized through under and over voltage protection, as well as under and over frequency protection. In [27], a review of different standards of distributed generation development in several countries was presented. For comparison, the selected settings of the mentioned protection, as well as disconnection time for view in European countries was grouped in Table 1.

\begin{tabular}{ccccc}
\hline Country & $\mathrm{U}<$ & $\mathrm{U}>$ & $\mathbf{f}<$ & $\mathbf{f}>$ \\
\hline Germany & $0.7 \div 1.0 \mathrm{U}_{\mathrm{N}} ; \mathrm{t} \leq 0.2 \mathrm{~s}$ & $1.0 \div 1.15 \mathrm{U}_{\mathrm{N}} ; \mathrm{t} \leq 0.2 \mathrm{~s}$ & $47 \mathrm{~Hz} ; \mathrm{t} \leq 0.2 \mathrm{~s}$ & $52 \mathrm{~Hz} ; \mathrm{t} \leq 0.2 \mathrm{~s}$ \\
\hline Italy & $0.8 \mathrm{U}_{\mathrm{N}} ; \mathrm{t} \leq 0.2 \mathrm{~s}$ & $1.2 \mathrm{U}_{\mathrm{N}} ; \mathrm{t} \leq 0.1 \mathrm{~s}$ & $\begin{array}{c}49 \div 49.7 \mathrm{~Hz} ; \\
\text { immediately }\end{array}$ & $\begin{array}{c}50.3 \div 51 \mathrm{~Hz} ; \\
\text { immediately }\end{array}$ \\
\hline Spain & $0.85 \mathrm{U}_{\mathrm{N}} ; \mathrm{t} \leq 1.2 \mathrm{~s}$ & $1.1 \mathrm{U}_{\mathrm{N}} ; \mathrm{t} \leq 0.5 \mathrm{~s}$ & $48 \mathrm{~Hz} ; \mathrm{t} \leq 3 \mathrm{~s}$ & $51 \mathrm{~Hz} ; \mathrm{t} \leq 0.2 \mathrm{~s}$ \\
\hline Belgium & $0.5 \div 0.85 \mathrm{U}_{\mathrm{N}} ; \mathrm{t} \leq 1.5 \mathrm{~s}$ & $1.06 \mathrm{U}_{\mathrm{N}} ;$ immediately & $49.5 \mathrm{~Hz} ;$ immediately & $50.5 \mathrm{~Hz} ;$ immediately \\
\hline
\end{tabular}

Table 1. Comparison of power system protection settings and disconnection time in selected countries.

\subsubsection{Change of the voltage level, slow voltage changes}

Changes in voltage at the point of common coupling of the generation unit depends on the short-circuit power of the upstream network at this node $\left(\mathrm{S}_{\mathrm{kPCC}}\right)$. Using short circuit calculations, the mentioned $S_{\mathrm{kPCC}}$ can be recalculated to short circuit impedance in point of common coupling $Z_{\mathrm{kPCC}}=\mathrm{R}_{\mathrm{kPCC}}+\mathrm{j} \mathrm{X}_{\mathrm{kPCC}}$, where:

$$
S_{k P C C}=\frac{U_{N}^{2}}{Z_{k P C C}} ; \quad Z_{k P C C}=\sqrt{R_{k P C C}^{2}+X_{k P C C}^{2}} ; \quad \psi_{k P C C}=\arctan \left(\frac{X_{k P C C}}{R_{k P C C}}\right)
$$

Considering the influence of the generation unit with the given maximum apparent power $S_{\text {Emax }}$ on voltage change (change of voltage level) in the PCC characterized by given $Z_{\mathrm{kPCC}}$ the regulation of active and reactive power of the DG can be also considered. Referring to characteristics shown in Figure 4 and Figure 5, static change of voltage level $\Delta \mathbf{u}_{\mathbf{a}}$ can be determined by generation or consumption of reactive power. When the generation unit delivers feed-in active and reactive power the change of voltage level can be expressed as:

$$
\Delta u_{a}=\frac{S_{E \max }\left(R_{k P C C} \cos \left(\varphi_{\text {ind }}\right)+X_{k P C C} \sin \left(\varphi_{\text {ind }}\right)\right)}{U_{N}^{2}} 100 \%
$$


For generation-only active power, the change of voltage level comes only from active power:

$$
\Delta u_{a}=\frac{S_{E m a x}\left(R_{k P C C}\right)}{U_{N}^{2}} 100 \%
$$

When the active power cross $50 \%$ of $\mathrm{P}_{\mathrm{EMAX}}$, then the regulation introduces consumption of reactive power. It means correction in influence of DG on voltage level in PCC as:

$$
\Delta u_{a}=\frac{S_{E \max }\left(R_{k P C C} \cos \left(\varphi_{c a p}\right)-X_{k P C C} \sin \left(\varphi_{c a p}\right)\right)}{U_{N}^{2}} 100 \%
$$

Revision of references $[13,27,33,34]$ allows to constitute the permissible limit for voltage level change in the PCC caused by the connection of DG should be not higher than $3 \%$ :

$$
\Delta u_{a} \leq 3 \%
$$

It should be added that the influence of many DG sources installed in the LV network on the voltage level in particular nodes of the network can be approximated using the superposition technique. For comparison to requirements dedicated to LV public network a permissible voltage level is $10 \%$.

\subsubsection{Rapid voltage changes}

Rapid voltage changes $\Delta \mathbf{u}_{\max }$ at the connection point of generation unit can be caused by switching operations. It is possible to estimate the impact of the operating condition of the generation unit on sudden voltage change at the connection point PCC using the formula:

$$
\begin{gathered}
\Delta u_{\max }=k \frac{S_{E \max }}{S_{k P C C}} 100 \%=k \cdot \frac{1}{R_{k}} 100 \% \\
k=\frac{I_{a E}}{I_{r E}} ; \quad R_{k}=\frac{S_{k P C C}}{S_{E \max }}
\end{gathered}
$$

where: $S_{\mathrm{kPCC}}$ - short-circuit power at PCC of the generation unit, $\mathrm{S}_{\mathrm{Emax}}$ - maximum apparent power of the generation units, $\mathrm{I}_{\mathrm{aE}}$ - start inrush current of generation unit, $\mathrm{I}_{\mathrm{rE}}$ - rated continuous output current of generation unit, $\mathrm{k}$ - start coefficient, $\mathrm{R}_{\mathrm{k}}$ - short circuit power coefficient.

If the coefficient $\mathrm{k}$ is not determined on the basis of accurate data generation unit, it can be assumed using the reference values: 
a. $\mathrm{k}=1.2$ - generation units being connected through an inverter, for example, photovoltaic systems

b. $\mathrm{k}=1.2-$ for synchronous generators

c. $\mathrm{k}=4$ - asynchronous generators connected to the network after reaching $95 \div 105 \%$ of the synchronous speed

d. $\mathrm{k}=8$ - asynchronous generators

Short circuit power coefficient $R_{k}$ is used in the test of the emission limits in the EMC standard $[32,34]$. In the mentioned documents, it is assumed that every tests are performed in the condition that $R_{k}$ is not less than 33.3. Taking into consideration the value 33.3 of $R_{k}$ and assuming start coefficient $k=1$, it is possible to estimate the influence of the switching condition of the generation unit on rapid voltage changes on the level of $3 \%$. The start of different generation sources using asynchronous generation where $k=8$ in the same node, $R_{k}=33.3$ will cause a rapid voltage change 8 time deeper, e.g., on the level of $24 \%$.

The revision of references $[13,27,33,34]$ allows to constitute that the DG unit in normal operation conditions should not generate rapid voltage changes exceeding $3 \%$ of the nominal voltage $\mathrm{U}_{\mathrm{N}}$ :

$$
\Delta u_{\max } \leq 3 \%
$$

The value cannot occur more than once every 10 minutes.

\subsubsection{Voltage fluctuation}

The technical parameters used in the evaluation of voltage fluctuation are long-term $\left(\mathbf{P}_{1 \mathrm{t}}\right)$ and short-term $\left(\mathbf{P}_{\mathrm{st}}\right)$ flicker severity indices. Investigation of voltage fluctuation emission is carried out, referring to the same standards as investigation of rapid voltage changes $[33,34]$. Thus, connection criteria of considered sources at given PCCs may also corresponds to the $R_{\mathrm{kPCC}}$ parameter as in case of rapid voltage changes. Revision of references $[13,27,33,44]$ allows to constitute permissible level of $\left(\mathrm{P}_{1 \mathrm{t}}\right)$ and short-term $\left(\mathrm{P}_{\mathrm{st}}\right)$ as:

$$
P_{l t} \leq 0.65 ; \quad P_{s t}<1
$$

It is worth mentioning that additionally, in [43] there is a recommendation that together all power generation units in LV networks shall not exceed $\mathrm{P}_{\mathrm{lt}}=0.5$ at the most unfavorable PCC. This condition seems to be hard to revise in practice. Requirements for the measurement of $\mathrm{P}_{1 \mathrm{t}}$ and $\mathrm{P}_{\mathrm{st}}$ follow a standard [37].

\subsubsection{Voltage asymmetry}

The unbalanced distribution of single-phase distribution generation units can become a source of negative sequence currents and voltage asymmetry. The asymmetry is depicted by changing 
the effective values of voltages or phase angles with respect to the symmetric arrangement of three-phase vectors. Voltage asymmetry can be expressed by the voltage asymmetry index $\mathbf{k}_{\mathrm{u} 2}$ calculated as the ratio of negative sequence component $U_{2}$ to positive sequence $U_{1}$ :

$$
k_{u 2}=\frac{U_{2}}{U_{1}} \cdot 100 \%
$$

Additionally, in [43] there is a recommendation that the asymmetry caused by connecting single-phase DG can be practicaly evaluated by the ratio of the power of the connected singlephase generation $S_{1 \text { Emax }}$ to the short-circuit power at the PCC $S_{\mathrm{kPCC}}$ :

$$
k_{u 2}=\frac{U_{2}}{U_{1}} \approx \frac{S_{1 E \max }}{S_{k P C C}}
$$

In [43], another practical requirement is proposed that connecting principle should be a symmetrical three-phase source or if at a given point, several one-phase generation units are considered, then the maximum permissible difference between individual phases should not be more than $4,6 \mathrm{kVA}$.

\subsubsection{Current harmonics, interharmonics, and DC injection}

The first approach corresponds to limits of harmonics in the current recommended for load in the EMC standards [31] and [32]. Examples of the limits for the rated current range to $16 \mathrm{~A}$ are presented in Table 2. If the limits are not preserved for the considered DG, then similar to rapid voltage changes and voltage fluctuation approach, a recalculation of the requirements is allowed using short-circuit power in investigated PCC $S_{\text {kPCC. }}$ In [43], acceptable limits for a particular current harmonic are expressed in A/MVA of $S_{\text {kPCC }}$ denoted as $i_{\text {vzul }}$. Absolute limits in Ampers $\mathrm{I}_{\mathrm{vzul}}$ can be recalculated using $\mathrm{S}_{\mathrm{kPCC}}$ by following fomula:

$$
i_{v z u l}=\frac{I_{v z u l}}{S_{k P C C}} \rightarrow I_{v z u l}=i_{v z u l} \cdot S_{k P C C}
$$

Table 3 consists of permissible current harmonics related to $S_{\mathrm{kPCC}}$. It should be noted that higher levels of $S_{\mathrm{kPCC}}$ correspond to higher levels of coefficient $R_{k}$, which is used in the EMC standards. For the EMC, the typical $R_{k}$ is 33.3. For a "stonger network", higher levels of $S_{k P C C}$ are introduced and the relation to the considered $S_{E \operatorname{Eax}}$ increases that finally reveals as higher levels of $R_{k}$. For higher levels of $R_{k}$, higher levels of current harmonics emission can be allowed.

The requirements for harmonic measurement method should follow the standard [36].

Additionally, revising $[29,40]$ constitutes that inverter-based systems should not inject DC current $\mathrm{I}_{\mathrm{DC}}>0.5 \%$ of the rated inverter output current $\mathrm{I}_{\mathrm{rE}}$. 


$$
\frac{I_{D C}}{I_{r E}}<0.5 \%
$$

where: $\mathrm{I}_{\mathrm{rE}}$ - rated continuous output current of generation unit.

The difference of current DC injection can be caused by different kinds of applied PV technologies and inverters [6, 25]. Generally, higher levels of DC injection are related to transformerless inverters. Application of inverters with a transformer gives the possibility of a better separation of AC from DC.

The methods of measurement and parameterization is discussed in standards [36, 39, 41, 42].

\begin{tabular}{cc}
\hline $\mathbf{n}$ & Permissible current harmonics \\
\hline 3 & OA] \\
\hline 5 & 2,30 \\
\hline 7 & 1,14 \\
\hline 9 & 0,77 \\
\hline 11 & 0,40 \\
\hline 13 & 0,33 \\
\hline $15 \leq n \leq 39$ & 0,21 \\
\hline $8 \leq n \leq 40$ & $0,15 \cdot \frac{15}{n}$ \\
\hline 2 & Even harmonics \\
\hline 4 & 1,08 \\
\hline 6 & 0,43 \\
\hline
\end{tabular}

Table 2. Limits for harmonic current emission for distributed generation units within the range of current up to $16 \mathrm{~A}$ that corresponds to limits for class A equipment [31] (for $\mathrm{R}_{k}=33.3$ ).

\begin{tabular}{cc}
$\begin{array}{c}\text { Order of harmonic } \\
(\mathrm{v}-\text { harmonics, } \mu \text { - interharmonics }),\end{array}$ & $\begin{array}{c}\text { Permissible harmonic current emission related to } \mathrm{S}_{\mathrm{kPCC}} \\
\boldsymbol{i}_{v z u l}[A / M V A]\end{array}$ \\
\hline 3 & Odd harmonics \\
\hline 5 & 3 \\
\hline 7 & 1,5 \\
\hline
\end{tabular}




\begin{tabular}{cc}
\hline $\begin{array}{c}\text { Order of harmonic } \\
(\mathbf{v}-\text { harmonics, } \boldsymbol{\mu} \text { - interharmonics }),\end{array}$ & $\begin{array}{c}\text { Permissible harmonic current emission related to } \mathbf{S}_{\mathrm{kPCC}} \\
\boldsymbol{i}_{v z u l}[\mathrm{~A} / \mathbf{M V A}]\end{array}$ \\
\hline 9 & 0,7 \\
\hline 11 & 0,5 \\
\hline 13 & 0,4 \\
\hline 17 & 0,3 \\
\hline 19 & 0,25 \\
\hline 23 & 0,2 \\
\hline 25 & 0,15 \\
\hline $25<v<40$ & $0,15-25 / v$ \\
\hline$v, \mu<40$ & $1,5 / v$ \\
\hline $42<v, \mu<178$ & $4,5 / v$ \\
\hline
\end{tabular}

Table 3. Limits for harmonic current emission related to short-circuit power in PCC $S_{\mathrm{kPCC}}$ [43].

\subsubsection{Voltage harmonics, interharmonics, and DC component}

There are no requirements for permissible voltage wave distortion of the DG. The assumption is that generation realizes good quality of voltage sinusoidal form. It is a similar approach used in the equipment that influence of the device on voltage shape distortion is controlled by limitation of current harmonics. It can be concluded that voltage represents environment and current the unit, load or generation equipments.

\subsubsection{Commutation notches}

Commutation notches in DG systems are disturbances typical for inverter-based integration. The disturbances can be expressed by index $d_{\text {com }}$ representing the relative depth of the collapse of voltage made by line-commutated converters:

$$
d_{c o m}=\frac{\Delta U_{c o m}}{U_{N}}
$$

where: $\Delta \mathrm{U}_{\text {com }}$ depth breakdown in $[\mathrm{V}], \mathrm{U}_{\mathrm{N}}$ phase to phase voltage nominal voltage The [43] provides acceptable limits for $\mathrm{d}_{\text {com }}$ not more than $5 \%$.

\subsubsection{Mains signaling, audio-frequency centralized ripple-control}

Transmission of control signals used by the system operator is usually in the range of frequencies 100-1500 Hz. The general principle is that the connection of distributed generation 
does not interfere with the transmission signals. In particular, connection of the LV DG to the network should not cause attenuation of mains singling greater than $5 \%$ in relation to the transmission without connected generation units. The given requirement does not include the issue of transmission of signals used in data transmission systems with the present popular power line communication technology (PLC) where transmission frequency range is 9-148 (400) $\mathrm{kHz}$ and 2-80 MHz depending on the technology.

\subsection{Summary}

The impact of DG on power quality can be considered for every parameter. The discussed "pro-prosumer" approach attaches a significance to EMC certification of DG products so that positive results of emission limits tests obtained using laboratory condition allow to prevent power quality deterioration by DG as it is in case of the equipment. At present the emission limits used for the DG is proposed to be the same as for the equipment. The mentioned approach inclines to unconditional decision about the interconnection of DG to LV public electrical networks as it is practical for the equipment that have EMC confirmation. On the other hand, DG can play an undisputed role in the regulation of electrical networks. Thus, the "pro-operator" approach aims on the impact of DG on static voltage stability, risk of islanding, risk of overload on the power system network, or impact on mains frequency or resynchronization of the subsystems. It can be noted that the mentioned issues are crucial for the operator. That is why the EMC certifications of the DG can be treated by the system operator as a necessary point of the documentation, but not the obligation for unconditional connection. Both mentioned approaches "pro-prosumer" and "pro-operator" do not have to be treated as opposites but should play complementary roles.

Comparisons of the permissible levels of power quality disturbances in LV distribution networks noted in standards [28] and [30], and LV DG proposed in [29] and [30], [31], [32], [33], [34] are shown in Table 4. It can be concluded that requirements for LV DG emission limits are usually much restricted than for the distribution network.

\begin{tabular}{|c|c|c|c|}
\hline Power quality parameter & Label & Limits for generator & $\begin{array}{l}\text { Limits in public } \mathrm{LV} \\
\text { network }\end{array}$ \\
\hline Power frequency, frequency variations & $f$ & $\begin{array}{l}\text { Additional reference to } \\
\text { characteristic } \\
\mathrm{f}(\mathrm{P})^{\text {section2.2.2. }}\end{array}$ & $\begin{array}{l}50 \mathrm{~Hz} \pm 2 \% \text { (e.g., } 49 \mathrm{~Hz} ; 51 \\
\mathrm{~Hz} \text { ) during } 95 \% \text { of a week; } \\
50 \mathrm{~Hz} \pm 15 \% \text { (e.g., } 42,5 \mathrm{~Hz} ; \\
57,5 \mathrm{~Hz} \text { ) during } 100 \% \text { of the } \\
\text { time. }\end{array}$ \\
\hline $\begin{array}{l}\text { Voltage magnitude variation, slow } \\
\text { voltage changes, level of voltage }\end{array}$ & $\Delta u_{a}$ & $\begin{array}{c}3,0 \% \\
\text { Additional reference to } \\
\text { characteristic } \\
\cos \varphi(\mathrm{P})^{\text {section } 2.2 .4}\end{array}$ & $10 \%$ \\
\hline Rapid voltage changes $\left(\Delta \mathrm{u}_{\max }\right)$ & $\Delta u_{\max }$ & $3,0 \%$ & $5 \%$, \\
\hline
\end{tabular}




\begin{tabular}{|c|c|c|c|}
\hline Power quality parameter & Label & Limits for generator & $\begin{array}{l}\text { Limits in public LV } \\
\text { network }\end{array}$ \\
\hline & & $\begin{array}{l}\text { Additional reference to } \mathrm{S}_{\mathrm{kPCC}} \\
\text { section 2.2.5 }\end{array}$ & $\begin{array}{l}\text { several times of the day - } \\
\qquad 10 \%\end{array}$ \\
\hline Voltage fluctuation, flicker severity $\left(\mathrm{P}_{\mathrm{st}}\right.$ & $P_{s t}$ & 1,0 & - \\
\hline $\left.\mathrm{P}_{\mathrm{lt}}\right)$ & $P_{l t}$ & 0,65 & 1,0 \\
\hline Voltage unbalanced (asymmetry) & $k_{u 2}$ & $2,0 \%$ & $2,0 \%$ \\
\hline $\begin{array}{l}\text { Current harmonics, inter } \\
\text { harmonics,DC injection }\end{array}$ & $\begin{array}{c}\text { THDI } \\
I_{n} / I 1 \\
I d c / I r E\end{array}$ & $\begin{array}{l}\text { Refer to emission limits for } \\
\text { load or recalculated to } \\
\text { condition of } S_{\mathrm{kPCC}} \text { section } \\
2.2 .8\end{array}$ & - \\
\hline $\begin{array}{l}\text { Voltage harmonics, inter harmonics, } \\
\text { DC component }\end{array}$ & $\begin{array}{l}\text { THDU } \\
U_{n} / U_{1}\end{array}$ & - & $\begin{array}{l}\text { Refer to the table of } \\
\text { emission limits for } \\
\text { particular components }\end{array}$ \\
\hline Commutation notches & $d_{c o m}$ & $5 \%$ & $5 \%$ \\
\hline $\begin{array}{l}\text { Mains signaling, audio-frequency } \\
\text { centralized ripple-control }\end{array}$ & $\begin{array}{l}\text { Suppression of the } \\
\text { voltage }\end{array}$ & $<5 \%$ & $<5 \%$ \\
\hline
\end{tabular}

Table 4. Comparison of power quality limits for distributed generation and public distribution networks.

\section{Field measurement case study results}

As supplement for the discussion provided in the previous sections, this chapter is dedicated to real measurements and assessments of power quality impact of photovoltaic (PV) systems with maximum apparent power $S_{\text {Amax }}=15 \mathrm{kVA}$. The system is based on three independent $P V$ generation subsystem of $S_{\text {Emax }}=5 \mathrm{kVA}$ integrated with the LV network by independent onephase PV inverters. The nominal power of the subsystems are the same, however, few differences should be emphasized. The described PV subsystems use different types of PV technologies: phase L1 - monocrystalline; phase L2 - thin layer copper indium gallium selenide; and phase L3 - polycrystalline. Due to the thin-layer technology applied in phase L2, a PV inverter with transformer is applied. Phases L1 and L3 have transformerless inverters. Additionally, the subsystem associated with phase L3 is localized in different geographical directions: phases L1 and L2 are in the $135^{\circ}$ South-East direction, phase L3 is in the $255^{\circ}$ SouthWest. Thus, irradiation of phase L3 has natural delay. PCC is the same for every subsystem and directly connected with main LV switchgear of the building with the transformer $630 \mathrm{kVA}$ MV/LV. The LV switchgear is supplemented by reactive power compensation realized by capacitor banks 120 kvar with step of regulation 20 kvar and set regulation of 1:1:2:2. Short circuit power on the level of MV switchgear is $340 \mathrm{MVA}$. The diagram of interconnection of the investigated PV system with the LV network and its short circuit equivalent is presented in Figure 7. 


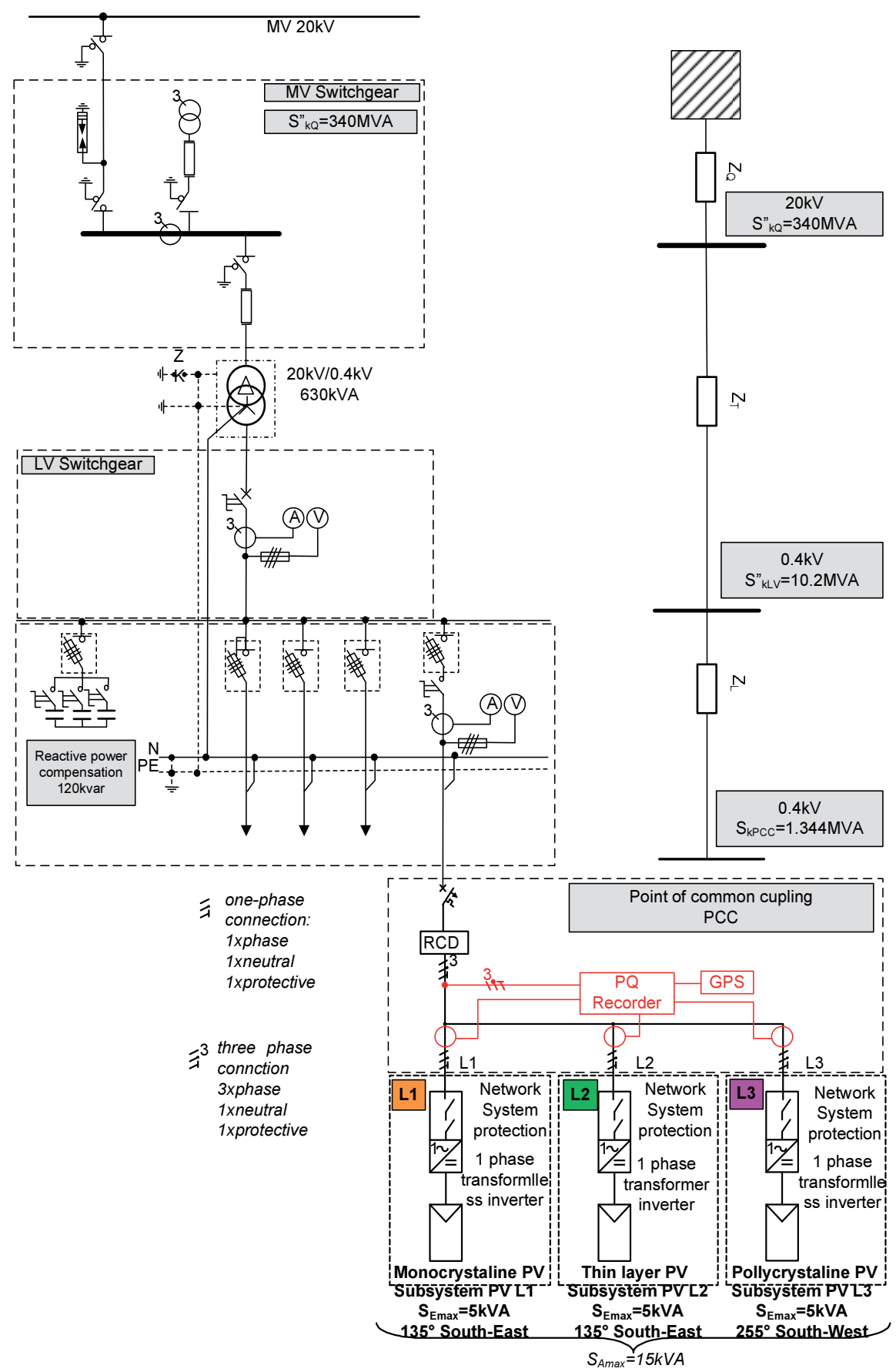

Figure 7. The diagram of interconnection of the investigated PV system with the LV network and its short circuit equivalent. 


\subsection{Calculation of short circuit condition in PCC}

This section contains an example of a simplified calculation of short circuit condition in PCC. The aim is to obtain short circuit apparent power in PCC $S_{\mathrm{kPCC}}$ as well as the equivalent of the short circuit system impedance in PCC $Z_{\mathrm{kPCC}}$ that can be used for the prediction of possible influences of the investigated PV system on changes of selected power quality parameters in the PCC.

\section{Medium voltage system:}

$$
\mathrm{U}_{\mathrm{NQ}}=20^{\circ} \mathrm{kV}, \mathrm{S}^{\prime \prime}{ }_{\mathrm{kQ}}=340 \mathrm{MVA}
$$

\section{Transformer in LV switchgear:}

$$
20 / 0.4^{\circ} \mathrm{kV}, \mathrm{S}_{\mathrm{NT}}=630^{\circ} \mathrm{kVA} \text {, short-circuit voltage } \Delta \mathrm{U}_{\mathrm{k} \%}=6 \% \text {, }
$$

load losses in cuprum $\Delta \mathrm{P}_{\mathrm{Cu}}=6.3 \mathrm{~kW}\left(\Delta \mathrm{P}_{\mathrm{CU} \%}=\Delta \mathrm{P}_{\mathrm{Cu}} / \mathrm{S}_{\mathrm{NT}}=1 \%\right)$

\section{Photovoltaic conductor from LV switchgear to PCC:}

Cuprum $(\mathrm{Cu}) 5 \times 16 \mathrm{~mm}^{2}$, section $(\mathrm{s})=16 \mathrm{~mm}^{2}$, length $(\mathrm{l})=100 \mathrm{~m}=0.1 \mathrm{~km}$, electrical conductivity $\left(\gamma_{\mathrm{Cu}}\right)=55 \mathrm{~m} / \Omega \mathrm{mm}^{2}$, unit resistance $\left(\mathrm{r}^{\prime}\right)=1.9 \Omega / \mathrm{km}$, unit reactance per $1 \mathrm{~km}\left(\mathrm{x}^{\prime}\right)=0.1 \Omega / \mathrm{km}$, unit capacitance $\left(\mathrm{C}^{\prime}\right)=61 \mathrm{nF} / \mathrm{km}$.

\section{a. Short circuit current at medium voltage switchgear $20 \mathrm{kV}$}

$$
I_{k Q}^{\prime \prime}=\frac{S_{k Q}^{\prime \prime}}{\sqrt{3} U_{N Q}}=\frac{340 \cdot 10^{6}}{\sqrt{3} \cdot 20 \cdot 10^{3}}=9.8 \mathrm{kA}
$$

b. Equivalent of the system impedance visible in $L V$ level $U_{N}=0.4 \mathrm{kV}$

$$
\begin{aligned}
& Z_{Q} \approx X_{Q}=\frac{c \cdot\left(U_{N}\right)^{2}}{S_{k Q}^{\prime}}=\frac{1.1 \cdot\left(0.4 \cdot 10^{3}\right)^{2}}{340 \cdot 10^{6}}=0.000518 \Omega=0.5 \mathrm{~m} \Omega \\
& R_{Q} \approx 0 m \Omega
\end{aligned}
$$

c. Equivalent of transformer impedance visible in $L V$ level $U_{N}=0.4 \mathrm{kV}$

$$
\begin{aligned}
& Z_{T}=\Delta u_{k \%} \cdot \frac{\left(U_{N}\right)^{2}}{S_{N T}}=\frac{6}{100} \cdot \frac{\left(0.4 \cdot 10^{3}\right)^{2}}{630 \cdot 10^{3}}=0.0152 \Omega=15.2 \mathrm{~m} \Omega \\
& R_{T}=\Delta P_{C u \%} \cdot \frac{\left(U_{N}\right)^{2}}{S_{N T}}=\frac{1}{100} \cdot \frac{\left(0.4 \cdot 10^{3}\right)^{2}}{630 \cdot 10^{3}}=0.0025 \Omega=2.5 \mathrm{~m} \Omega \\
& X_{T}=\sqrt{Z_{T}^{2}-R_{T}^{2}}=0.01499 \Omega=15.0 \mathrm{~m} \Omega
\end{aligned}
$$


d. Short circuit condition in LV switchgear $U_{N}=0.4 \mathrm{kV}$

$$
\begin{aligned}
& R_{k L V}=R_{Q}+R_{T}=0+2.5 \mathrm{~m} \Omega=2.5 \mathrm{~m} \Omega \\
& X_{k L V}=X_{Q}+X_{T}=0.5 \mathrm{~m} \Omega+15 \mathrm{~m} \Omega=15.5 \mathrm{~m} \Omega \\
& Z_{k L V}=\sqrt{R_{k L V}^{2}+X_{k L V}^{2}}=15.7 \mathrm{~m} \Omega \\
& \frac{R_{k L V}}{X_{k L V}}=\frac{2.5}{15.5}=0.16 \\
& S_{k L V}^{\prime \prime}=\frac{U_{N}^{2}}{Z_{k L V}}=\frac{\left(0.4 \cdot 10^{3}\right)^{2}}{15.7 \cdot 10^{-3}}=10.2 \mathrm{MVA} \\
& I_{k L V}^{\prime \prime}=\frac{S_{k L V}^{\prime \prime}}{\sqrt{3} U_{N}}=\frac{10.2 \cdot 10^{6}}{\sqrt{3} \cdot 0.4 \cdot 10^{3}}=14.7 \mathrm{kA}
\end{aligned}
$$

e. Equivalent of the conductor impedance from LV switchgear to PCC $U_{N}=0.4 \mathrm{kV}$

$$
\begin{aligned}
& R_{L}=\frac{l}{\gamma \cdot s}=\frac{100}{55 \cdot 16}=0.113 \Omega=113.6 \mathrm{~m} \Omega \\
& X_{L}=x_{L}^{\prime} \cdot l=0.1 \cdot 100 \mathrm{~m} \Omega=10 \mathrm{~m} \Omega
\end{aligned}
$$

f. Short circuit condition in point of common coupling PCC $U_{N}=0.4 \mathrm{kV}$ for symmetrical three-phase fault scenario

$$
\begin{aligned}
& R_{k P C C}=R_{Q}+R_{T}+R_{L}=0+2.5 m \Omega+113.6 m \Omega=116.1 \mathrm{~m} \Omega \\
& X_{k P C C}=X_{Q}+X_{T}+X_{L}=0.5 m \Omega+15 m \Omega+10 m \Omega=25.5 m \Omega \\
& \underline{Z}_{k P C C}=R_{k P C C}+j X_{k P C C}=(116.1+j 25.5) m \Omega \\
& \frac{R_{k P C C}}{X_{k P C C}}=\frac{115.5}{25.5}=4.55 ; \quad Z_{k P C C}=\sqrt{R_{k P C C}^{2}+X_{k P C C}^{2}}=119.0 m \Omega, \quad \psi_{k P C C}=\arctan \left(\frac{X_{k P C C}}{R_{k P C C}}\right)=12.4^{0} \\
& S_{k P C C}=\frac{U_{N}^{2}}{Z_{k P C C}}=\frac{\left(0.4 \cdot 10^{3}\right)^{2}}{119 \cdot 10^{-3}}=1.344 M V A \\
& S_{k P C C}=\sqrt{3} \cdot U_{N} \cdot I_{k P C C} \rightarrow I_{k P C C}=\frac{S_{k P C C}}{\sqrt{3} U_{N}}=\frac{1.344 \cdot 10^{6}}{\sqrt{3} \cdot 0.4 \cdot 10^{3}}=1.941 \mathrm{kA}=1941 \mathrm{~A}
\end{aligned}
$$




\subsection{Estimation of influence of the investigated PV system on power quality parameters in} PCC

Having short circuit condition in the PCC, it is possible to estimate the influence of the considered PV system on particular power quality parameters in the PCC. At the same time, it is worth stressing that the general level of the power quality in the investigated PCC depends on the network and should be treated as the background. It means that estimation should be dedicated to independent influences coming from the investigated PV system. In order to precisely present the estimation, the calculation is performed for the whole PV system is considered as a three-phase unit not particularly a one-phase subsystem. Thus, $S_{\text {Amax }}=15 \mathrm{kVA}$ is used instead of $S_{\text {Emax }}=5 \mathrm{kVA}$.

\section{a. Estimation of change of voltage level, slow voltage changes in PCC}

The influence of the investigated PV system on voltage level in PCC depends on the regulation of $\cos \varphi(\mathrm{P})$. If the system is considered working with $\operatorname{constant} \cos \varphi=1$ the influence on static voltage change can be approximated as:

$$
\Delta u_{a}=\frac{S_{A \max }\left(R_{k P C C}\right)}{U_{N}^{2}} 100 \%=\frac{15 \cdot 10^{3}\left(116.1 \cdot 10^{-3}\right)}{\left(0.4 \cdot 10^{3}\right)^{2}} 100=1.01 \%
$$

If the characteristic $\cos \varphi(\mathrm{P})$ is implemented and reactive power consumption is realized, then the static voltage changes can be reduced to:

$$
\begin{aligned}
& \Delta u_{a}=\frac{S_{A \max }\left(R_{k P C C} \cos \left(\varphi_{c a p}\right)-X_{k P C C} \sin \left(\varphi_{\text {cap }}\right)\right)}{U_{N}^{2}} 100 \%= \\
& =\frac{15 \cdot 10^{3}\left(116.1 \cdot 10^{-3} \cdot 0.9-25.5 \cdot 10^{-3} \cdot 0.44\right)}{\left(0.4 \cdot 10^{3}\right)^{2}} 100 \%=0.88 \%
\end{aligned}
$$

It is worth noticing that the permissible level is noted at 3\%.

\section{b. Estimation of rapid voltage changes in PCC}

For PV systems, the start coefficient is $\mathrm{k}=1.1$. The influence of the PV system on rapid voltage changes caused by the switching operation can be estimated using the formula:

$$
\Delta u_{\max }=k \frac{S_{A \max }}{S_{k P C C}} 100 \%=1.1 \cdot \frac{15 \cdot 10^{3}}{1.344 \cdot 10^{6}} 100 \%=1.22 \%
$$


In comparison to the obtained value, the permissible level of fast voltage changes is $3 \%$.

\section{c. Estimation of voltage fluctuation in PCC}

For given short circuit conditions in PCC, the short circuit power coefficient $R_{k}$ equals:

$$
R_{k}=\frac{S_{k P C C}}{S_{E \max }}=\frac{1.344 \cdot 10^{6}}{15 \cdot 10^{3}}=89.7
$$

It is not possible to estimate directly the level of $\mathrm{P}_{1 \mathrm{t}}$ or $\mathrm{P}_{\mathrm{st}}$ coefficients contributed by the investigated PV system. However, corresponding to EMC standards [33] and [34] where the limits of $P_{1 t}=0.65$ and $P_{s t}=1$ are given for the condition $R_{k}=33.3$, it can be concluded that for obtained $R_{k}=89.7$, the influence of the PV system on voltage fluctuation should be not higher than the required standards.

\section{d. Estimation of voltage asymmetry in PCC}

Because the PV system consists of three subsystems with the same nominal power $S_{\text {Emax }}=5$ $\mathrm{kVA}$, no influence on voltage asymmetry can be assumed. However, it should be precisely noted that subsystems are based on different solar technologies and one of the subsystem in phase L3 has a different geographical direction (L3: $255^{\circ}$ South-West) than other subsystems (L1 and L2: $135^{\circ}$ South-East). From these reasons, some possible influence on voltage asymmetry is predicted but cannot be directly estimated.

\section{e. Estimation of current harmonic, interharmonics, and DC injection}

For the considered PCC, short circuit power coefficient $R_{k}=89.7$. Thus, it can be assumed that the current harmonics should not be higher than the limits given in the EMC standards [31] and [32] established for the condition $R_{k}=33.3$. However, due to higher levels of the coefficient $R_{k}=89.7$, the permissible harmonic current can be higher and recalculated basing on estimated $\mathrm{S}_{\mathrm{kPCC}}=1.344 \mathrm{MVA}$ following the proposed formula in [43]:

$$
i_{v z u l}=\frac{I_{v z u l}}{S_{k P C C}} \rightarrow I_{v z u l}=i_{v z u l} \cdot S_{k P C C}
$$

Following by this suggestion Table 5 express comparison of the permissible current harmonics taking into consideration directly from standard [31] as well permissible values recalculated on the basis of the short circuit apparent power in PCC as it is proposed in [43].

There is no possibility to asses DC injection. However, it should be emphasized that due to different PV technologies in phase L2 a PV inverter with transformer is applied. Phases L1 and L3 have transformerless inverters. Following the EN standard [29] and IEEE standard [40] it can be specified that PV systems shall not inject DC current greater than $0.5 \%$ of the full-rated output current. Thus, it is required that DC injection should not cross value: 


$$
I_{d c}=0.005 \cdot I_{r E}=0.005 \cdot \frac{S_{E \max }}{U_{N}}=0.005 \cdot \frac{5000}{230}=108.7 \mathrm{~mA}
$$

\begin{tabular}{|c|c|c|c|}
\hline Order of harmonic & 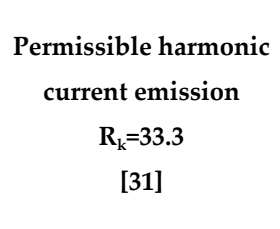 & $\begin{array}{c}\text { Permissible harmonic } \\
\text { current emission related to } \\
\mathrm{S}_{\mathrm{kPCC}} \\
{[43]}\end{array}$ & $\begin{array}{c}\text { Permissible harmonic } \\
\text { current emission } \\
\text { recalculated for considered } \\
\text { PCC S } \mathrm{S}_{\mathrm{kPCC}}=1.344 \mathrm{MVA} \text {, } \\
\mathrm{R}_{\mathrm{k}}=89.7\end{array}$ \\
\hline $\mathbf{n}$ & $\mathrm{I}[\mathrm{A}]$ & $i_{v z u l}[A / M V A]$ & $I_{\mathrm{vzul}}[\mathrm{A}]$ \\
\hline \multicolumn{4}{|c|}{ Odd harmonics } \\
\hline 3 & 2.3 & 3 & 4.03 \\
\hline 5 & 1.14 & 1.5 & 2.02 \\
\hline 7 & 0.77 & 1 & 1.34 \\
\hline 9 & 0.40 & 0.7 & 0.94 \\
\hline 11 & 0.33 & 0.5 & 0.67 \\
\hline 13 & 0.21 & 0.4 & 0.54 \\
\hline 17 & 0.132 & 0.3 & 0.40 \\
\hline 19 & 0.118 & 0.25 & 0.34 \\
\hline 23 & 0.098 & 0.2 & 0.27 \\
\hline 25 & 0.077 & 0.15 & 0.20 \\
\hline \multicolumn{4}{|c|}{ Even harmonics } \\
\hline 2 & 1.080 & 0.75 & 1.01 \\
\hline 4 & 0.430 & 0.38 & 0.50 \\
\hline 6 & 0.300 & 0.25 & 0.34 \\
\hline 8 & 0.230 & 0.19 & 0.25 \\
\hline 10 & 0.184 & 0.15 & 0.20 \\
\hline 12 & 0.153 & 0.13 & 0.17 \\
\hline 14 & 0.131 & 0.11 & 0.14 \\
\hline 16 & 0.115 & 0.09 & 0.13 \\
\hline 18 & 0.102 & 0.08 & 0.11 \\
\hline
\end{tabular}




\begin{tabular}{|c|c|c|c|}
\hline Order of harmonic & 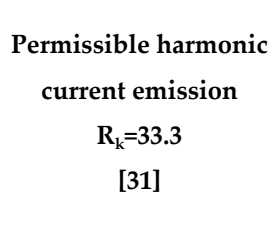 & $\begin{array}{l}\text { Permissible harmonic } \\
\text { current emission related to } \\
\qquad \mathrm{S}_{\mathrm{kPCC}} \\
{[43]}\end{array}$ & $\begin{array}{c}\text { Permissible harmonic } \\
\text { current emission } \\
\text { recalculated for considered } \\
\text { PCC S }_{\mathrm{kPCC}}=1.344 \mathrm{MVA} \text {, } \\
\mathrm{R}_{\mathrm{k}}=89.7\end{array}$ \\
\hline $\mathbf{n}$ & $\mathrm{I}[\mathrm{A}]$ & $i_{v z u l}[A / M V A]$ & $\mathbf{I}_{\mathrm{vzul}}[\mathrm{A}]$ \\
\hline 20 & 0.092 & 0.08 & 0.10 \\
\hline 22 & 0.084 & 0.07 & 0.09 \\
\hline 24 & 0.077 & 0.07 & 0.08 \\
\hline
\end{tabular}

Table 5. Limits for harmonic current emission for distributed generation units within the range of current up to $16 \mathrm{~A}$ in correspondence to limits for class A equipment [31] (for $R_{k}=33.3$ ) and limits for harmonic current emission for the considered PV system recalculated for the given $\mathrm{S}_{\mathrm{kPCC}}=1.344$ MVA [43] - fragment up to 25 harmonics.

\subsection{Verification of the influence of the investigated PV system on power quality parameters in PCC using real measurement}

In order to compare the estimated contribution of the investigated PV system on changes of particular power quality disturbances in the PCC, some real measurement was performed. A class A power quality recorder was installed in the PCC in order to analyze the influence of the PV system on power quality disturbances using field measurement data. In real measurement, the crucial problem is separating the influence of the PV from whole measurement. It constitutes a hard task to separate the background, which characterizes network and desired influence of the object. In order to obtain this aim, some correlation analysis is performed taking into account the production of energy with changes of the observed quality parameter. Due to one point measurement in some cases, a sharp separation between background and impact of the PV is not possible, and summary disturbances are evaluated in point of network requirements.

The general assessment of power quality parameters in the PCC was performed on the basis of one week of data following by the EN standard [28]. Thus, in this chapter, statistics is calculated on the basis of one week of data. However, in order to present the impact of the observed PV system on power quality parameters, one-day data is selected with high generation level. Secondly, in order to express the relationship between active power generation and changes of the investigated power quality parameter the construction of the figures has common manner. The bottom part of the figures contains the daily shape of active power production of particular phases associated with right additional Y-axis (L1, monocrystalline, $135^{\circ}$ South-East - black; L2, thin-layer copper indium gallium selenide, $135^{\circ}$ South-East brown, L3, polycrystalline $255^{\circ}$ South-West - gray) also with an additional line representing characteristic coordinates $\left(0.2_{\mathrm{PEmax}}=1 \mathrm{~kW}\right.$ red dashed and $0.5 \mathrm{P}_{\mathrm{Emax}}=2.5 \mathrm{~kW}$ red continuous $)$. In the higher part of the figures, investigated parameters of particular phases are presented associated with left Y-axis (L1 - orange, L2 - green, L3 - magenta). The aim of the figures 
construction is to represent the behavior of power quality parameters with relations to active power generation.

Classification of the relative impact of the PV subsystems on the investigated power quality parameters can be achieved using classical correlation index $r_{x y}$. In searching relations, $x$ is the active power generated by the PV subsystem, $y$ is the particular power quality parameter. Then using mean values of $x$ and $y$, the correlation index $r_{x y}$ can be expressed by:

$$
r_{x y}=\frac{\sum_{i=1}^{N}\left(x_{i}-\bar{x}\right)\left(y_{i}-\bar{y}\right)}{\sqrt{\sum_{i=1}^{N}\left(x_{i}-\bar{x}\right)^{2} \sum_{i=1}^{N}\left(y_{i}-\bar{y}\right)^{2}}} ;-1 \leq r_{x y} \leq 1
$$

Using the correlation index, a classification of the correlation can be introduced. Table 6 consists of ranges of correlation index and classification of the correlation.

\begin{tabular}{ccl}
\hline Positive correlation & Negative correlaiton & Classification \\
\hline$r_{x y}=0$ & $r_{x y}=0$ & Lack of correlation \\
\hline $0<r_{x y} \leq 0.1$ & $-0.1 \leq r_{x y}<0$ & Faint correlation \\
\hline $0.1<r_{x y} \leq 0.4$ & $-0.4 \leq r_{x y}<-0.1$ & Weak correlation \\
\hline $0.4<r_{x y} \leq 0.7$ & $-0.7 \leq r_{x y}<-0.4$ & Visible correlation \\
\hline $0.7<r_{x y} \leq 0.9$ & $-0.9 \leq r_{x y}<-0.7$ & High correlation \\
\hline$r_{x y}>0.9$ & $r_{x y}<-0.9$ & Force correlation \\
\hline
\end{tabular}

Table 6. Classification of the correlation using correlation index $\mathrm{r}_{\mathrm{xy}}$.

\subsubsection{Assessment of power factor regulation}

Referring to Figure 4, every $5 \mathrm{~kW}$ one-phase subsystem realizes a reactive power regulation in relation to active power generation. Standard characteristic $\cos \varphi(\mathrm{P})$ contains two characteristic points: $0.2_{\mathrm{PE} \max }=1 \mathrm{~kW}$ and $0.5 \mathrm{P}_{\mathrm{Emax}}=2.5 \mathrm{~kW}$. After $0.5 \mathrm{P}_{\mathrm{Emax}} \mathrm{PV}$ inverters are forced to consume reactive power. Figure 8 emphasizes that $\cos \varphi(\mathrm{P})$ regulation is performed by the PV inverters. However, the level of reactive power consumption is less than the noted standard characteristic $\cos \varphi(\mathrm{P})$. Figure 9 shows that the reduction of reactive power is performed before characteristic point $0.5 \mathrm{P}_{\mathrm{Emax}}$, but the speed of the reduction is slower than th standard characteristic. Maximum reactive power consumption is $\mathrm{P}_{\mathrm{Emax}}=5 \mathrm{~kW}$ should be on the level of $\mathrm{Q}_{\mathrm{Emax}}=$ -1.65 kvar (the ratio $\mathrm{Q}_{\mathrm{Emax}} / \mathrm{P}_{\mathrm{Emax}}-0.33$ ). 


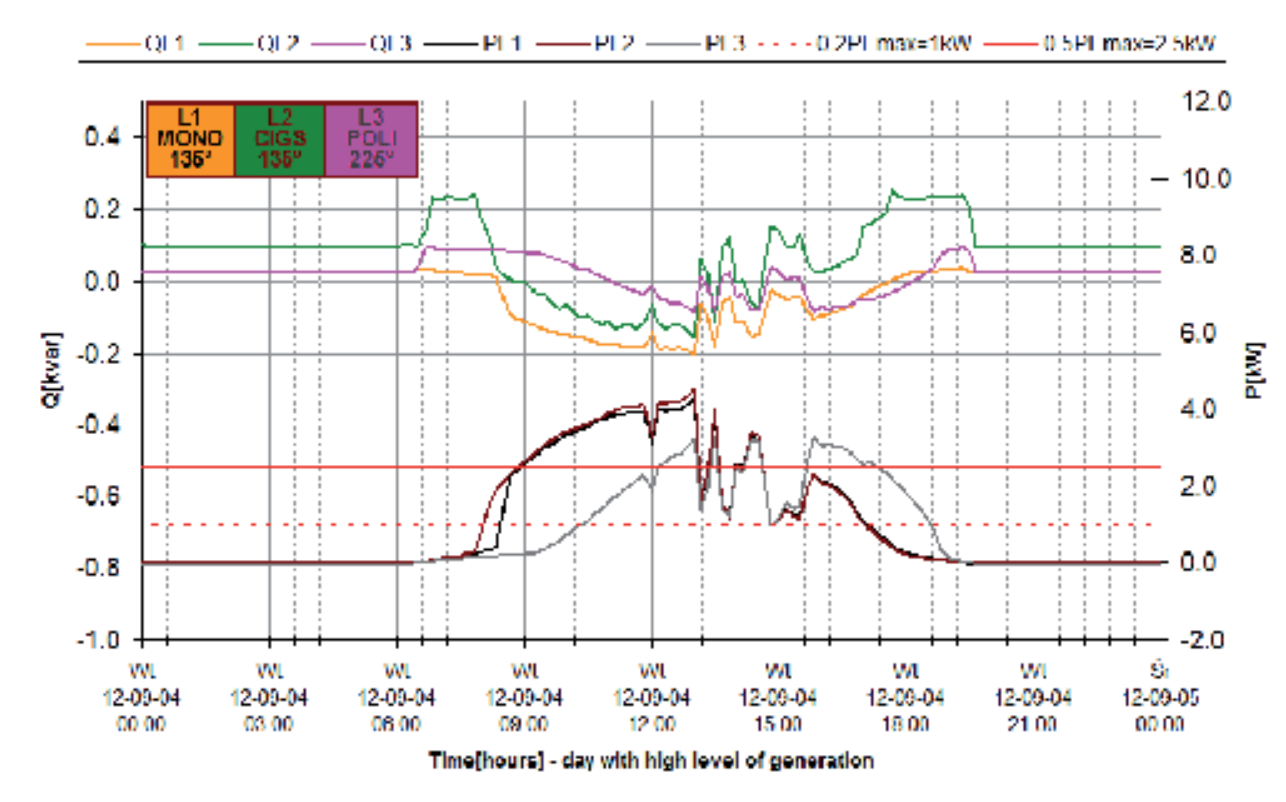

Figure 8. Reactive power regulation in relation to active power generation with characteristic coordintaes $0.2 \mathrm{P}_{\mathrm{Emax}}=1$ $\mathrm{kW}$ and $0.5 \mathrm{P}_{\text {Emax }}=2.5 \mathrm{~kW}$.

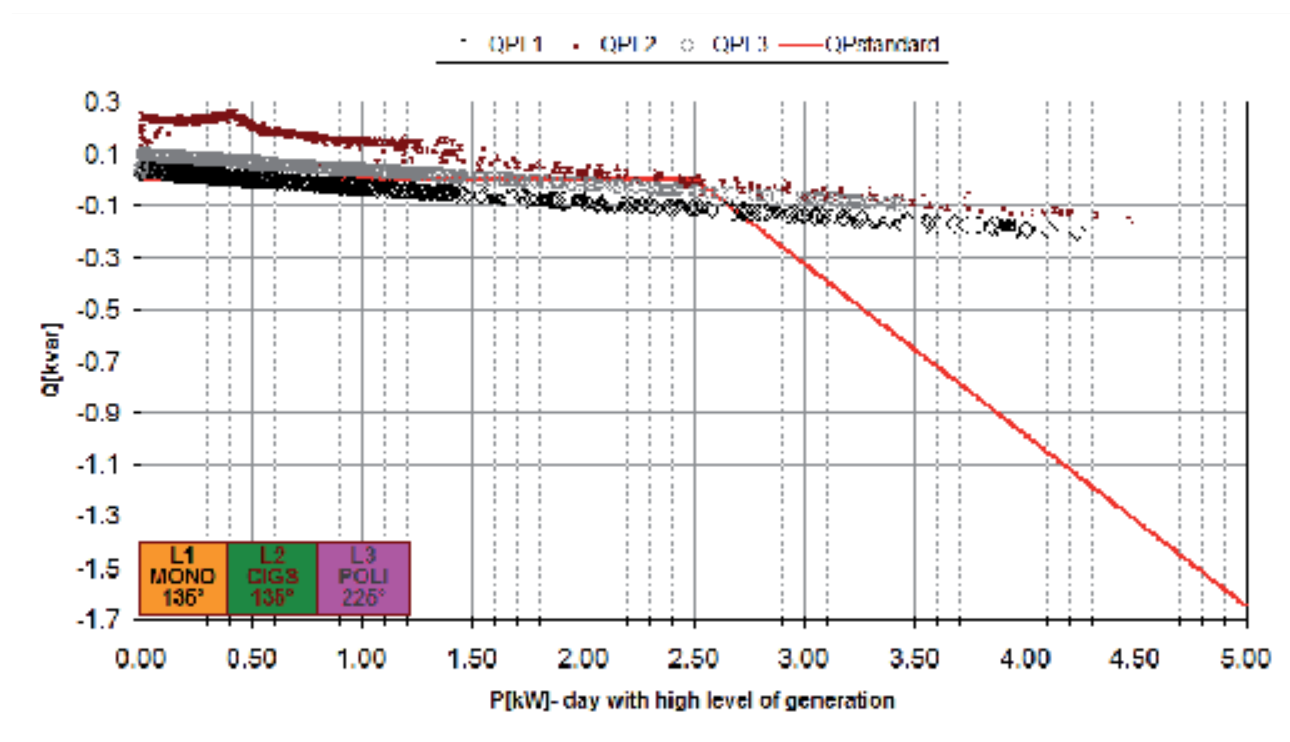

Figure 9. Comparison of reactive power regulation for particular PV subsystems in relation to the standard $\cos \varphi(\mathrm{P})$ characteristic. 


\subsubsection{Assessment of frequency change}

Generally, faint impact of the PV subsystems on mains frequency is concluded. In Figure 10, some relations are visible especially when production of active power changes rapidly, however, direct relation is hard to identify. Moreover, the fluctuation of frequency is contaminated by changes of network parameters. The general statistics using $10 \mathrm{~s}$ averaging data shows that during one week of measurement, the PCC has fulfilled the low-voltage network requirements for frequency changes.

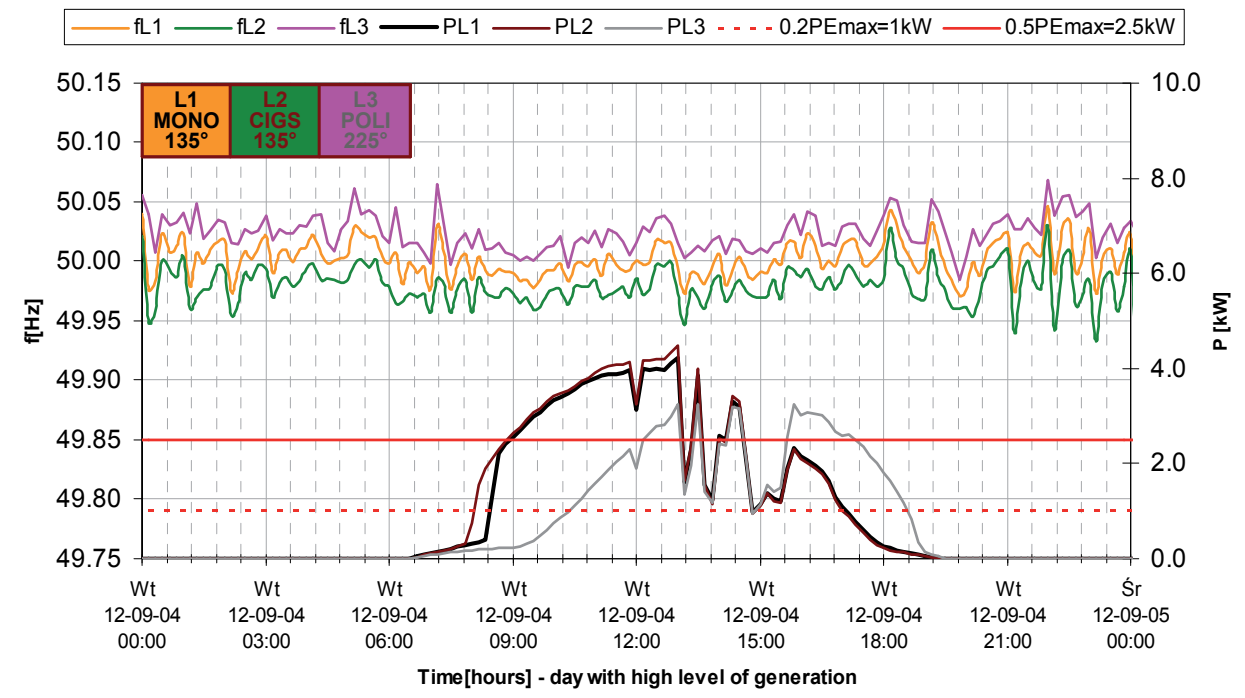

\begin{tabular}{|c|c|c|}
\hline \multicolumn{2}{|c|}{$\begin{array}{c}\text { One week frequency changes } \\
\text { parameters }\end{array}$} & $\mathrm{f}$ \\
\cline { 2 - 3 } & $\min$ & $4 \mathrm{~Hz}]$ \\
\hline \multirow{3}{*}{$\mathrm{f}$} & $\mathrm{P} 99.5$ & 59.902 \\
\cline { 2 - 3 } & $\max$ & 50.088 \\
\cline { 2 - 3 } & \multicolumn{2}{|c|}{} \\
\hline
\end{tabular}

Figure 10. Mains frequency changes in the PCC with reference to the PV subsystem's active power generation and selected one-week data statistics.

\subsubsection{Assessment of change of voltage level, slow voltage changes}

Figure 11 shows the visible impact of PV subsystems on voltage levels in the PCC. This impact stays in relation to the $\cos \varphi(\mathrm{P})$ characteristic. Increasing active power generation causes an increase in voltage levels. However, after crossing $0.5 \mathrm{P}_{\mathrm{Emax}}$ the positive aspect of consumption of reactive power generation on reduction of voltage increase is visible. Additional proof for the relationship between the voltage level and active power generation is the independent behavior of voltage levels in phase L3, where different geographical positions introduce natural delay in the irradiation and energy production that affects the delay of voltage changes. 
Calculation of the statistics using one week of data with a 10-minute average time concludes that the maximum voltage changes in the PCC is not higher than $1.7 \%$. This value consists of changes caused by the network and the considered PV subsystems. However, referring to the standards, the limit of $3 \%$ of the voltage change is preserved. Additionally, referring to section 3.2 where the estimated influence of the static voltage change caused by connecting the PV system was calculated on the level of $0.88 \div 1.01 \%$, it can then be concluded that the estimation is near percentile $95 \%$ of real measured data.

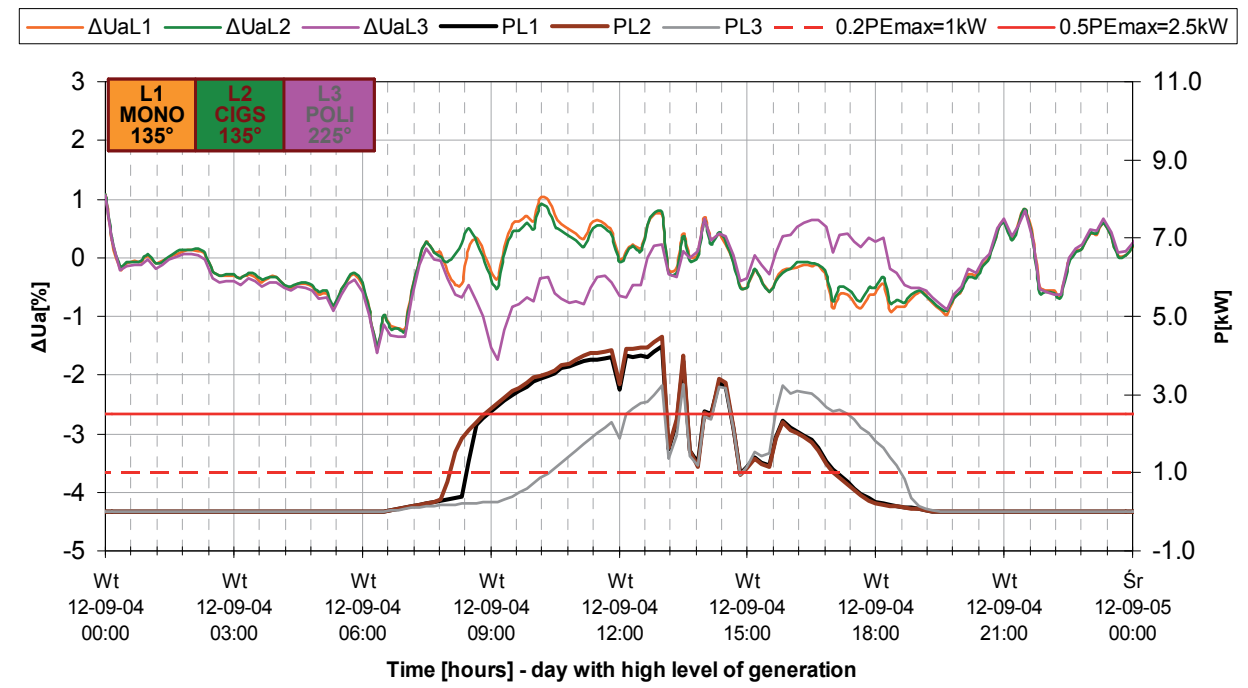

\begin{tabular}{|c|c|c|c|c|}
\hline \multirow{2}{*}{$\begin{array}{c}\text { One week static voltage } \\
\text { changes parameters }\end{array}$} & $\begin{array}{c}\text { L1 / MONO } \\
\mathbf{1 3 5 ^ { 0 }}\end{array}$ & {$[\%]$} & 1350 & \\
\cline { 2 - 5 } & min. & 0 & 0 & {$[\%]$} \\
\hline \multirow{3}{*}{$\left|\Delta \mathcal{u}_{a}\right|$} & mean & 0,5 & 0,5 & 0 \\
\cline { 2 - 5 } & percentile 95 & 1,1 & 1,2 & 0,6 \\
\cline { 2 - 5 } & $\max$ & 1,5 & 1,6 & 1,2 \\
\hline
\end{tabular}

Figure 11. Static voltage changes in the PCC with reference to the PV subsystem's active power generation and selected one-week data statistics.

In order to emphasise the relationship between PV generation and voltage in the PCC, the correlation index $\mathrm{r}_{\mathrm{xy}}$ can be calculated. Correlation analysis is presented in Figure 12 and reveals that the impact of active power generation on voltage level classifies the relation as visible.

\subsubsection{Assessment of rapid voltage changes}

In order to investigate the influence of the operating condition of the PV system on transient voltage behavior, a sudden switching off test was performed. Figure 13 represents rapid 
voltage changes during the test. Parameterization of the voltage behavior allows to find the maximum rapid voltage changes equals $2.4 \%$. Corresponding to the estimates in section 3.2 with rapid voltage changes on the level of $1.22 \%$, it can be concluded that the real influence is about two times higher.
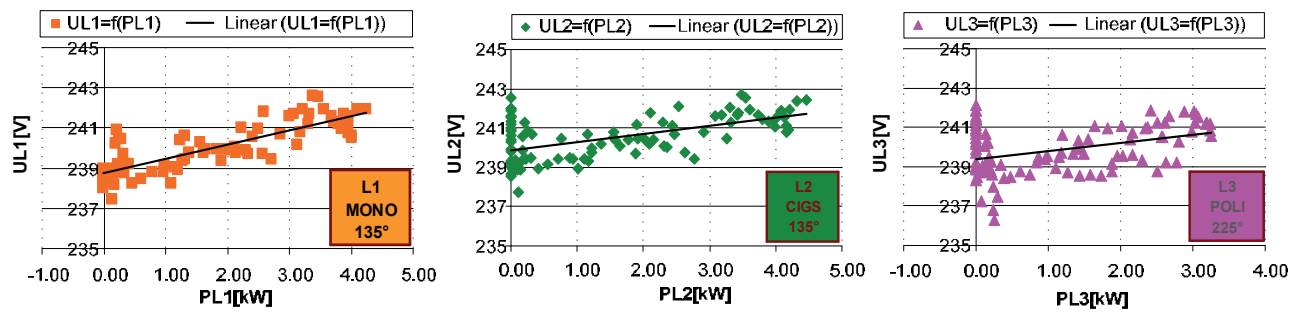

\begin{tabular}{|c|c|c|c|}
\hline \multirow{2}{*}{$\begin{array}{l}\text { Correlation index } \\
\text { between } \mathrm{P} \text { and } \Delta u_{a}\end{array}$} & $\begin{array}{c}\text { L1 / MONO } \\
135^{\circ}\end{array}$ & $2 / \mathrm{CIG}$ & 2 \\
\hline & {$[-]$} & {$[-]$} & {$[-]$} \\
\hline$r_{x y}$ & 0.59 & 0.57 & 0.38 \\
\hline
\end{tabular}

Figure 12. Correlation analysis of the impact of active power generation on static voltage levels.

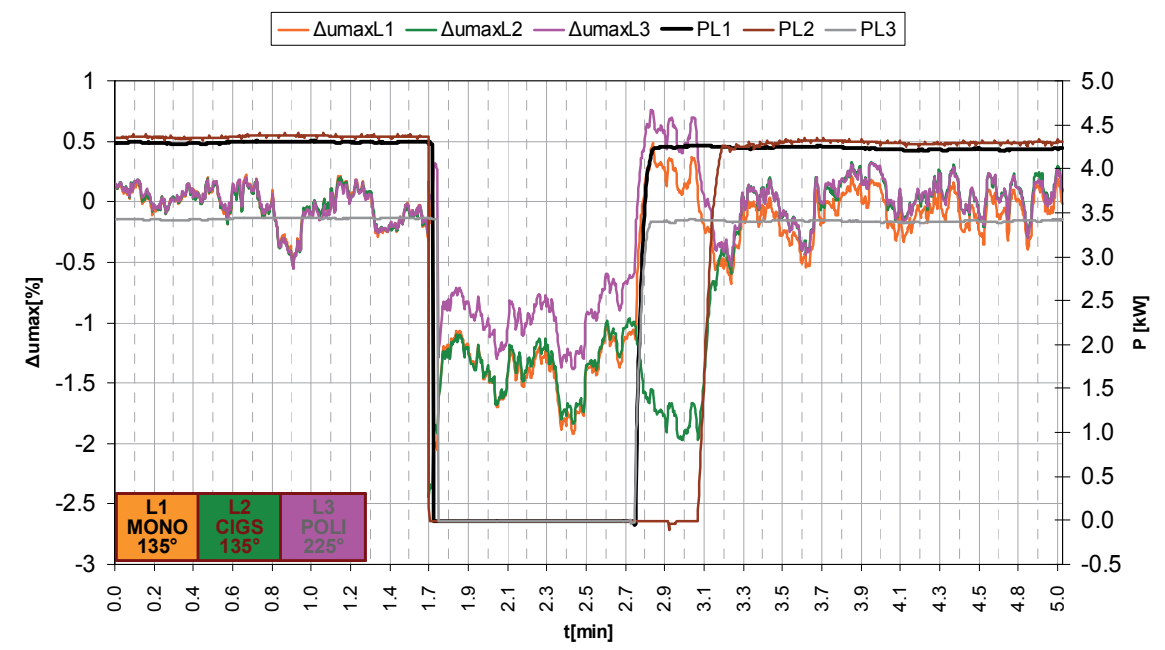

\begin{tabular}{|c|c|c|c|}
\hline \multirow{2}{*}{$\begin{array}{l}200 \mathrm{~ms} \text { rapid voltage } \\
\text { changes parameters }\end{array}$} & $\begin{array}{c}\text { L1/ MONO } \\
135^{\circ} \\
\end{array}$ & $135^{\circ}$ & \\
\hline & [\%] & [\%] & [\%] \\
\hline$\Delta u_{\max }$ & 2,1 & 2,4 & 1,4 \\
\hline
\end{tabular}

Figure 13. Rapid voltage changes caused by switching off the generation and selected parameters of the change on the basis of continuous $200 \mathrm{~ms}$ recording. 


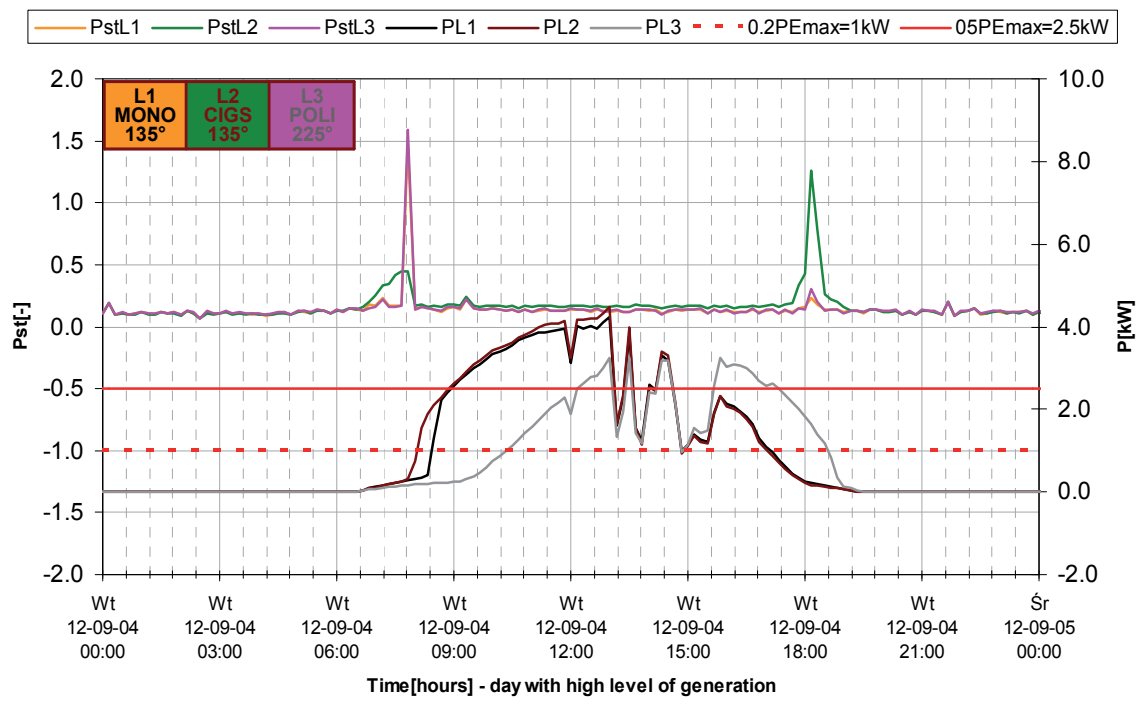

\begin{tabular}{|c|c|c|c|c|}
\hline \multicolumn{2}{|c|}{$\begin{array}{c}\text { One week voltage } \\
\text { fluctuation parameters }\end{array}$} & $\begin{array}{c}\text { L1 / MONO } \\
135^{0}\end{array}$ & & \\
\cline { 3 - 5 } & & {$[\%]$} & {$[\%]$} & {$[\%]$} \\
\hline \multirow{3}{*}{$P_{s t}$} & min. & 0,07 & 0,07 & 0,07 \\
\cline { 2 - 5 } & mean & 0,13 & 0,17 & 0,13 \\
\cline { 2 - 5 } & percentile 95 & 0,17 & 0,35 & 0,16 \\
\cline { 2 - 5 } & $\max$ & 1,46 & 1,77 & 1,58 \\
\hline
\end{tabular}

Figure 14. Voltage fluctuations in the PCC with reference to the PV subsystem's active power generation and selected one-week data statistics.

\subsubsection{Assessment of voltage fluctuations}

In section 3.2, it was estimated that due to the higher levels of short circuit coefficient $R_{k}=89.7$ than the standard $R_{k}=33.3$, voltage fluctuation should be not higher than $P_{l t}=0.65$ and $P_{s t}=1$. Verification of this assumption using real measurement of $\mathrm{P}_{\mathrm{st}}$ is presented in Figure 14 . Generally, it can be concluded that $95 \%$ of one week short term flicker severity index is not higher than 0.35 , which follows what is expected. However, some local extremes are founded with cross-permissible value equals 1 . Unfortunately, it cannot be acertained if the local increase of voltage fluctuation comes from the PV systems or is an effect of network influence. A wider investigation should be performed in order to eliminate influence of dominating loads or capacitor banks, or focus on specific point of regulation characteristic of $\cos \varphi(\mathrm{P}) 0.2 \mathrm{P}_{\mathrm{Emax}}$ when PV systems are forced to produce only active power.

\subsubsection{Assessment of voltage asymmetry}

Rough assessment assuming the same nominal power of the three PV subsystems brings to the conclusion that the PV system has no influence on voltage asymmetry. However, detailed investigation should be taken into consideration and fact that one of the subsystem in phase 


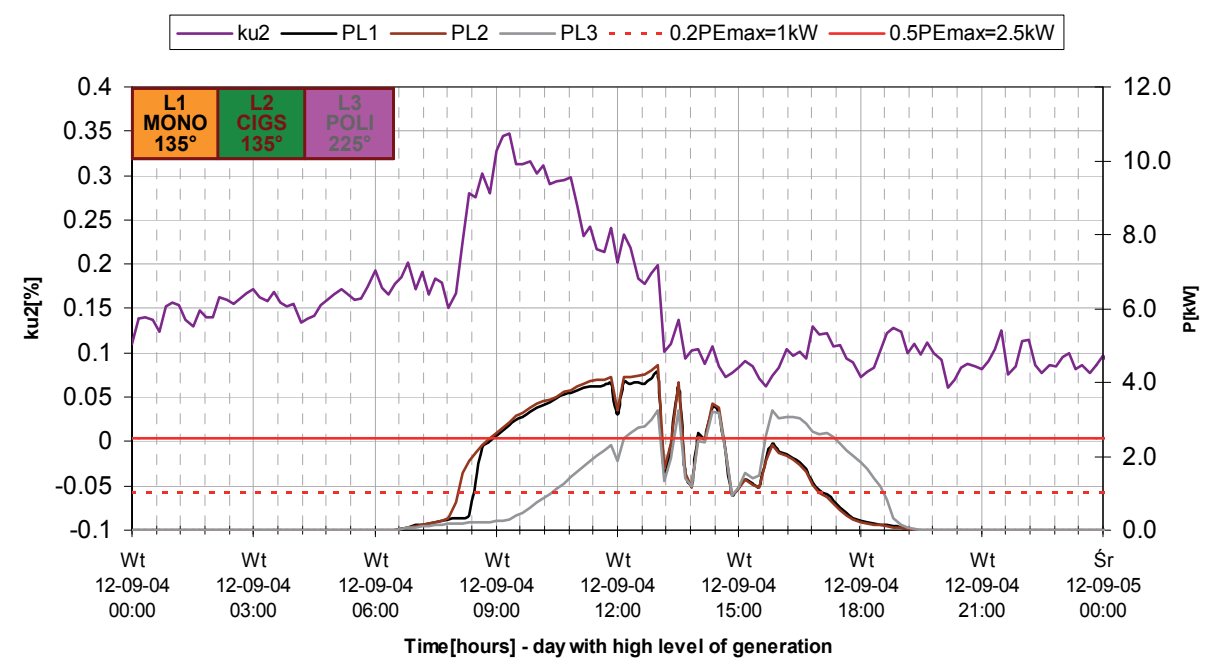

\begin{tabular}{|c|c|c|}
\hline \multicolumn{2}{|c|}{$\begin{array}{c}\text { One week voltage asymmetry } \\
\text { parameters }\end{array}$} & $k_{u 2}$ \\
\cline { 2 - 3 } & min. & {$[\%]$} \\
\hline \multirow{4}{*}{$k$ k2 } & mean & 0,02 \\
\cline { 2 - 3 } & percentile 95 & 0,12 \\
\cline { 2 - 3 } & max & 0,21 \\
\cline { 2 - 3 } & & 0,35 \\
\hline
\end{tabular}

Figure 15. Voltage asymmetry in the PCC with reference to the PV subsystem's active power generation and selected one-week data statistics.

L3 has a different geographical direction (L3: 255 South-West) than other subsystems (L1 and L2: $135^{\circ}$ South-East). From these reason, Figure 15 shows that an influence on voltage asymmetry is visible due to the delay in irradiation in subsystem L3. Maximum asymmetry coefficient $\mathrm{k}_{\mathrm{u} 2}$ found among one-week data measurement is 0.35 .

\subsubsection{Assessment of current harmonics, DC injection}

Field measurement uncovers relationships between active power generation and the types of PV technologies on current harmonics. Observing Figure 16 and Figure 17, it can be concluded that the total harmonic distortion index in the current is high negative correlated with generated active power. It means that for higher levels of generation, current harmonics is reduced. Additionally, in phase L2 where thin-layer copper indium gallium selenide PV technology with inverter and transformer is applied, the THDI is higher than in other technologies with transformerless inverters. Maximum measurement of harmonics from 1 to 25 during one week of measurement was collected in Table 7. Corresponding to section 3.2 , the table shows that using limits from the EMC standard as base of the assessment, $7^{\text {th }}$ and $15^{\text {th }}$ harmonics have not passed the assessment. However, assessment using recalculated limits related to short circuit power condition gives a positive assessment for all presented harmonics. 
One week measurement

\begin{tabular}{|c|c|c|c|c|c|c|c|}
\hline \multirow[b]{2}{*}{ Harmonic order } & \multicolumn{3}{|c|}{$\begin{array}{l}\text { One week measurement } \\
\text { max. }\end{array}$} & \multirow{2}{*}{$\begin{array}{c}\text { Limits } \\
\mathbf{R}_{\mathrm{k}}=33.3 \\
{[31]}\end{array}$} & \multirow{2}{*}{$\begin{array}{c}\text { Assessment } \\
\qquad \mathbf{R}_{\mathrm{k}}=33.3\end{array}$} & \multirow{2}{*}{$\begin{array}{c}\text { Limits } \\
\mathrm{R}_{\mathrm{k}}=89.7 \\
{[43]}\end{array}$} & \multirow{2}{*}{$\begin{array}{c}\text { Assessment } \\
\mathbf{R}_{\mathrm{k}}=89.7\end{array}$} \\
\hline & $\begin{array}{c}\text { L1 / } \\
\text { MONO } \\
135^{\circ}\end{array}$ & $\begin{array}{c}\text { L2 / CIGS } \\
135^{\circ}\end{array}$ & $\begin{array}{c}\text { L3 / POLI } \\
225^{\circ}\end{array}$ & & & & \\
\hline $\mathrm{n}$ & {$[\mathrm{mA}]$} & {$[\mathrm{mA}]$} & {$[\mathrm{mA}]$} & {$[\mathrm{mA}]$} & {$[\mathrm{mA}]$} & & \\
\hline 2 & 15,47 & 115,04 & 17,70 & 1080 & $\sqrt{ }$ & 1010 & $\sqrt{ }$ \\
\hline 3 & 120,54 & 443,08 & 134,53 & 2300 & $\sqrt{ }$ & 4030 & $\sqrt{ }$ \\
\hline 4 & 13,79 & 65,17 & 12,21 & 430 & $\sqrt{ }$ & 500 & $\sqrt{ }$ \\
\hline 5 & 94,61 & 836,59 & 116,04 & 1140 & $\sqrt{ }$ & 2020 & $\sqrt{ }$ \\
\hline 6 & 13,71 & 52,22 & 13,07 & 300 & $\sqrt{ }$ & 340 & $\sqrt{ }$ \\
\hline 7 & 103,06 & 786,21 & 140,34 & 770 & - & 1340 & $\sqrt{ }$ \\
\hline 8 & 9,65 & 34,73 & 11,27 & 230 & $\sqrt{ }$ & 250 & $\sqrt{ }$ \\
\hline 9 & 43,32 & 235,22 & 46,63 & 400 & $\sqrt{ }$ & 940 & $\sqrt{ }$ \\
\hline 10 & 6,87 & 33,67 & 7,00 & 184 & $\sqrt{ }$ & 200 & $\sqrt{ }$ \\
\hline 11 & 32,45 & 177,10 & 46,15 & 330 & $\sqrt{ }$ & 670 & $\sqrt{ }$ \\
\hline 12 & 6,23 & 27,86 & 6,51 & 153 & $\sqrt{ }$ & 170 & $\sqrt{ }$ \\
\hline 13 & 17,05 & 150,90 & 16,00 & 210 & $\sqrt{ }$ & 540 & $\sqrt{ }$ \\
\hline 14 & 4,32 & 26,33 & 5,50 & 131 & $\sqrt{ }$ & 140 & $\sqrt{ }$ \\
\hline 15 & 17,05 & 150,90 & 16,00 & 150 & - & $x$ & $x$ \\
\hline 16 & 5,73 & 25,81 & 5,08 & 115 & $\sqrt{ }$ & 130 & $\sqrt{ }$ \\
\hline 17 & 24,18 & 128,54 & 33,44 & 132 & $\sqrt{ }$ & 400 & $\sqrt{ }$ \\
\hline 18 & 5,01 & 25,67 & 5,18 & 102 & $\sqrt{ }$ & 110 & $\sqrt{ }$ \\
\hline 19 & 12,08 & 110,96 & 17,38 & 118 & $\sqrt{ }$ & 340 & $\sqrt{ }$ \\
\hline 20 & 5,33 & 27,28 & 6,03 & 92 & $\sqrt{ }$ & 100 & $\sqrt{ }$ \\
\hline 21 & 14,73 & 88,03 & 21,28 & 107 & $\sqrt{ }$ & $x$ & $x$ \\
\hline 22 & 5,42 & 30,69 & 5,00 & 84 & $\sqrt{ }$ & 90 & $\sqrt{ }$ \\
\hline 23 & 19,84 & 83,83 & 26,06 & 98 & $\sqrt{ }$ & 270 & $\sqrt{ }$ \\
\hline 24 & 5,22 & 33,33 & 5,42 & 77 & $\sqrt{ }$ & 80 & $\sqrt{ }$ \\
\hline 25 & 21,64 & 82,41 & 26,91 & 90 & $\sqrt{ }$ & 200 & $\sqrt{ }$ \\
\hline
\end{tabular}

$\sqrt{ }$ - positive assessment; - negative assessment, $\mathrm{x}$ - not specified in the standard

Table 7. Assessment of harmonic current emissions in correspondence to limits for class A equipment [31] (for $R_{k}=33.3$ ) and limits for harmonic current emission for the considered PV system recalculated for the given $S_{\mathrm{kPCC}}=1.344 \mathrm{MVA}$ (for $\mathrm{R}_{\mathrm{k}}=89.7$ ) [43] - fragment up to 25 harmonics. 


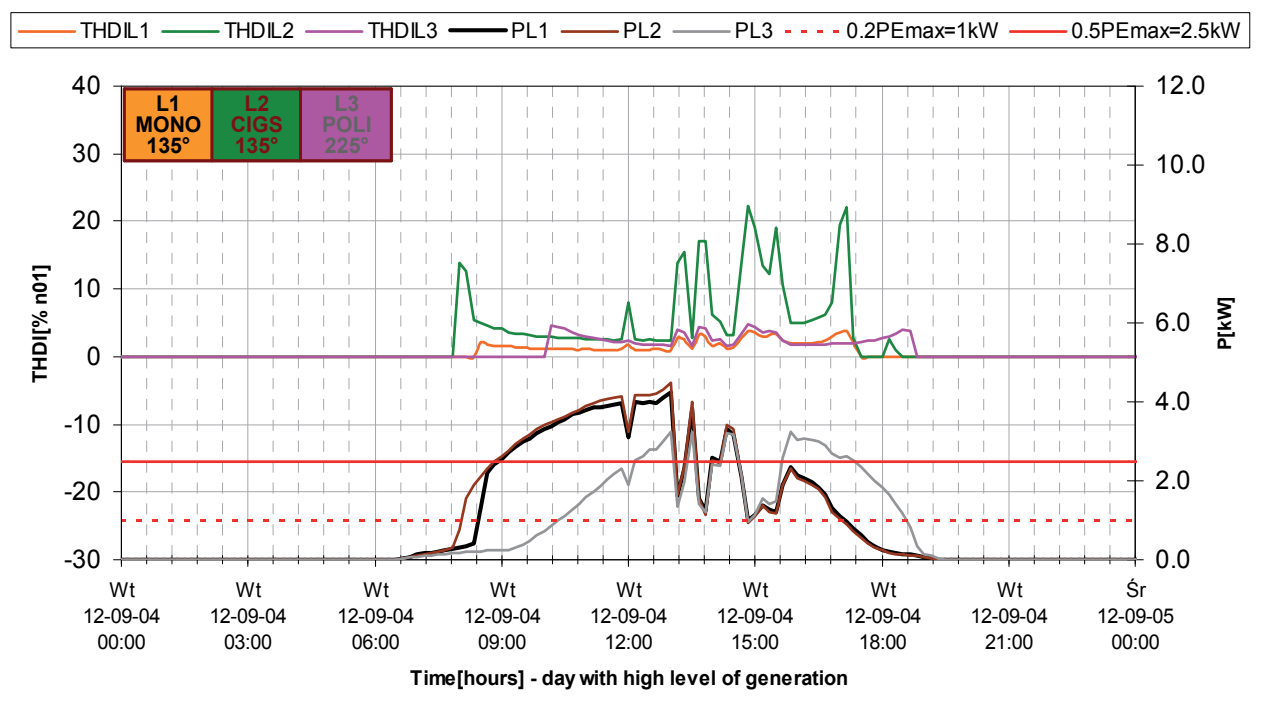

\begin{tabular}{|c|c|c|c|c|}
\hline \multicolumn{2}{|c|}{$\begin{array}{c}\text { One week THDI } \\
\text { parameters }\end{array}$} & $\begin{array}{c}\text { L1 / MONO } \\
135^{0}\end{array}$ & L2 CIGS & \\
\cline { 3 - 5 } \multicolumn{2}{|c|}{} & {$[\%]$} & {$[\%]$} & {$[\%]$} \\
\hline \multirow{3}{*}{ THDI } & min. & 0,00 & 0,00 & 0,00 \\
\cline { 2 - 5 } & mean & 0,64 & 3,12 & 0,79 \\
\cline { 2 - 5 } & percentile 95 & 3,23 & 19,50 & 4,18 \\
\cline { 2 - 5 } & max & 4,03 & 30,36 & 5,41 \\
\hline
\end{tabular}

Figure 16. Total current harmonic distortion index in the PCC with reference to the PV subsystem's active power generation and selected one-week data statistics.
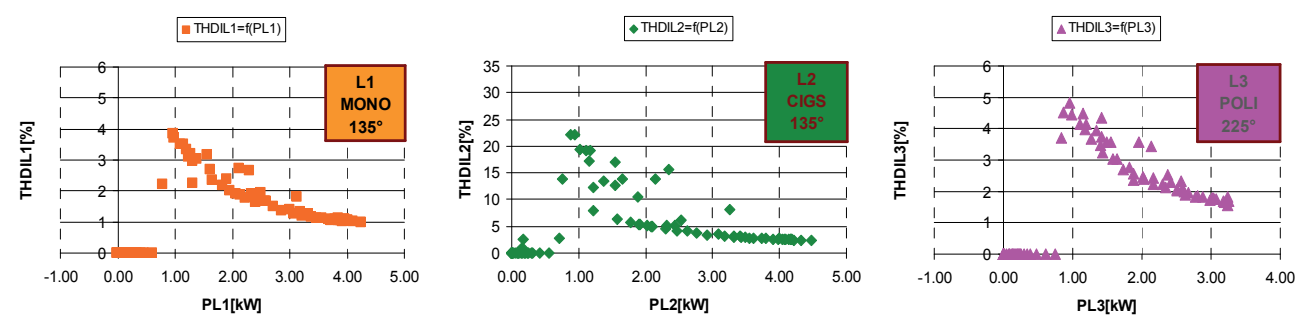

\begin{tabular}{|c|c|c|c|}
\hline \multirow{2}{*}{$\begin{array}{c}\text { Correlation index } \\
\text { between P and THDI }\end{array}$} & $\begin{array}{c}\text { L1 / MONO } \\
\mathbf{1 3 5 ^ { 0 }}\end{array}$ & $135^{0}$ & \\
\cline { 2 - 4 } & {$[-]$} & {$[-]$} & {$[-]$} \\
\hline$r_{x y}$ & -0.26 & -0.70 & -0.94 \\
\hline
\end{tabular}

Figure 17. Correlation analysis of the impact of active power generation on current harmonics THDI. 
In order to investigate DC current injection, a maximum $200 \mathrm{~ms}$ data recorded during one week of measurement was utilized. Corresponding to section 3.2, the limit for DC current injection is $0.5 \%$ of the rated output current, which in case of investigated PV subsystems, gives a limit of about $108.7 \mathrm{~mA}$. Figure 18 presents the measured changes of DC current injection. It can be concluded that $95 \%$ of the one-week measurement data fulfill the requirements. Additionally, phase L2 where thin-layer copper indium gallium selenide PV technology with inverter and transformer is applied is characterized by higher levels of DC current injection. The presented results provide a general assessment due to medium class precision of the DC current measurement.

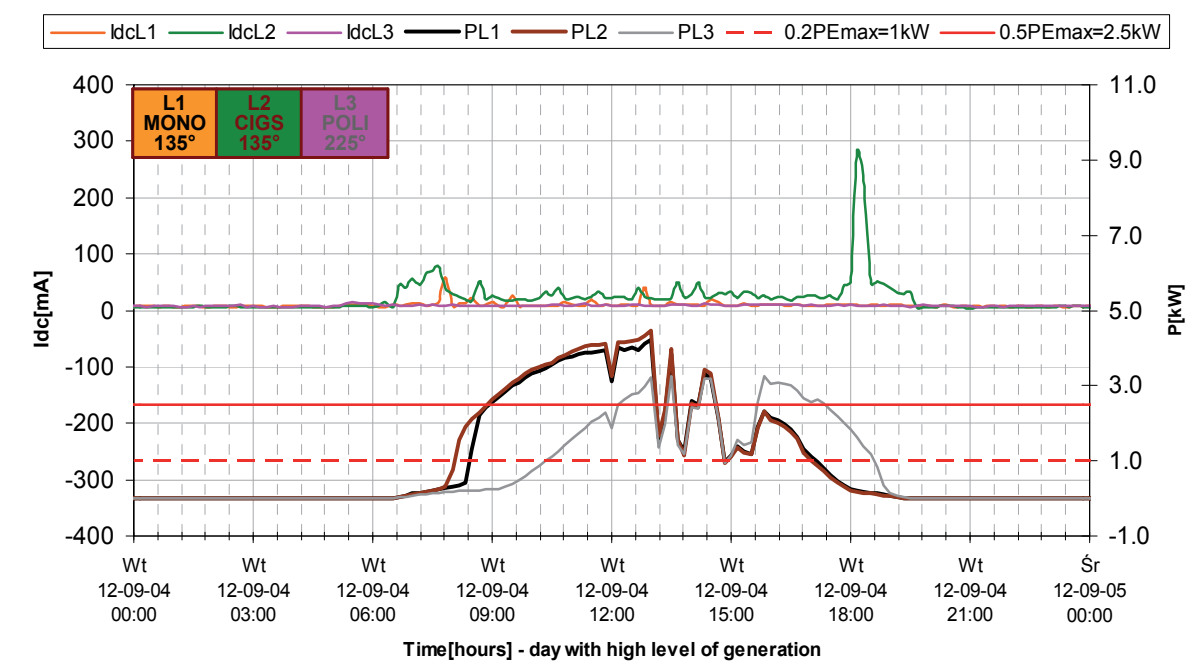

\begin{tabular}{|c|c|c|c|c|}
\hline \multicolumn{2}{|c|}{$\begin{array}{l}\text { One week dc current } \\
\text { injection parameters }\end{array}$} & $\begin{array}{c}\text { L1 / MONO } \\
\mathbf{1 3 5 ^ { 0 }}\end{array}$ & {$[350$} & \\
\cline { 2 - 5 } & {$[\mathrm{mA}]$} & {$[\mathrm{mA}]$} & {$[\mathrm{mA}]$} \\
\hline \multirow{3}{*}{$I_{d c}$} & min. & 5.610 & 3.700 & 5.745 \\
\cline { 2 - 5 } & mean & 9.231 & 20.214 & 8.476 \\
\cline { 2 - 5 } & percentile 95 & 14.222 & 55.717 & 11.791 \\
\cline { 2 - 5 } & $\max$ & 209.650 & 279.980 & 27.876 \\
\hline
\end{tabular}

Figure 18. DC current injection in the PCC with reference to the PV subsystem's active power generation and selected one-week data statistics.

\subsubsection{Assessment of voltage harmonics}

Generally, faint impact of the PV subsystems on voltage harmonic distortion is recognized. In Figure 19, some relations are visible when generation units start working with reactive power consumption mode (e.g., near $0.5 \mathrm{P}_{\mathrm{Emax}}$ ). However, this effect is not prominent. The general statistics using 10-minute averaging data shows that during one week of measurement, the PCC has fulfilled the low-voltage network requirements for total harmonic distortion index. 


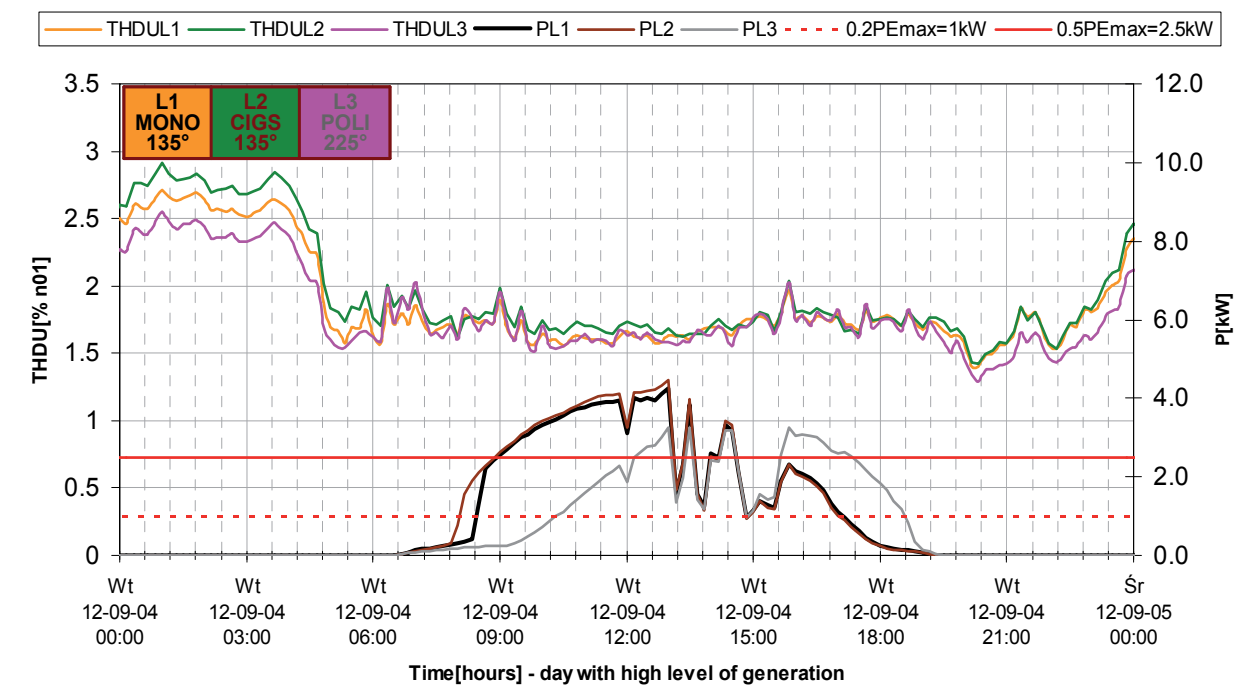

\begin{tabular}{|c|c|c|c|c|}
\hline \multirow{2}{*}{\multicolumn{2}{|c|}{$\begin{array}{c}\text { One week voltage } \\
\text { harmonic distortion } \\
\text { parameters }\end{array}$}} & $\begin{array}{c}\text { L1 / MONO } \\
135^{\circ}\end{array}$ & 2/ CIGS & DQ \\
\hline & & {$[\%]$} & {$[\%]$} & {$[\%]$} \\
\hline \multirow{4}{*}{ THDU } & min. & 1,32 & 1,40 & 1,27 \\
\hline & mean & 1,88 & 1,92 & 1,77 \\
\hline & percentile 95 & 2,64 & 2,78 & 2,43 \\
\hline & $\max$ & 2,92 & 3,05 & 2,69 \\
\hline
\end{tabular}

Figure 19. Total voltage harmonics distortion index in the PCC with reference to the PV subsystem's active power generation and selected one-week data statistics.

\section{Summary}

The review of the current approaches that impact DG power quality in LV networks reveals a few issues. Generally, one of the direction is to consider DG as LV public equipment and adopt the EMC approach, i.e., the same rules of interconnections, test methods, and emission limits as defined for the equipment before they obtain permission for unconditional connection in every point of the LV network. This approach can be named "pro-prosumer" approach. Second direction is to demand certifications of EMC as an undisputed part of equipment documentation, and additionally implement some rules and regulation in the point of integration of power system networks. This regulation considers reactive power regulation as a function of active power generation, active power reduction as a function of mains system frequency, as well as protective rules in case of under and over voltage or under and over frequency conditions. This chapter believes that both of the mentioned approaches should be used as complementary methods, which finally brings improvement on the possible impacts of the DG on power system networks. As it was shown, the combined approach allows to define a proposition of the limits of particular power quality parameters associated with the investi- 
gated node of LV network, but also allows to estimate the possible influences of DG on changes of particular power quality parameters in the PCC. This combination brings desirable effects in making the criteria for integration of DG with LV network.

The mentioned attitude was investigated using a real case study of a PV subsystem consisting of three independent one-phase subsystems. The estimated possible influence of the investigated PV on power quality parameters was delivered and calculated. As supplement, real measurement was also performed. Comparisons of measured power quality parameters with their calculated equivalent show similarities in the $95 \%$ range of the data. In reality, usually maximum results of measurement can be found in the $5 \%$ range of data, which exceed the calculated estimation. It should be emphasized that not every power quality can be estimated by calculations precisely. Measurement procedure allows to verify real influence of the investigated DG on power quality in the PCC, however, the task in not easy due to problems of separation of the searched influence from the measurement background.

One of the proposed approach is to affiliate changes of the investigated power quality parameters with the activities of the investigated DG, e.g., energy production. As it was presented, influence of the investigated PV static voltage changes or total harmonic distortion in current in the PCC correlation index can be also implemented in order to classify the force of the influence.

\section{Author details}

Tomasz Sikorski* and Jacek Rezmer

*Address all correspondence to: tomasz.sikorski@pwr.edu.pl

Wroclaw University of Technology, Faculty of Electrical Engineering, Poland

This work was supported by Polish Ministry of Higher Education and Science, project S40036.

\section{References}

[1] Ackerman T., Andersson G., Soder L., Distributed generation: A definition, Electrical Power System Research, vol. 57, s. 195-204, 2001.

[2] Ackerman T., Knyazkin V., Interaction between distributed generation and the distribution network: Operation aspects, Transmission and Distribution Conference, s. 1357-1362, 2002.

[3] Arrillaga J., Watson N.R., Power system harmonics, John Wiley \& Sons, 2003. 
[4] Arrillaga J. Watson N.R., Chen S., Power quality assessment, John Wiley \& Sons, 2001.

[5] Baggini A., Handbook of Power Quality, John Wiley \& Sons, 2008.

[6] Baocheng W., Xiaoquang G., Herong W., Qiang M, Real-time DC injection measurement technique for transformerless PV systems, IEEE International Symposium on Power Electronics in Distributed Generation Systems, 2010.

[7] Barker P.P., De Mollo R.W., Determining the impact of distributed generation on power system: I. Radial distribution systems, Power Engineering Society Meeting, vol. 3, s. 1645-1656, 2000.

[8] Bollen M.H.J., Understanding Power Quality Problems. Voltage sags and interruptions, IEE Press Series on Power Engineering, 2000.

[9] Bollen M.H.J, Gu Y.H.I., Signal processing of power quality disturbances, John Wiley \& Sons, 2006.

[10] Bollen M.H.J., Renders B., et al, Distributed Generation for Mitigating Voltage Dips in Low-Voltage Distribution Grids, IEEE Transaction on Power Delivery vol. 23, no. 3, 2008.

[11] Bollen M., Hassan F., Integration of distributed generation in the power systems, Wiley and IEEE Press, 2011.

[12] Caramia P., Carpinelli G., Verde P., Power Quality Indices in Liberalized Markets, John Wiley \& Sons, 2009.

[13] cigre Influence enhanced distributed generation on power system, TF 37.23 Report, Paris 1998.

[14] CIGRE Task Force C6.04.01 Connection criteria at the distribution network for distributed generation, Brochure 313, February 2007.

[15] Dondi P., Byoumi D., Headerli C., Julian D, Suter M., Network integration of distributed power generation, Journal of Power Sources, vol. 106, s. 1-9, 2002.

[16] Dugan R.C. Mcdermontt E., et al, Distributed Generation, IEEE Industry Application Magazine, 2002.

[17] Dugan R.C. Mcdermontt E., et al, PQ, Reliability and DG, IEEE Industry Application Magazine, 2003.

[18] Dugan R.C., et al., Electrical Power Systems Quality, McGraw-Hill, 2004.

[19] Dugan R.C., Walling R.A., et al, Summary of Distributed Resources Impact on Power Delivery Systems, IEEE Transactions on power delivery, vol. 23, no. 3, 2008.

[20] Freris L., Infield D., Renewable energy in power systems, John Wiley \& Sons, 2010.

[21] Fuchs E., Masoum M., Power quality in power systems and electrical machines, Academic Press, 2008. 
[22] Jenkins N., Embedded generation - Tutorial, Power Engineering Journal, s. 145-150, 1995.

[23] Kusko A., Thompson M.T., Power quality in electrical systems, McGraw Hill, 2007.

[24] Moreno-Munoz A., et al., Power Quality. Mitigation Technologies in Distributed Environments, Springer, 2007.

[25] Salas V., Olias E., Alonso M., Chenlo F., Barrado A., DC Current Injection into the Netwrok from PV Grid Inverters, IEEE 4th World Conference on Photovoltaic Energy Conversion, 2006.

[26] Sankaran C., Power quality, CRC Press, 2011.

[27] Stadler I., Study about International Standards for the connection of Small Distributed Generation to the power grid, Cologne University of Aplied Science, 2007.

[28] EN 50160, Voltage characteristics of electricity supplied by public distribution networks.

[29] EN 50438, Requirements for the connection if micro-generators in parallel with public low-voltage distribution networks.

[30] IEC 61000-2-2, Part 2-2: Environment - Compatibility levels for low-frequency conducted disturbances and signalling in public low-voltage power supply systems.

[31] IEC 61000-3-2, Part 3-2: Limits - Limits for harmonic current emissions (equipment input current $\leq 16$ A per phase).

[32] IEC 61000-3-12, Part 3-12: Limits - Limits for harmonic currents produced by equipment connected to public low-voltage systems with input current $>16 \mathrm{~A}$ and $\leq 75 \mathrm{~A}$ per phase.

[33] IEC 61000-3-3, Part 3-3: Limits - Limitation of voltage changes, voltage fluctuations and flicker in public low-voltage supply systems, for equipment with rated current $\leq$ 16 A per phase and not subject to conditional connection.

[34] IEC 61000-3-11, Part 3-11: Limits - Limitation of voltage changes, voltage fluctuations and flicker in public low-voltage supply systems - Equipment with rated current $\leq$ $75 \mathrm{~A}$ and subject to conditional connection.

[35] IEC/TR 61000-3-15, Project of Part 3-15 Limits - Assessment of low frequency electromagnetic immunity and emission requirements for dispersed generation systems in LV Network.

[36] IEC 61000-4-7, Part 4-7: Testing and measurement techniques - General guide on harmonics and interharmonics measurements and instrumentation, for power supply systems and equipment connected thereto.

[37] IEC 61000-4-15, Part 4-15: Testing and measurement techniques - Flickermeter Functional and design specifications. 
[38] IEC 61000-4-30, Part 4-30: Testing and measurement techniques - Power quality measurement methods.

[39] IEEE Std. 519, IEEE Recommended Practices and Requirements for Harmonic Control in Electrical Power Systems

[40] IEEE Std. 929, IEEE Recommended Practice for Utility Interface of Photovoltaic (PV) Systems, 2000.

[41] IEEE Std. 1159, Monitoring Electric Power Quality, IEEE Working Group on Monitoring Electric Power Quality reports to the Power Quality Subcommittee of the IEEE Power Engineering Society, 2003-2009.

[42] IEEE Std. 1547 - Series of Interconnection Standards, IEEE SCC21 Standards Coordinating Committee on Fuel Cells, Photovoltaics, Dispersed Generation, and Energy Storage, 2005-2011.

[43] VDE-AR-N 4105:2011-8, Power generation systems connected to the low-voltage distribution network - technical minimum requirements for the connection to and parallel operation with low-voltage distribution networks 

Chapter 2

\title{
Applications of Switch-Mode Rectifiers on Micro-grid Incorporating with EV and BESS
}

\author{
K. W. Hu and C. M. Liaw \\ Additional information is available at the end of the chapter \\ http://dx.doi.org/10.5772/61248
}

\begin{abstract}
A switch-mode rectifier (SMR) can provide adjustable and well-regulated DC output voltage from the available AC source with good line drawn power quality. Depending on the input/output voltage transfer characteristics, the schematics, the operation quadrant, and control, SMRs possess many classifications and application. Typical potential application examples include grid powered motor drives, battery chargers, various power electronic facilities, micro-grids, and grid-connected battery energy storage system (BESS), etc. In micro-grids, the SMR can be employed as the AC generator-followed converter to yield better generating efficiency. The SMR operation of its grid-connected inverter let the grid-to-microgrid (G2M) operation be conductable in addition to the microgrid-to-grid (M2G) operation. As for the electric vehicle (EV), the bidirectional inverter can be arranged to perform G2V/V2G operations in idle case, wherein the SMR operation is made in G2V battery charging.

To promote the application potential and improve the operation performance of SMRs, this article presents the operation controls and applications of SMRs in microgrid systems incorporating BESS and EV as supplemental facilities. First, the classifications, operation principle, and some key issues of SMRs are explored. Secondly, the configuration of the studied system is introduced. Third, the controls and operations of SMRs in micro-grid, wind generators, and grid-connected interface power converters are described. Then the ones in BESS (B2G/G2B) and EV are introduced. Finally, some conclusions and suggestions are given.
\end{abstract}

Keywords: Power quality, power factor correction, switch-mode rectifier, control, micro-grid, BESS, electric vehicle, battery charger 


\section{Introduction}

Energy exhaustion, carbon-dioxide emission, and global warming issues have seriously received attention worldwide in recent years. The use of micro-grid [1-4] incorporating with various distributed and renewable sources and energy storage devices is an effective means to reduce these problems. Compared with the AC micro-grid, the DC micro-grid possesses the merits of simpler interface converters, allowing longer common DC bus length and having fewer losses [1]. For establishing a high-performance micro-grid, many interdisciplinary affairs should be properly treated, such as:

i. Interfacing the renewable sources to the system with proper interface converters and controls. Each specific source possesses its own key issues to be adequately handled. For a wind AC generator, the SMR is a natural choice to yield better energy conversion characteristics;

ii. Equipped with proper storage devices and their coordinated controls. If the auxiliary charging from the mains is arranged, the SMR must also be adopted to have good charging performance and line drawn power quality; and

iii. Energy management control for the constituted sources, storage devices, and loads. Recently, many droop control approaches [1,5] have been developed to enhance the autonomous operation control characteristics of micro-grids.

Similar to micro-grids, the popularization of electric vehicles (EVs) [6] is also effective in reducing fossil energy consumption and carbon-dioxide emission. Moreover, by regarding EV as a movable energy storage device and performing its interconnected operations to a microgrid (M2V/V2M) [7,8] or utility grid (G2V/V2G) [9-14], the effectiveness in achieving these goals will be more prominent. Among the commonly used motors, permanent-magnet synchronous motor (PMSM) is one of the commonly used motors for commercialized EVs $[15,16]$, owing to its many distinguished features. Battery is the major source of an EV, hence its type and ratings should be properly chosen [17-19]. Different from the energy type of battery, the super-capacitor belongs to the power type energy storage device that has faster response and lower capacity. By incorporating battery with super-capacitor, one can preserve better total energy utilization characteristics. Then, intermittent battery charging/discharging operations can be avoided to increase battery life. The super-capacitor can be directly paralleled to the battery [20], or they can be interconnected via various configured interface DC/DC converters [21,22].

Battery is an important energy source of various portable and movable appliances, such as laptop computers and electric vehicles [23-25]. To effectively use battery storage energy, the study of the use of batteries in emergency application for a laptop computer has been presented in $[25,26]$. The vehicle-to-grid (V2G)/grid-to-vehicle (G2V) operations have also gradually received attention [27-29]. Besides, there are specific battery energy storage systems (BESSs) being developed [30-35]. In addition to the autonomous operation of supplying power to 
critical loads [30-32,35], BESSs also possess grid-to-battery charging and battery-to-grid discharging capabilities. The line current in grid-side can also be regulated to be nearly sinusoidal, thanks to its power conditioning control ability. In the studied BESS, its DC-link $\operatorname{voltage}\left(V_{d c}=400 \mathrm{~V}\right)$ is established from the Li-ion battery bank $\left(v_{B}=96 \mathrm{~V}\right)$ via an interleaved DC/ DC boost-buck converter that has fault-tolerance capability. For effectively utilizing other renewable sources, a plug-in energy harvesting system is developed to make battery supplementary charging from the possible AC and DC sources. As far as the AC source is concerned, a suitable SMR and its control are needed.

In a DC micro-grid or distributed power system, the DC sources and energy storage devices must be interfaced to its common DC-link using suited DC/DC converter [36,37]. For batteries and supercapacitors, bidirectional DC/DC converters are needed to perform charging and discharging operations. For applications with battery voltage being lower than its interfaced DC-link, one can apply the one-leg half-bridge boost-buck bidirectional DC/DC converter [20]. To possess lower current ripples and fault-tolerance capability, the interleaved DC/DC converter [38] can be adopted.

Basically, SMR is formed by inserting a suited DC/DC converter between the diode bridge rectifier and the output filtering capacitor. The surveys for single-phase and three-phase SMRs can be found in [39-43]. For three-phase plants with less stringent power quality requirement, one can adopt the three-phase single-switch (3P1SW) SMR [44,45]. By operating it under discontinuous conduction mode (DCM), the power factor correction is inherently preserved without current feedback control. If higher efficiency is desired, the bridgeless DCM threephase SMR presented in [35] can be employed. To yield good line drawn current waveform tracking control with the minimum switch number, the three-phase three-switch (3P3SW) Vienna SMR $[46,47]$ is a good choice. However, these two types of SMRs possess only AC-toDC unidirectional power flow capability. For interfacing the output of a wind AC generator, such as wind permanent-magnet synchronous generator (PMSG), to the common DC-bus in DC micro-grid, a suited AC/DC converter is needed. The de-rated characteristics for various AC/DC followed converters can be found in [48]. From the compromised considerations in switch number, switch voltage stress, conversion loss, operation quadrant number, and control performance, the Vienna rectifier [49-51] with three switches is a better choice to be the interface converter of AC wind generators. On the other hand, the standard three-phase six-switch (3P6SW) SMR [35] should be used for conducting bidirectional power transfer operations.

SMR can directly provide adjustable and well-regulated DC output voltage from the available AC source with good line drawn power quality. This article presents the operation controls and applications of SMRs in micro-grid system incorporating BESS and EV as supplemental facilities. The contents of this article mainly include: (i) Exploration of classifications, operation principle, and some key issues of SMRs; (ii) Functional description of the studied system; (iii) Introduction to the controls and operations of SMRs in micro-grid, wind generators, gridconnected interface power converters, BESS, and EV; (iv) Experimental evaluations for the studied plant in various operation cases. 


\section{System configuration}

System configuration of the studied system is shown in Fig. 1. It mainly consists of a gridconnected DC micro-grid, an EV PMSM drive with G2V/V2H/V2G functions, and a gridconnected BESS. The detailed schematics of the constituted plants are shown in Fig. 2. The key system components and features of these three power stages are:

\section{A. DC Micro-grid}

a. Sources: DC source and wind PMSG and their interface converters. For the latter, the advantages of using SMR in de-rated characteristics and generation efficiency enhancements are presented. The other possible harvested AC and DC sources can also be plugged into the system via embedded interface converter schematics.

b. Hybrid energy storage system that consists of a battery bank, a super-capacitor (SC) bank, and a PMSM-driven flywheel. Each device is interfaced to the common DC bus via a bidirectional DC-DC boost-buck converter. The output of the flywheel system can be directly connected to the micro-grid common-DC bus for its voltage boosting ability.

c. Bidirectional single-phase three-wire $(1 \mathrm{P} 3 \mathrm{~W})$ load inverter wherein the following operations are allowed: (i) M2G operation: the inverter can power the local load to reduce the power fed from utility. Moreover, the programmed power can be sent back to the utility grid; (ii) G2M operation: the single-phase SMR is formed to allow the utility supply power to the micro-grid for energy supporting or making the battery supplementary charging. The EV can also perform the G2V/V2G operations via its own schematics or via the micro-grid interface converters $(\mathrm{G} 2 \mathrm{M}+\mathrm{M} 2 \mathrm{~V}) /(\mathrm{V} 2 \mathrm{M}+\mathrm{M} 2 \mathrm{G})$.

\section{B. EV PMSM Drive}

The developed battery/SC powered EV IPMSM drive possesses G2V/V2H/V2G operation capabilities. The battery bank and SC bank are integrated to the common DC-link, respectively, via an interleaved and a standard bidirectional front-end DC/DC converter. And the SC bank is connected to the battery bank through a diode to allow the restored regenerative braking energy in SC be charged to battery automatically. Through proper arrangement, the G2V charging and $\mathrm{V} 2 \mathrm{H} / \mathrm{V} 2 \mathrm{G}$ discharging operations are applicable using the integrated converters and inverters formed by the motor drive embedded components.

In idling G2V operation mode, the battery bank can be charged by the utility grid. A singlephase boost SMR and a three-phase boost SMR are formed to charge the battery bank through the bidirectional interleaved buck DC/DC converter with satisfactory line drawn power quality from the mains. The interconnected operations of the EV to the micro-grid and BESS are also conductible. Moreover, the V2G/G2V via micro-grid or BESS is achievable.

\section{BESS}

The DC-link voltage $(400 \mathrm{~V})$ is established from the $96 \mathrm{~V}$ battery bank via an interleaved bidirectional interface DC/DC converter with two cells. A multifunctional inverter is established to perform the autonomous and grid-connected operations: 


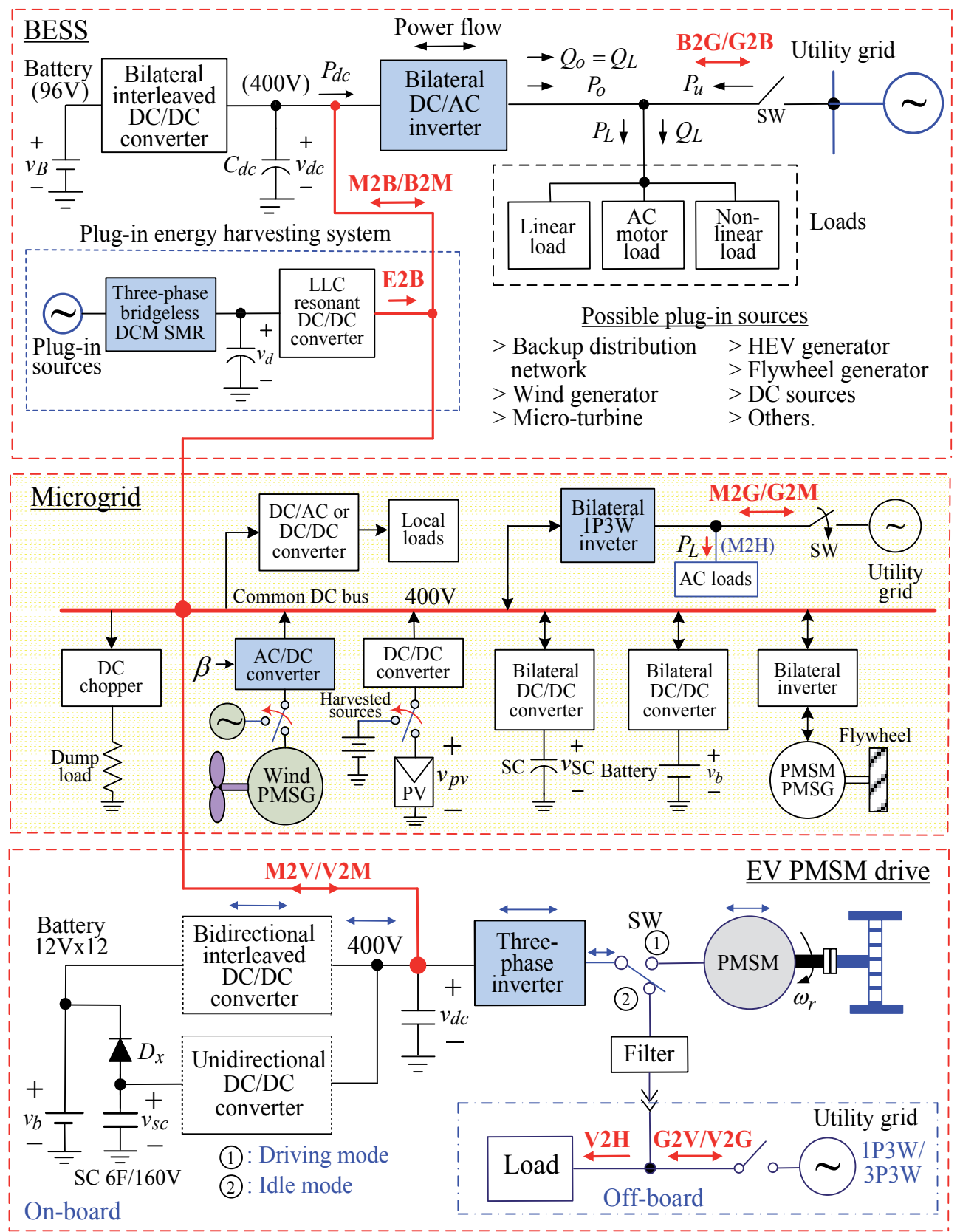

G2V: grid-to-vehicle, V2G: vehicle-to-grid, V2H: vehicle-to-home, M2G: microgrid-to-grid, M2V: microgrid-to-vehicle, V2M: vehicle-to-microgrid, E2B: energy-harvetser-to-BESS,

$\mathrm{B} 2 \mathrm{G}$ : BESS-to-grid, G2B: grid-to-BESS, M2B: microgrid-to-BESS, B2M: BESS-to-microgrid.

Figure 1. System configuration of the studied micro-grid incorporating with EV and BESS. 

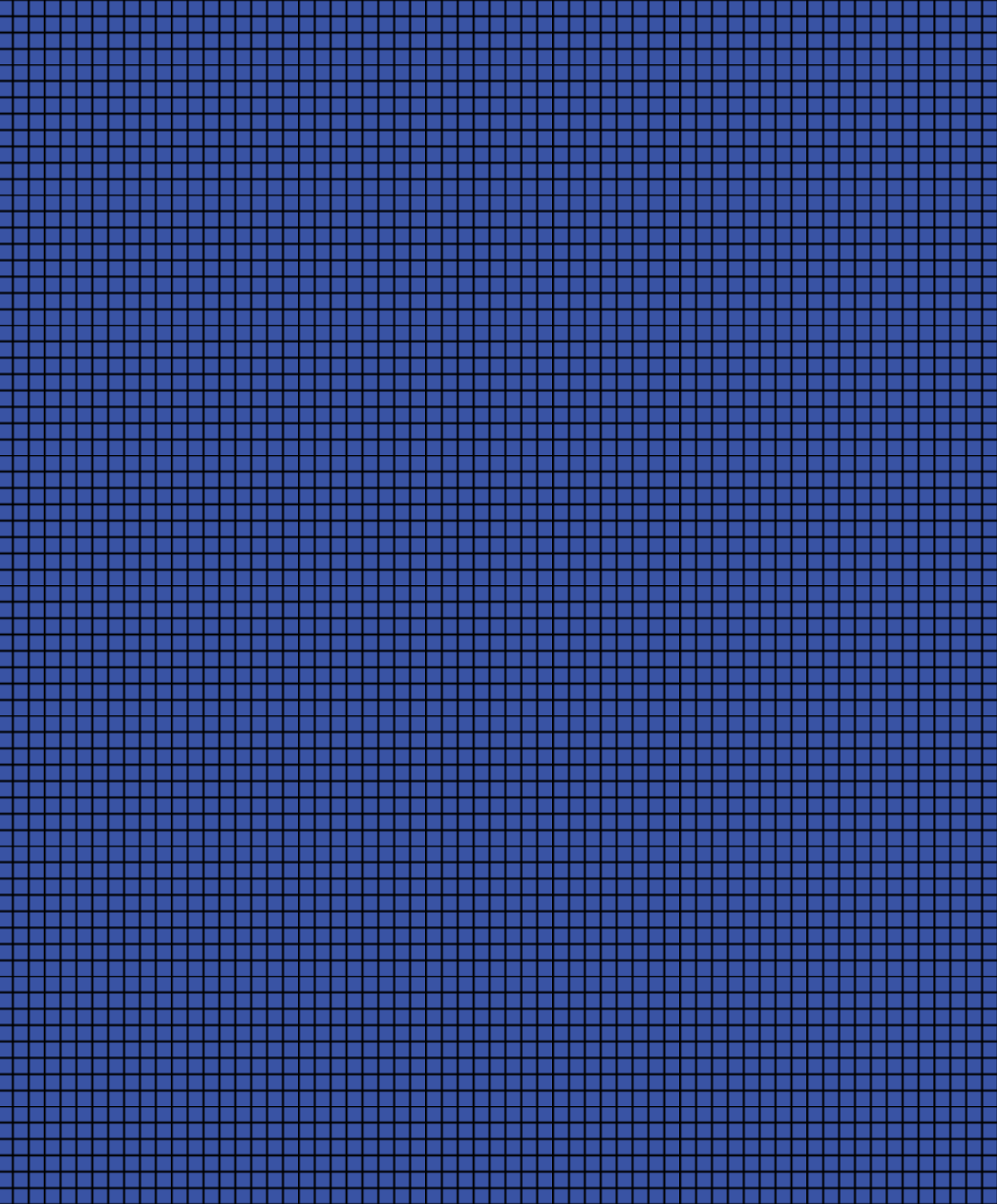

(a) 


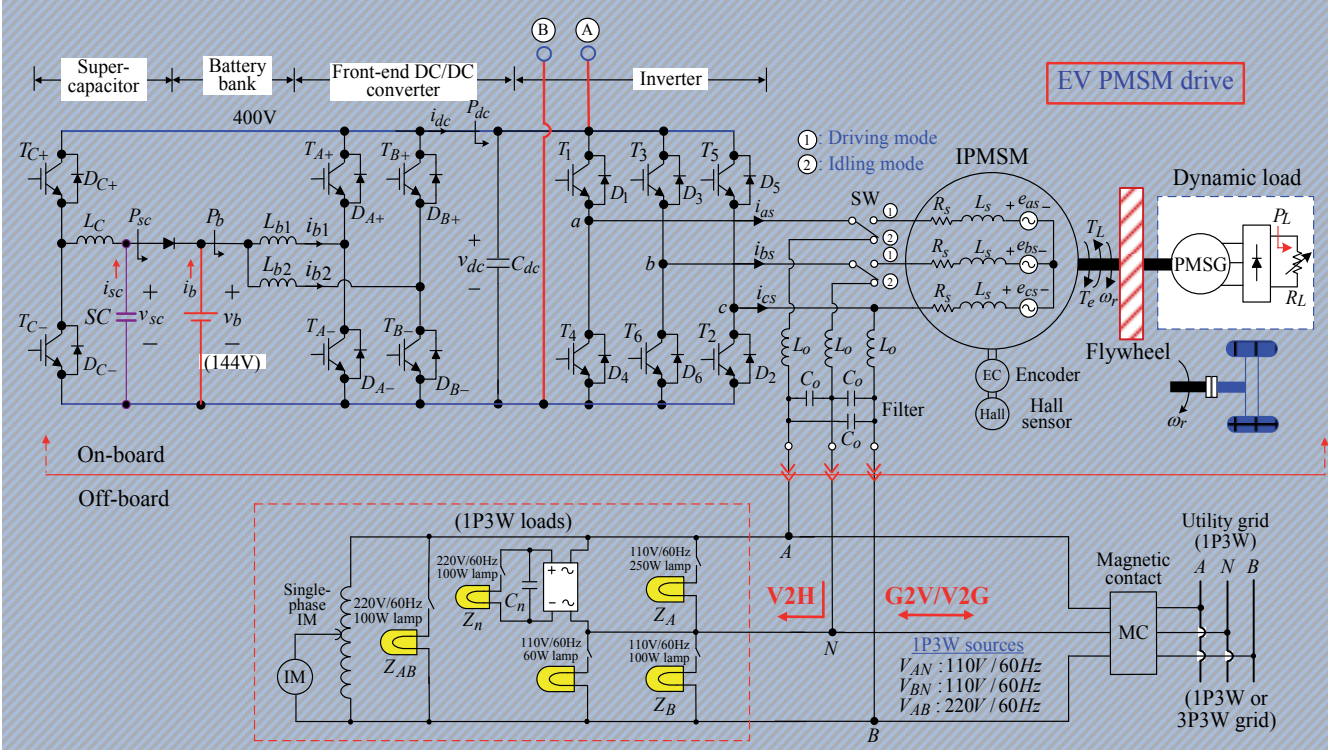

(b)

Figure 2. Schematics of all constituted power stages in the studied system: (a) BESS and microgrid; (b) EV PMSMdrive.

\section{a. Autonomous operation}

The BESS is independent from the utility grid and supplies power to the load.

b. Grid-connected operation

The BESS with three-phase six-switch bidirectional inverter can be arranged to operate in three modes: (i) battery-to-grid (B2G) discharging mode: the BESS provides all load powers and sends the preset real power to the utility grid; (ii) grid-to-battery $(\mathrm{G} 2 \mathrm{~B})$ charging mode: the utility grid supplies the load real power and also charges the battery bank with good line drawn power quality; (iii) floating mode: all load real powers are supplied by the utility grid. The BESS can compensate all load reactive and harmonic powers under all grid connected operation modes.

The BESS energy can be supported from the possible AC sources and DC sources via the developed plug-in energy harvesting system, i.e., the energy-harvester-to-BESS (E2B) operation mode. Various AC sources and DC sources can be connected to the BESS via the threephase bridgeless discontinuous current mode (DCM) SMR through proper schematic and control arrangements. Similarly, the interconnected operations of the BESS to the micro-grid and EV are also applicable. Specifically, the EV can be charged by the BESS employing its harvested renewable energies. 


\section{Classification of SMRs}

From the viewpoints of schematics and control approaches, the SMRs can be categorized as follows.

\subsection{Schematics}

The SMR schematics can be categorized into: (i) Single-phase or three-phase, the three-phase SMR is a natural choice for the plants with larger ratings; (ii) Non-isolated or isolated, normally, the latter type SMR possesses lower energy conversion efficiency; (iii) Buck, boost, or buck/ boost: the boost-type SMR possesses the best PFC control ability since its AC input current is directly related to the energy storage inductor current. As for the buck and buck/boost SMRs, the input low-pass filter is necessary for the inherently discontinuous current; (iv) Single-stage or multi-stage; (v) One-quadrant or multi-quadrant: the multiple quadrant SMR possesses reverse power flow capability from DC side to AC source to achieve the regenerative braking of a SMR-fed AC motor drive; (vi) Hard-switching or soft-switching; (vii) Standard or bridgeless: the bridgeless SMR possesses slightly larger efficiency for the reduced diode voltage drop; (viii) Single-module or interleaved multi-module: the interleaved SMR may have the advantages of rating enlargement, higher reliability owing to redundancy, and smaller current and voltage ripples.

\subsection{Control methods}

a. Low-frequency control: for the single-phase boost SMR, only v-loop is needed and only one switching per half AC cycle is applied. It is simple but subject to having limited power quality characteristics.

b. High-frequency voltage-follower control: without current control loop, only some specific SMRs operating in DCM possess this feature; see for example, the standard buck-boost SMR and the flyback SMR.

c. High-frequency standard control: it belongs to multiplier-based current-mode control scheme with cascade $\mathrm{v}$ - and i-control loops.

\section{Single-Phase SMRs}

\subsection{Operation and schematics}

For a properly designed single-phase SMR, the AC input current $i_{a c}$ can be regulated to be sinusoidal and kept in phase with $v_{a c}$, then the SMR can be regarded as an emulated resistor with the effective resistance of $R_{e}$ viewing from the utility grid. However, the double line frequency output voltage ripple always exists. It can be derived to obtain the peak to peak value of output ripple voltage: 


$$
\Delta v_{d c}=\frac{V_{d c}}{\omega C_{d c} R_{d c}}
$$

where $R_{d c}=$ equivalent DC load resistance, $\omega=2 \pi f_{1}$ and $f_{1}=60 \mathrm{~Hz}$.

In reality, the operation characteristics of an SMR including DC output voltage and AC input power quality are highly affected by the energy storage inductor current PWM control behavior.

Figs. 3(a) to 3(e) show some typical single-phase boost SMR circuits, including: (a) standard type SMR; (b) bridgeless SMR: its efficiency is increased by reducing one diode voltage drop in each half AC cycle; (c) curret-fed push-pull (CFPP) isolated SMR: the higher voltage boosting ratio is obtained by the duty ratio control and the turn ratio; (d) zero-voltage transition (ZVT) soft-switching SMR: the ZVT soft switching is achieved by adding an auxiliary resonant branch [52]; (e) four-quadrant SMR: the H-bridge converter based SMR possesses four operation quadrants. A bidirectional battery energy storage system [25] is shown in Fig. 3(e)

The single-phase standard buck SMR is depicted in Fig. 4(a), the input filter is needed for its discontinuous input current. The power factor will become worse for the higher output DC voltage. Figs. 4(b) to 4(c) correspond to the standard, the Cuk continuous, and the flyback isolated buck/boost SMRs, respectively. Except for the Cuk SMR, the input filtering is still necessary for the other two types of buck/boost SMRs. In control aspect, the simple voltagefollower control scheme can be applied for these buck/boost SMRs operated in DCM.

\subsection{Some key issues}

Some key issues for a boost SMR and a buck/boost SMR are indicated in Fig. 5 and Fig. 6. Some comments are given as:

a. The input filter is needed for buck/boost SMRs due to the discontinuous input current.

b. The ripples and ratings of the power circuit constituted components must be properly designed and implemented.

c. For the boost SMR in CCM operation, the standard cascade multiplier-based control scheme with $\mathrm{v}$ and $\mathrm{i}$ loops must be adopted.

d. The voltage follower control scheme without inner current loop can be applied for the buck/boost SMR in DCM operation owing to its inherent PFC capability.

e. In treating the control affairs, the sensed inductor current and output voltage should be filtered with suited low-pass cut-off frequencies. The feedack controller must first be properly designed considering the desired transient and static performances and the effects of comtaminated noises in sensed variables. Normally, the voltage dynamic response speed is: $<<\left(2 f_{1}=120 \mathrm{~Hz}\right)$, whereas the inner current dynamic response is set as: $<<$ switching frequency, but $>>\left(2 f_{1}=120 \mathrm{~Hz}\right)$. 


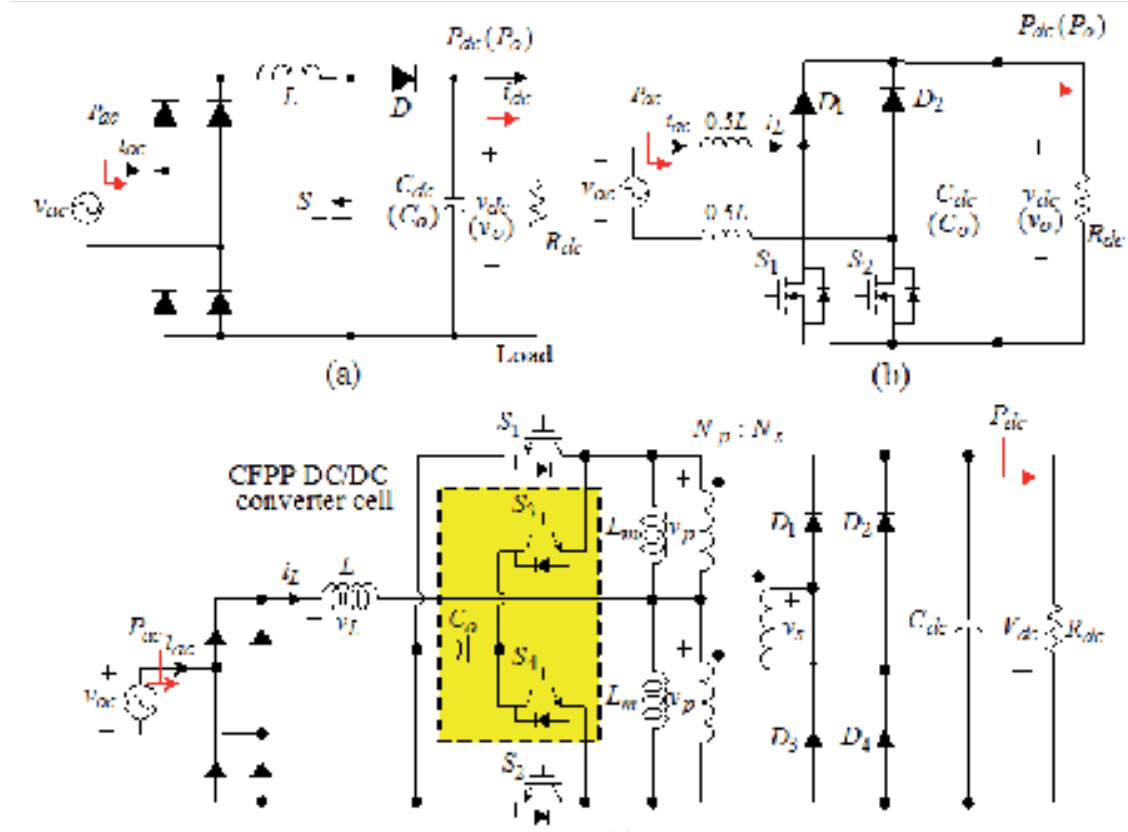

(c)

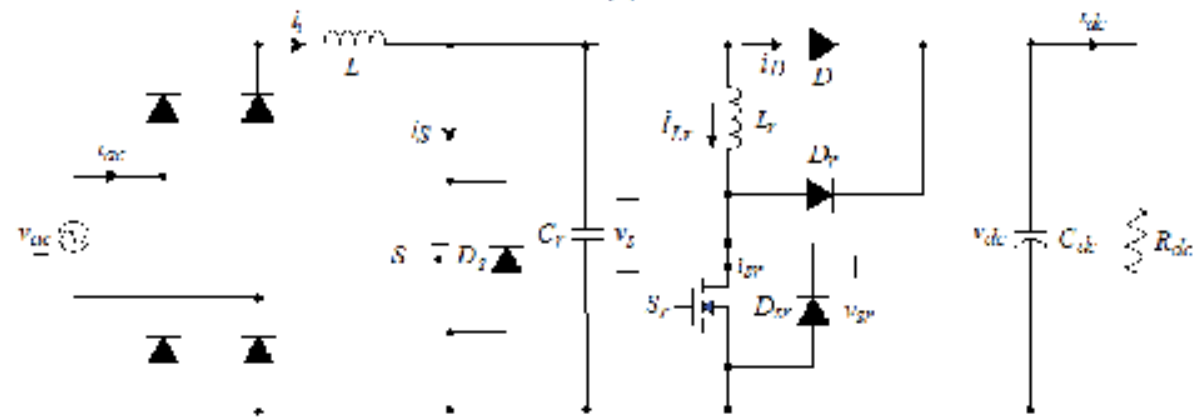

(d)

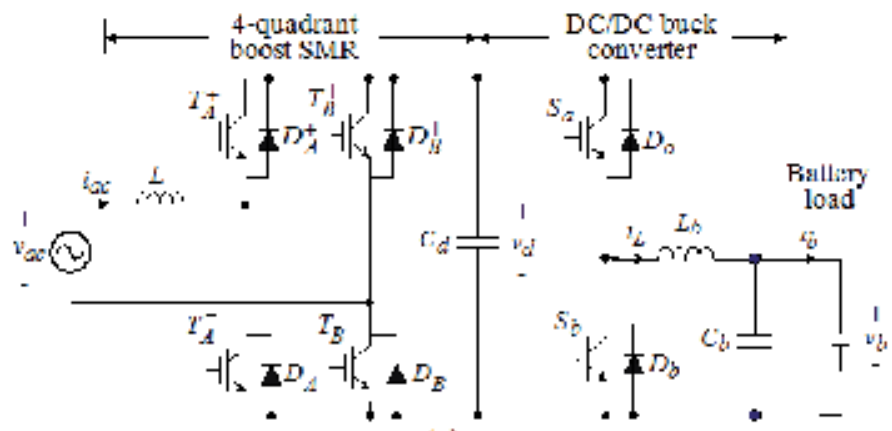

(c)

Figure 3. Some typical single-phase boost SMR circuits: (a) standard SMR; (b) bridgeless SMR; (c) CFPP isolated SMR; (d) ZVT soft-switching SMR; (e) four-quadrant SMR. 


\section{Three-phase SMRs}

\subsection{Operation and schematics}

Detailed surveys for the existing three-phase SMR circuits can be referred to [41-43]. The complexities of schematic and control mechanism depend on the control ability and the desired performances. Some commonly used three-phase boost SMRs shown in Figs. 7(a) to 7(e) include:

a. Three-phase, single-switch (3P1SW) DCM SMR (Fig. 7(a)): by operating it in DCM, the PFC is naturally preserved without applying current PWM control. However, it possesses the following limiations: (i) Having higher input peak current and switch stress; (ii) The input line current contains significant lower-frequency harmonics with the orders of $6 \mathrm{n}$ $\pm 1, n=1,2, \ldots$, and the dominant ones are the $5^{\text {th }}$ and $7^{\text {th }}$ harmonics. Thus, suitably designed AC-side, low-pass filter is required to yield satisfactory power quality; (iii) The line drawn power quality is limited, typically the power factor is slightly higher than 0.95; (iv) It possesses only one-quadrant capability.

b. Bridgeless, three-phase DCM SMR: As shown in Fig. 7(b) [35], one diode drop is eliminated in each line-current path to increase the efficiency compared to 3P1SW SMR.

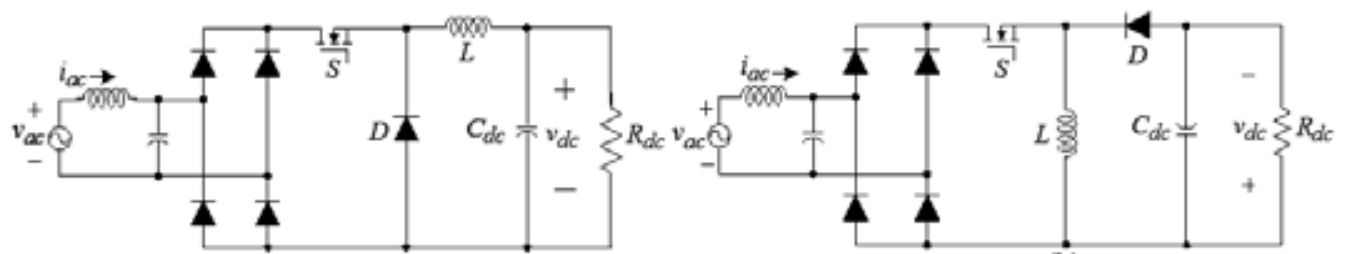

(a)

(b)

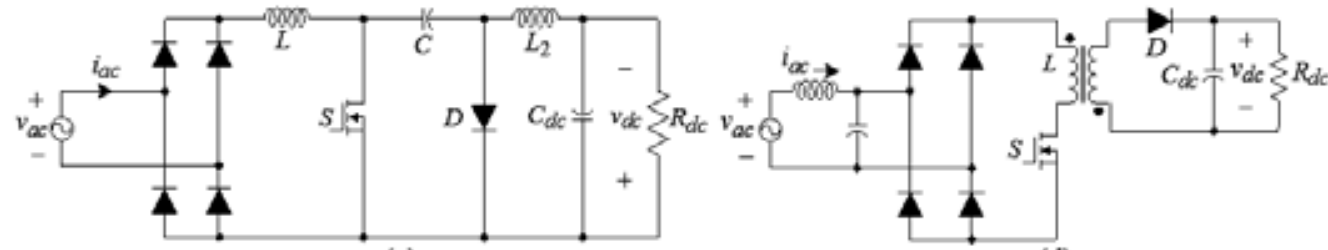

(c)

(d)

Figure 4. Some typical single-phase buck and buck/boost SMR circuits: (a) standard buck SMR; (b) standard buck/ boost SMR; (c) Cuk buck/boost SMR; (d) flyback isolated SMR.

c. Three-phase Vienna SMR [46,47] (Fig. 7(c)): it uses only three switches to achieve good current command tracking control. It can be regarded as a simplified version of three single-phase PFCs connected to the same intermediate bus voltage. The major features of this SMR are: (i) three output voltage levels $\left(0.5 v_{0^{\prime}}, v_{o^{\prime}}-0.5 v_{0}\right)$ providing larger switching control flexibility; (ii) lower switch voltage rating of, $0.5 v_{0}$ rather than $v_{0}$; and (iii) lower input current distortion. However, it has only unidirectional power flow capability, and 


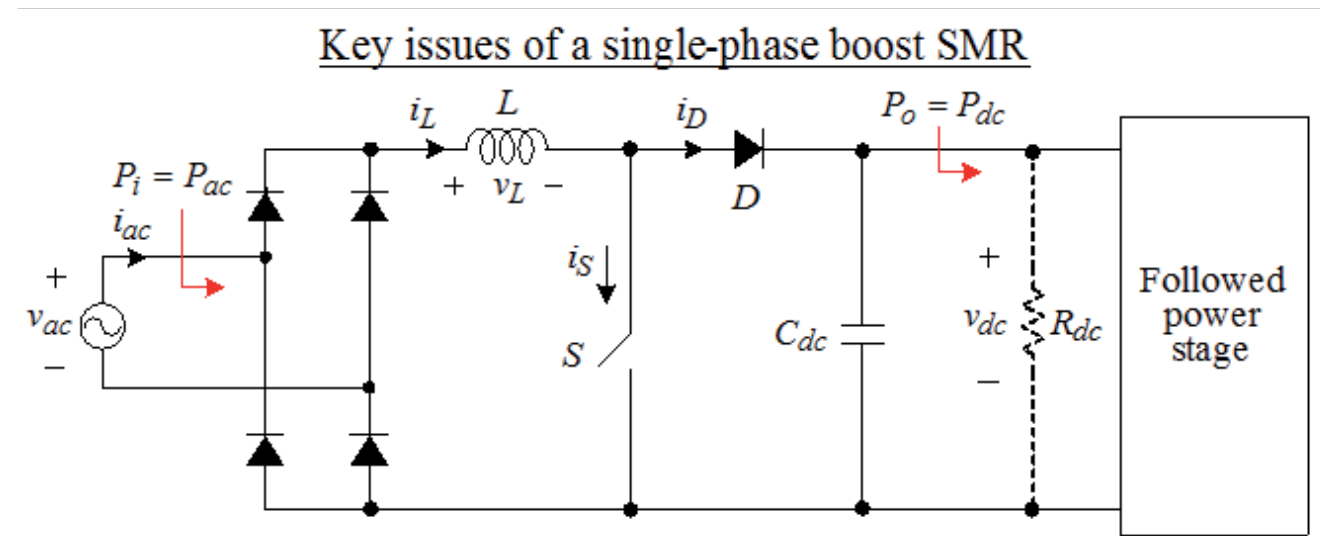

Power circuit issues:

$\square$ Circuit component ratings, circuit realization.

- Inductor current ripple and capacitor voltage ripple, $\square$ Input filtering is not required. design of energy storage components .

$\square$ Efficiency improvement via schematic arrangement

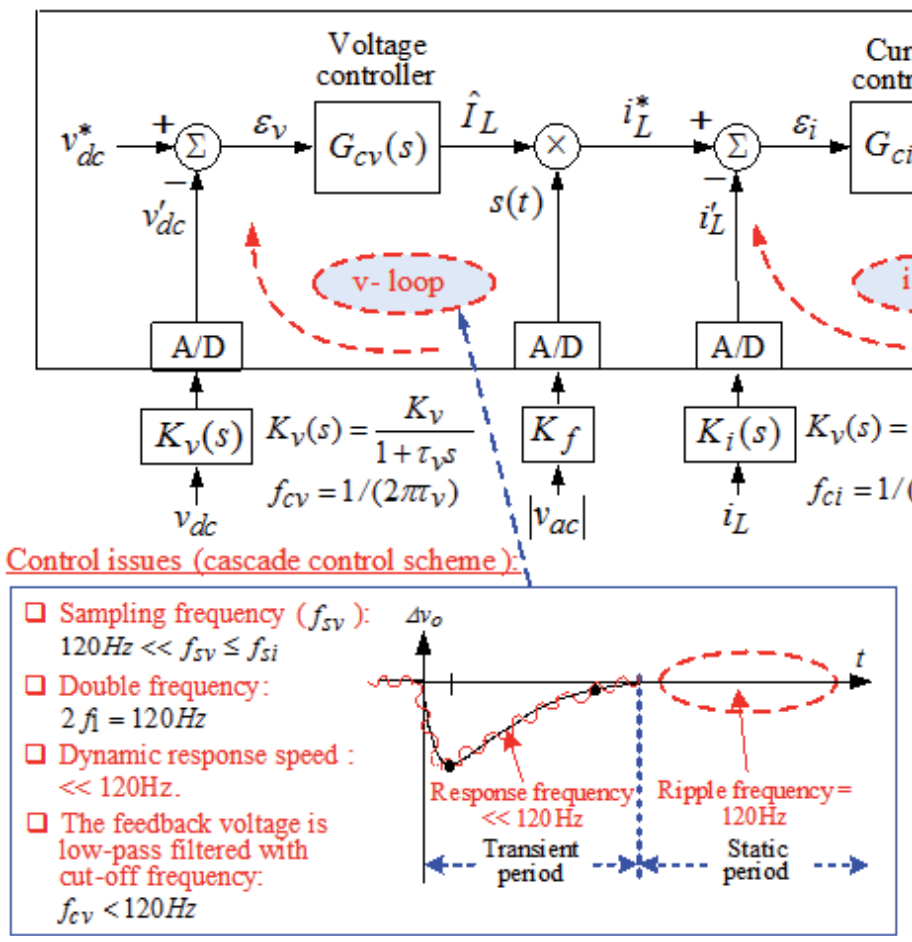

Current controller

$G_{c i}(s) \stackrel{v_{\text {cont }}}{\longrightarrow} \mathrm{PWM}$ switching
scheme $v_{s a w}$ DSP

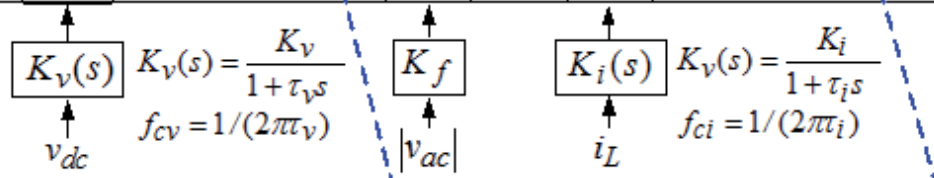
(cascade control scheme):

Sampling frequency $\left(f_{S V}\right)$ : $120 \mathrm{~Hz}<f_{s v} \leq f_{s i}$

Double frequency: $2 f_{1}=120 \mathrm{~Hz}$

Dynamic response speed $\ll 120 \mathrm{~Hz}$.

The feedback voltage is ow-pass filtered wi $f_{c v}<120 \mathrm{~Hz}$

Figure 5. Some key issues of single-phase boost SMRs.

needs a complicated power switch and two serially connected capacitors. The specific power switch (VUM 25-05) for implementing this SMR is available from IXYS Corporation, USA.

d. Three-phase six-switch standard SMR (Fig. 7(d)): the standard three-phase six-switch SMR [41,42] possesses four operation quadrants and high flexibility in power conditioning 


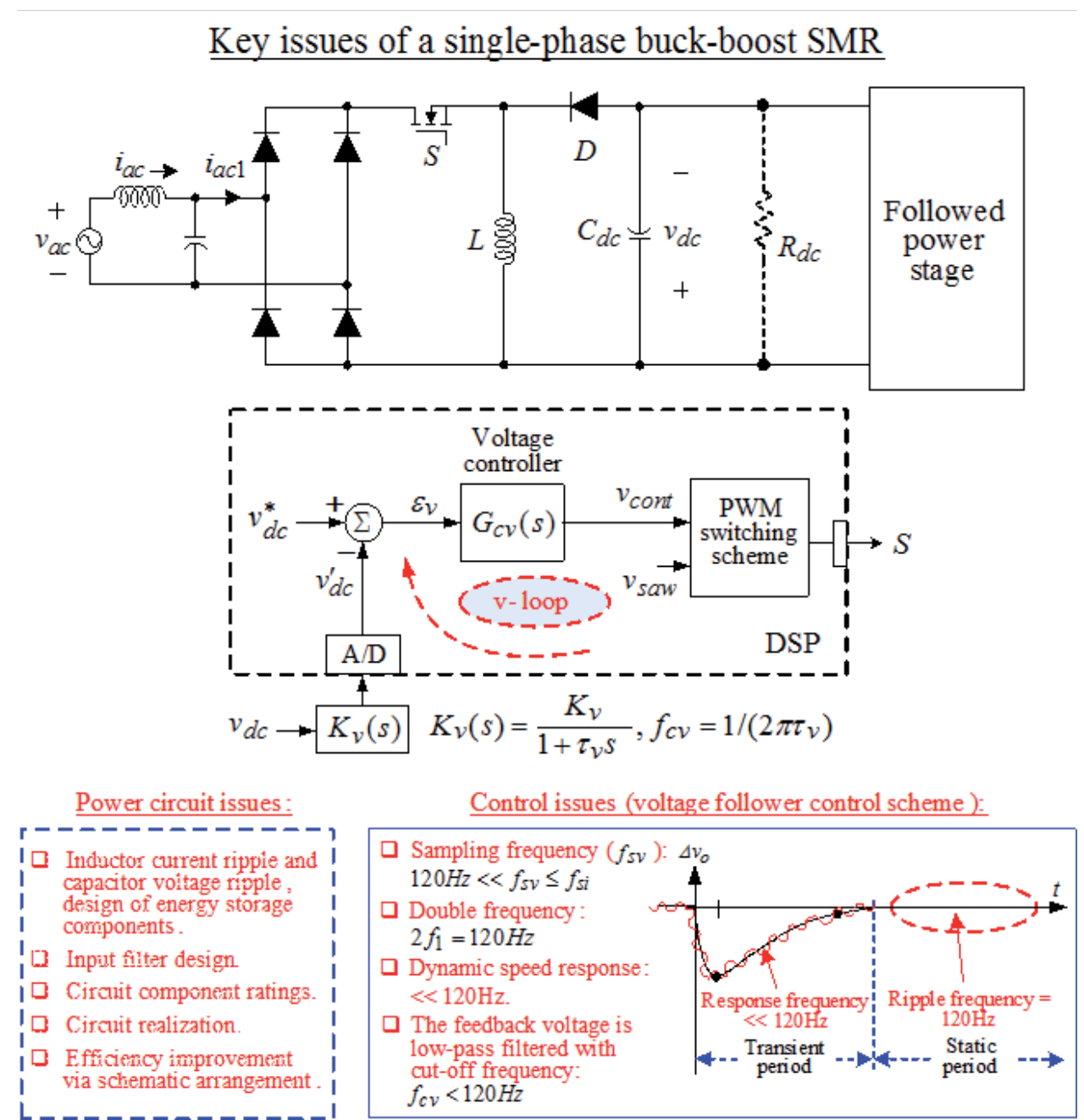

Figure 6. Some key issues of single-phase buck/boost SMRs.

control. For a motor drive equipped with such SMR, it may possess regenerative braking ability. However, the switch utilization ratio of this SMR is low, and its control is complicated.

e. Neutral-point clamped (NPC) three-phase standard SMR: the three-level NPC threephase SMR is shown in Fig. 7(e) where the voltage ratings of its constituted power switches and diodes can be only one-half of the DC-link voltage, rather than the full voltage for the standard SMR shown in Fig. 7(d).

\section{Three-phase single-switch (3P1SW) DCM SMR:}

For a well-regulated three-phase single-switch (3P1SW) DCM SMR shown in Fig. 7(a), it can be regarded as a loss-free emulated resistor $R_{e}$ viewing from the phase AC source with line 
drawn current having dominant 5 th and 7 th harmonics [44]. Hence, the three-phase line drawn instantaneous power can be approximately expressed as:

$$
\begin{aligned}
& p_{a c}=v_{a n} i_{a}+v_{b n} i_{b}+v_{c n} i_{c}=\frac{V_{m}^{2} \sin \omega t}{R_{e}}\left[\sin \omega t-\frac{1}{5} \sin 5 \omega t-\frac{1}{7} \sin 7 \omega t\right]+ \\
& \frac{V_{m}^{2} \sin (\omega t-2 \pi / 3)}{R_{e}}\left[\sin (\omega t-2 \pi / 3)-\frac{1}{5} \sin 5(\omega t-2 \pi / 3)-\frac{1}{7} \sin 7(\omega t-2 \pi / 3)\right]+ \\
& \frac{V_{m}^{2} \sin (\omega t+2 \pi / 3)}{R_{e}}\left[\sin (\omega t+2 \pi / 3)-\frac{1}{5} \sin 5(\omega t+2 \pi / 3)-\frac{1}{7} \sin 7(\omega t+2 \pi / 3)\right] \\
& =\frac{3 V_{m}^{2}}{2 R_{e}}+\frac{3 V_{m}^{2}}{35 R_{e}} \cos 6 \omega t \stackrel{\Delta}{=} P_{a c}+\delta p_{a c}
\end{aligned}
$$

where $\delta p_{a c}=$ ripple $\mathrm{AC}$ power and the average $\mathrm{AC}$ power $P_{a c}$ is:

$$
P_{a c}=\frac{3 V_{m}^{2}}{2 R_{e}}=\frac{V_{d c}^{2}}{R_{d c}}
$$

The AC charging current flowing the output filtering capacitor is:

$$
C_{d c} \frac{d v_{d c}}{d t}=\frac{2 V_{d c}}{35 R_{d c}} \cos 6 \omega t
$$

Thus, one can derive the peak-to-peak output voltage ripple from (4):

$$
\Delta v_{d c}=\frac{2 V_{d c}}{105 \omega R_{d c} C_{d c}}
$$

\section{Three-phase Vienna SMR and three-phase six-switch standard SMR:}

For the Vienna SMR and three-phase six-switch standard SMR with satisfactory current mode control, the three-phase line drawn currents will be balanced without harmonics. Hence, from (2) one can find that the DC output voltage ripple will be nearly zero.

\subsection{Derated characteristics of a PMSG followed by different AC-DC converters}

The total derate factor of a surface-mounted PMSG (SPMSG) and an interior PMSG (IPMSG) followed by various AC-DC converters can be derived to be [48]: 
Low-pass filter Boost inductors

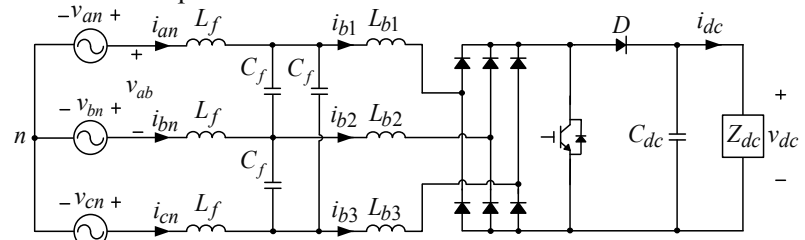

(a)

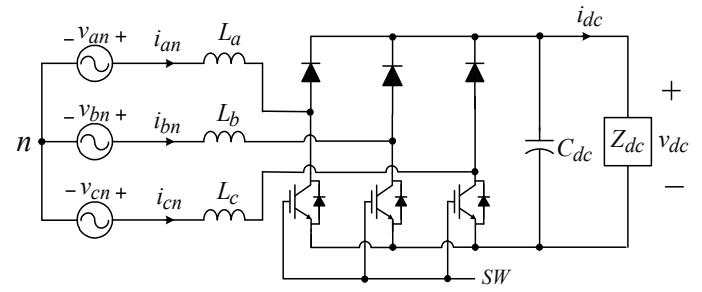

Boost inductors

(b)

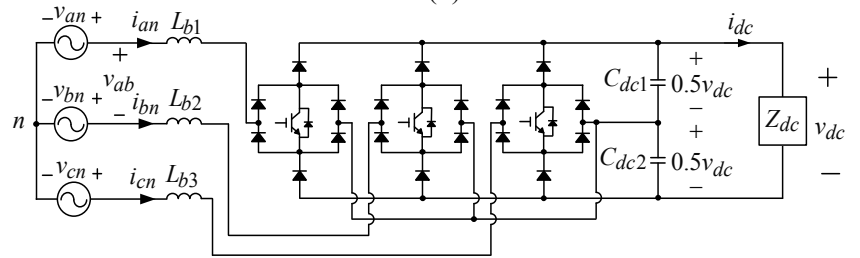

(c)

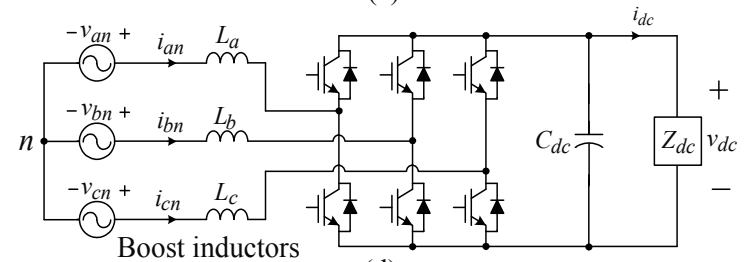

(d)

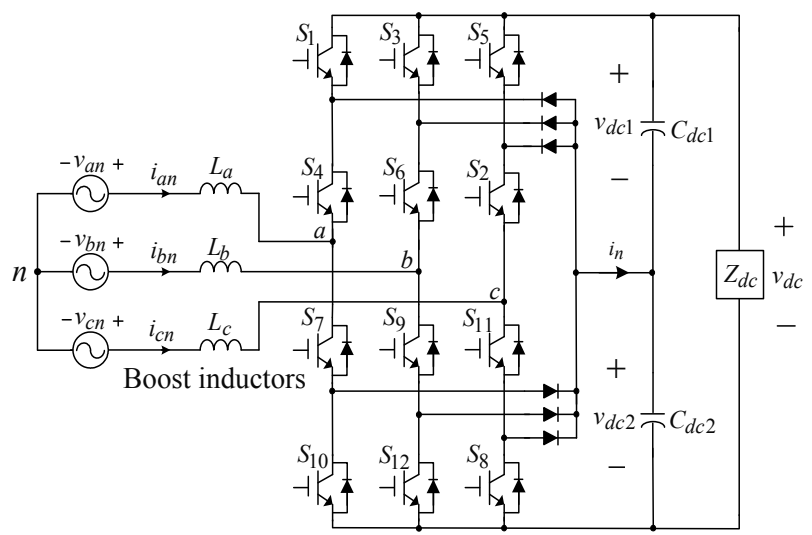

(e)

Figure 7. Some typical three-phase boost SMR circuits: (a) 3P1SW SMR; (b) Bridgeless three-phase DCM SMR; (c) Three-phase Vienna SMR; (d) Three-phase six-switch standard SMR; (e) NPC three-phase standard SMR. 


$$
\begin{aligned}
& D F \stackrel{\Delta}{=}\left(D F_{1}\right)\left(D F_{2}\right)= \begin{cases}\left(D F_{1}\right) \cos \delta & \text { for SPMSG } \\
\left(D F_{1}\right) \cos \delta\left(\frac{P_{f}}{P_{f}+P_{r}}\right) & \text { for IPMSG }\end{cases} \\
& D F_{1}=\frac{\Delta}{I_{a s}}=\frac{1}{\left(1+T H D_{i}^{2}\right)^{0.5}} \\
& D F_{2}=\cos \delta \frac{P_{f}}{P_{e}}=\cos \delta \frac{P_{f}}{P_{f}+P_{r}}
\end{aligned}
$$

where, $I_{a s}=$ rms value of armature phase current $i_{a s}, I_{a s 1}=$ rms value of fundamtal armature phase current $i_{a s 1}$, TH $D_{i}=$ total harmonic distortion of $i_{a s} \delta=$ the power angle between the backEMF $e_{a s}$ and the terminal voltage $v_{a s}, P_{e}=$ electromagnetic developed power, $P_{f}=$ magnetic field developed power, $P_{r}=$ reluctance developed power.

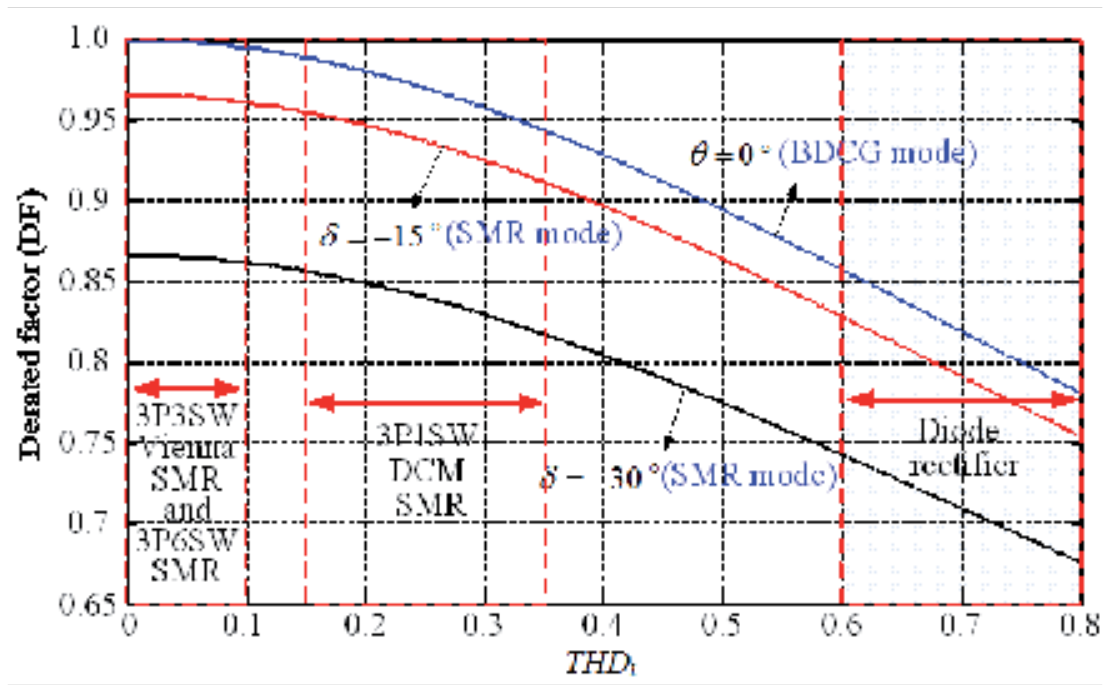

Figure 8. The de-rated characteristics of a PMSG with various AC-DC followed converters and operation control modes.

The de-rated characteristics of a wind PMSG followed by various AC-DC converters and operation control modes are shown in Fig. 8. Obviously, the conventional diode rectifier possesses significant derate. The three-phase Vienna SMR is a good candidate for being the followed interface converter of the PMSG from the following compromised considerations: (i) 
minimum switch number; (ii) winding current PWM control ability; (iii) the commutation shift control ability for an IPMSG; and (iv) only one operation quadrant is required.

\section{SMR operations and performances}

\subsection{Wind IPMSG based micro-grid}

In the developed wind IPMSG-based DC micro-grid shown in Fig. 2, its common DC bus voltage $v_{d c}=400 \mathrm{~V}$ is established by the interleaved DC/DC boost converter from the possible harvested DC sources (here a DC power supply with $v_{d}=35 \mathrm{~V}$ is used as a substitute), and also by the plug-in Vienna switch-mode rectifier (SMR) from the wind PMSG or other possible harvested AC sources. The equipped hybrid energy storage system consists of battery/SC/ flywheel. The M2G/G2M operations can be made by the developed 1P3W inverter. The microgrid incorporating with EV can allow the V2G/G2V operations to be applicable via the 1P3W inverter in the established micro-grid. The EV on-board battery can supply power to the microgrid local loads, and even send the programmed power back to the utility grid.

\section{A. System Components}

1. AC source: wind IPMSG followed by Vienna SMR

- IPMSG: 1 kW, 3.23 N-m, 3,000 rpm, 4.8 A. An SPMSM (2 kW, 9.8 N-m, 2,000 rpm, 9.6 A) is served as the prime mover for driving the IPMSG.

- Vienna SMR:

- $L_{b 1}=3.28 \mathrm{mH} / 60 \mathrm{~Hz}, L_{b 2}=3.28 \mathrm{mH} / 60 \mathrm{~Hz}, L_{b 3}=3.29 \mathrm{mH} / 60 \mathrm{~Hz}, C_{d c 1}=C_{d c 2}=2200 \mu \mathrm{F} / 400 \mathrm{~V}$

- Possible plug-in sources: Various harvested AC and DC sources as indicated in Fig. 1 can be plugged into the micro-grid via the input of the Vienna SMR.

2. DC source interleaved DC-DC boost converter

- $v_{d}=35 \mathrm{~V}, v_{d c}=400 \mathrm{~V}, P_{d c}=1 \mathrm{~kW}$.

- $L_{1}=2.17 \mathrm{mH} / 30 \mathrm{kHz}, L_{2}=2.16 \mathrm{mH} / 30 \mathrm{kHz}, C_{d}=100 \mu \mathrm{F} / 400 \mathrm{~V}$

- Possible plug-in DC sources: Photovoltaic, fuel cell, battery, or other possible harvested sources. A DC source is employed here as an alternative.

3. Storage device interface DC-DC converters

- Battery: 96 V/15 Ah; SC bank: 96 V/40 F; SPMSM driven flywheel: 2 kW, 2,000 rpm, J $=0.9263(\mathrm{~kg}-\mathrm{m} 2)$.

- $L_{4}=965.7 \mu \mathrm{H}, L_{5}=947.3 \mu \mathrm{H} / 30 \mathrm{kHz}, C_{d c}=2200 \mu \mathrm{F} / 450 \mathrm{~V}$.

4. $1 \mathrm{P} 3 \mathrm{~W}$ load inverter 
It can yield the $220 \mathrm{~V} / 110 \mathrm{~V}$ AC voltages for powering the domestic appliances and performing the M2G/G2M bidirectional operations.

- AC output: $220 \mathrm{~V} / 110 \mathrm{~V} 60 \mathrm{~Hz}, 1 \mathrm{~kW}$.

- $L_{o}=401.62 \mu \mathrm{H} / 30 \mathrm{kHz}, C_{o}=10 \mu \mathrm{F} / 400 \mathrm{VAC}$.

5. Dump load: $R_{D}=36 \Omega / 2 \mathrm{~kW}$

\section{B. Control Schemes}

In the DC micro-grid shown in Fig. 2, the control scheme of the wind IPMSG with followed Vienna SMR is shown in Fig. 9(a), and the differential mode (DM) and common mode (CM) control schemes of the 1P3W inverter are depicted in Fig. 9(b). The detailed design description is being neglected here. The designed controllers are [51]:

1. Wind IPMSG followed Vienna SMR

$$
\begin{aligned}
& G_{c v}(s)=4.5+\frac{675}{s}, W_{v}(s)=\frac{W_{v}}{1+\tau_{v} s}=\frac{0.6}{1+1.59 \times 10^{-3} s} \\
& G_{c i}(s)=4+\frac{6000}{s}, W_{i}(s)=\frac{W_{i}}{1+\tau_{i} s}=\frac{0.3}{1+1.59 \times 10^{-4} s}
\end{aligned}
$$

2. $1 P 3 W$ inverter G2M SMR charging mode: The micro-grid can be supported energy from the mains via the SMR formed using the power devices of the 1P3W inverter with power factor correction by the control scheme as shown in Fig. 9(b). The single-phase SMR with $220 \mathrm{~V} / 60 \mathrm{~Hz}$ input is formed by $\left(Q_{7}, Q_{8}, Q_{11}, Q_{12}\right)$. The predictive current control is applied to yield fast tracking response. And the voltage and active power controller are set as:

$$
G_{c v}(s)=0.1+\frac{2.5}{s}, G_{a p c}(s)=5+\frac{150}{s}, L P F: H_{L P}(s)=\frac{1}{1+1.591 \times 10^{-2} s}
$$

By properly selecting the current magnitude command $\hat{I}_{a s}$ and the commutation shift angle $\beta$, the developed IPMSG with Vienna SMR can be operated in voltage control mode $\left(\hat{I}_{a s}=\hat{I}_{a s v}\right.$ $\left.\beta=\beta_{v}\right)$ and in MPPT control mode for a wind generator $\left(\hat{I}_{a s}=\hat{I}_{a s w}, \beta=\beta_{w}\right)$.

\section{Experimental Results}

\section{a. IPMSG with followed Vienna SMR}

Using the estimated parameters of the IPMSG and the given torque command $T_{e}$ from the wind power MPPT control mechanism, the relationship of its phase current magnitude command $I_{\text {asw }}$ and the commutation shift angle $\beta_{w}$ can be found [51]. The developed wind generator torque command is preset as $T_{e}=3.23(\mathrm{~N}-\mathrm{m})$, and the corresponding optimal variables found are $\left(\beta_{w}, \hat{I}_{a s w}\right)=(-7.8,5.7 \mathrm{~A})$. The measured steady state $\left(v_{d c^{\prime}}, \theta_{r}, \hat{\theta}_{r}, i_{a s}\right)$ at 
$\left(\omega_{r}=2000 \mathrm{rpm}, R_{d c}=200 \Omega\right)$ and $\hat{I}_{a s w}=5.7 \mathrm{~A}$ under $\left(\beta_{w}=-7.8\right.$ and $\left.\beta_{w}=0\right)$ are compared in Figs. 10(a) and 10(b), wherein $\hat{\theta}_{r}=\theta_{r}+\beta$ denotes the shifted rotor angular position for making current PWM switching control. The measured DC-bus voltages $v_{d c}$ under four $\beta_{w}$ values are $\left(\beta_{w}=-15\right.$, $\left.v_{d c}=372.1 \mathrm{~V}\right),\left(\beta_{w}=-7.8, v_{d c}=374.3 \mathrm{~V}\right),\left(\beta_{w}=0, v_{d c}=369.6 \mathrm{~V}\right),\left(\beta_{w}=15, v_{d c}=355.8 \mathrm{~V}\right)$. The results indicate that $\beta_{w}=-7.8$ yields the highest value of $v_{d c}(=374.3 \mathrm{~V})$. This implies that the MPPA for the wind IPMSG with followed Vienna SMR can be achieved. Good IPMSG armature current waveforms are also observed.

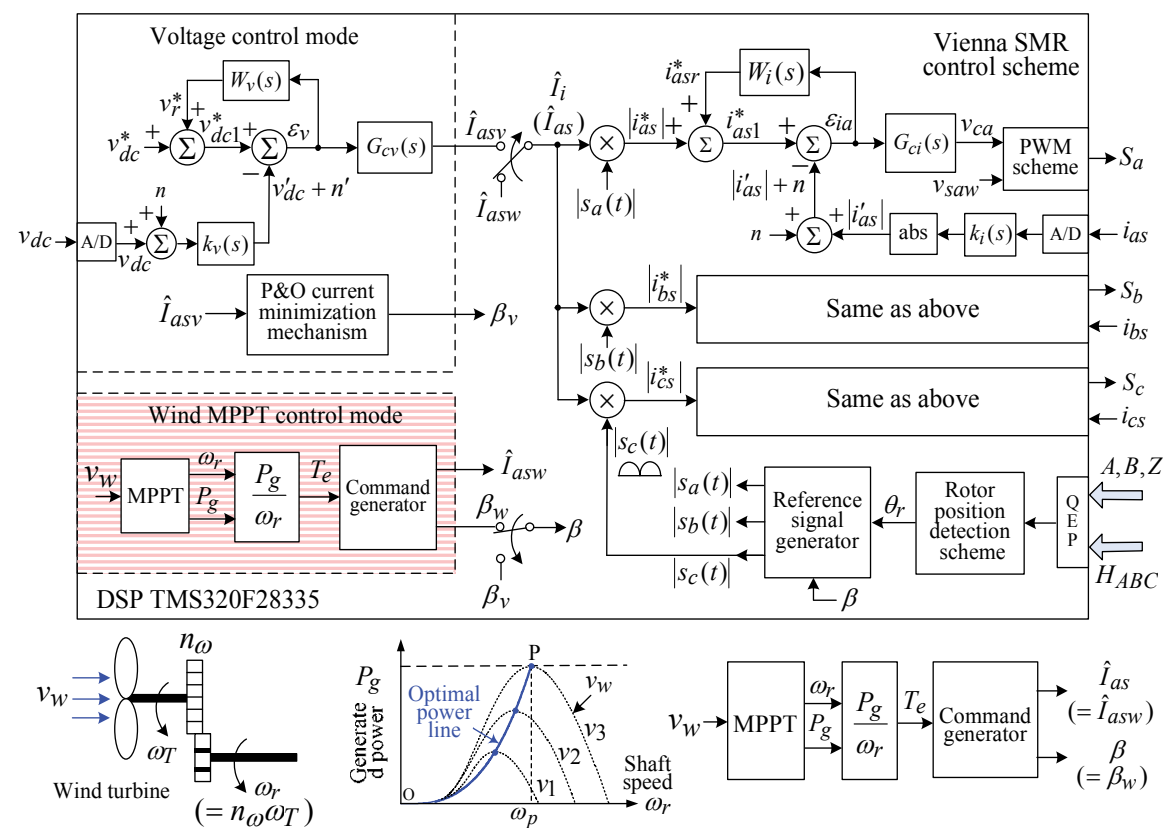

(a)
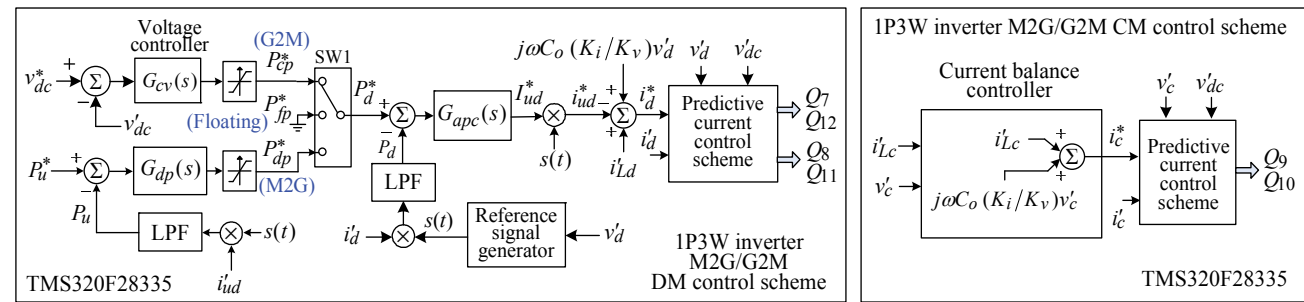

(b)

Figure 9. Control schemes of the developed wind IPMSG based DC micro-grid system: (a) IPMSG with followed Vienna SMR; (b) DM and CM control schemes of 1P3W inverter in M2G/G2M modes.

b. Inter-connected operation between EV IPMSM drive, micro-grid, and utility grid-G2V via micro-grid: 
The grid-connected micro-grid is connected to the DC-link of the EV, and the 1P3W inverter load resistors in Fig. 2 are set as $\left(Z_{A}=201.7 \Omega, Z_{B}=201.7 \Omega, Z_{A B}=484 \Omega\right)$. Let the EV on-board battery be charged from the mains $(\mathrm{G} 2 \mathrm{~V})$ via the micro-grid and the EV interfaced DC/DC converter. Figs. 11(a) to 11(c) show the measured EV, micro-grid and grid variables. Good operation performances and line drawn power quality can be observed from the measured results.

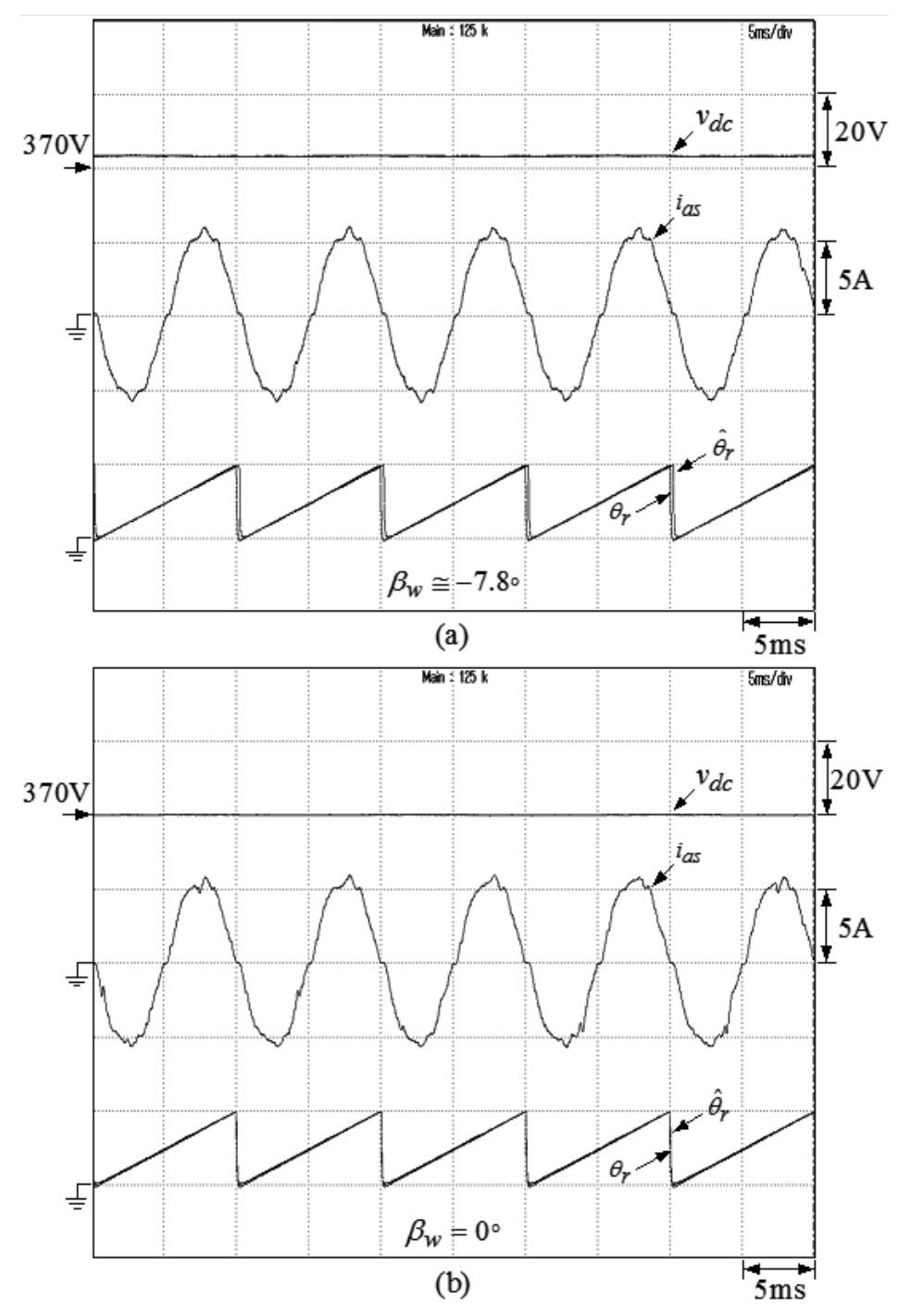

Figure 10. Measured steady state $\left(v_{d c^{\prime}} \theta_{r^{\prime}}, \hat{\theta}_{r^{\prime}} i_{a s}\right)$ of the wind IPMSG with Vienna SMR at $\left(\omega_{r}=2000 \mathrm{rpm}\right.$, $R_{d c}=200 \Omega$ and $\hat{I}_{a s w}=5.7 \mathrm{~A}$ ) under: (a) $\beta_{w} \cong-7.8 ;$ (b) $\beta_{w}=0$. 


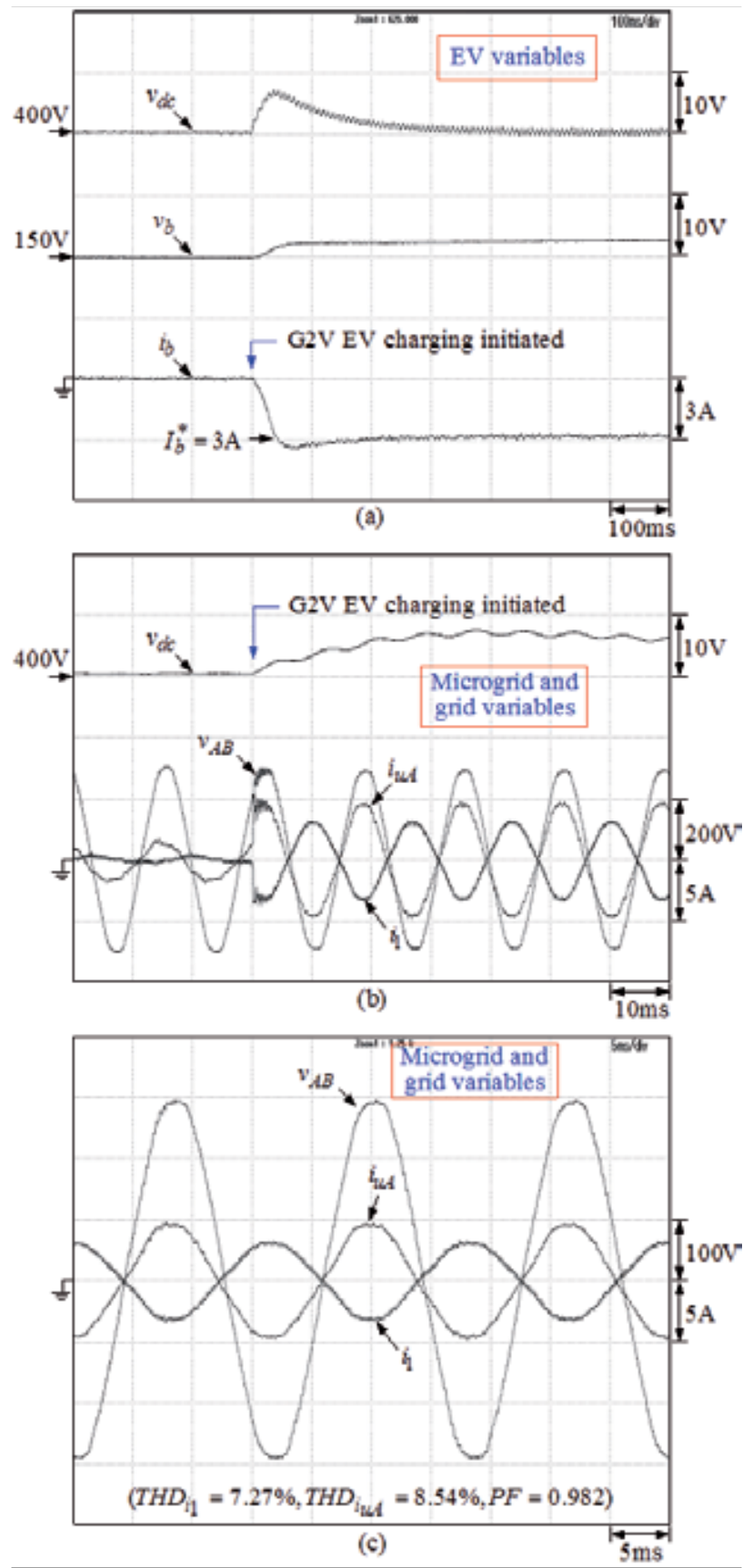

Figure 11. Measured results for EV battery charging $\left(I_{b}{ }^{*}=3 \mathrm{~A}\right)$ from the mains $(\mathrm{G} 2 \mathrm{~V})$ via the micro-grid at resistive loads of $\left(Z_{A}=201.7 \Omega, Z_{B}=201.7 \Omega\right.$ and $\left.Z_{A B}=484 \Omega\right)$ : (a) dynamic responses of $\left(v_{d c^{\prime}}, v_{b}, i_{b}\right) ;($ b) dynamic responses of $\left(v_{d c^{\prime}} v_{A B}, i_{u A^{\prime}}, i_{1}\right) ;\left(\right.$ c) steady-state waveforms of $\left(v_{A B}, i_{u A^{\prime}} i_{1}\right)$. 


\subsection{Grid-connected BESS}

The system configuration and schematic of the developed grid-connected BESS is shown in Figs. 1 and 2. It can be operated under floating, discharging, and charging modes. All load reactive and harmonic powers can be compensated by the BESS. In charging mode, the bidirectional inverter is operated in SMR mode to let the BESS be supported energy from the grid (G2B).

In addition, a plug-in energy harvesting system is also equipped for the grid-connected BESS. The harvested AC and DC sources can be inputted to the system via a three-phase bridgeless DCM SMR to establish a $350 \mathrm{~V}$ DC-link. Then, it is connected to the developed BESS common DC-link (400 V) via a LLC resonant DC/DC isolated converter.

\section{A. System Components}

The constituted system parameters are listed below:

a. Interleaved DC/DC converter

i. $\quad$ Battery bank voltage: $v_{B}=96 \sim 105.6 \mathrm{~V}$

ii. DC-link: $V_{d c}=400 \mathrm{~V}$ (nominal), $C_{d c}=6400 \mu \mathrm{F} / 450 \mathrm{~V}$

iii. Storage energy inductor: $L_{1}=L_{2}=1.74 \mathrm{mH} / 30 \mathrm{kHz}$

iv. IGBT: STGW35NC60WD by STMicroelectronics Company

b. Grid-connected inverter

i. Isolation transformer: $\mathrm{Y}-\Delta$ connected using three single-phase transformers of $60 \mathrm{~Hz}, 127 \mathrm{~V} / 220 \mathrm{~V}(1 / 1.73), 1 \mathrm{kVA}$

ii. Inverter output filter: $L=1.71 \mathrm{mH} / 30 \mathrm{kHz}, \mathrm{C}=3.3 \mu \mathrm{F} / 400 \mathrm{~V}$

iii. IGBT: STGW35NC60WD by STMicroelectronics company

iv. Inverter output: $3 \varphi \mathrm{AC}, v_{a b}=220 \mathrm{~V} / 60 \mathrm{~Hz}, 2 \mathrm{~kW}$

v. Utility grid: $3 \varphi \mathrm{AC}, v_{a b}=220 \mathrm{~V} / 60 \mathrm{~Hz}$

c. Plug-in energy harvesting system

i. $\quad$ Storage energy inductors (at 20kHz): $L_{c 1}=41.12 \mu \mathrm{H}, L_{c 2}=40.95 \mu \mathrm{H}, L_{c 3}=41.55 \mu \mathrm{H}$

ii. DC-link: $V_{d}=350 \mathrm{~V}$ (nominal), $C_{d}=2200 \mu \mathrm{F} / 500 \mathrm{~V}$

iii. Power devices: IGBT: MG100J2YS50 by Toshiba Semiconductor; Diode: fast diode IXYS DSEP 2x-61-12A

\section{B. Control Schemes}

Fig. 12(a) shows the control schemes of the BESS in charging mode including the battery interface interleaved DC/DC converter and the bidirectional grid-connected three-phase 
inverter. Figs. 12(b) and 12(c) are the control schemes of the 3P1SW SMR and LLC resonant $\mathrm{DC} / \mathrm{DC}$ converter in the developed plug-in energy harvesting system.

a. Bidirectional DC/DC interleaved converter

The current and voltage feedback controllers under discharging and charging modes are:

1. Discharging mode

$$
G_{c i}(s)=K_{P i}+\frac{K_{I i}}{s}=3+\frac{10}{s}, G_{c v}(s)=K_{P v}+\frac{K_{I v}}{s}=1.2+\frac{21.6}{s}
$$

2. Charging mode

$$
G_{c i}(s)=K_{P i}+\frac{K_{I i}}{s}=4.2+\frac{500}{s}, G_{c v}(s)=K_{P v}+\frac{K_{I v}}{s}=3+\frac{90}{s}
$$

b. Grid-connected inverter

1. Current feedback controller: $G_{c b i}(s)=4.5$

2. Disturbance and command feed-forward controllers:

$$
G_{d f i}^{\prime}(s)=1.333, G_{f d i}^{\prime \prime}(s)=\frac{1.133 \times 10^{-4} s}{\left(1+5.305 \times 10^{-4} s\right)}+0.603, G_{c f i}(s)=\frac{1.133 \times 10^{-4} s}{\left(1+5.305 \times 10^{-5} s\right)}
$$

3. Active power controller: $G_{p c}(s)=3+\frac{135}{s}$

4. Charging mode controller: $G_{c p}(s)=3+\frac{150}{s}$

\section{Experimental Results}

a. BESS battery charging from grid (G2B)

In making the test, the local loads in BESS are set as linear resistive and motor reactive loads with: $\left(R_{a}=R_{b}=R_{c}=104 \Omega\right)$, AC motor with $\left(V_{I M}=110 \mathrm{~V}_{\mathrm{rms}}\right)$. The utility grid supplies the local load real power and also charges the battery bank. The inverter establishes the 400V DC link and also compensates reactive and harmonic powers of local loads. The battery bank charging is conducted via the bidirectional interface DC/DC converter in buck mode. Initially, the battery is charged under constant current mode with $I_{B}=5 \mathrm{~A}(0.33 \mathrm{C})$ until the voltage is raised to $114 \mathrm{~V}$, then the constant voltage floating charging is applied instead. The measured results are shown in Figs. 13(a) and 13(b). Satisfactory line drawn current waveform and power quailty can be observed from the measured results. 

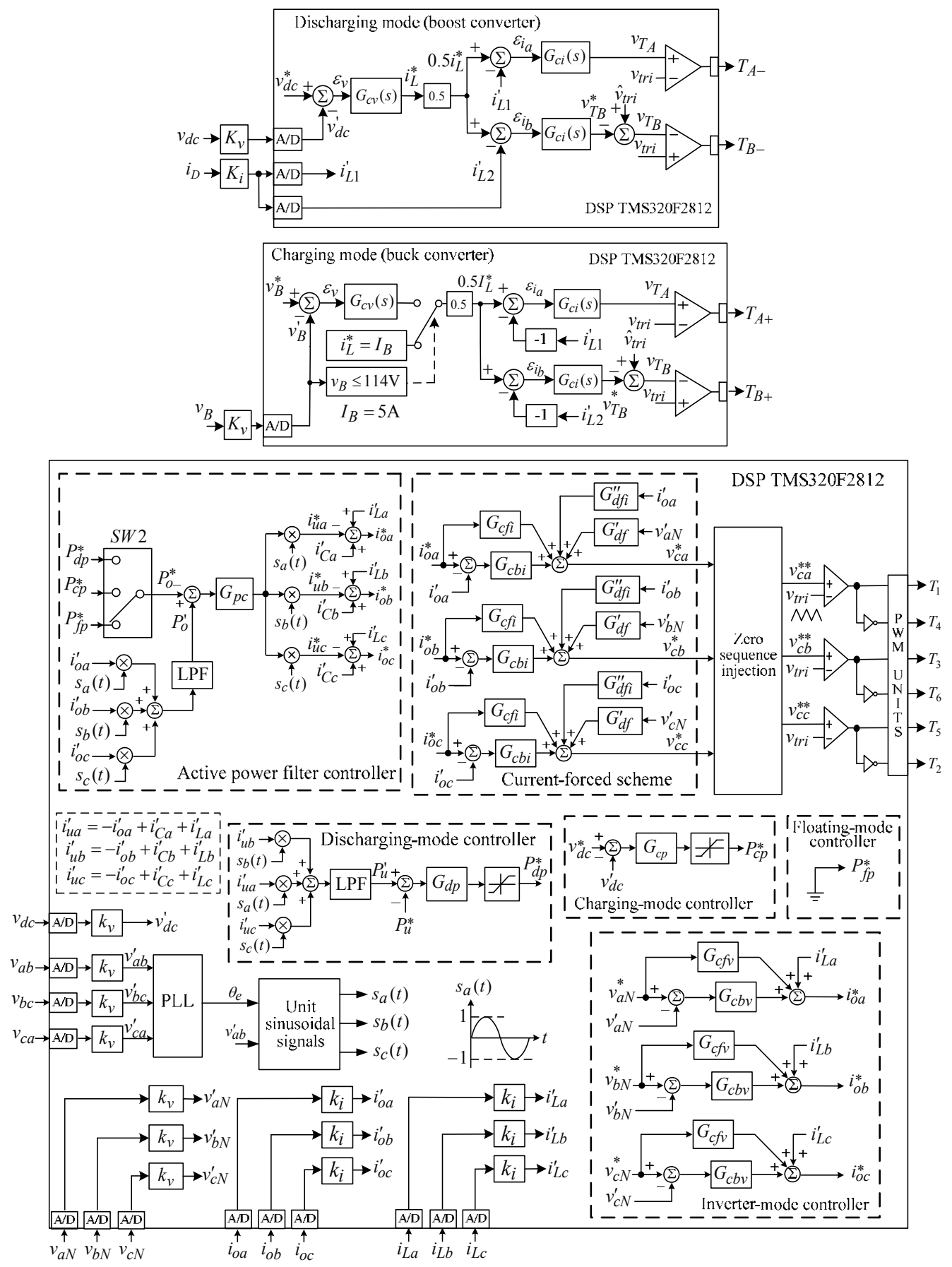

(a) 


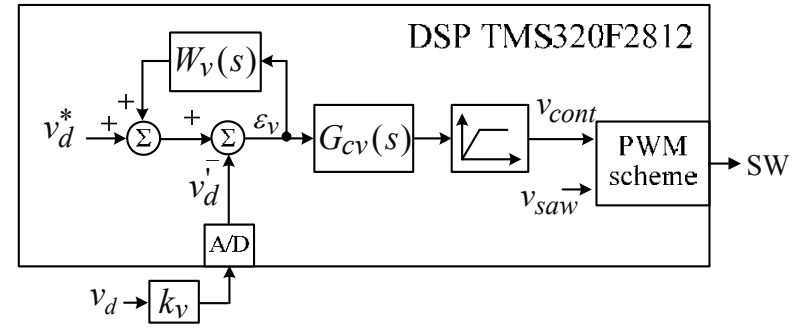

(b)

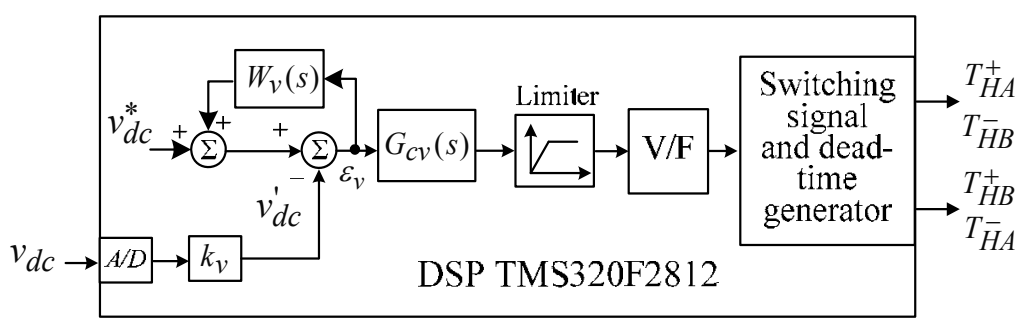

(c)

Figure 12. Control schemes of the developed grid-connected BESS: (a) BESS in charging mode from grid; (b) 3P1SW SMR in plug-in energy harvesting system; (c) LLC resonant DC/DC converter in plug-in energy harvesting system.

b. BESS battery charging from harvested three-phase AC source (E2B)

The harvested three-phase auxiliary AC sources are inputted to the system via the three-phase bridgeless DCM SMR. Through the LLC resonant DC/DC converter, the well-regulated BESS $400 \mathrm{~V}$ DC bus voltage is established. And the battery bank is charged from the DC bus via the BESS interleaved DC/DC interface converter in buck mode. The measured $\left(v_{d c}, v_{d}, v_{a n}, i_{a n}\right)$ and $\left(v_{B}, i_{L}, i_{L}{ }_{1}, i_{L}{ }_{2}\right)$ are shown in Figs. 14(a) and 14(b). Normal and good operation characteristics of all the constituted power stages can be seen from the results. The corresponding measured steady-state characteristics are:

- $P_{\text {in }}=721.91, P_{B}=564.25, \eta=0.78$.

- $i_{a n}: \mathrm{THD}_{i}=24.17 \%, \mathrm{PF}=0.963$.

- $i_{b n}: \mathrm{THD}_{i}=26.00 \%, \mathrm{PF}=0.955$.

- $i_{c n}: \mathrm{THD}_{i}=24.42 \%, \mathrm{PF}=0.962$.

\section{Plug-in Energy Harvesting System with Single-phase AC Source and DC Source Inputs}

a. Schematic 

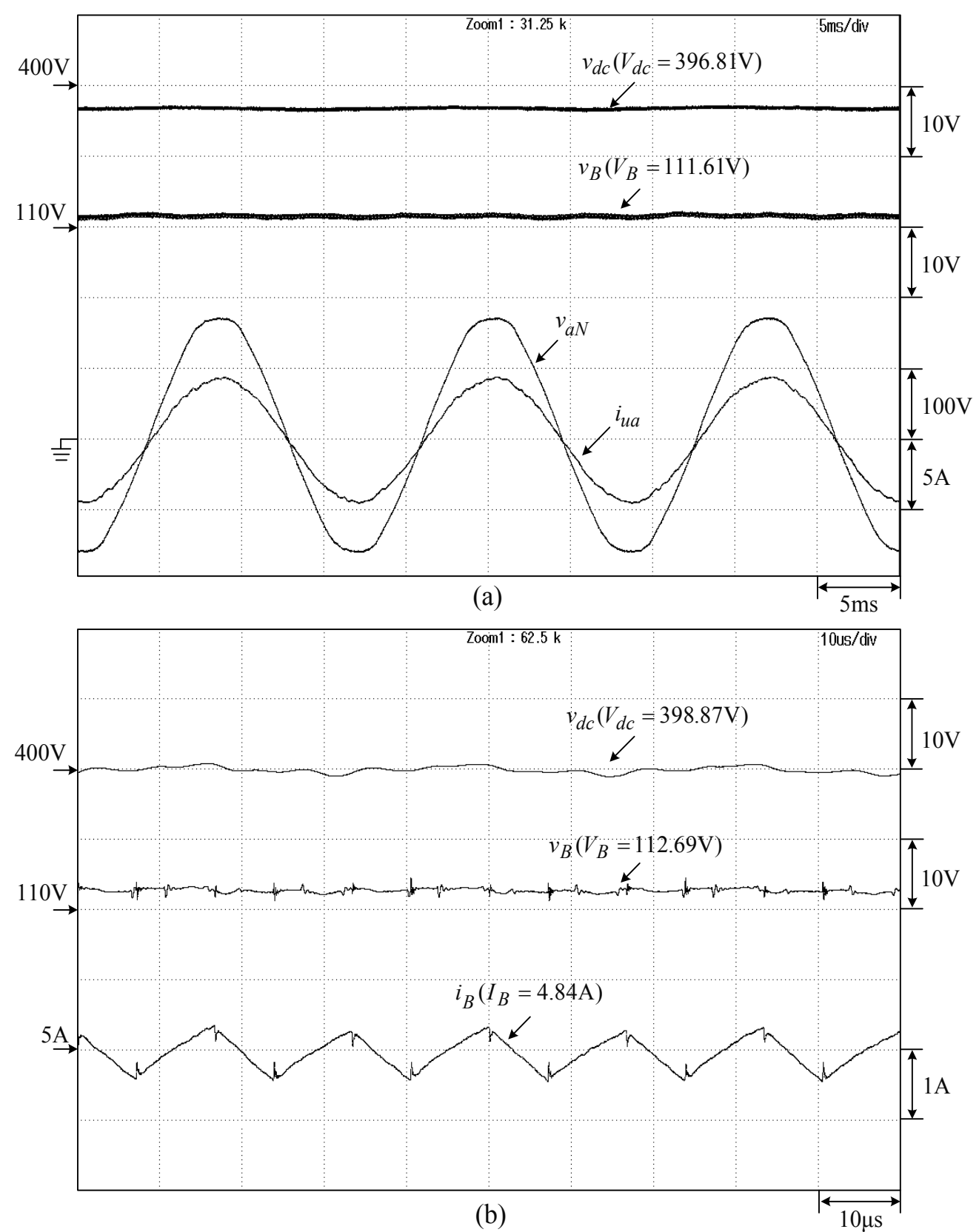

Figure 13. Measured results of the established BESS in charging modes at linear resistive and induction motor reactive load: (a) $v_{d c^{\prime}}, v_{B}$ and $\left(v_{a N}, i_{u a}\right) ;\left(\right.$ b) $v_{d c^{\prime}}, v_{B}$ and $i_{B}$. 

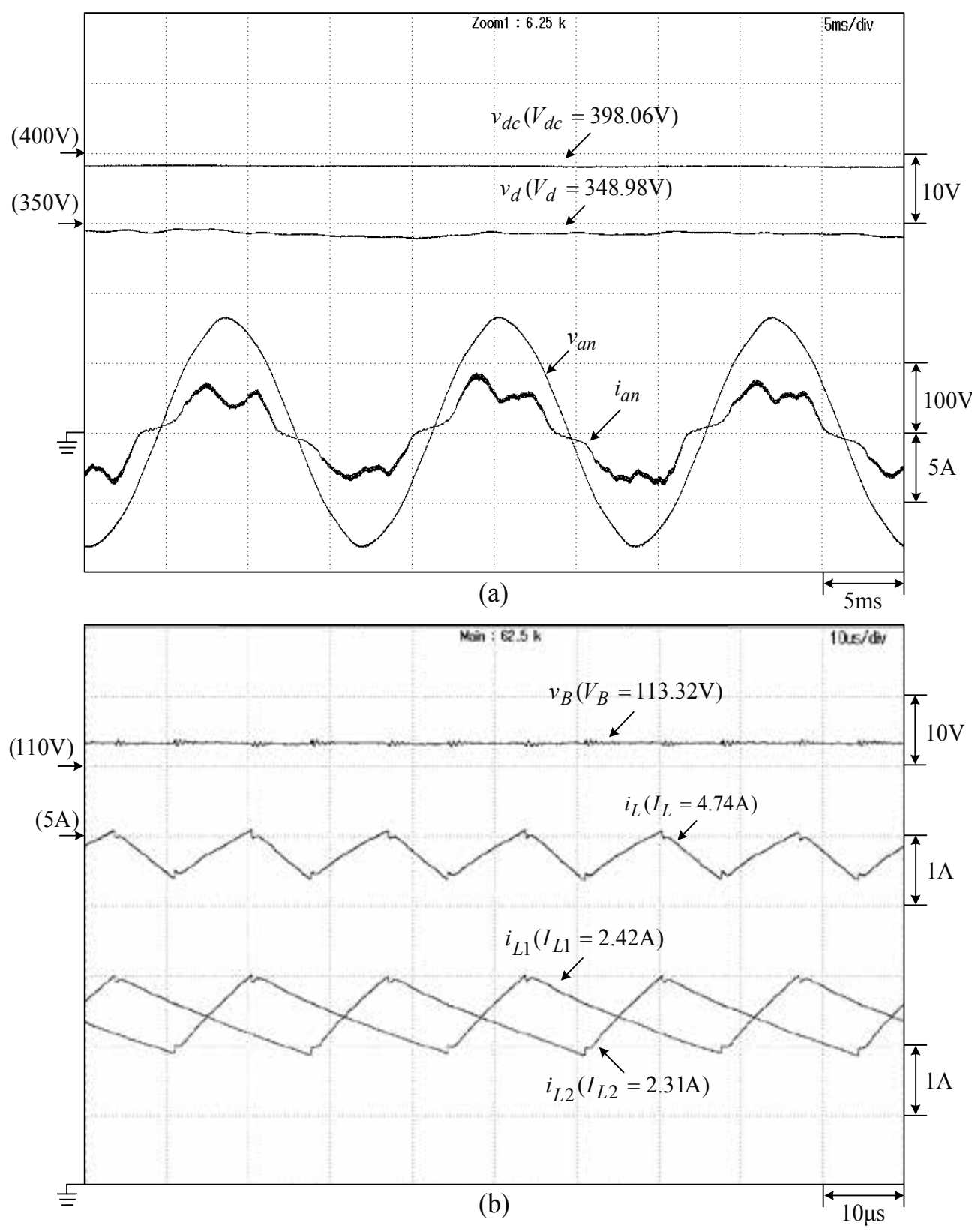

Figure 14. Measured results of the developed isolated plug-in energy harvesting system for the BESS battery charging from three-phase AC source with three-phase bridgeless DCM SMR front-end converter: (a) $\left(v_{d c^{\prime}}, v_{d}, v_{a n^{\prime}} i_{a n}\right)$; (b) (v $v_{B^{\prime}}$ $\left.i_{L}, i_{L 1}, i_{L} 2\right)$. 
The single-phase AC source and DC source can also be inputted to the BESS via the developed plug-in three-phase DCM SMR. The power circuits and control schemes of these two cases are shown in Fig. 15(a) and Fig. 15(b). The single-phase bridgeless boost SMR formed in Fig. 15(a) is operated using a standard SMR control scheme in CCM. Only two extra energy storage inductors $\left(L_{b 1}, L_{b 2}\right)$ are externally added, and the other constituted circuit components are the embedded ones in the original three-phase SMR. The working switches are $s_{1}$ and $s_{2}$ being operated simultaneously.

Some system parameters are set as: (i) PWM switching frequency: $f_{s}=37.5 \mathrm{kHz}$; (ii) DC output voltage $V_{d}=350 \mathrm{~V}$; (iii) $v_{a c} \triangleq \sqrt{2 V_{a c}} \sin \omega t, V_{a c}=220 \mathrm{~V} \pm 10 \%$; (iv) The inductor current ripple is treated at $\omega t=0.5 \pi$, at which the current ripple is maximum; (v) Total energy storage inductance $L=L_{b 1}+L_{b 2}+L_{c 1}+L_{c 2}$. The measured inductances of the two wound inductors $L_{b 1}$ and $L_{b 2}$ using the HIOKI 3532-50 LCR meter are $L_{b 1}=(3.55 \mathrm{mH}, \mathrm{ESR}=183.4 \mathrm{~m} \Omega$ at $60 \mathrm{~Hz}$, and $827.0 \mu \mathrm{H}$, $\mathrm{ESR}=124.6 \Omega$ at $37.5 \mathrm{kHz})$ and $L_{b 2}=(3.44 \mathrm{mH}, \mathrm{ESR}=206.1 \mathrm{~m} \Omega$ at $60 \mathrm{~Hz}$, and $794.8 \mu \mathrm{H}, \mathrm{ESR}=120.7$ $\Omega$ at $37.5 \mathrm{kHz})$.

b. Control schemes

1. Current control scheme

- Feedback controller: $G_{c i}(s)=K_{P i}+\frac{K_{I i}}{s}=4.2+\frac{3150}{s}$

- Robust current error controller (RCEC):

$W_{i}(s)=\frac{W_{i}}{1+\tau_{i} s}, W_{i}=0.1, \tau_{i}=2.652 \times 10^{-4}$ (cut-off frequency $1 / 2 \pi \tau_{i}=600 \mathrm{~Hz}$ )

And the current sensing factor is set as $k_{i}=0.05 \mathrm{~V} / \mathrm{A}$.

2. Voltage control scheme: $G_{c v}(s)=K_{P v}+\frac{K_{I v}}{s}=1.5+\frac{39.37}{s}$

c. Measured results

A load resistor $R_{d}$ is placed at the SMR output of Fig. 2 for making the performance test. At the condition of $\left(v_{a c}=200 \mathrm{~V} / 60 \mathrm{~Hz}, v_{d}=350 \mathrm{~V}, R_{d}=150 \Omega\right)$, the measured stead-state $\left(v_{a c}, i_{a c}, i_{a c}^{*}, i_{a c}^{\prime}\right)$ of the bridgeless single-phase boost SMR formed using the embedded components of the developed plug-in energy harvesting system are plotted in Fig. 16. The corresponding static characteristics are: $\left(I_{a c}=4.09 \mathrm{~A}, \mathrm{TH} D_{i}=3.35 \%, P F=0.997\right)$ and $\left(P_{d}=839.1 \mathrm{~W}, P_{i n}=867.5 \mathrm{~W}, \eta=96.72 \%\right)$ with the efficiency being defined as $\eta \triangleq P_{d} / P_{\text {in }}$. The powers are measured using the power analyzer PM100. Good power quality and high energy conversion efficiency are observed from the results.

By replacing the AC input in Fig. 15(a) with the DC source, the DC source harvesting circuit using the three-phase bridgeless DCM SMR embedded components is formed as shown in Fig. 15(b). Its control scheme is also depicted in Fig. 15(b). The energy storage inductors designed in Fig. 15(a) is also suited in this case. 

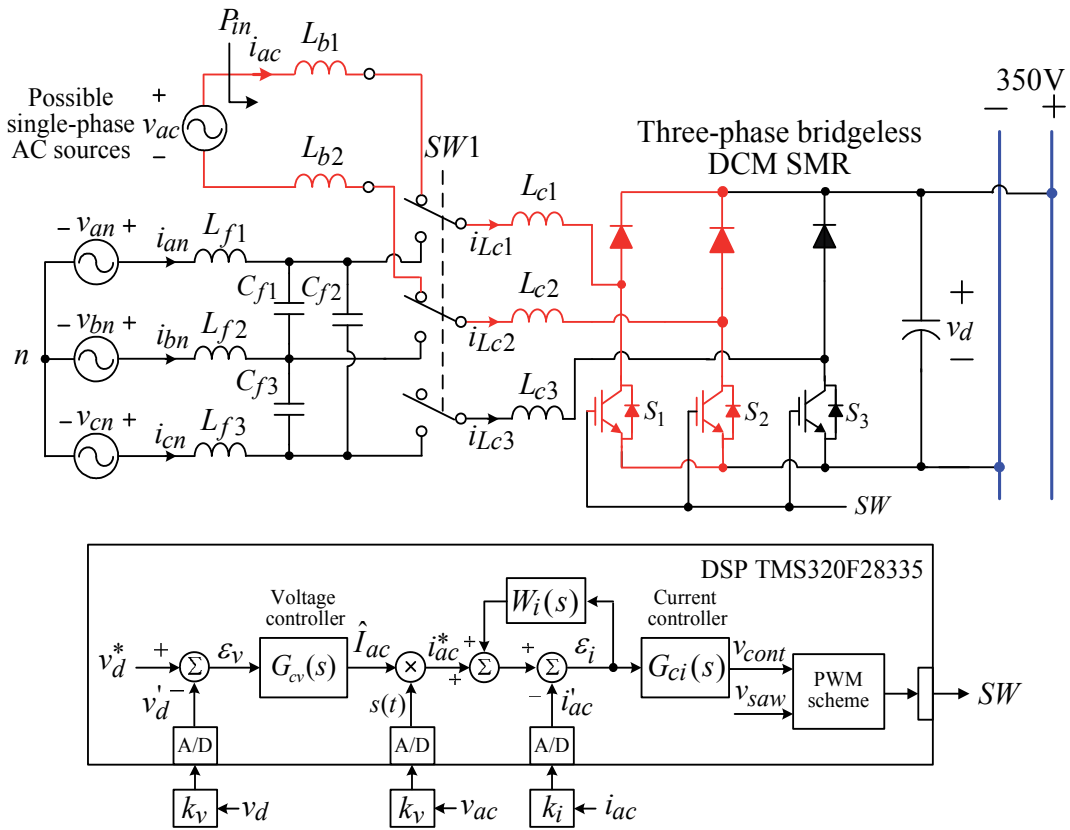

(a)
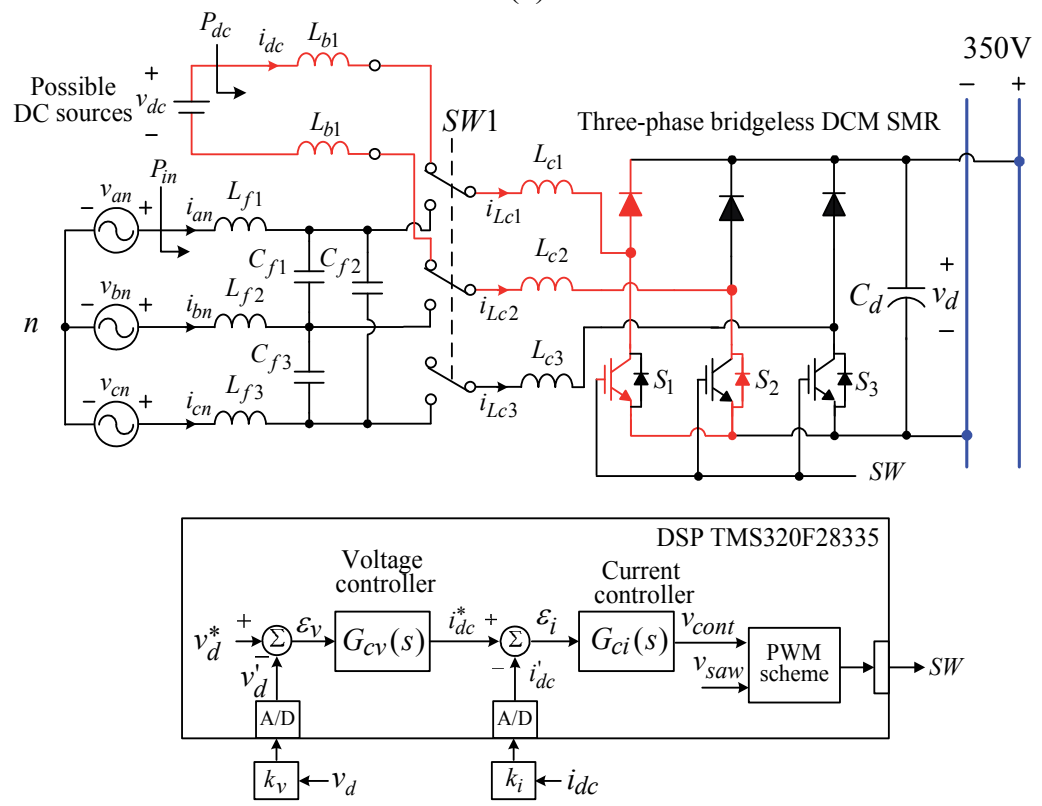

(b)

Figure 15. The schematics and control schemes of the developed plug-in energy havesting system with single-phase AC source and DC source inputs: (a) single-phase AC source input; (b) DC source input. 


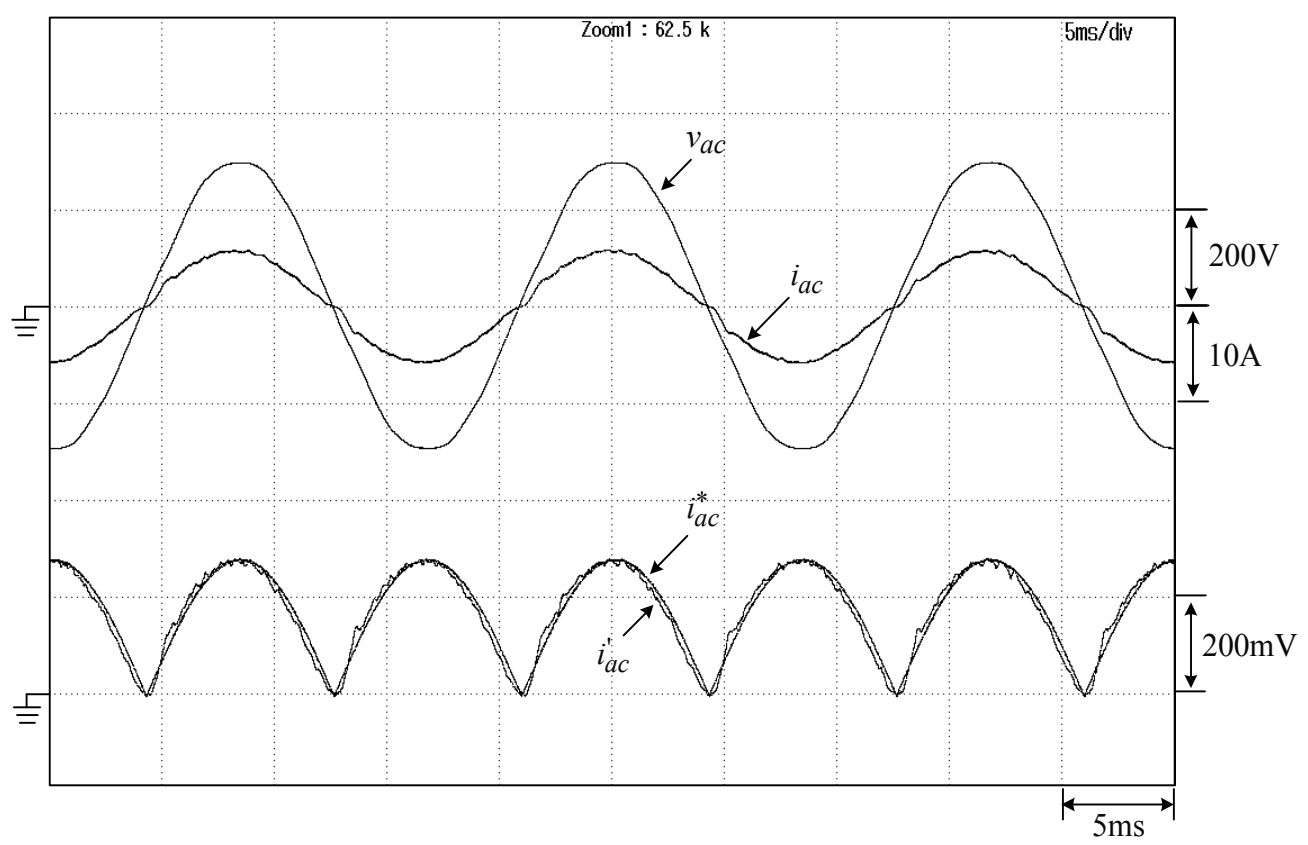

Figure 16. Measured $\left(v_{a c^{\prime}} i_{a c^{\prime}} i_{a c^{\prime}}^{*} i_{a c}^{\prime}\right)$ of the bridgeless single-phase boost SMR formed using the embedded components of the developed plug-in energy harvesting system at $\left(v_{d}=350 \mathrm{~V}, R_{d}=150 \Omega\right)$.

\subsection{G2V operation of the IPMSM EV drive with single-phase SMR based battery charger}

In the developed EV IPMSM drive shown in Fig. 2, a single-phase and a three-phase boost SMR based chargers can be formed using its embedded circuit components. By placing the changeover switch at the position (2), a two-stage single-phase SMR based battery charger is formed as shown in Fig. 17(a). It consists of an H-bridge boost SMR formed by the two outer inverter IGBT legs and a followed interleaved buck DC/DC converter based charger. Fig. 17(b) shows the proposed control schemes of the two power stages. The batteries are first charged under constant current mode with $0.25 \mathrm{C}=3.5 \mathrm{~A}$. The current of $3.5 \mathrm{~A}$ is set by $i_{b m}^{*}$ in the current limiter at the output of $G_{c v}(s)$. When the battery bank voltage reaches $v_{b}=165 \mathrm{~V}$, the charging enters constant-voltage floating mode automatically.

\section{A. System Components}

The constituted system parameters are listed below:

a. Interleaved buck DC/DC converter

i. Battery bank voltage: $V_{b}=140 \sim 152 \mathrm{~V}$

ii. Maximum battery charging voltage: $165 \mathrm{~V}$ 

iii. Maximum battery charging current: $i_{b}=0.25 \mathrm{C}=3.5 \mathrm{~A}$ set by $i_{b m}^{*}$
iv. Switching frequency: $f_{s}=25 \mathrm{kHz}$
v. Energy storage inductors: $L_{b 1}=4.140 \mathrm{mH} / 25 \mathrm{kHz}, L_{b 2}=4.029 \mathrm{mH} / 25 \mathrm{kHz}$
vi. IGBT: STGW35NC60WD by STMicroelectronics Company

b. Single-phase SMR
i. DC-link voltage: $V_{d c}=400 \mathrm{~V}$
ii. AC input voltage: $V_{A B}=220 \mathrm{~V} \pm 10 \% / 60 \mathrm{~Hz}$
iii. Input energy storage inductors: $L_{1}=L_{3}=0.88 \mathrm{mH}$
iv. Output filter capacitor: $C_{d c}=2200 \mu \mathrm{F} / 450 \mathrm{~V}$
v. Switching frequency: $f_{s}=30 \mathrm{kHz}$

\section{B. Control Schemes}

a. Interleaved buck DC/DC converter

The current and voltage feedback controllers are set as:

$$
\begin{aligned}
& G_{c i}(s)=K_{P i}+\frac{K_{I i}}{s}=1.2+\frac{30}{s}, K_{i}(s)=\frac{K_{i}}{1+\tau_{i} s}=\frac{0.1}{1+1.59 \times 10^{-4} s} \\
& G_{c v}(s)=K_{P v}+\frac{K_{I v}}{s}=1.5+\frac{37.5}{s}, K_{v}(s)=\frac{K_{v}}{1+\tau_{v} s}=\frac{0.002}{1+2.65 \times 10^{-4} s}
\end{aligned}
$$

b. Single-phase SMR

The current and voltage feedback controllers are set as:

$$
\begin{aligned}
& G_{c i}(s)=K_{P i}+\frac{K_{I i}}{s}=0.9+\frac{2700}{s}, K_{i}(s)=\frac{K_{i}}{1+\tau_{i} s}=\frac{0.125}{1+1.59 \times 10^{-5} s} \\
& G_{c v}(s)=K_{P v}+\frac{K_{I v}}{s}=0.1+\frac{2.5}{s}, K_{v}(s)=\frac{K_{v}}{1+\tau_{v} s}=\frac{0.002}{1+2.65 \times 10^{-4} s}
\end{aligned}
$$

\section{Experimental Results}

In the single-phase H-bridge boost SMR based charging system shown in Fig. 17(a), the AC input $220 \mathrm{~V} / 60 \mathrm{~Hz}$ and the DC-link voltage command $V_{d c}^{*}=400 \mathrm{~V}$ are set in G2V operation. By setting the constant current charging with $i_{b}^{*}$ to be $i_{b m}^{*}=0.25 \mathrm{C}=3.5 \mathrm{~A}$, the measured $\left(v_{A B}, i_{u A}\right)$ and 


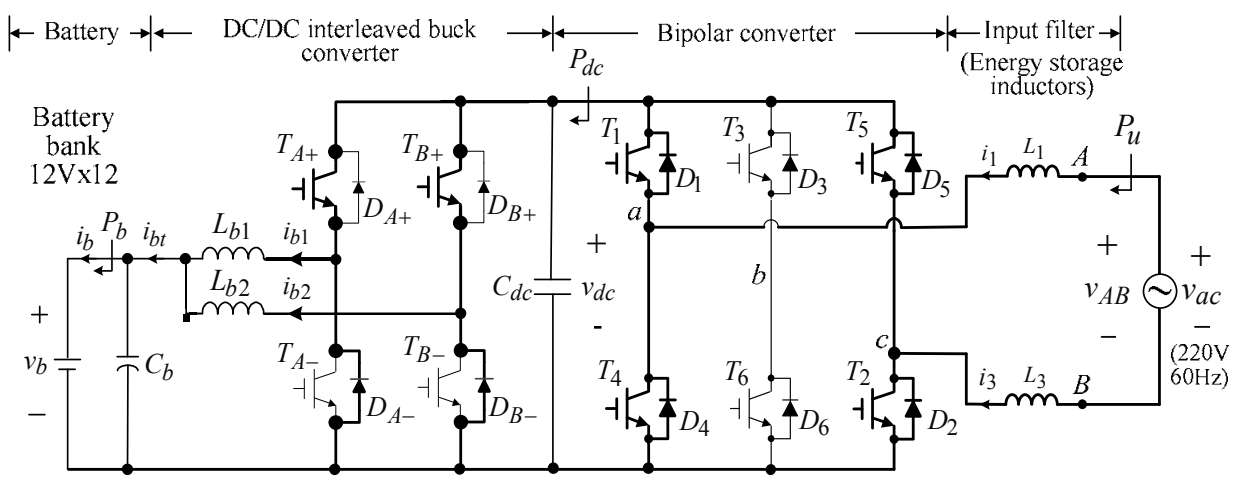

(a)

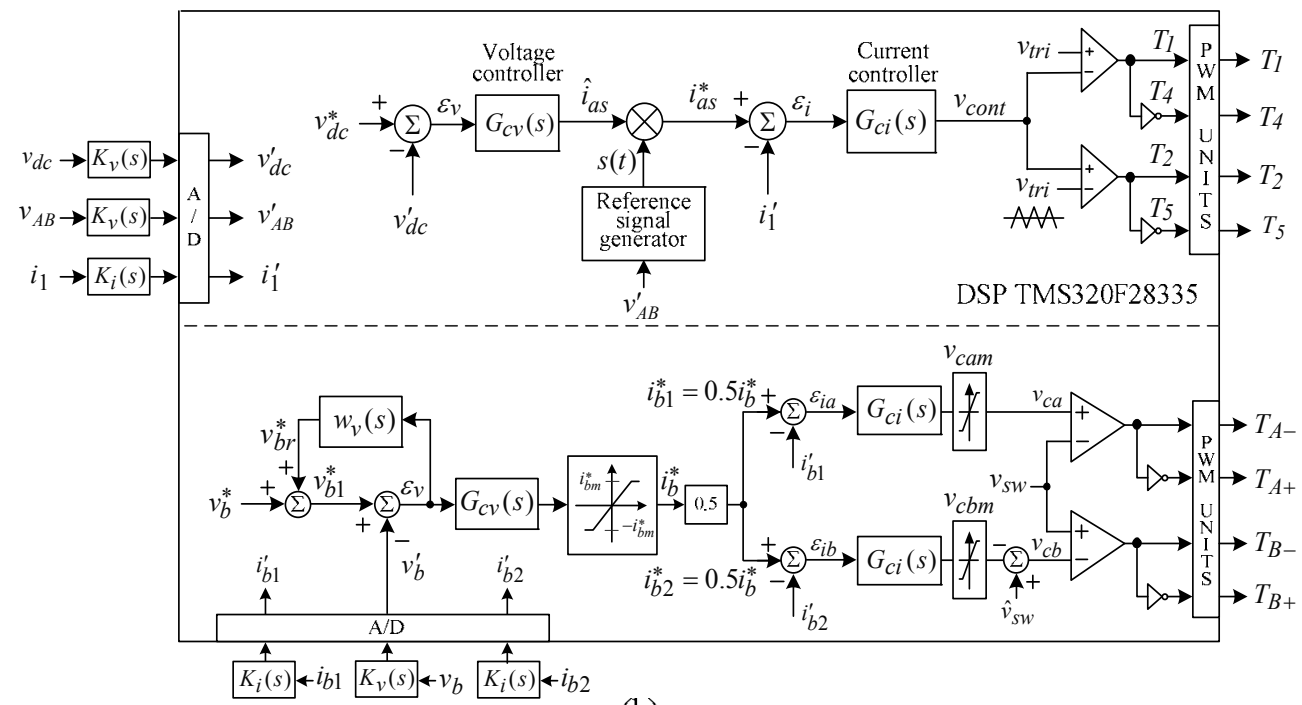

(b)

Figure 17. System configuration and control scheme of the established single-phase H-bridge boost SMR based battery charger: (a) schematic; (b) control scheme.

$\left(v_{b}, i_{b}\right)$ of the developed charging system are shown in Figs. 18(a) and 18(b). Satisfactory SMR operation can be observed from the results.

\subsection{G2V operation of the IPMSM EV drive with three-phase SMR based battery charger}

\section{A. System Components of Three-phase SMR}

i. DC-link voltage: $V_{d c}=400 \mathrm{~V}$

ii. AC input voltage: $V_{A B}=220 \mathrm{~V} \pm 10 \% / 60 \mathrm{~Hz}$

iii. Input energy storage inductors: $L_{1}=L_{2}=L_{3}=0.88 \mathrm{mH}$ 


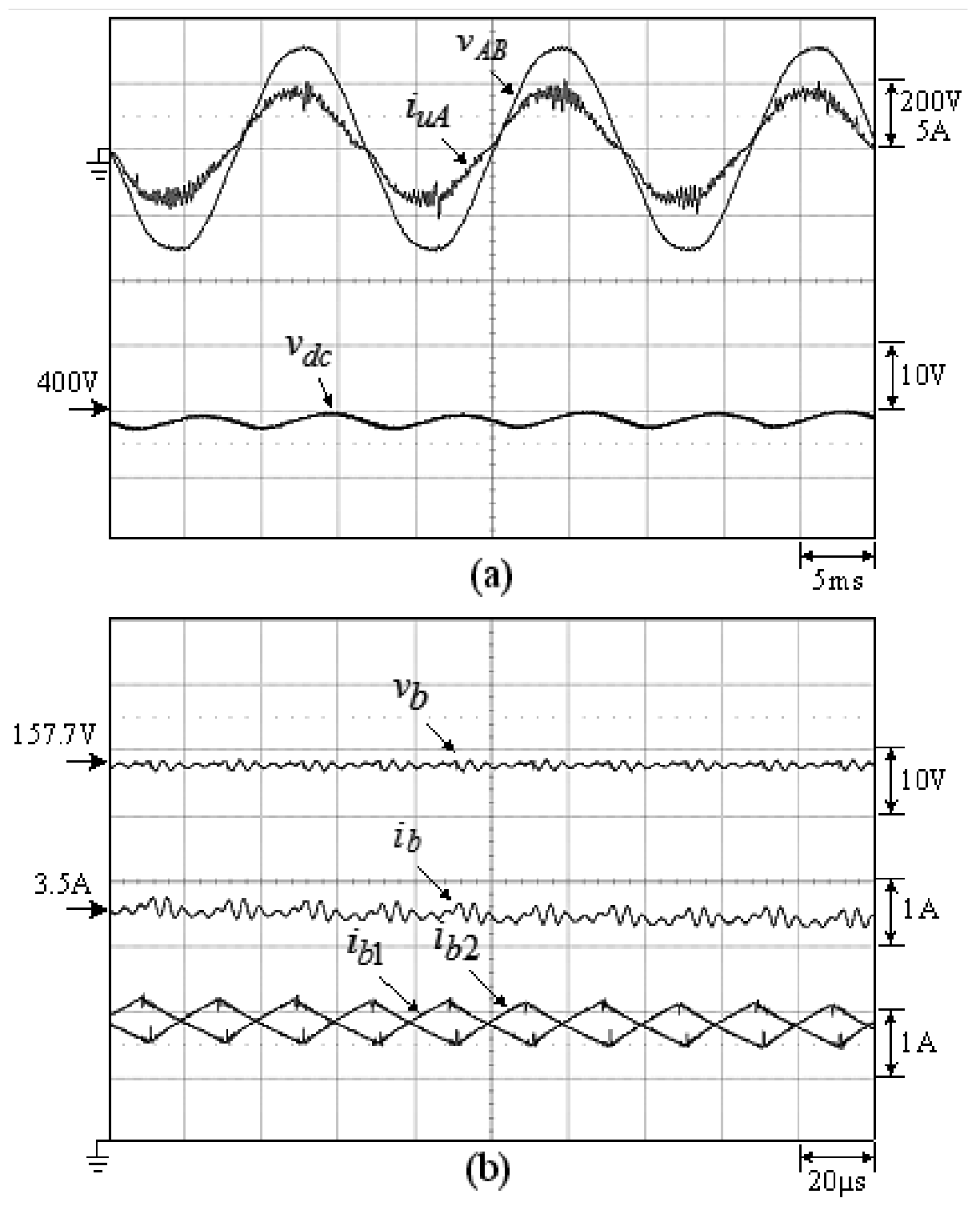

Figure 18. Measured results of the established single-phase charging system at $\left(i_{b}^{*}=3.5 \mathrm{~A}, V_{b}=157.7 \mathrm{~V}, V_{d c}^{*}=400 \mathrm{~V}\right.$, $\left.V_{A B}=220 \mathrm{~V} / 60 \mathrm{~Hz}\right):(\mathrm{a})\left(v_{d c^{\prime}}, v_{A B}, i_{u A}\right) ;(\mathrm{b})\left(v_{b}, i_{b}, i_{b 1}, i_{b 2}\right)$.

iv. Output filter capacitor: $C_{d c}=2200 \mu \mathrm{F} / 450 \mathrm{~V}$

v. Switching frequency: $f_{s}=30 \mathrm{kHz}$

\section{B. Control Schemes of Three-phase SMR}

The current and voltage feedback controllers are set as: 


$$
\begin{aligned}
& G_{c i}(s)=K_{P i}+\frac{K_{I i}}{s}=2.0+\frac{50}{s}, K_{i}(s)=\frac{K_{i}}{1+\tau_{i} s}=\frac{0.125}{1+1.59 \times 10^{-5} s} \\
& G_{c v}(s)=K_{P v}+\frac{K_{I v}}{s}=0.2+\frac{10}{s}, K_{v}(s)=\frac{K_{v}}{1+\tau_{v} s}=\frac{0.002}{1+1.59 \times 10^{-4} s}
\end{aligned}
$$

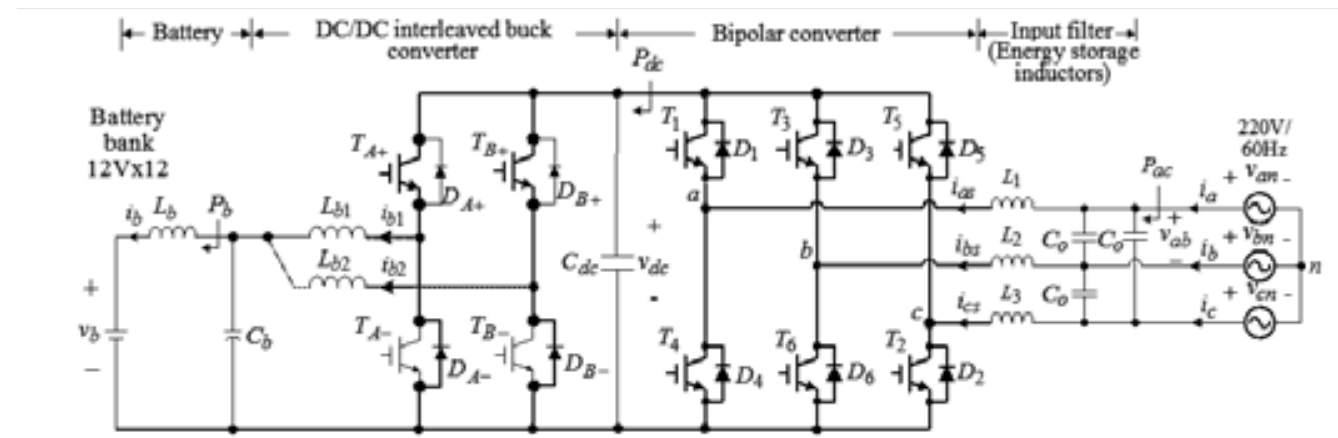

(a)

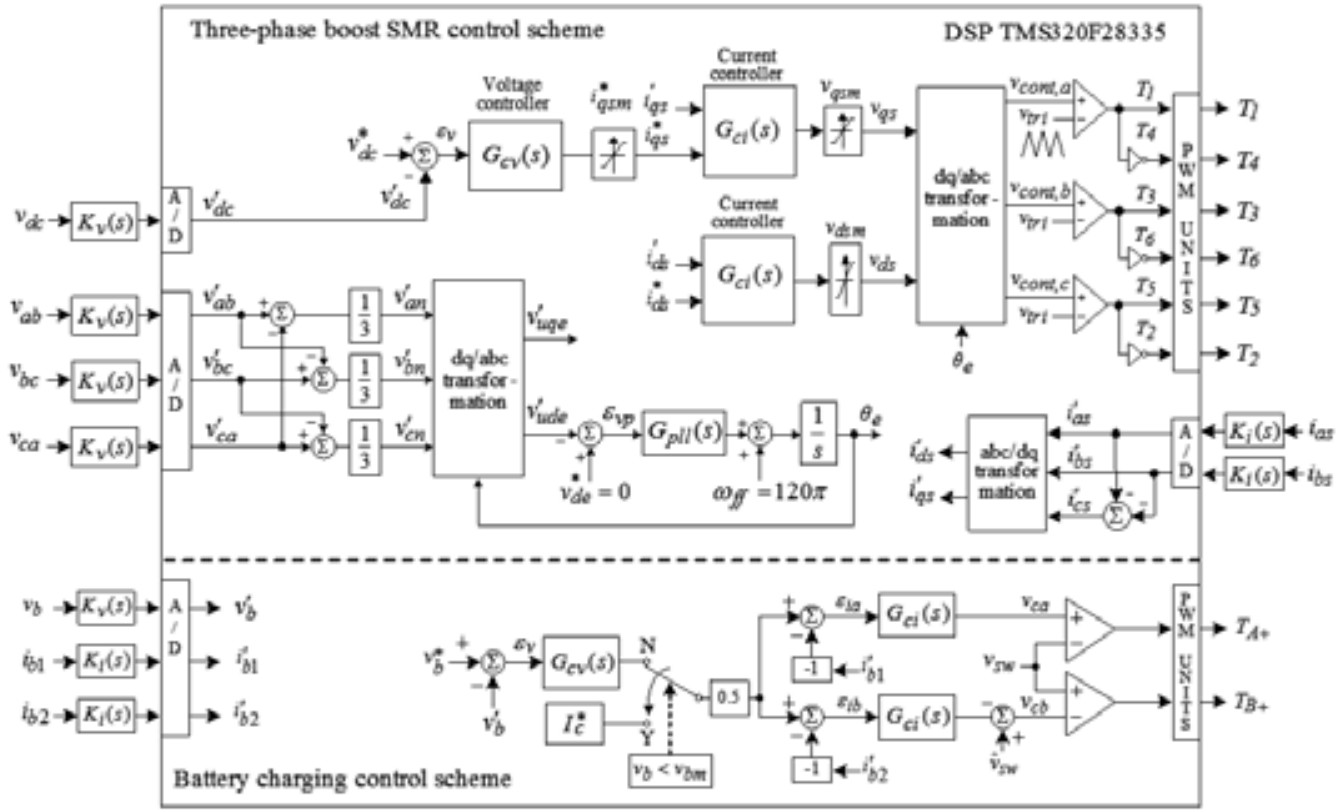

(b)

Figure 19. Schematic and control scheme of the established three-phase SMR based battery charger: (a) schematic; (b) control scheme.

\section{Experimental Results}

Under the conditions of $\left(V_{a b}=220 \mathrm{~V} / 60 \mathrm{~Hz}, V_{d c}^{*}=400 \mathrm{~V}, i_{b m}^{*}=0.25 \mathrm{C}=3.5 \mathrm{~A}\right)$, the measured $\left(v_{a s}\right.$, $\left.i_{a s}\right)$ and $\left(v_{b}, i_{b}\right)$ of the developed three-phase charging system are shown in Figs. 20(a) and 20(b). 
Similarly, good operation performance of the established three-phase SMR based charger is also seen from the results.

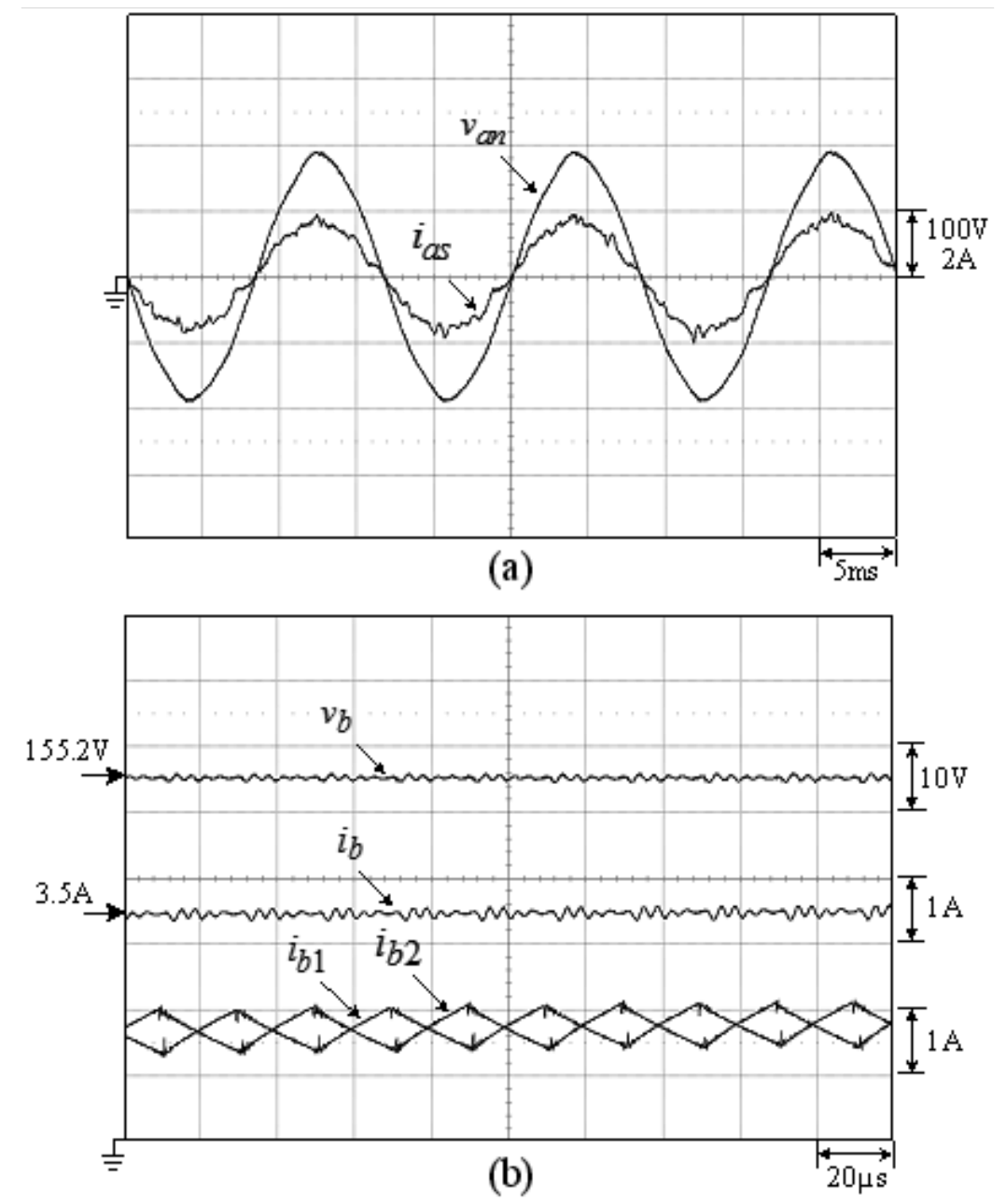

Figure 20. Measured $\left(v_{a n}, i_{a s}\right)$ and $\left(v_{b}, i_{b}\right)$ of the established three-phase SMR based battery charger at $\left(i_{b m}^{*}=0.25 \mathrm{C}=\right.$ 3.5A, $\left.V_{a b}=220 \mathrm{~V} / 60 \mathrm{~Hz}, V_{d c}=400 \mathrm{~V}, V_{b}=155.2 \mathrm{~V}\right):(\mathrm{a})\left(v_{a n^{\prime}} i_{a s}\right)$; (b) $\left(v_{b}, i_{b}, i_{b 1}, i_{b 2}\right)$.

\section{Conclusions}

Switch-mode rectifier can provide adjustable and well-regulated DC voltage with good AC line drawn power quality. Hence, it has been widely applied in many power electronic equipments to yield improved operation characteristics. However, the schematic and control scheme should be properly selected, designed, and implemented in accordance with the 
specific application. During the past decades, the development and employment of microgrids and EVs have received much attention worldwide for reducing fossil energy comsumption. This article has presented the applications of switch-mode rectifiers on micro-grids incorporating with EV and BESS. After introducing the basics and some key issues of SMRs, the configuration of the studied system is introduced. Then, the applications and performance evalutions of SMRs in micro-grid, BESS, and EV are presented.

Some conclusions and comments for the practical issues of SMRs in the related plants covered in this article are summarized as follows:

1. DC Micro-grid: (i) The 3P3SW Vienna SMR is adopted as the followed converter of wind PMSG. It possesses the advantages of having good compromised characteristics in derate, switch number, single-quadrant operation, current PWM control flexibility, and commutation shifting ability. (ii) Load inverter: the bidirectional 1P3W inverter is adopted for providing the $110 \mathrm{~V} / 220 \mathrm{~V}$ AC sources for powering the home appliances. It can successfully perform the M2G and G2M operations. In G2M operation, the single-phase SMR is formed to allow the utility supply power to the micro-grid for energy support or for making the battery supplementary charging. The EV can also perform G2V/V2G operations via the micro-grid interface converters.

2. EV PMSM Drive: The developed battery/SC powered EV IPMSM drive possesses G2V/V2H/V2G operation capabilities. In G2V operation, a single-phase boost SMR and a three-phase boost SMR can be formed using the embedded components to charge the battery bank through the bidirectional interleaved buck DC/DC converter with satisfactory line drawn power quality from the mains. The interconnected operations of the EV to the micro-grid and the BESS can also be conducted.

3. BESS: (i) Grid-connected operation: the three-phase six-switch bidirectional inverter can be arranged to operate in G2B charging mode. The utility grid supplies the load real power and also charges the battery bank with good line drawn power quality. The latter task is achieved by arranging the inverter to be operated as a three-phase 4-quadrant SMR with proper control. The BESS can compensate all load reactive and harmonic powers. (ii) Plugin energy harvesting system: Various AC sources and DC sources can be connected to the BESS via the three-phase bridgeless discontinuous current mode (DCM) SMR through proper schematic and control arrangements. This type of SMR is chosen owing to the single-quadrant operation requirement. In addition, the interconnected operations of the BESS to the micro-grid and EV are also applicable.

\section{Author details}

K. W. Hu and C. M. Liaw*

*Address all correspondence to: cmliaw@ee.nthu.edu.tw

National Tsing Hua University, Taiwan 


\section{References}

[1] Ito, Y.; Yang, Z. \& Akagi, H. DC microgrid based distribution power generation system. Proceedings of IEEE International Power Electronics and Motion Control Conference, pp. 1740-1745, ISBN 7-5605-1869-9.

[2] Hatziargyriou, N.; Asano, H.; Iravani, R. \& Marnay, C. Microgrids. IEEE Power and Energy Magazine, Vol. 5, No. 4, July-Aug. 2007, pp. 78-94, ISSN 1540-7977.

[3] Boroyevich, D.; Cvetkovic, I.; Dong, D. \& Burgos, R. Future electronic power distribution systems a contemplative view. Proceedings of IEEE Transportation Optimization of Electrical and Electronic Equipment Conference, pp. 1369-1380, ISBN 978-1-4244-7019-8.

[4] Valderrama-Blavi, H.; Bosque, J.M.; Guinjoan, F. \& Marroyo, L. Power adaptor device for domestic DC microgrids based on commercial MPPT inverters. IEEE Transactions on Industrial Electronics, Vol. 60, No. 3, March 2013, pp. 1191-1203, ISSN 0278-0046.

[5] Guerrero, J.M.; Vasquez, J.C.; Matas, J.; de Vicuna, L.G. \& Castilla, M. Hierarchical control of droop-controlled AC and DC microgrids-A general approach toward standardization. IEEE Transactions on Industrial Electronics, Vol. 58, No. 1, January 2011, pp. 158-172, ISSN 0278-0046.

[6] Zeraoulia, M.; Benbouzid, M.E.H. \& Diallo, D. Electric motor drive selection issues for HEV propulsion systems : A comparative study. IEEE Transactions on Vehicular Technology, Vol. 55, No. 6, November 2006, pp. 1756-1764, ISSN 0018-9545.

[7] Villafafila-Robles, R.; Lloret-Gallego, P.; Heredero-Peris, D.; Sumper, A.; Cairo, I.; Cruz-Zambrano \& Vidal, N. Electric vehicles in power systems with distributed generation : Vehicle to microgrid (V2M) project. Proceedings of IEEE Electrical Power Quality and Utilisation Conference, pp. 1-6, ISBN 978-1-4673-0379-8.

[8] Hu, K.W. \& Liaw, C.M. On a DC microgrid incorporating with electric vehicle as movable energy storage source. Proceedings of IEEE Internaitonal Conference on Industrial Technology, March 2015, pp. 2606-2611.

[9] Kramer, B.; Chakraborty, S. \& Kroposki, B. A review of plug-in vehicle and vehicleto-grid capability. Proceedings of IEEE Indutrial Electronics Conference, pp. 2278-2283, ISBN 978-1-4244-1767-4.

[10] Madawala, U.K. \& Thrimawithana, D.J. Bidirectional inductive power interface for electric vehicle in V2G systems. IEEE Transactions on Industrial Electronics, Vol. 58, No. 10, October 2011, pp. 459-473, ISSN 0278-0046.

[11] Verma, A.K.; Singh, B. \& Shahani, D.T. Grid to vehicle and vehicle to grid energy transfer using single-phase bidirectional AC-DC converter and bidirectional DC-DC 
converter. Proceedings of IEEE Energy, Automation, and Signal Conference, pp. 1-5, ISBN 978-1-4673-0137-4.

[12] Kramer, W.; Chakraborty, S.; Kroposki, B.; Hoke, A.; Martin, G. \& Markel, T. Grid interconnection and performance testing procedure for vehicle-to-grid (V2G) power electronics. Technical Report NREL/CP-5500-545005.

[13] Dehaghani, E.S. \& Williamson, S.S. On the inefficiency of vehicle-to-grid (V2G) power flow: Potential barriers and possible research directions. Proceedings of IEEE Transportation Electrification Conference and Exposition, pp. 1-5, ISBN 978-1-4673-1407-7.

[14] Ota, Y.; Taniguchi, H.; Nakajima, T.; Liyanage, K.M.; Baba, J. \& Yokoyama, A. autonomous distributed V2G (vehicle-to-grid) satisfying scheduled charging. IEEE Transactions on Smart Grid, Vol. b3, No. b1, March 2012, pp. 559-564, ISSN 1949-3053.

[15] Yimin, G. \& Ehsani, M. Design and control methodology of plug-in hybrid electric vehicles. IEEE Transactions on Industrial Electronics, Vol. 57, No. 2, February 2010, pp. 633-640, ISSN 0278-0046.

[16] Yeh, T.H.; Cheng, W.F.; Hu, K.W. \& Liaw, C.M. An EV IPMSM drive with supercapacitor energy storage and PV energy harvesting. R.O.C. 35th Symposium on Electrical Power Engineering.

[17] Cao, J. \& Emadi, A. batteries needs electronics. IEEE Industrial Electronics Magazine, Vol. 5, No. 1, March 2011, pp. 27-35, ISSN 1932-4529.

[18] Onar, O.C.; Kobayashi, J. \& Khaligh, A. A fully directional universal power electronic interface for EV, HEV, and PHEV applications. IEEE Transactions on Power Electronics, Vol. 28, No. 12, December 2013, pp. 5489-5498, ISSN 0885-8993.

[19] Yilmaz, M. \& Krein, P.T. Review of battery charger topologies, charging power levels, and infrastructure for plug-in electric and hybrid vehicles. IEEE Transactions on Power Electronics, Vol. 28, No. 5, May 2013, pp. 2151-2169, ISSN 0885-8993.

[20] He, J.J.; Hu, K.W. \& Liaw, C.M. On a battery/supercapacitor powered SRM drive for EV with integrated on-board charger. Proceedings of IEEE Internaitonal Conference on Industrial Technology, March 2015, pp. 2667-2672.

[21] Cao, J. \& Emadi, A. A new battery/ultracapacitor hybrid energy storage system for electric, hybrid, and plug-in hybrid electric vehicles. IEEE Transactions on Power Electronics, Vol. 27, No. 1, January 2012, pp. 122-132, ISSN 0885-8993.

[22] Blanes, J.M.; Gutierrez, R.; Garrigos, A.; Lizan, J.L. \& Cuadrado, J.M. Electric vehicle battery life extension using ultracapacitors and an FPGA controlled interleaved buck-boost converter. IEEE Transactions on Power Electronics, Vol. 28, No. 12, December 2013, pp. 5940-5948, ISSN 0885-8993.

[23] Burke, A.F. Batteries and ultracapacitors for electric, hybrid and fuel cell vehicles. Proceedings of IEEE, Vol. 95, No. 4, April 2007, pp. 806-820, ISSN 0018-9219. 
[24] Vazquez, S.; Lukic, S.M.; Galvan, E.; Franquelo, L.G. \& Carrasco, J.M. Energy storage systems for transport and grid applications. IEEE Transactions on Industrial Electronics, Vol. 57, No. 12, December 2010, pp. 3881-3895, ISSN 0278-0046.

[25] Hu, K.W. \& Liaw, C.M. On a bidirectional adapter with G2B charging and B2X emergency discharging functions. IEEE Transactions on Industrial Electronics, Vol. 61, No. 1, January 2014, pp. 243-257, ISSN 0278-0046.

[26] Hu, K.W. \& Liaw, C.M. On an auxiliary power unit with emergency AC power output and its robust controls. IEEE Transactions on Industrial Electronics, Vol. 60, No. 10, October 2013, pp. 4387-4402, ISSN 0278-0046.

[27] Ustun, T.S.; Ozansoy, C.R. \& Zayegh, A. Implementing vehicle-to-grid (V2G) technology with IEC 61850-7-420. IEEE Transactions on Smart Grid, Vol. 4, No. 2, June 2013, pp. 1180-1187, ISSN 1949-3053.

[28] Khan, M.A.; Husain, I. \& Sozer, Y. Integrated electric motor drive and power electronics for bidirectional power flow between the electric vehicle and DC or AC grid. IEEE Transactions on Power Electronics, Vol. 28, No. 12, December 2013, pp. 5774-5783, ISSN 0885-8993.

[29] Yilmaz, M. \& Krein, P.T. Review of the impact of vehicle-to-grid technologies on distribution systems and utility interfaces. IEEE Transactions on Power Electronics, Vol. 28, No. 12, December 2013, pp. 5673-5689, ISSN 0885-8993.

[30] Liaw, C.M. \& Chiang, S.J. Design and implementation of a single-phase three-wire transformerless battery energy storage system. IEEE Transactions on Industrial Electronics, Vol. 41, No. 5, October 1994, pp. 540-549, ISSN 0278-0046

[31] Chiang, S.J.; Huang, S.C. \& Liaw, C.M. (1995). Three-phase multifunctional battery energy storage system. IET Electric Power Applications, Vol. 142, No. 4, July 1995, pp. 275-284, ISSN 1350-2352.

[32] Chiang, S.J.; Liaw, C. M.; Chang, L.C. \& Chang, W.Y. Multi-module parallel small battery energy storage system. IEEE Transactions on Energy Conversion, Vol. 11, No. 1, March 1996, pp. 146-154, ISSN 0885-8969.

[33] Yoshimi, K.; Osawa, M.; Yamashita, D.; Niimura, T.; Yokoyama, R.; Masuda, T.; Kondou, H. \& Hirota, T. Practical storage and utilization of household photovoltaic energy by electric vehicle battery. Proceedings of IEEE Innovative Smart Grid Technologies, pp. 1-8, ISBN 978-1-4577-2158-8.

[34] Kawakami, N. \& Lijima, Y. Overview of battery energy storage systems for stabilization of renewable energy in Japan. Proceedings of IEEE Renewable Energy Research and Applications Conference, pp. 1-5, ISBN 978-1-4673-2328-4.

[35] Peng, S.J.; He, J.J.; Hu, K.W. \& Liaw, C.M. Development of a plug-in energy harvesting system for battery energy storage system. Power Electronics Technology Monthly, Vol. 12, No. 6, 2014, pp. 49-67. 
[36] Caricchi, F.; Crescimbini, F.; Giulii Capponi, F. \& Solero, L. Study of bi-directional buck-boost converter topologies for application in electrical vehicle motor drives. Proceedings of IEEE Applied Power Electronics Conference and Exposition, pp. 287-293, ISBN 0-7803-4340-9.

[37] Hegazy, O.; Barrero, R.; Van Mierlo, J.; Lataire, P.; Omar, N. \& Coosemans, T. An advanced power electronics interface for electric vehicles applications. IEEE Transactions on Power Electronics, Vol. 28, No. 12, December 2013, pp. 5508-5521, ISSN 0885-8993.

[38] Hegazy, O.; Van Mierlo, J. \& Lataire, P. Analysis, modeling, and implementation of a multidevice interleaved DC/DC converter for fuel cell hybrid electric vehicles. IEEE Transactions on Power Electronics, Vol. 27, No. 11, November 2012, pp. 4445-4458, ISSN 0885-8993.

[39] Garcia, O.; Cobos, J.A.; Prieto, R.; Alou, P. \& Uceda, J. Single-phase power factor correction: A Survey. IEEE Transactions on Power Electronics, Vol. 18, No. 3, May 2003, pp. 749-755, ISSN 0885-8993.

[40] Singh, B.; Singh, B.N.; Chandra, A.; Al-Haddad, K.; Pandey, A. \& Kothari, D.P. A Review of single-phase improved power quality AC-DC converter. IEEE Transactions on Industrial Electronics, Vol. 50, No. 5, October 2003, pp. 962-981, ISSN 0278-0046.

[41] Singh, B.; Singh, B.N.; Chandra, A.; Al-Haddad, K.; Pandey, A. \& Kothari, D.P. A review of three-phase improved power quality AC-DC converter. IEEE Transactions on Industrial Electronics, Vol. 51, No. 3, June 2004, pp. 641-660, ISSN 0278-0046.

[42] Kolar, J.W. \& Friedli, T. The essence of three-phase PFC rectifier systems- Part I. IEEE Transactions on Power Electronics, Vol. 28, No. 1, January 2013, pp. 176-198, ISSN 0885-8993.

[43] Friedli, T.; Hartmann, M. \& Kolar, J.W. The essence of three-phase PFC rectifier systems- Part II. IEEE Transactions on Power Electronics, Vol. 29, No. 2, February 2014, pp. 543-560, ISSN 0885-8993.

[44] Chai, J.Y.; Chang, Y. C. \& Liaw, C. M. On the switched-reluctance motor drive with three-phase single-switch-mode rectifier front-end. IEEE Transactions on Power Electronics, Vol. 25, No. 5, May 2010, pp. 1135-1148, ISSN 0885-8993.

[45] Hui, J.; Bakhshai, A. \& Jain, P.K. Control and modeling of a wind energy system with a three-phase DCM boost converter and a sensorless maximum point power tracking method. Proceedings of IEEE Transmission and Distribution Conference and Exposition, pp. 1-7, ISBN 978-1-4673-1934-8.

[46] Kolar, J.W.; Ertl, H. \& Zach, F.C. Design and experimental investigation of a threephase high power density high efficiency unity power factor PWM (VIENNA) rectifier employing a novel integrated power semiconductor module. Proceedings of IEEE Applied Power Electronics Conference and Exposition, pp. 514-523, ISBN 0-7803-3044-7. 
[47] Youssef, N.B.H.; Al-Haddad, K. \& Kanaan, H.Y. Real-time implementation of a discrete nonlinearity compensating multiloops control technique for a $1.5-\mathrm{kW}$ threephase/switch/level Vienna converter. IEEE Transactions on Industrial Electronics, Vol. 55, No. 3, March 2008, pp. 1225-1234, ISSN 0278-0046.

[48] Hu, K.W. \& Liaw, C.M. A position sensorless surface-mounted permanent-magnet synchronous generator and its operation control. IET Power Electronics, 2015.

[49] Hao, C. \& Aliprantis, D.C. Analysis of squirrel-cage induction generator with Vienna rectifier for wind energy conversion sytem. IEEE Transactions on Energy Conversion, Vol. 26, No. 3, September 2011, pp. 967-975, ISSN 0885-8969.

[50] Hao, C.; David, N. \& Aliprantis, D.C. Analysis of permanent-magnet synchronous generator with Vienna rectifier for wind energy conversion system. IEEE Transactions on Sustainable Energy, Vol. 4, No. 1, January 2013, pp. 154-163, ISSN 1949-3029.

[51] Hu, K.W. \& Liaw, C.M. Development of a wind interior permanent-magnet synchronous generator based microgrid and its operation control. IEEE Transactions on Power Electronics, Vol. 30, No. 9, September 2015, pp. 4973-4985,ISSN 0885-8993.

[52] Spiazzi, G. \& Lee, F.C. Implementation of single-phase boost power-factor-correction circuits in three-phase application. IEEE Transactions on Industrial Electronics, Vol. 44, No. 3, June 1997, pp. 365-371, ISSN 0278-0046. 

Chapter 3

\title{
A Comprehensive Modeling and Simulation of Power Quality Disturbances Using MATLAB/SIMULINK
}

\author{
Rodney H.G. Tan and \\ Vigna K. Ramachandaramurthy \\ Additional information is available at the end of the chapter \\ http://dx.doi.org/10.5772/61209
}

\begin{abstract}
This book chapter presents a comprehensive set of MATLAB/Simulink models used to simulate various power quality disturbances. The models presented include distribution line fault, induction motor starting, and transformer energizing that are used to simulate various types of voltage sag event. Capacitor bank switching model used to simulate oscillatory transient event, lightning impulse model used to simulate impulsive transient event, nonlinear load models used to simulate triplen harmonic and voltage notching disturbances generated from the load side, and lastly electric arc furnace model used to simulate flicker disturbance are also presented. This chapter presents each power quality disturbance in MATLAB/Simulink model. The presented models are used to simulate various power quality disturbances and waveforms for power quality analysis research as well as contribute to the development of power quality education and learning curriculum.
\end{abstract}

Keywords: Power quality, simulation model, MATLAB/Simulink

\section{Introduction}

Power quality is an important branch of power system engineering. It plays an important role to ensure the quality of power being delivered to the industry customer. The emergence of smart grids further distinguishes the importance of power quality. A single power quality event such as voltage sag caused by a fault in transmission or distribution level may cost the 
affected industries up to millions of monetary losses [1]. Power quality disturbances are categorized into voltage sag, voltage swell, transient, harmonic, voltage notch, and flicker. Power quality research is the study of various phenomena that cause power quality disturbance to occur and the development of mitigation strategy. To develop the right mitigation strategy for the power quality problem, the power quality disturbance phenomenon and its root cause must be fully understood. With the advancement of computer technology and software development, simulation of power quality disturbance is made possible. It allows the researcher to model and simulate a given power system to trace, analyze, and understand the root cause of power quality disturbance [2]. It also allows the researcher to carry out what-if scenarios by changing the model or simulation parameters to test their hypothesis [3]. It provides an insight of how power quality disturbance propagates from the source and through the entire power system network. With that in mind, modeling and simulation approach became one of the widely used research method to model and simulate various power quality disturbances. There are many power system simulation tools [4] available, and each simulation tool has its own merits. However, the widely used tools in the academic research community are PSCAD/EMTDC [5], ATP/EMTP [6], MATLAB with Power System Toolbox [7, 8], Power System Analysis Toolbox [9, 10], Simulink with SimPowerSystems blockset [11-13], and Power Analysis Toolbox [14]. In this book chapter, MATLAB/Simulink with SimPowerSystems is chosen as the simulation platform. A comprehensive set of basic models developed to simulate voltage sag, swell, transient, harmonic, and flicker power quality disturbance are presented in this chapter.

\section{Modeling approach}

The simulation models were developed using MATLAB/Simulink with SimPowerSystems. It is then used to simulate various power quality disturbances and observe how these disturbances distort the power system sinusoidal waveform. The models were developed with minimum number of blocks in mind and use their default settings whenever possible to reserve their simplicity and reproducibility for the reader. The developed models present in the book chapter also serve as basic building blocks to a larger power system. The distribution voltage level used in the models is based on the Malaysia grid code. Simulation models including line fault, induction motor starting, transformer energizing, capacitor bank energizing, lightning impulse, nonlinear load, and electric arc furnace models used to simulate various power quality disturbances are described in Sections 2.1 to 2.8 .

\subsection{Line fault model}

The line fault model developed in Simulink is show in Figure 1. The line fault model is used to simulate voltage sag caused by line fault. The line fault model consists of $11 \mathrm{kV}, 30 \mathrm{MVA}$, $50 \mathrm{~Hz}$ three-phase source block feeding through $11 \mathrm{kV} / 0.4 \mathrm{kV}, 1 \mathrm{MVA}$ delta/wye transformers to a $10 \mathrm{~kW}$ resistive and 100VAR inductive load. There are instantaneous waveform and RMS measurement scopes located at $11 \mathrm{kV}$ and $0.4 \mathrm{kV}$ buses. There are two fault blocks located at 
the $11 \mathrm{kV}$ bus to simulate line fault and multistage fault. A 0.4 second simulation time is set and ode23tb solver is selected to run the simulation.

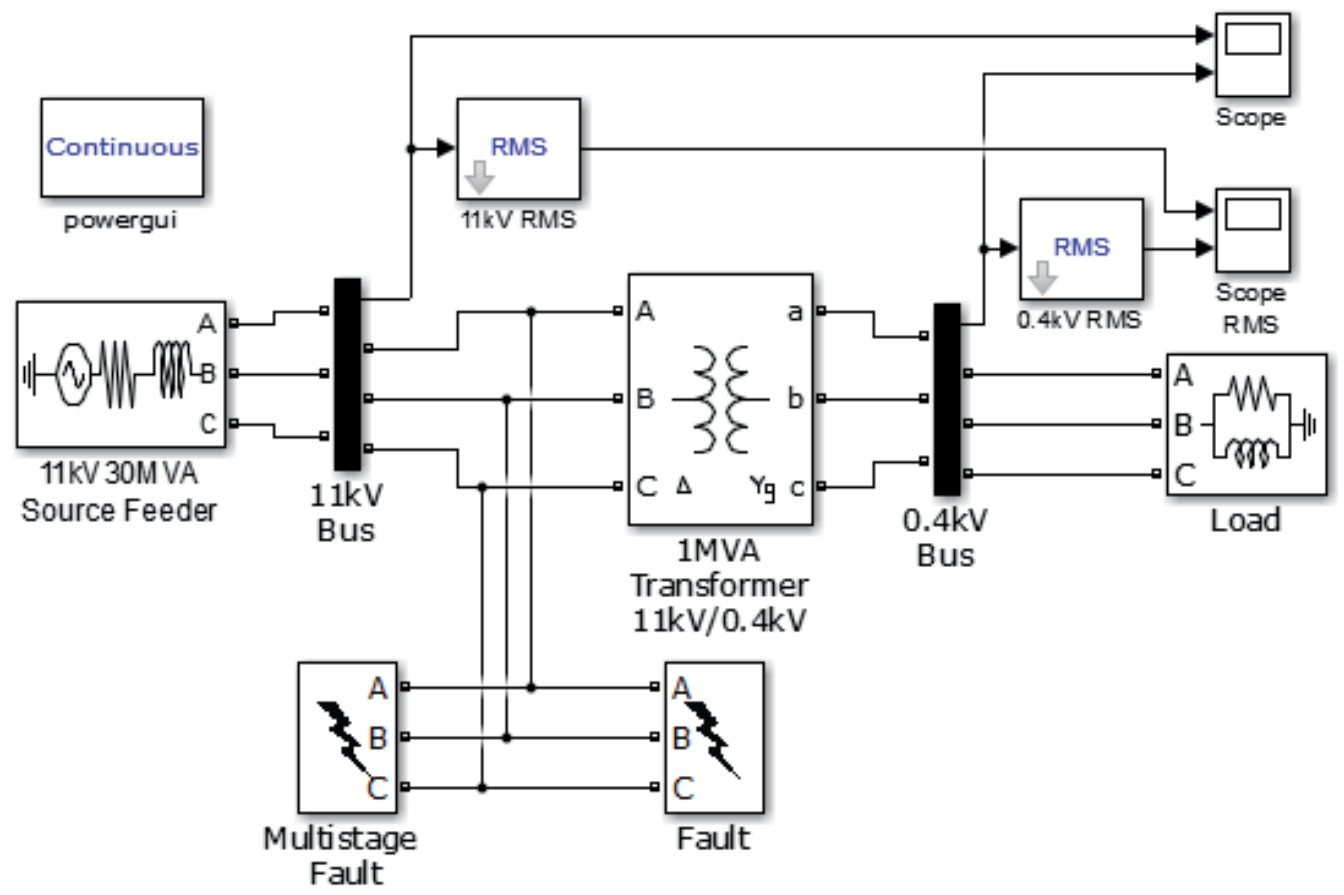

Figure 1. Line fault Simulink model.

This line fault model is capable of simulating various line faults including single line to ground, double line to ground, line-to-line, three phase fault, and multistage. Figure 2 shows voltage sag waveforms caused by a line-to-line fault between phase A and phase B at $11 \mathrm{kV}$ feeder lines at 0.1 to 0.168 seconds. It can be observed that the $11 \mathrm{kV}$ bus experiences two voltage sags at phase A and phase B with different sag magnitude. This is due to high fault resistance of 8 $\Omega$ between the two faulted lines. As the voltage sag propagates downstream through the 11 $\mathrm{kV} / 0.4 \mathrm{kV}, 1 \mathrm{MVA}$ transformer to the load and the fault type [15] is altered by the delta/wye configuration of the transformer. The unfaulted phase $\mathrm{C}$ at $0.4 \mathrm{kV}$ bus experiences a slight voltage swell due to the absent of ground point in the line-to-line fault and high fault resistance.

In power quality studies, voltage sag waveform magnitude is commonly presented in RMS waveform and normalized for better visualization. Figure 3 shows the RMS analysis of lineto-line fault voltage sag waveforms in Figure 2. The sag magnitudes for each phase can be clearly visualized. The slight oscillation occurs at the pre- and post-sag and swell is due to the phase shift during fault [16].

The line fault model is also capable of simulating multistage line faults. The multistage voltage sag is typically due to multiple faults protection relay clearing mechanisms that are not 

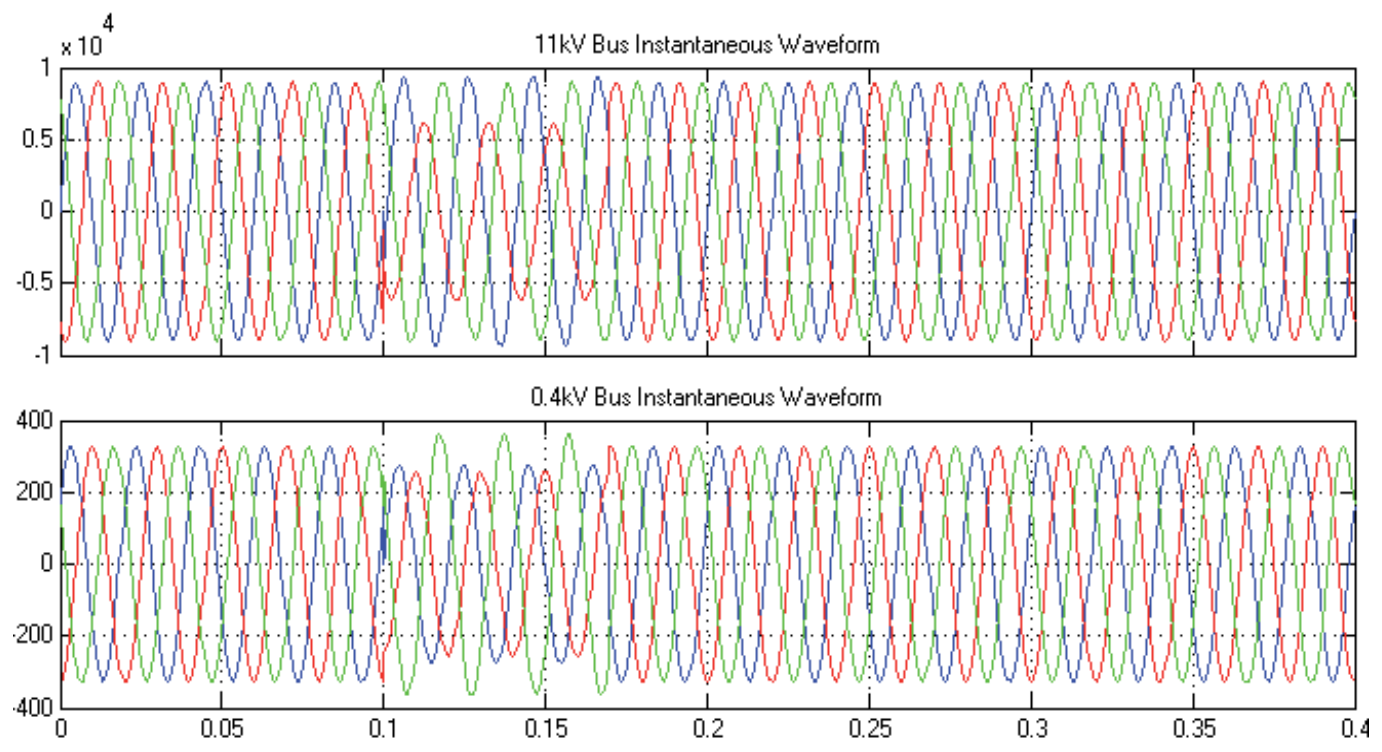

Figure 2. Voltage sag and swell caused by line-to-line fault at $11 \mathrm{kV}$ line.
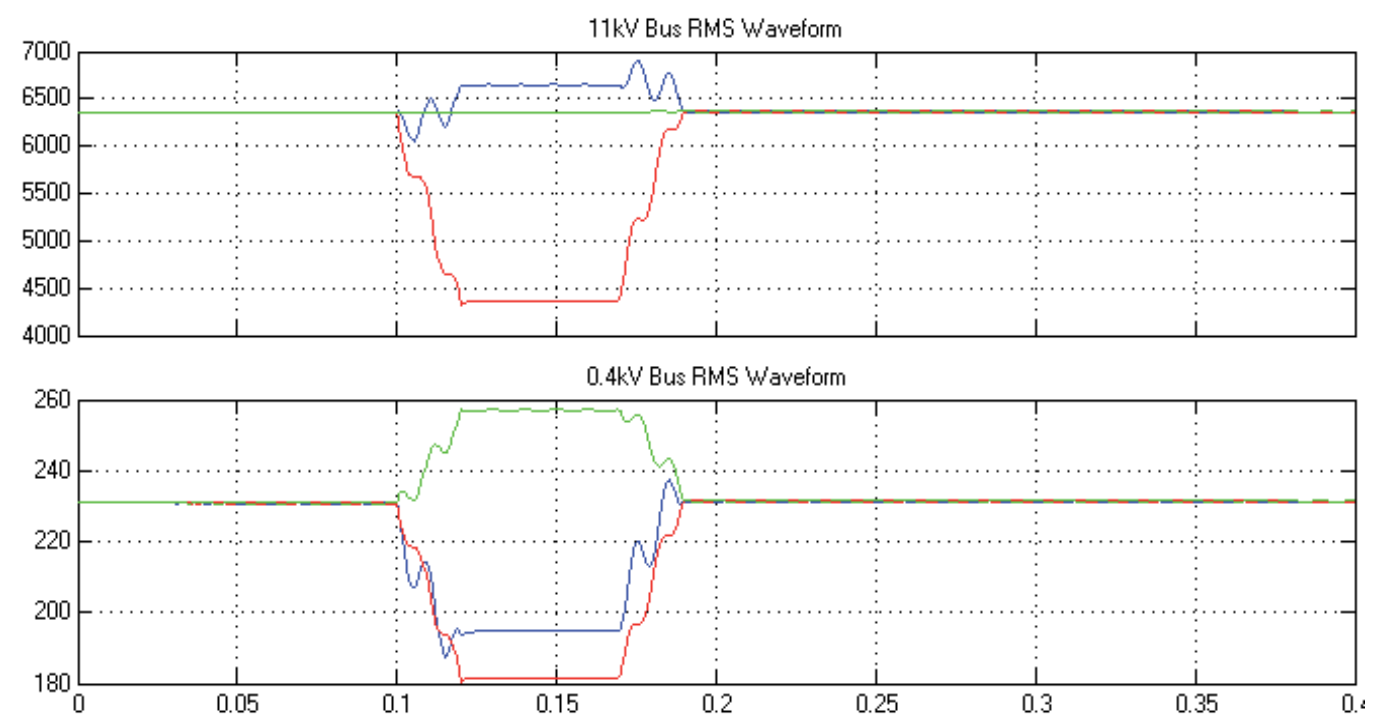

Figure 3. Voltage sag and swell in RMS waveform.

synchronous with each other, thus changing the power system impedance and network configuration leading to multiple stages of voltage sag before fully recovering to its nominal level [17], or the changes of fault or ground impedance during fault. It is sometimes also defined as multiple faults that occur consecutively within a short interval of time and captured within one single record as one event. Figure 4 shows multistage voltage sag instantaneous 
waveforms caused by double line to ground fault. The fault block is set to simulate fault from 0.1 to 0.168 second with fault impedance of $1 \Omega$ and the multistage fault block is set to simulate fault from 0.168 to 0.3 second with fault impedance of $0.1 \Omega$. The changes of fault impedance during a fault create a multistage voltage sag power quality disturbance.
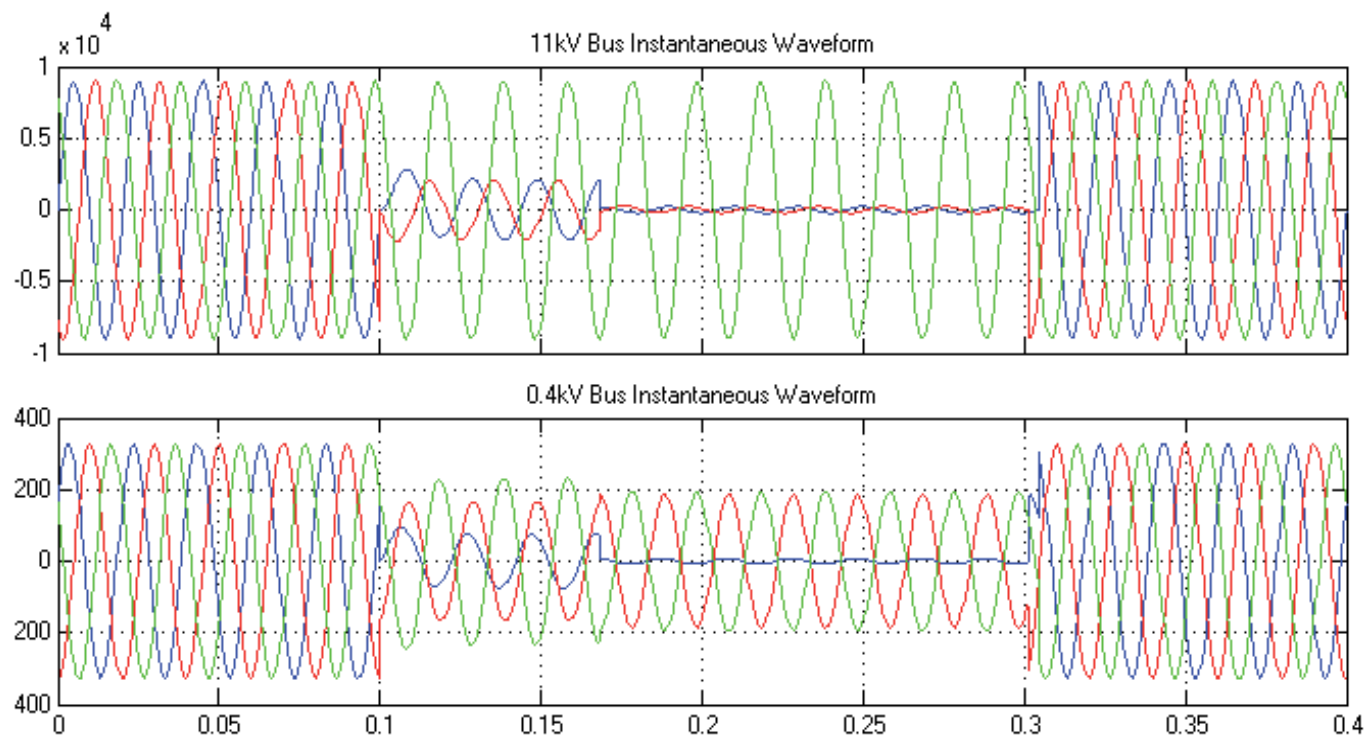

Figure 4. Multistage voltage sag waveform caused by double line to ground fault at $11 \mathrm{kV}$ line.

Figure 5 shows the RMS waveform of multistage voltage sag to better visualize the multistage voltage sag.

\subsection{Induction motor starting model}

The induction motor starting model is used to simulate voltage sag caused by starting a highpower industry induction motor. The induction motor starting model developed in Simulink is shown in Figure 6. The induction motor starting model can be used to simulate voltage sag caused by induction motor starting, The model consists of a $11 \mathrm{kV}, 30 \mathrm{MVA}, 50 \mathrm{~Hz}$ three-phase source feeder block feeding through $11 \mathrm{kV} / 0.4 \mathrm{kV}, 1$ MVA delta/wye transformers, a threephase breaker as motor starting contactor, a three-phase induction motor, and $10 \mathrm{~kW}$ resistive load. There are instantaneous and RMS waveform scopes located at $11 \mathrm{kV}$ and $0.4 \mathrm{kV}$ buses for measurement. Similarly, a 0.4 second simulation time is set and ode23tb solver is selected to run the simulation

Figure 7 shows a three-phase voltage sag instantaneous waveform caused by a $75 \mathrm{~kW}$ (100 hp) induction motor starting upon closing of motor starting contactor at 0.1 second. The speed of the induction motor during starting is set at $1 \mathrm{rad} / \mathrm{sec}$ using the constant block. The voltage sag at $0.4 \mathrm{kV}$ bus propagates upstream through the transformer to the $11 \mathrm{kV}$ feeder bus. The 

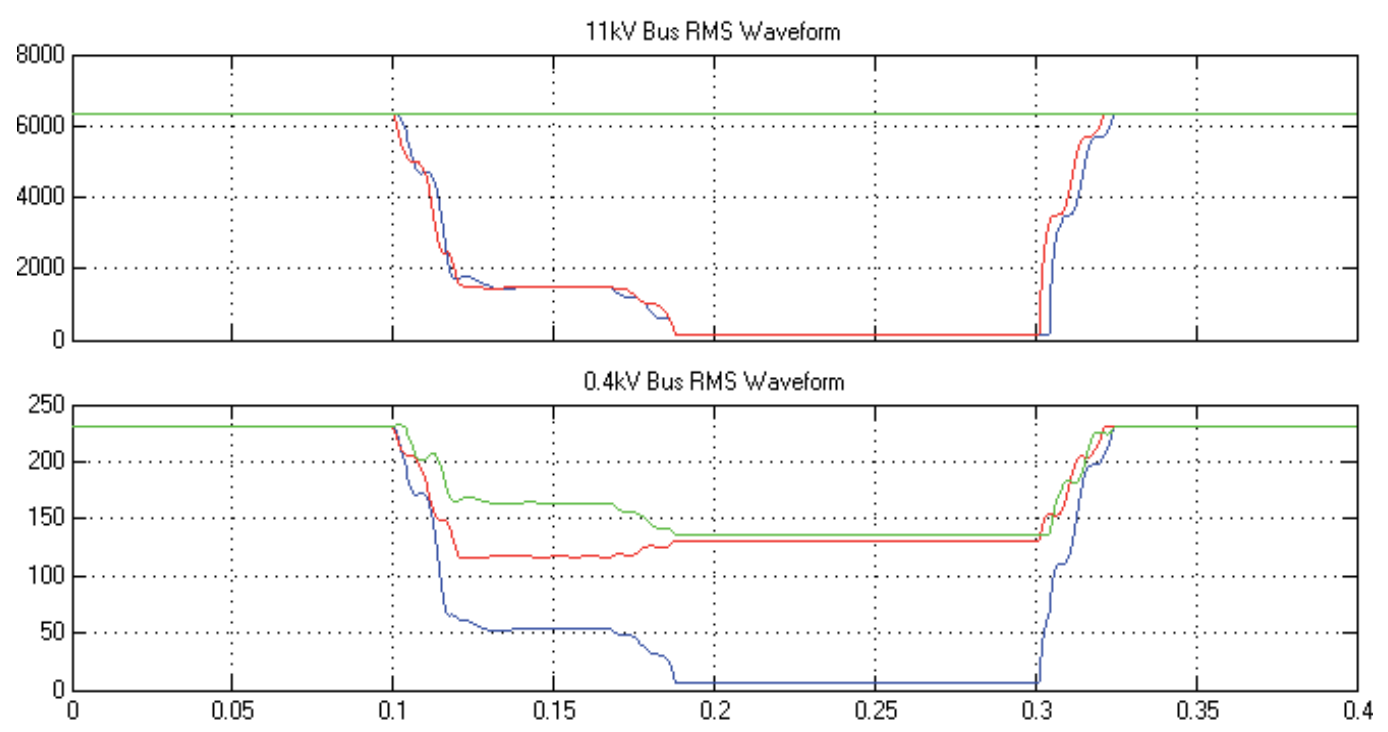

Figure 5. Multistage voltage sag in RMS waveform.

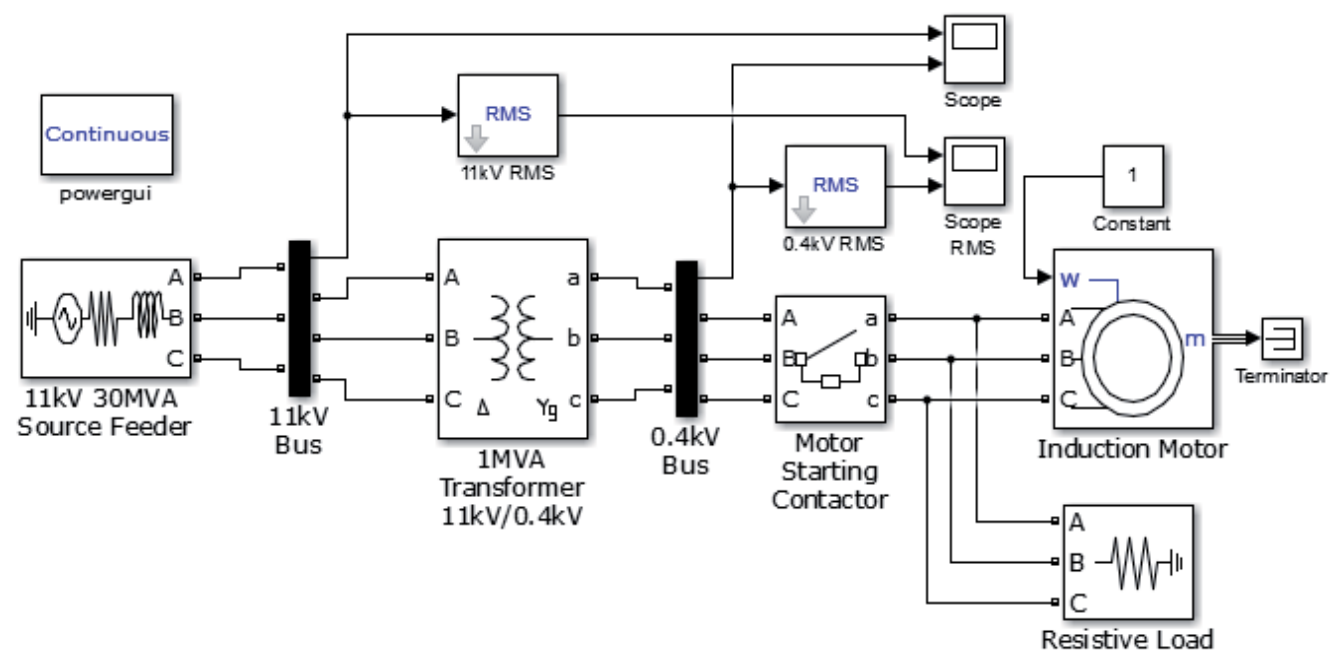

Figure 6. Induction motor starting/load Simulink model.

voltage sag can only be noticed at $0.4 \mathrm{kV}$ bus waveform. The voltage sag magnitude reduces as it propagates upstream toward the $11 \mathrm{kV}$ feeder where the voltage sag becomes insignificant and not noticeable.

Three-phase induction motor starting voltage sag is typically balanced and has a shallow drop up to $15 \%$ from its nominal magnitude. The sag magnitude of the induction motor voltage sag is dependent on the induction motor power rating. A higher induction motor power rating 

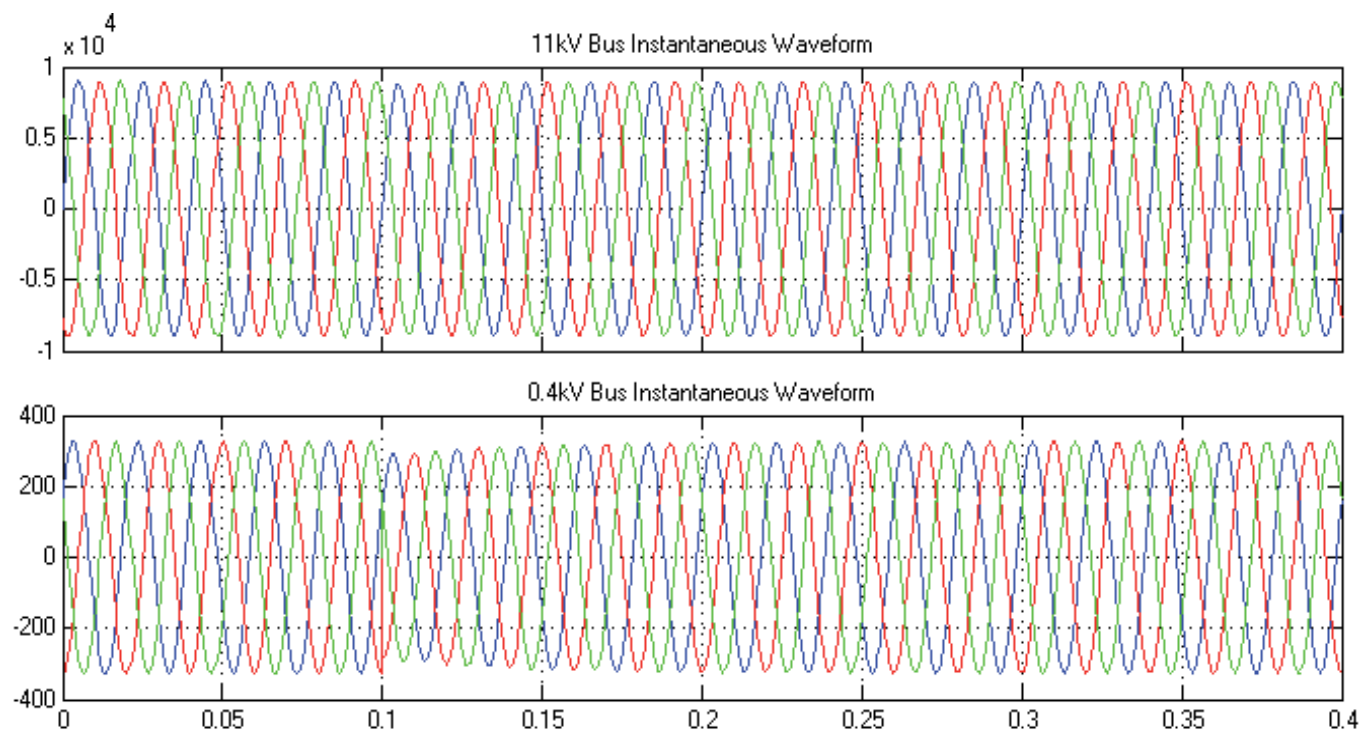

Figure 7. Voltage sag instantaneous waveform caused by the starting of $75 \mathrm{~kW}(100 \mathrm{hp})$ induction motor at $0.4 \mathrm{kV}$ feeder.

leads to a lower sag magnitude. The voltage sag pattern can be visualized clearly in RMS waveform as shown in Figure 8.
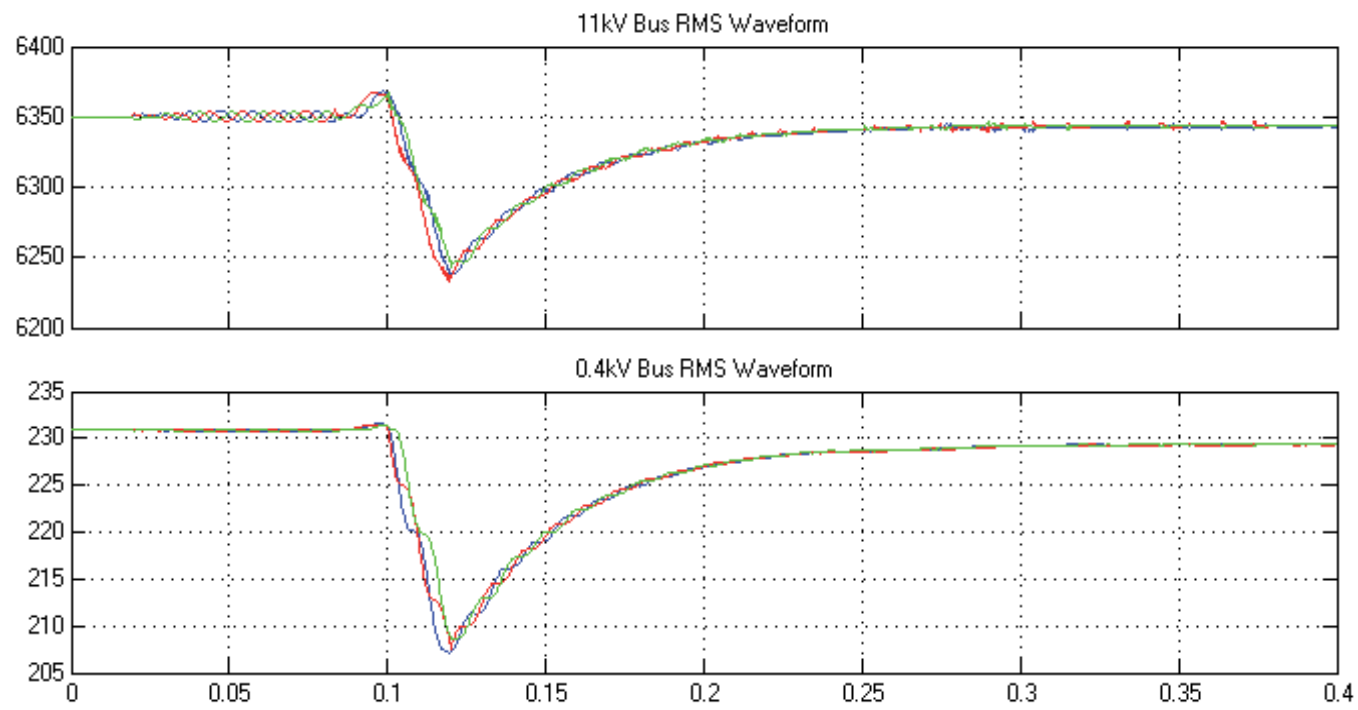

Figure 8. Voltage sag RMS waveform caused by the starting of $75 \mathrm{~kW}(100 \mathrm{hp})$ induction motor at $0.4 \mathrm{kV}$ feeder. 


\subsection{Transformer energizing model}

The transformer energizing model developed in Simulink is shown in Figure 9. It is used to simulate voltage sag caused by transformer inrush current and core saturation during energizing. The model consists of an $11 \mathrm{kV}, 30 \mathrm{MVA}, 50 \mathrm{~Hz}$ three-phase source block feeding through a three-phase breaker block to a $11 \mathrm{kV} / 0.4 \mathrm{kV}, 1 \mathrm{MVA}$ saturable core transformer block to a $10 \mathrm{~kW}$ resistive and $100 \mathrm{VAR}$ inductive load. The measurements of instantaneous waveform and RMS are located at the $11 \mathrm{kV}$ feeder bus. The simout block is used to store the simulated data for harmonic FFT analysis using the power gui block. This model enables the simulation of voltage sag caused by transformer energizing. The switchgear is set to open at initiate stage and close at 0.06 second during simulation to simulate voltage sag caused by transformer energizing. A 1 second simulation time is set and ode23tb solver is selected to run the simulation. The voltage sag usually takes more than 1 second to rise back to its nominal voltage level.

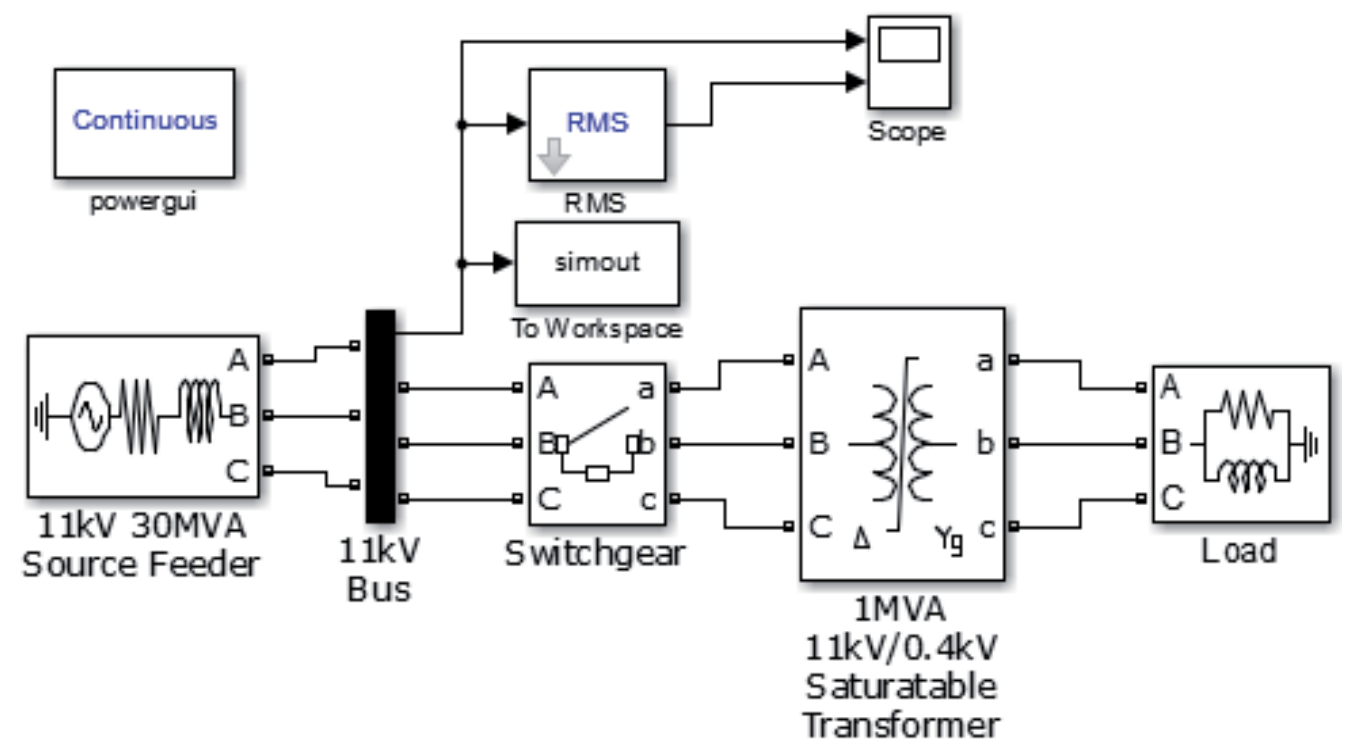

Figure 9. Transformer energizing model in Simulink.

Figure 10 shows voltage sag due to the energizing of the transformer upon closing of the switchgear that feeds the transformer. All three phases experience unbalanced voltage sag and gradually rise to its nominal voltage level. The sag magnitude of the transformer energizing voltage sag is dependent on the source feeder power rating and transformer power rating. The higher the transformer power rating, the lower the sag magnitude.

The unique characteristics of voltage sag caused by transformer energizing are as follows: it is unbalanced, has a shallow voltage sag up to $15 \%$ from its nominal magnitude, and consists high even harmonic of 2 nd order. The power gui block is used to analyze the harmonic content with the setting of up to $2,000 \mathrm{~Hz}$ and 10 cycles window, which is the standard measurement 

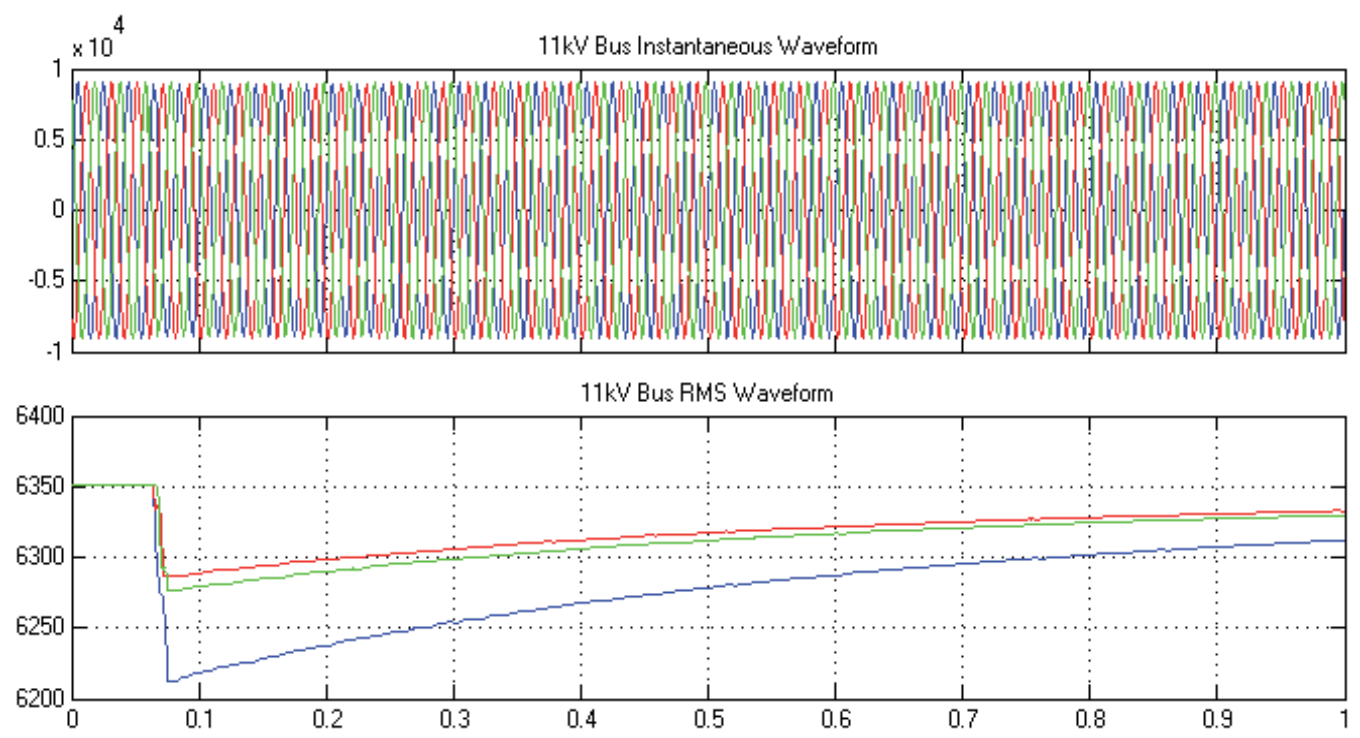

Figure 10. Voltage sag caused by transformer energizing at $11 \mathrm{kV}$ bus.

window size based on the IEC 61000-4-7 standard. It can analyze up to 40 orders of harmonic content. The analysis starts at 0.2 second up to 0.4 second to allow coverage of voltage sag waveform because the voltage sag begins at 0.06 second. Figure 11 clearly shows phase A consisting of unusual high $2 \mathrm{nd}$, 6th, 12th, 18th, and 24th order of even harmonic, which is the unique characteristic of transformer energizing voltage sag.

\subsection{Capacitor bank energizing model}

The capacitor bank energizing model developed in Simulink is shown in Figure 12. It is used to simulate voltage oscillatory transient caused by capacitor banking energizing for power factor correction in the power system [18, 19]. The model consists of $11 \mathrm{kV}, 30 \mathrm{MVA}, 50 \mathrm{~Hz}$ three-phase source block feeding through $11 \mathrm{kV} / 0.4 \mathrm{kV}, 1 \mathrm{MAV}$ delta/wye transformers to 100 $\mathrm{kW}$ resistive and $100 \mathrm{kvar}$ inductive load. There are instantaneous waveform scopes located at $11 \mathrm{kV}$ and $0.4 \mathrm{kV}$ buses for measurement. Each feeder bus consists of a capacitor bank connecting through a three-phase breaker as a switching contactor block. The capacitor bank at $0.4 \mathrm{kV}$ bus has a capacity of $40 \mathrm{kvar}$, which can compensate power factor up to 0.857 for a 100 kvar inductive load. The capacitor bank at $11 \mathrm{kV}$ bus usually has a higher capacity, in this model 100 kvar is used. The capacitor bank energizing model is capable of simulating oscillatory voltage transient caused by energizing of capacitor bank at $11 \mathrm{kV}$ bus or at $0.4 \mathrm{kV}$ bus. A 0.1 second simulation time is set and ode23tb solver is selected to run the simulation.

Figure 13 shows the energizing of capacitor bank upon closing of three-phase breaker at 0.4 $\mathrm{kV}$ feeder line causing voltage transient at $0.4 \mathrm{kV}$ and $11 \mathrm{kV}$ bus. The voltage transient magnitude decreases significantly as it propagates upstream toward the $11 \mathrm{kV}$ bus feeder due to a strong source. The oscillatory voltage transient frequency is determined by the size of the 

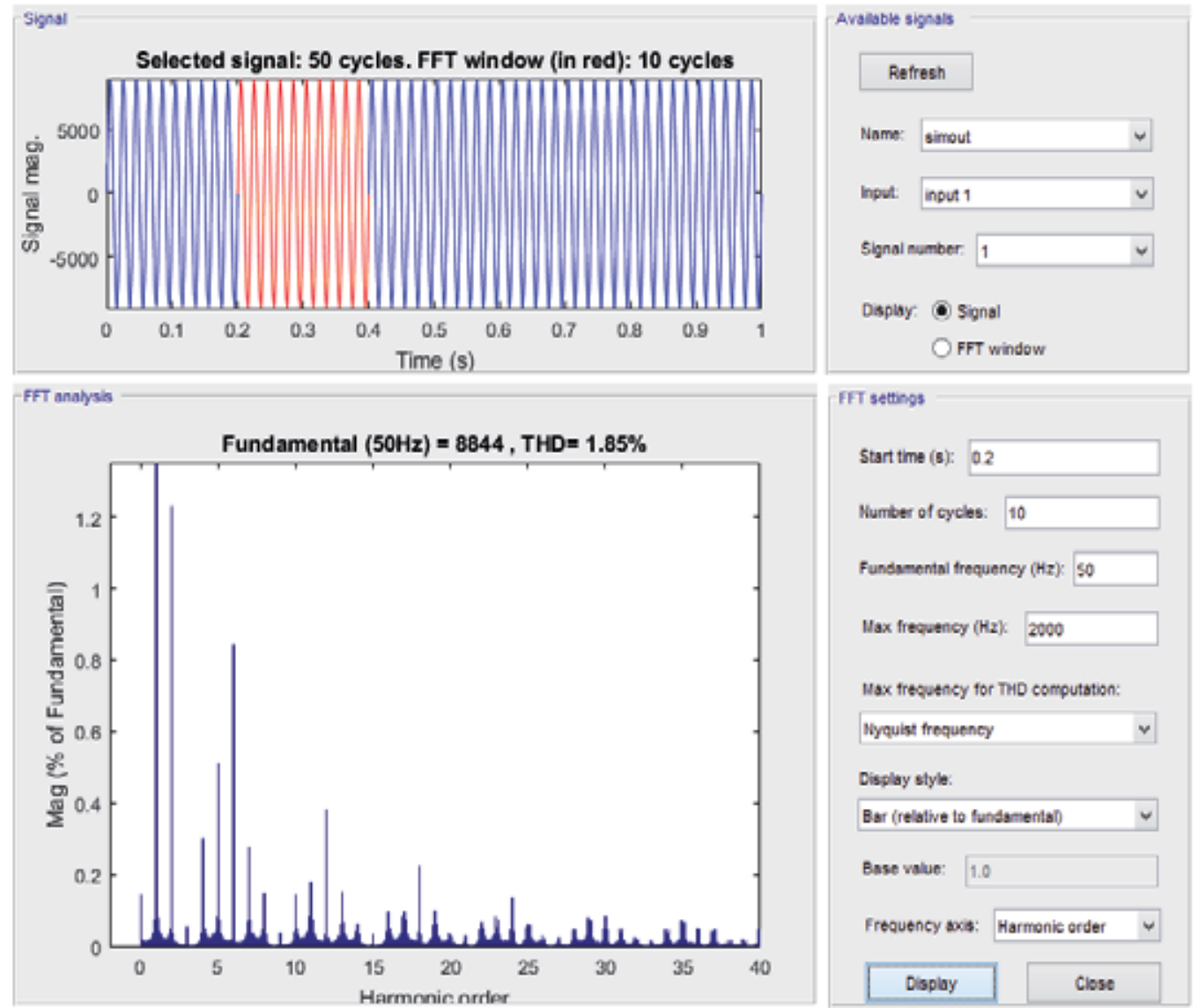

Figure 11. Harmonic analysis of phase A voltage sag caused by transformer energizing at $11 \mathrm{kV}$ bus.

capacitor bank. The larger the capacitor bank size, the lower the voltage transient frequency. The speed of the transient settles down its oscillation depending on the size of the real power load. Larger resistive load size leads to higher damping factor, thus faster settling of transient oscillation.

Figure 14 shows oscillatory voltage transient at $0.4 \mathrm{kV}$ and $11 \mathrm{kV}$ bus caused by the energizing of the capacitor bank at $11 \mathrm{kV}$ feeder line while the capacitor bank at $0.4 \mathrm{kV}$ remains closed. The voltage transient magnitude does not decrease as it propagates downstream toward the $0.4 \mathrm{kV}$ bus feeder due to strong sources at $11 \mathrm{kV}$ bus. It can also be clearly seen that the transient frequency is higher due to the higher capacitive power energized at $11 \mathrm{kV}$ bus.

\subsection{Lightning impulse model}

The lightning impulse model developed in Simulink is shown in Figure 15. It is used to simulate impulsive transient caused by lightning near the transmission line. The model consists of 0.4 $\mathrm{kV}, 1 \mathrm{MVA}, 50 \mathrm{~Hz}$ three-phase source block fed to a $10 \mathrm{~kW}$ resistive and $10 \mathrm{kvar}$ inductive load. 


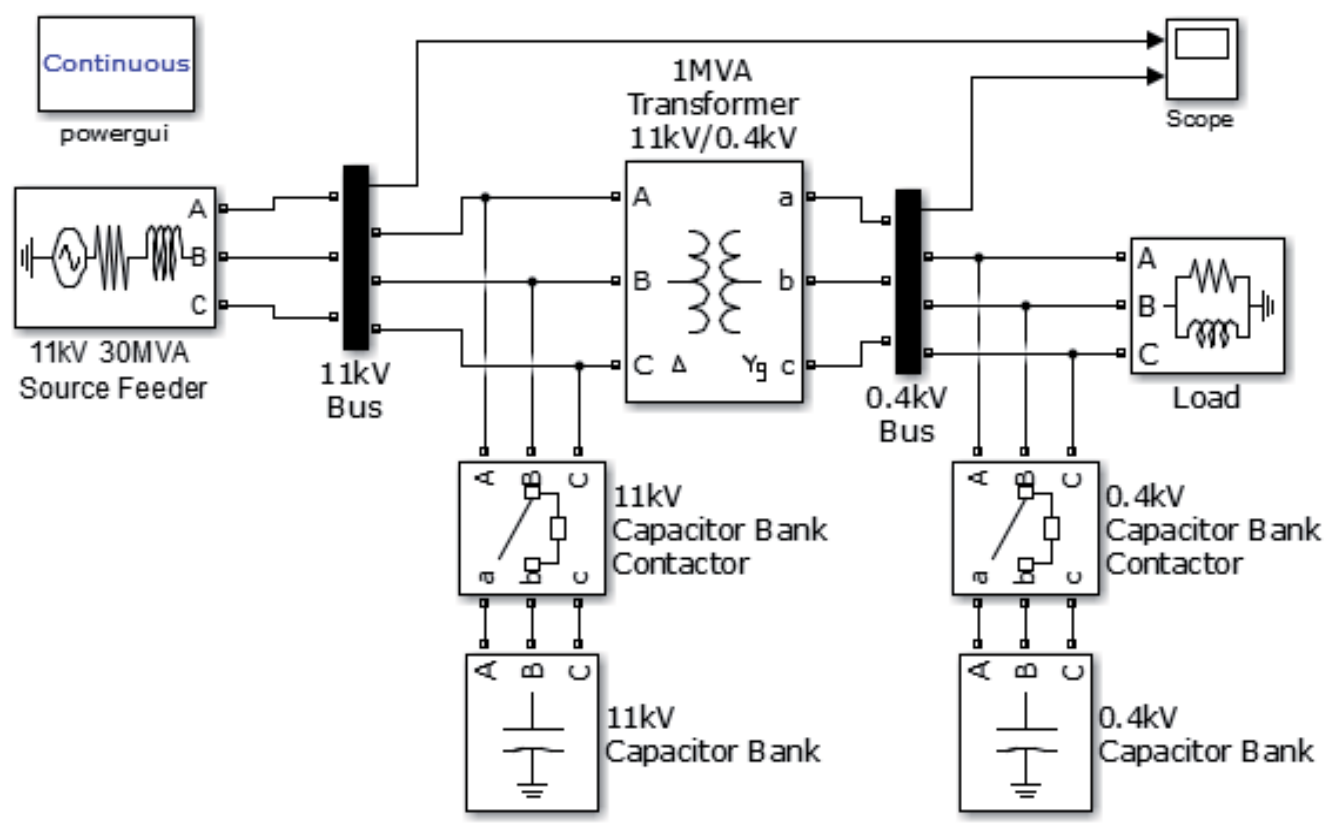

Figure 12. Capacitor bank energizing Simulink model.
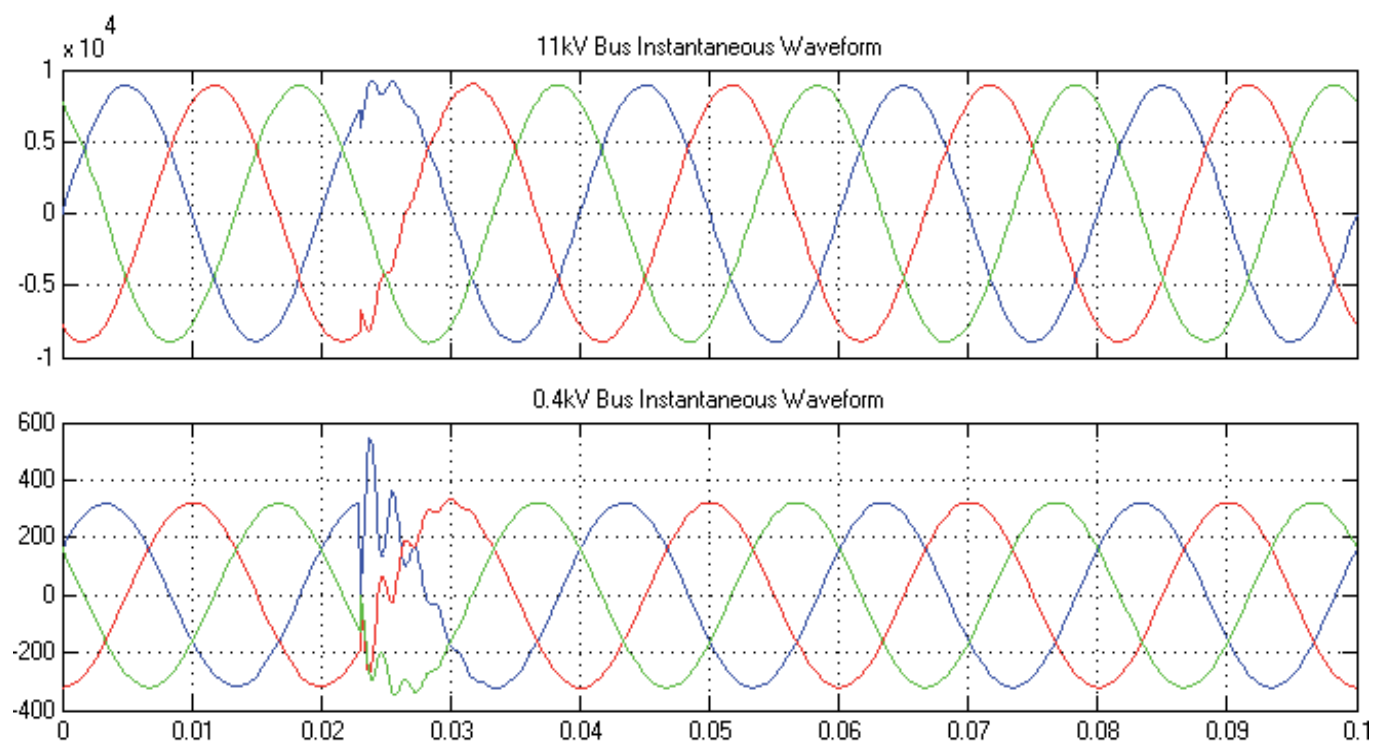

Figure 13. Oscillatory transient caused by capacitor bank energizing at $0.4 \mathrm{kV}$ feeder line.

There are instantaneous waveform scopes located at $0.4 \mathrm{kV}$ buses for measurement. The lightning block is connected to the feeder line to induce impulsive transient. Since there is no 

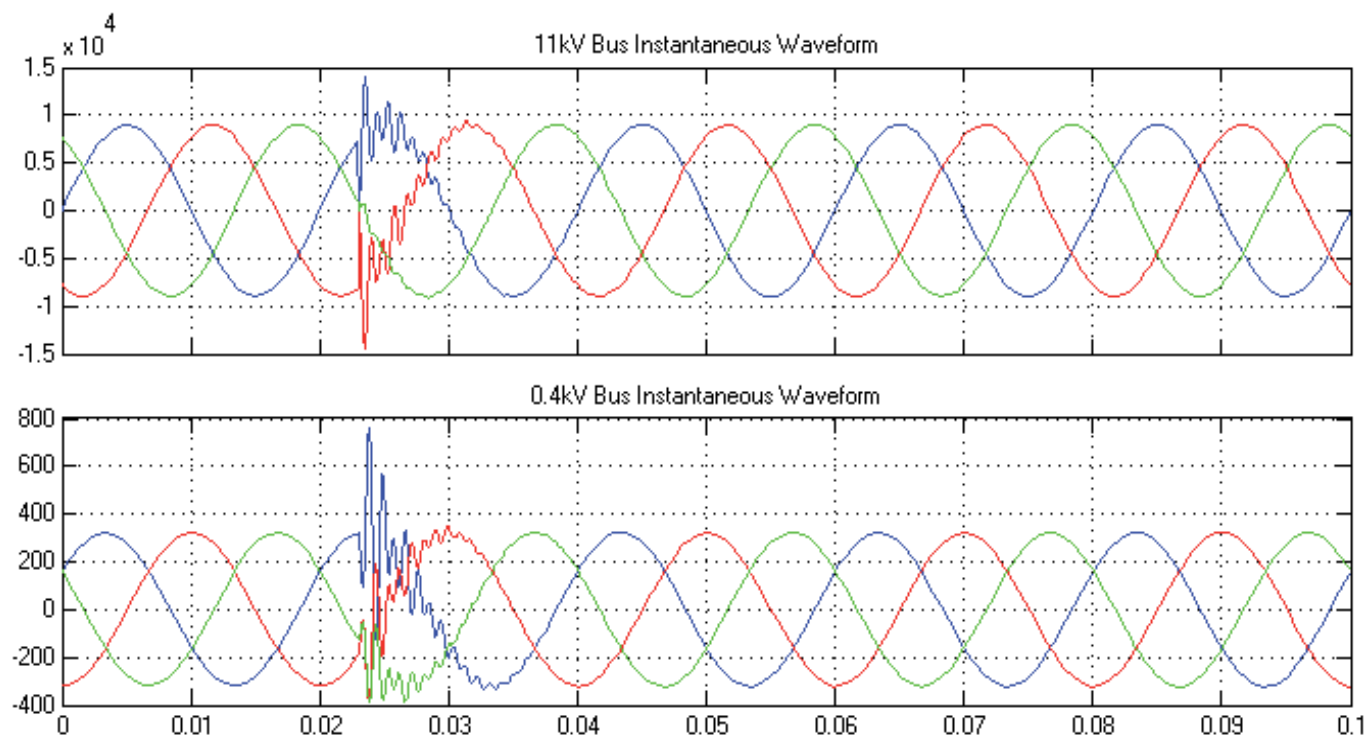

Figure 14. Oscillatory transient caused by capacitor bank energizing at $11 \mathrm{kV}$ feeder line.

lightning block available in the MATLAB/Simulink blockset library, it can be built by using existing Simulink blocks.

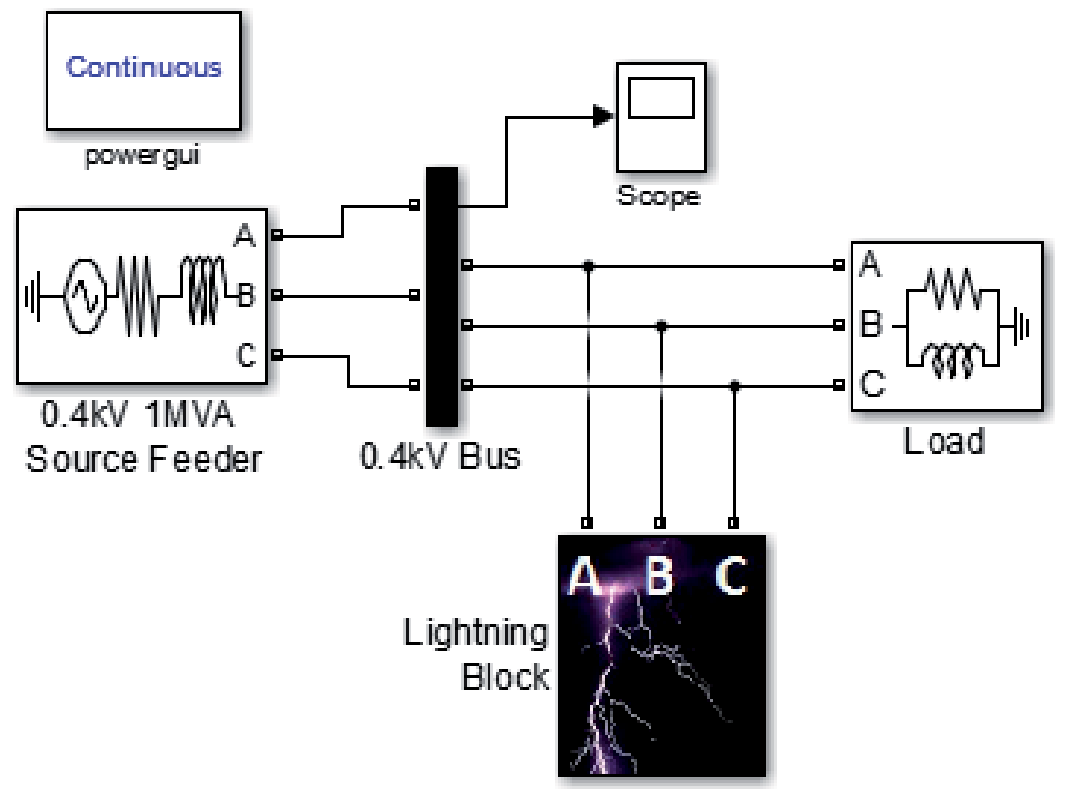

Figure 15. Lightning impulsive transient model 
The lightning block subsystem is shown in Figure 16. A controlled voltage source with resistive and inductive network is used to couple the generated lightning impulse to a given phase of the power system line. For a three-phase system, three sets of controlled voltage source, resistive and inductive networks are required. The lightning impulse that is fed to the voltage controlled source input is computed using Equation 1, where $A$ is the impulse magnitude, $\alpha$ is the damping factor, $t_{1}$ is the time when the impulse starts, $t$ is the time function, and $u$ is the impulse rise step function.

$$
v(t)=A e^{\left(-\alpha\left(\left|t-t_{1}\right|\right)\right)} \cdot u\left(t-t_{1}\right)
$$

The lightning impulse model can be implemented using MATLAB Function block, ramp block, constant block, and step function block as shown in Figure 16. The ramp block is used as time function $t$, constant block for impulse magnitude $A$ and impulse start time $t_{1}$, and lastly step function block $u$ for step rising. Figure 17 shows how Equation 1 is coded in the MATLAB function block.

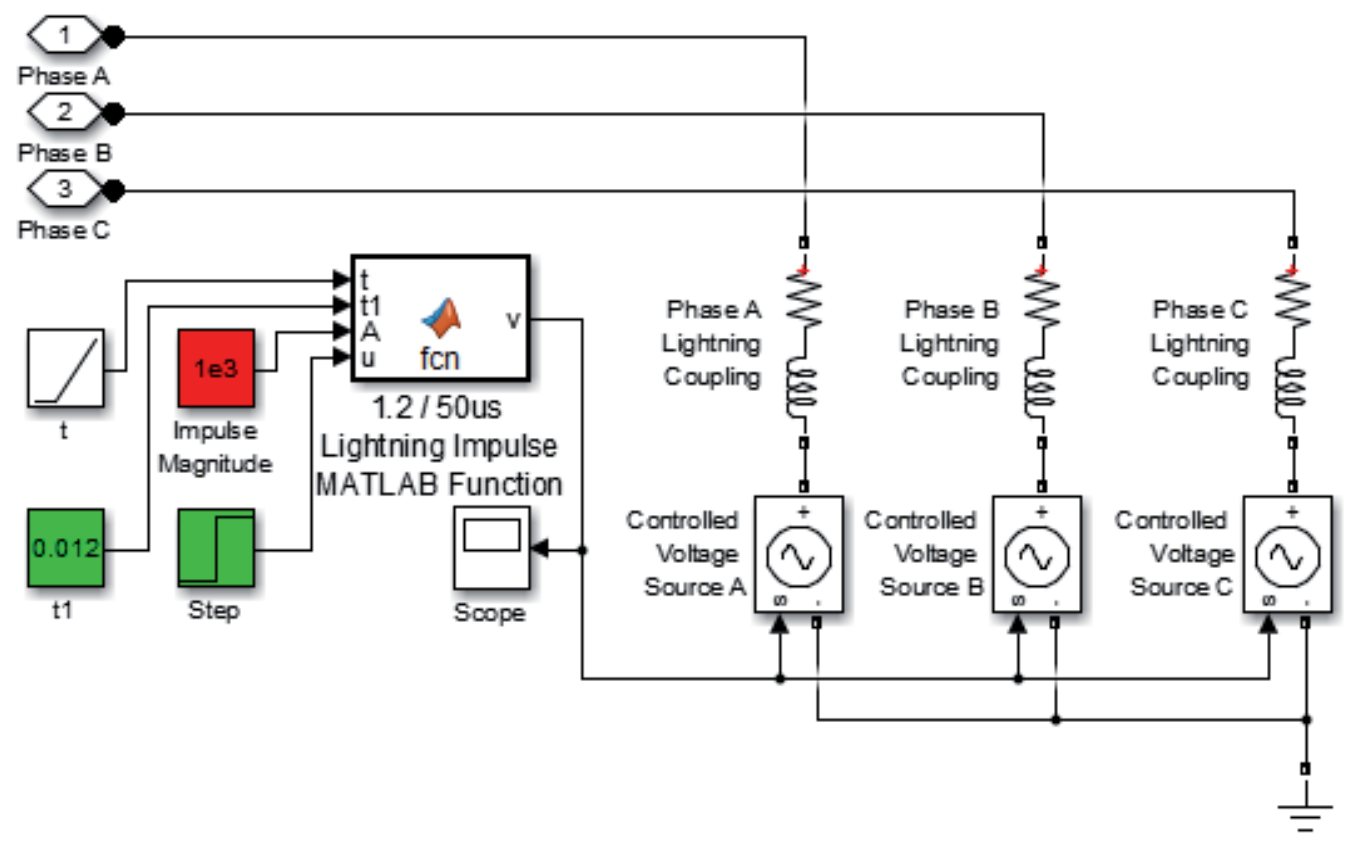

Figure 16. Lightning block subsystem.

The standard lightning impulse characteristic is $1.2 / 50 \mu \mathrm{s}$, where the impulse rises to a peak of $1.2 \mu$ s and decay to $50 \%$ at $50 \mu$ s time as defined by IEEE 1159.12009 and IEEE C62-41.2 2002 standards [20]. Figure 18 shows the 1.2/50 $\mu$ s lightning impulse waveform model computed by Equation 1 with damping factor of alpha $=14,000$ in the MATLAB function block. The 


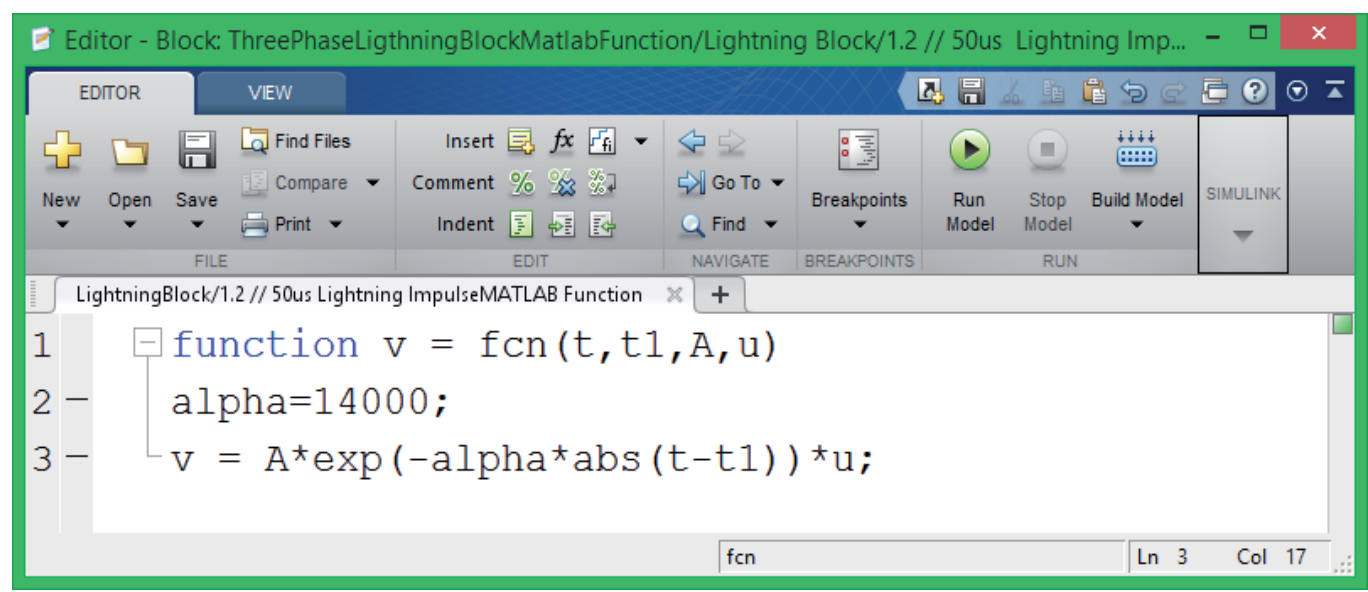

Figure 17. Lightning impulse equation in MATLAB function block.

waveform is captured using the scope sampled at $1 \mathrm{MHz}$, which yields $1 \mu \mathrm{s}$ per sample. At sample 10,000 , which is 0.01 second the impulse rise to the peak magnitude of 1 , and at 10,050 sample, which is $50 \mu$ s later, the impulse magnitude decays to 0.5036 . This validates that the model is closely approximate to the $1.2 / 50 \mu$ s lightning impulse characteristic defined by the standard.

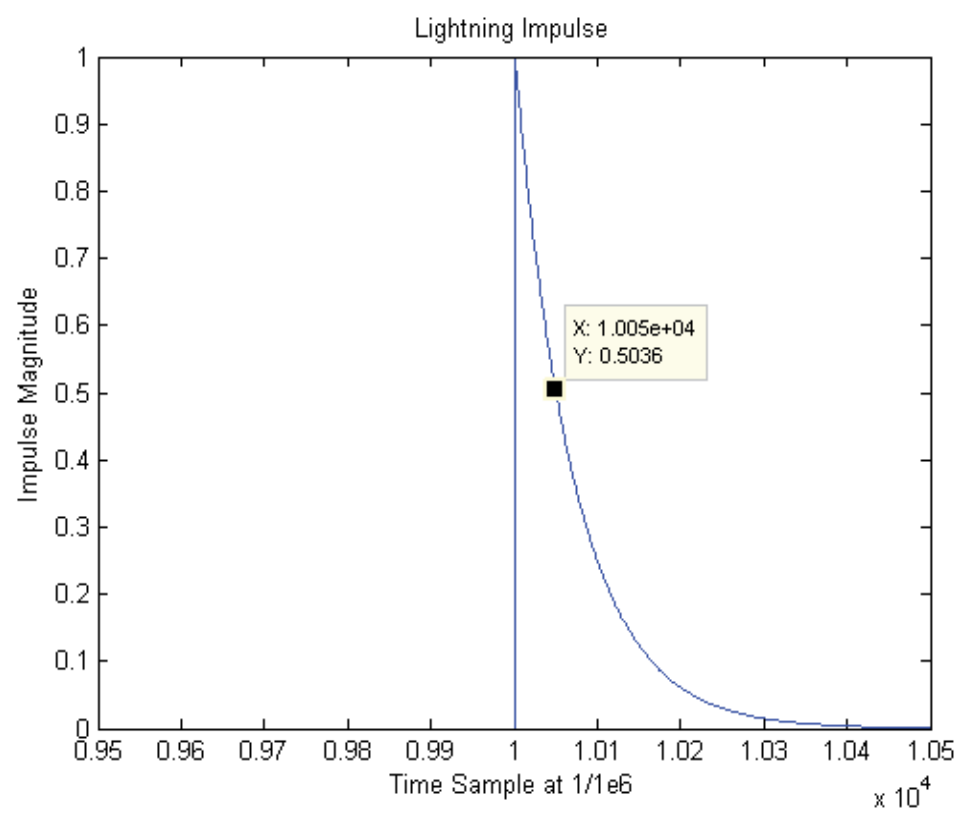

Figure 18. 1.2/50 $\mu$ s lightning impulsive waveform. 
A 0.04 second simulation time is set and ode23tb solver is selected to run the simulation. The impulse magnitude is set at $1 \mathrm{kV}$, begins at 0.012 second, and the coupling network is set at 10 $\Omega$ and $1 \mu \mathrm{H}$. Figure 19 shows the simulated impulsive transient waveform for all three phase. The coupling network impedance determines how close the lightning discharge is to the transmission line, which in turn determines the impulsive transient magnitude induced in the waveform. The lower the coupling network impedance, the closer the lightning to the transmission line.

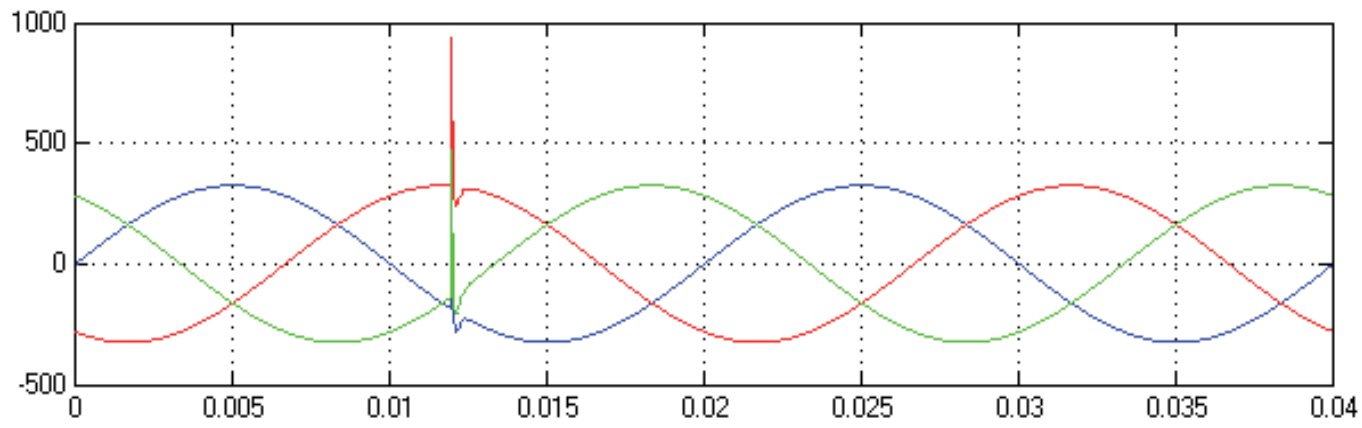

Figure 19. Impulse transient caused by lightning near $0.4 \mathrm{kV}$ transmission line.

\subsection{Single phase nonlinear load model}

The single-phase, nonlinear model developed in Simulink is shown in Figure 20. It is used to simulate triplen harmonic voltage disturbance caused by single-phase bridge rectifier with filter capacitor that is commonly found in domestic and commercial buildings [21]. The model consists of $11 \mathrm{kV}, 30 \mathrm{MVA}, 50 \mathrm{~Hz}$ three-phase source block feeding through a $11 \mathrm{kV} / 0.4 \mathrm{kV}, 1$ MVA delta/wye transformer to a $1 \mathrm{MW}$ resistive load, single-phase bridge with 2,000 $\mu \mathrm{F}$ capacitive filter and $10 \Omega$ resistive load for each phase. There are instantaneous waveform scopes located at $11 \mathrm{kV}$ and $0.4 \mathrm{kV}$ buses for measurement. A 0.1 second simulation time is set and ode23tb solver is selected to run the simulation. Figure 21 shows the harmonic waveforms at $11 \mathrm{kV}$ and $0.4 \mathrm{kV}$ bus. Harmonic distortions at $0.4 \mathrm{kV}$ are still noticeable along $60^{\circ}$ and $240^{\circ}$ of each cycle waveform. However, at $11 \mathrm{kV}$ bus harmonic distortion has be significantly suppressed by the delta/wye transformer.

To visualize the harmonic distortion, the simulation time is set at 0.2 second so that 10 cycles will be simulated. The power gui block is used to analyze the harmonic content with the setting of up to $2,000 \mathrm{~Hz}$ and 10 cycles window, which is the standard measurement window size based on the IEC 61000-4-7 standard. Figure 22 clearly shows that at $0.4 \mathrm{kV}$, phase A consists of odd harmonic order with high 3rd order zero sequence harmonic, which is the unique characteristic of triplen harmonic generated by the single phase nonlinear load. However, as the waveform propagates upstream to $11 \mathrm{kV}$ it can be clearly see that all the triplen harmonics 3rd, 9th, 15th, and 21st generated from the single phase nonlinear load has been suppressed by the delta/wye transformer. 


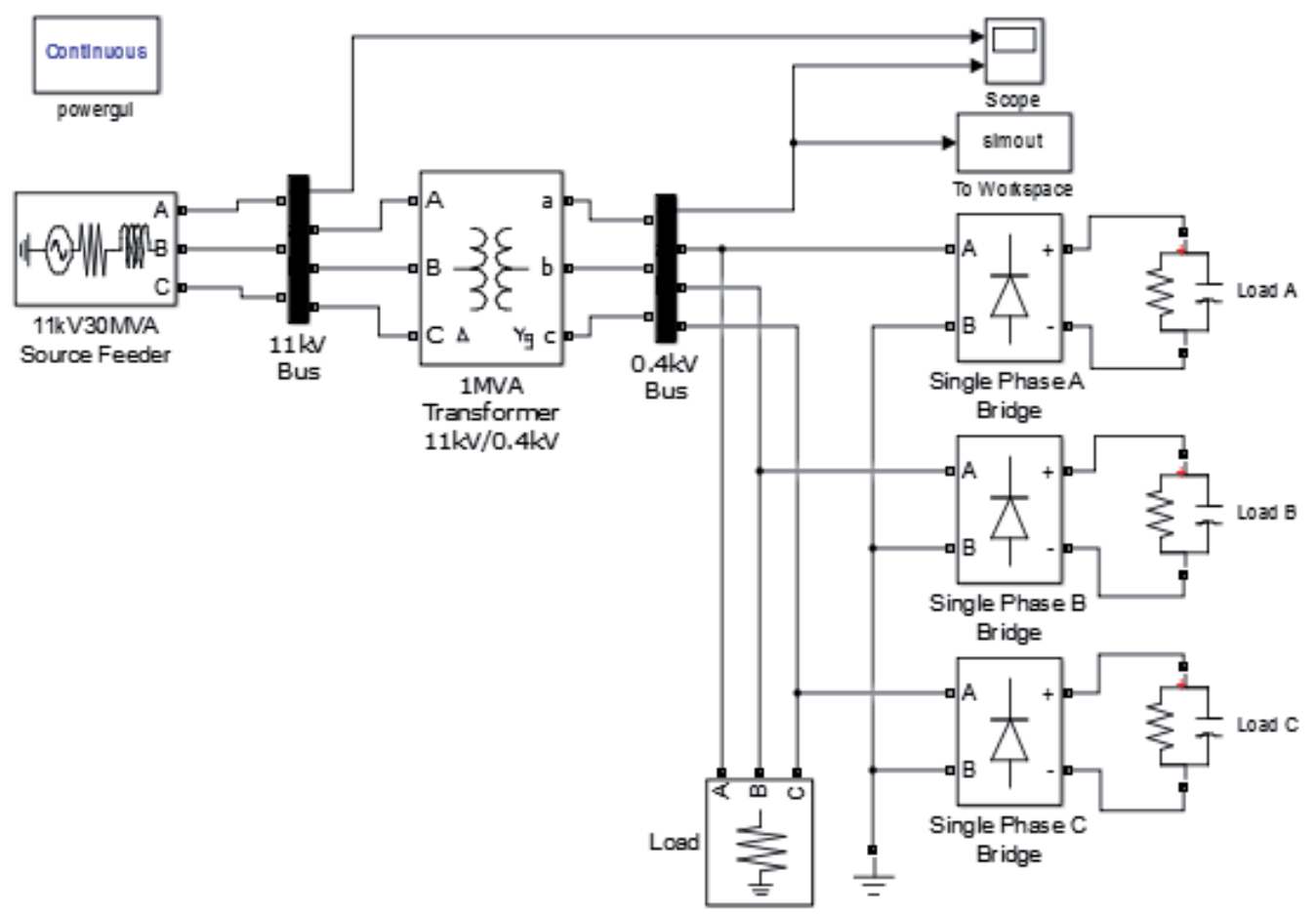

Figure 20. Single-phase nonlinear load model.
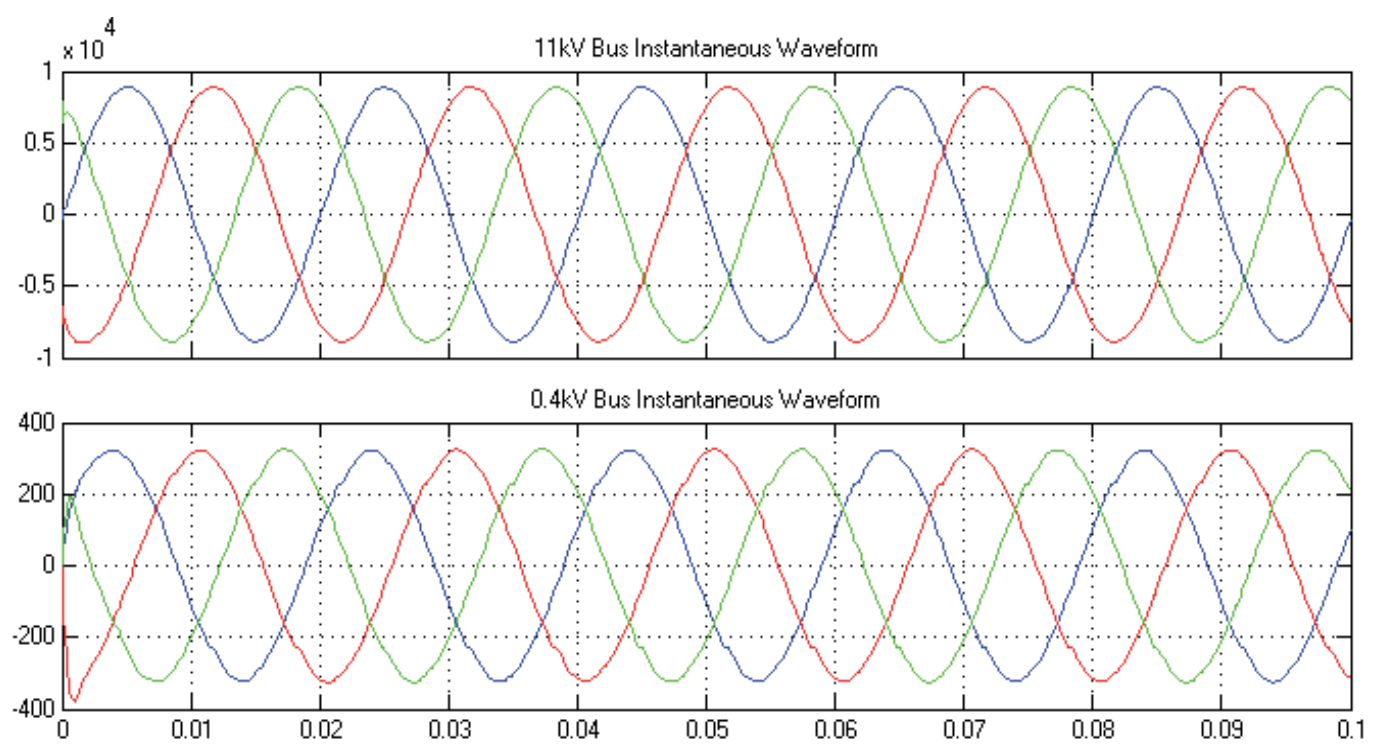

Figure 21. Harmonic distortion waveforms at $11 \mathrm{kV}$ and $0.4 \mathrm{kV}$ bus. 

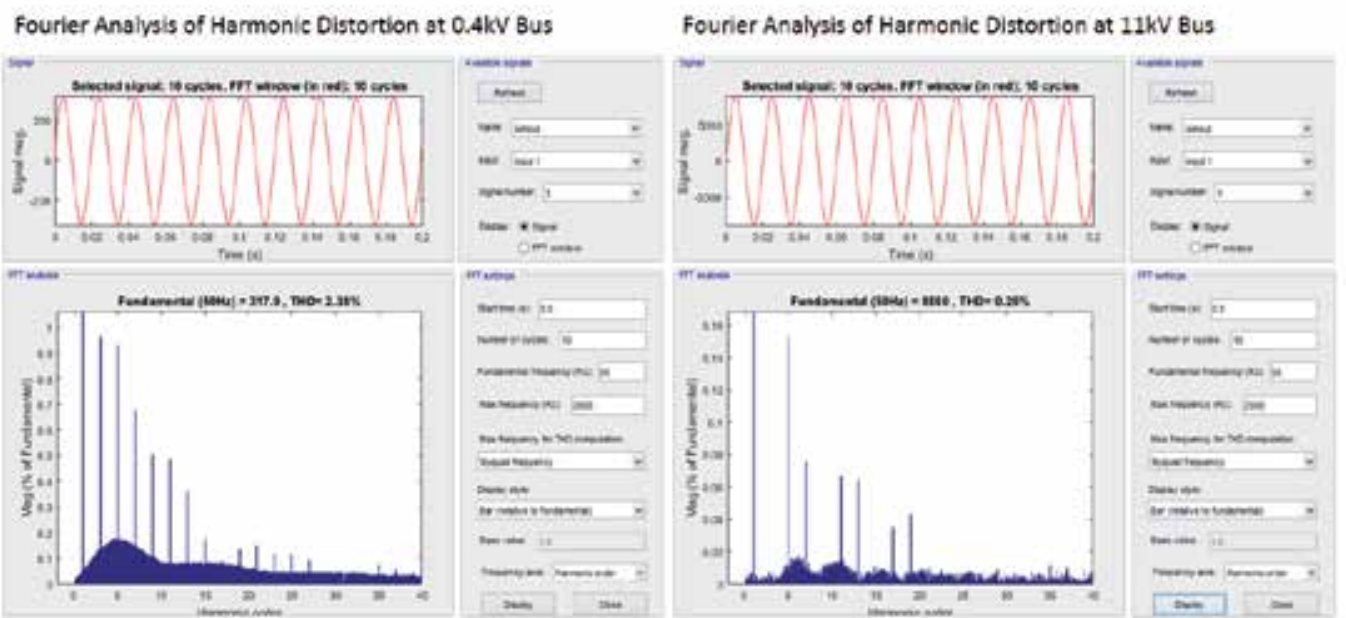

Figure 22. Harmonic analysis of phase A harmonic distortion at $0.4 \mathrm{kV}$ and $11 \mathrm{kV}$ bus.

\subsection{Three-phase nonlinear load model}

The three-phase nonlinear load model developed in Simulink is show in Figure 23. This nonlinear load model is used to simulate voltage notches and harmonic caused by a 6-pulse three-phase rectifier [22]. The model consists of $11 \mathrm{kV}, 30 \mathrm{MVA}, 50 \mathrm{~Hz}$ three-phase source block feeding through a $11 \mathrm{kV} / 0.4 \mathrm{kV}, 1 \mathrm{MAV}$ delta/wye transformer to a 6-pulse controlled threephase rectifier connected to a $600 \mathrm{~V}, 10 \mathrm{~kW}$ resistive and $1 \mathrm{kVA}$ inductive load. A phase lock loop (PLL) block is used to provide synchronization to the pulse generator block to generate the required pulses to control the three-phase rectifier. A constant block set the firing angle for the pulse-controlled, three-phase rectifier. There is a $400 \mathrm{~V}, 10 \mathrm{~kW}$ resistive load connected in front of the three-phase rectifier. There is a scope to monitor the instantaneous waveform at $11 \mathrm{kV}$ and $0.4 \mathrm{kV}$ bus. This three-phase nonlinear load model is capable to simulate voltage notches and negative sequence harmonic caused by the pulse-controlled, three-phase rectifier.

Figure 24 shows voltage notches caused by pulse controlled three-phase rectifier with pulse firing angle of $30^{\circ}$. The voltage notches for all three phase clearly visible across the sinusoidal waveform at $0.4 \mathrm{kV}$ bus, again the voltage notches are significantly suppressed after it propagates upstream to $11 \mathrm{kV}$ bus through the transformer.

Since voltage notches seriously distort the sinusoidal waveform, therefore it also introduces harmonic distortion. To visualize the harmonic distortion, the power gui block is used to analyze the harmonic content with the setting of up to $2,000 \mathrm{~Hz}$ and 10 cycles window start at 1 second. Figure 25 clearly shows that at $0.4 \mathrm{kV}$ phase A consists of high 5th, 7th, 11th, 13th, 17th, 19th, 23rd, 25th, 29th, 31st, 35th, and 37th harmonic order, which is governed by a harmonic composite law in Equation 2, where $H_{0}$ is the harmonic order, $n$ is the natural number, and $q$ is the converter pulse number. As the waveform propagates upstream to $11 \mathrm{kV}$ it can be clearly seen that all these harmonic magnitudes have been suppressed by the strong $11 \mathrm{kV}$ source harmonic order but still remain there. 


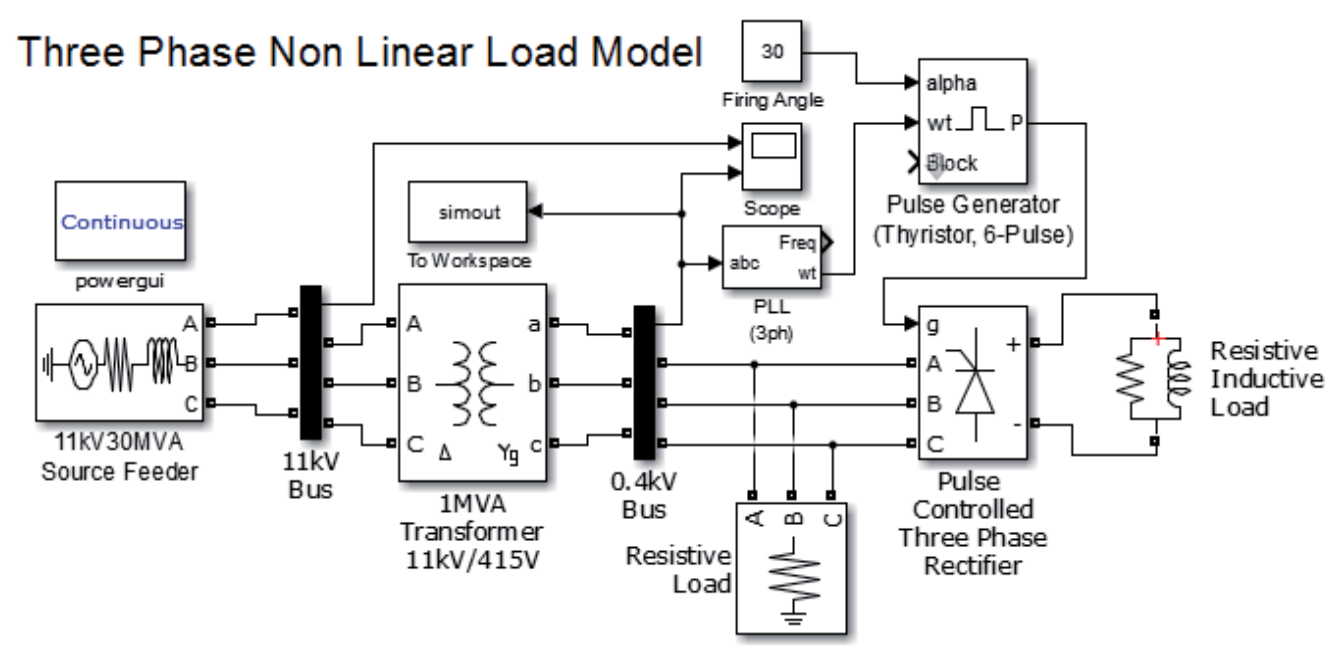

Figure 23. Three-phase nonlinear load model.
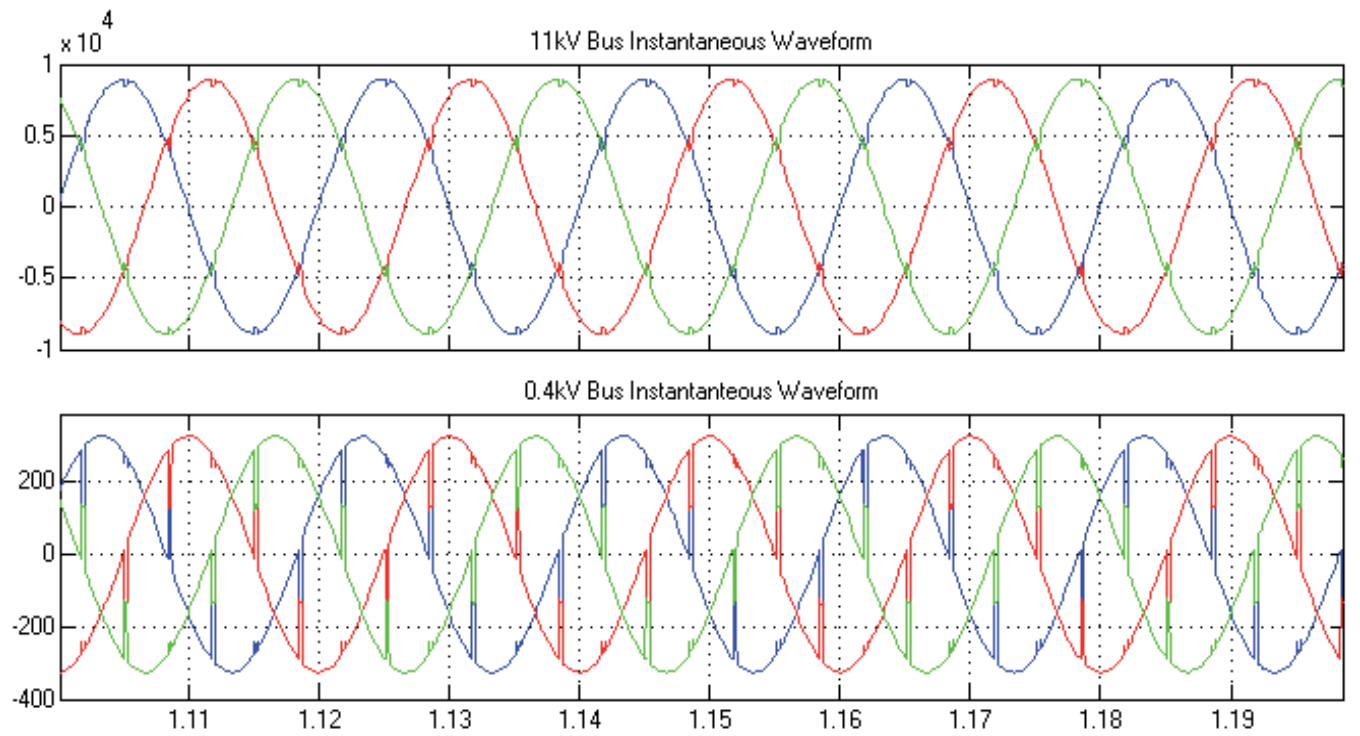

Figure 24. Voltage notch waveforms at $11 \mathrm{kV}$ and $0.4 \mathrm{kV}$ bus.

$$
H_{o}=n q \pm 1
$$

The voltage notch location and depth is dependent on the firing angle control of the threephase rectifier and the voltage notch width is dependent on the inductive load. The larger the inductive load, the wider the voltage notch. The voltage notch usually does not propagate upstream because it will be damped by the feeder line and transformer. 

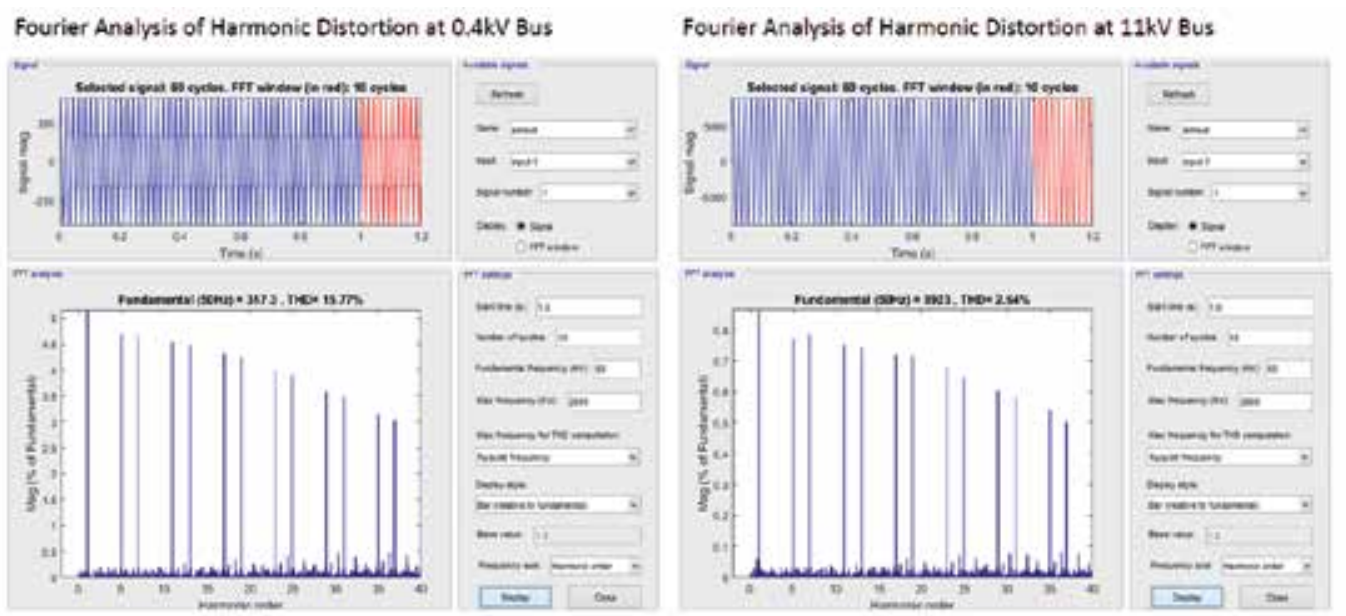

Figure 25. Harmonic analysis of phase A voltage notches at $0.4 \mathrm{kV}$ and $11 \mathrm{kV}$ bus.

\subsection{Electric arc furnace model}

The electric arc furnace model developed in Simulink is shown in Figure 26. It is used to simulate flicker disturbance caused by the electric arc furnace. The model consists of $0.4 \mathrm{kV}, 1$ MVA, $50 \mathrm{~Hz}$ three-phase source block fed directly to an electric arc furnace block. There are instantaneous waveform scopes located at $0.4 \mathrm{kV}$ buses for monitoring. Since there is no electric arc furnace block available in MATLAB/Simulink blockset library, it can be built by using existing Simulink blocks.

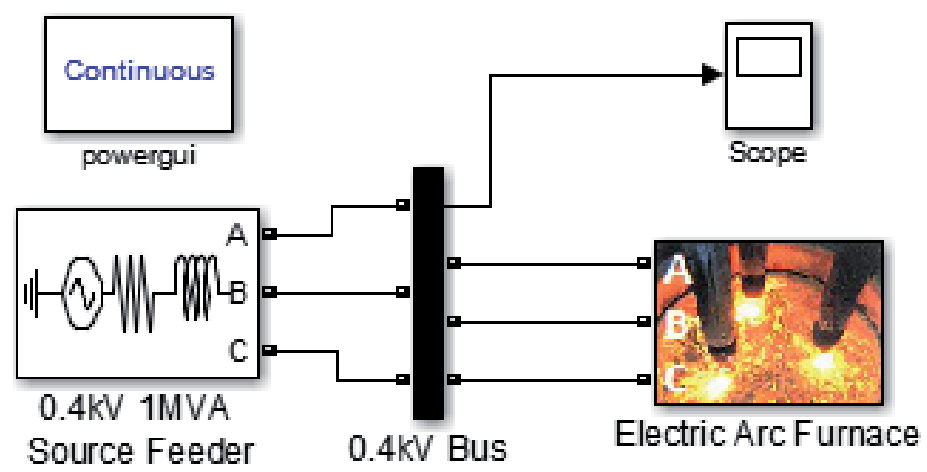

Figure 26. Electric arc furnace model.

The electric arc furnace subsystem block developed in Simulink is shown in Figure 27. A controlled voltage source with resistive and inductive network is used to couple the generated flicker disturbance to a given phase of the power system line. For a three-phase system, three sets of controlled voltage source and resistive and inductive networks are required. The electric 
arc furnace model uses a hyperbolic model $[23,24]$ defined in Equation 3, where $V_{a t}$ is the arc length threshold voltage, $i$ is the phase current, $\mathrm{C}$ is the arc power, and $\mathrm{D}$ is the arc current.

$$
v(i)=\left(V_{a t}+\frac{C}{D+|i|}\right) \operatorname{sign}(i)
$$

The effect of voltage flicker is determined by the threshold voltage shown in Equation 4, where $V_{a t 0}$ is the base reference voltage when there is no arc activity, $m$ is the modulation index, and $\omega_{f}$ is the flicker frequency.

$$
V_{a t}(t)=V_{a t 0}\left[1+m \cdot \sin \left(\omega_{f} t\right)\right]
$$

The electric arc furnace model can be implemented using the MATLAB function block and a sinusoidal block as shown in Figure 27. Each electric arc furnace MATLAB Function block represent each electrode at each phase; therefore, three MATLAB function blocks are required for each phase. The sinusoidal is used to model the flicker frequency and magnitude variation. Lastly, an XY graph scope is located at phase $C$ to monitor the electric arc furnace voltage and current curve. Figure 28 shows how Equations 2 and 3 are coded in the MATLAB function block.

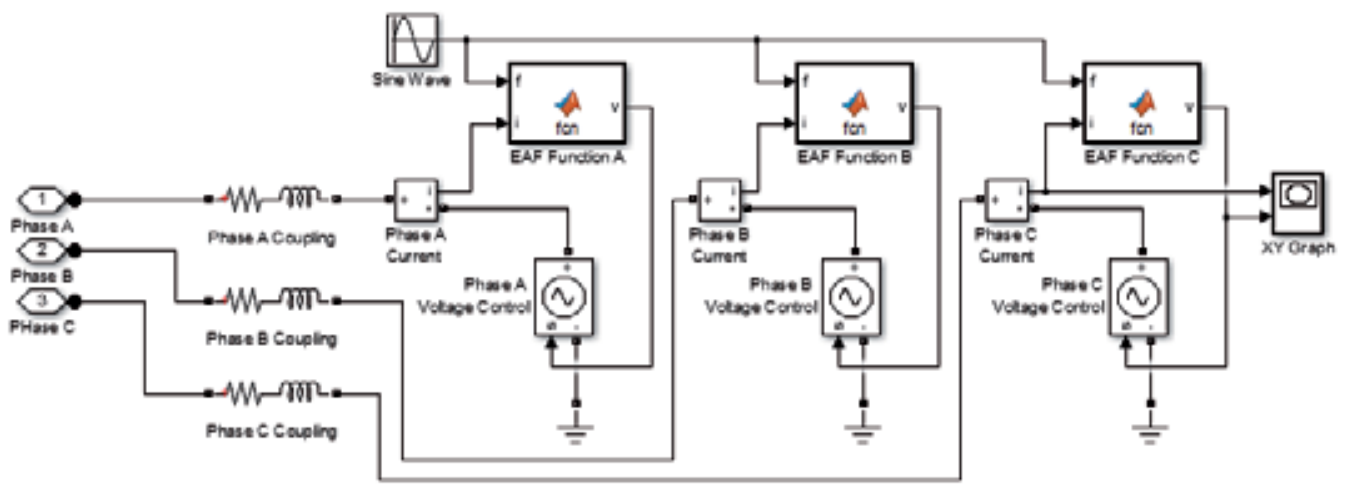

Figure 27. Electric arc furnace block subsystem.

To run the simulation, the sinusoidal block frequency is set at $55.3 \mathrm{rad} / \mathrm{sec}$, which is approximately $8.8 \mathrm{~Hz}$. This is the frequency of interest that can cause the light flickering effect that is sensitive and causes discomfort to the human eye [25]. The arc power $C$ is set at $19 \mathrm{~kW}$, the arc current $\mathrm{D}$ is set at $5 \mathrm{kA}$, the base threshold voltage is set at $200 \mathrm{~V}$, the modulation index is set at 0.2 and lastly the coupling network is set at $0.01 \Omega$ and $1 \mathrm{mH}$. The simulation time is set at 0.04 second and ode $23 \mathrm{tb}$ solver is selected. Figure 29 shows the electric arc furnace voltage and current curve through the $\mathrm{XY}$ graph scope at phase $\mathrm{C}$. The curve resembles the characteristics 


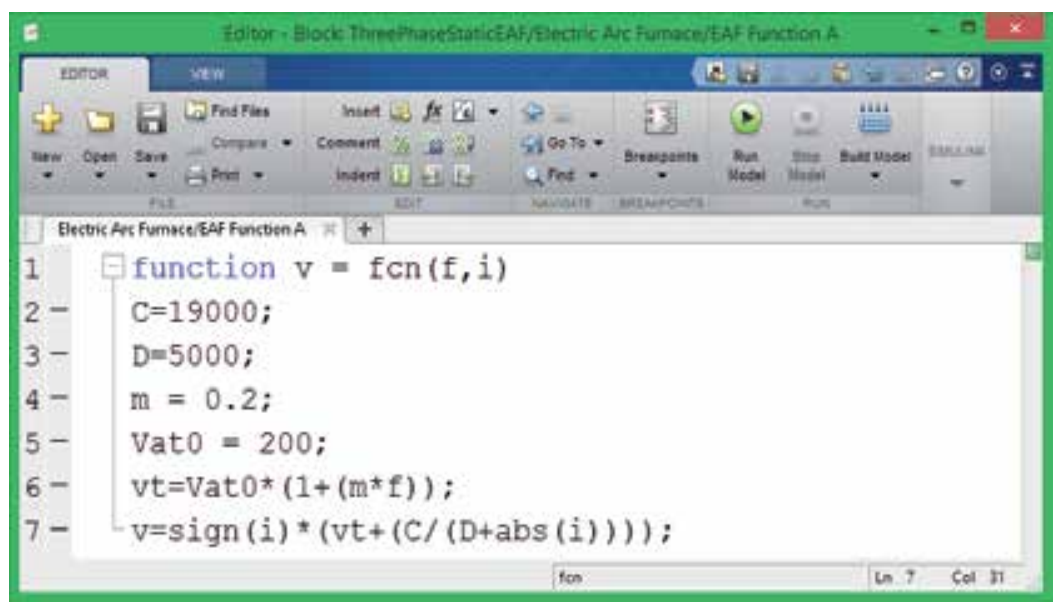

Figure 28. Electric arc furnace function coded in MATLAB function block.

of an electric arc furnace operation. Figure 30 shows the instantaneous waveform at $0.4 \mathrm{kV}$ bus and the flicker disturbances are clearly visible for all three phases.

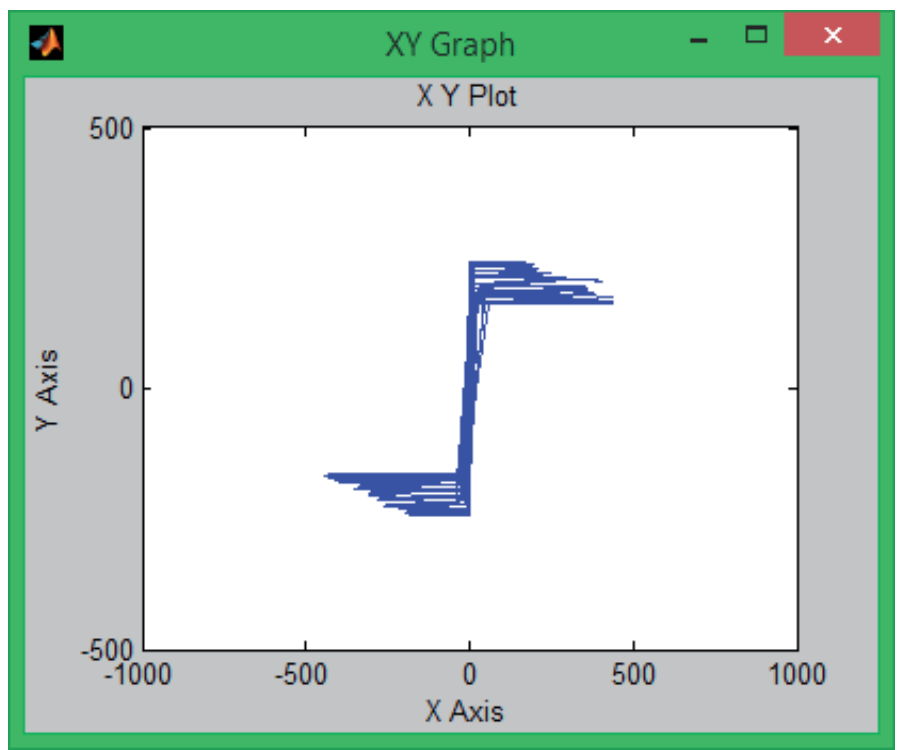

Figure 29. Electric arc furnace voltage current curve.

Since flicker waveform also distorts the sinusoidal waveform in some way, therefore it also introduces harmonic distortion. To visualize the harmonic distortion the power gui block is used to analyze the harmonic content with settings of up to 2,000 Hz and 10 cycles window start at 0.1 second. Figure 31 clearly shows that at $0.4 \mathrm{kV}$ phase A consists of odd harmonic of 3rd, 5th, 7th, 9th, 11th, and 13th order with high magnitude of 3rd harmonic order. 


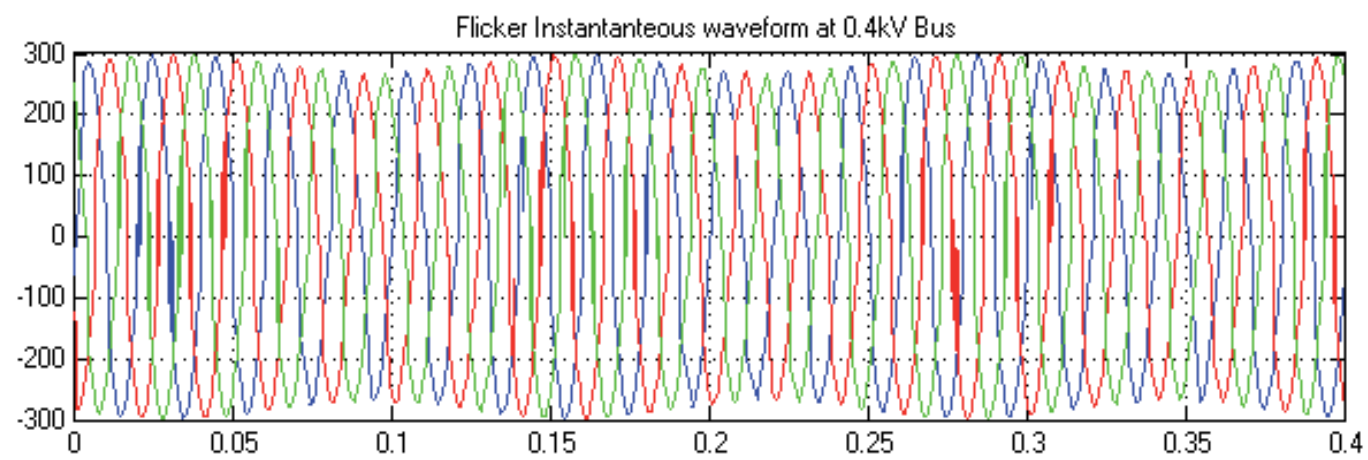

Figure 30. Flicker waveform disturbance caused by electric arc furnace at $0.4 \mathrm{kV}$ bus.
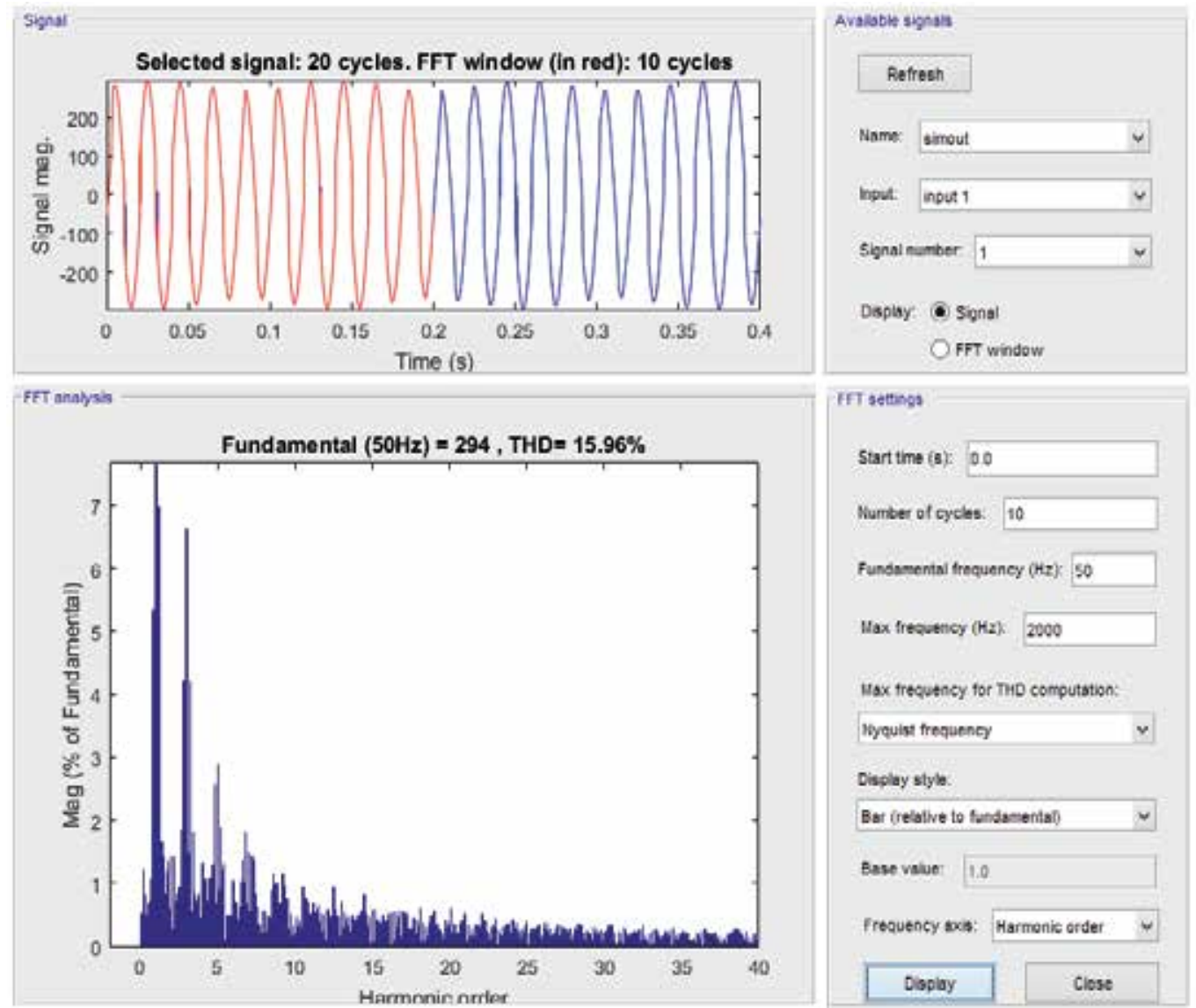

Figure 31. Harmonic analysis of flicker waveform at phase A caused by electric arc furnace at $0.4 \mathrm{kV}$ bus. 


\section{Conclusion}

The simulation approach provides the researcher the flexibility to create power system models to simulate power quality disturbance by connecting various functional building blocks in the simulation environment. It gives an insight on how power quality disturbance propagates and behaves within the simulated power system model. The limitation of the simulation approach is its dependency on the capability of the chosen simulation software, basic knowledge of power quality and the simulation software, and the availability of power system building blocks required to build the power system model to simulate the intended power quality disturbance. This book chapter presents simulation models that are able to simulate power quality disturbance, including voltage sag due to fault, induction motor starting, transformer energizing, voltage swell, oscillatory transient, impulsive transient, harmonic, voltage notch, and flicker. These simulation models contribute as basic models to the power quality study as well as the development of power quality education and learning curriculum.

All Simulink models presented in this book chapter has been uploaded to the official Mathworks MATLAB Central File Exchange by the author for reader to download the model. The links for each model are listed below.

1. Line Fault Model; http://www.mathworks.com/matlabcentral/fileexchange/51928

2. Induction Motor Starting Model; http://www.mathworks.com/matlabcentral/fileexchange/51929

3. Transformer Energizing Modelhttp://www.mathworks.com/matlabcentral/fileexchange/ 51931

4. Capacitor Bank Energizing Model; http://www.mathworks.com/matlabcentral/fileexchange $/ 51933$

5. Lightning Impulse Model; http://www.mathworks.com/matlabcentral/fileexchange/ 51934

6. Single Phase Non Linear Load Model; http://www.mathworks.com/matlabcentral/ fileexchange/51935

7. Three Phase Non Linear Load Model; http://www.mathworks.com/matlabcentral/ fileexchange $/ 51936$

8. Electric Arc Furnace Model; http://www.mathworks.com/matlabcentral/fileexchange/ 51937

\section{Author details}

Rodney H.G. Tan ${ }^{1 *}$ and Vigna K. Ramachandaramurthy ${ }^{2}$

*Address all correspondence to: rodneytan72@hotmail.com 
1 UCSI University, Department of Electrical \& Electronics Engineering, Kuala Lumpur, Malaysia

2 Universiti Tenaga Nasional, Power Quality Research Group, Putrajaya, Malaysia

\section{References}

[1] McGranaghan M, Roettger B (2002) Economic Evaluation of Power Quality, IEEE Power Engineering Review, 22: 8-12.

[2] McGranaghan M, Santoso S (2007) Challenges and Trends in Analyses of Electric Power Quality Measurement Data, EURASIP Journal on Advances in Signal Processing.

[3] McEachern A (2007) A Free Simulator Program for Teaching Power Quality Concepts, 9th International Conference Electrical Power Quality and Utilisation.

[4] Bam L, Jewell W (2005) Review: Power System Analysis Software Tools, IEEE PES General Meeting 1: 139-144.

[5] Patne N R, Thakre K L (2007) Stochastic Estimation of voltage Sag Due to Faults in the Power System by Using PSCAD/EMTDC Software as a Tool for Simulation, Journal of Electrical Power Quality and Utilisation 13: 59-63.

[6] Filho J M C, Leborgne R C, Abreu J P G, Novaes E G C, Bollen M H J (2008) Validation of Voltage Sag Simulation Tools: ATP and Short Circuit Calculation Versus Field Measurements. IEEE Transactions on Power Delivery 23: 1472-1480.

[7] Hadi S (2004) Power System Analysis, 2nd edn, McGraw Hill.

[8] Ntombela M, Kaberere K K, Folly K A, Petroianu A I (2005) An Investigation into the Capabilities of MATLAB Power System Toolbox for Small Signal Stability Analysis in Power Systems, IEEE PES Conference and Exposition.

[9] Milano F (2005) An Open Source Power System Analysis Toolbox, IEEE Transaction on Power Systems 20: 1199-1206.

[10] Vanfretti L, Milano F (2007) Application of the PSAT, an Open Source Software for Educational and Research Purposes, IEEE PES General Meeting.

[11] Sybille G, Hoang L. H (2000) Digital Simulation of Power Systems and Power Electronics using the MATLAB/Simulink Power System Blockset, IEEE PES Winter Meeting 4: 2973-2981.

[12] Sybille G, Brunelle P, Hoang L H, Dessaint L A, Al-Haddad K (2000) Theory and Applications of Power System Blockset, A MATLAB/Simulink-Based Simulation Tool for Power Systems, IEEE PES Winter Meeting 1: 774-779. 
[13] Dessaint L A, Al-Haddad K, Hoang L H, Sybille G, Brunelle P (1999) A Power System Simulation Tool Based on Simulink, IEEE Transactions on Industrial Electronics 46: $1252-1254$.

[14] Schoder K, Hasanovic A, Feliachi A, Hasanovic A (2003) PAT: A Power Analysis Toolbox for MATLAB/Simulink. IEEE Transactions on Power Systems 18: 42-47.

[15] Bollen M H J, Zhang L D (2003) Different Methods for Classification of Three-Phase Unbalanced Voltage Dips Due to Faults. Electric Power Systems Research 66: 59-69.

[16] Djokic S Z, Milanovic J V (2006) Advanced Voltage Sag Characterisation. Part 1: Phase Shift. IEE Proceeding on Generation Transmission and Distribution 153: 423-430.

[17] Styvaktakis E, Bollen M H J (2003) Signatures of Voltage Dips: Transformer Saturation and Multistage Dips. IEEE Transactions on Power Delivery 18: 265-270.

[18] Bollen M H J, Styvaktakis E, Gu I Y H (2005) Categorization and Analysis of Power System Transients. IEEE Transactions on Power Delivery 20: 2298-2306.

[19] Bollen M H J, Gu I Y H (2007) On the Analysis of Voltage and Current Transients in Three-Phase Power Systems. IEEE Transactions on Power Delivery 22: 1194-1201.

[20] Okabe S, Takami J, Tsuboi T, Ueta G (2013) Discussion on Standard Waveform in the Lightning Impulse Voltage Test. IEEE Transactions on Dielectrics and Electrical Installation 20: 147-156.

[21] Grady W M, Santoso S (2001) Understanding Power System Harmonics. IEEE Power Engineering Review: 8-11.

[22] Tang L, McGranaghan M, Ferraro R, Morganson S, Hunt B (1996) Voltage Notching Interaction Caused by Large Adjustable Speed Drives on Distribution Systems with Low Short Circuit Capacities. IEEE Transactions on Power Delivery 11:1444-1453.

[23] Bhonsle D C, Kelkar R B (2011) Simulation of Electric Arc Furnace Characteristics for Voltage Flicker Study using MATLAB. International Conference on Recent Advancements in Electrical, Electronics and Control Engineering: 174-181.

[24] Golkar M A, Tavakoli Bina M, Meschi S (2007) A Novel Method of Electrical Arc Furnace Modeling for Flicker Study. International Conference on Renewable Energies and Power Quality: 1-8.

[25] Gomez J C, Morcos M M (2002) Flicker Measurement and Light Effect. IEEE Power Engineering Review: 11-15. 



\title{
Chapter 4
}

\section{An Application of Simple and Compact Genetic Algorithms for Estimating Harmonic Components}

\author{
Andre L. S. Pessoa, Pedro H. C. Ulisses, Hermes M. G. C. Branco and \\ Ricardo de Andrade Lira Rabêlo
}

Additional information is available at the end of the chapter

http://dx.doi.org/10.5772/61203

\begin{abstract}
This work presents an approach for the harmonic components estimation problem present in electrical power systems by making use of evolutionary algorithms. The referential data were obtained by the ATP (Alternative Transients Program) software. Compact and simple genetic algorithms were applied to estimate the parameters of non-linear function to generate a waveform as similar as possible to the one provided by the ATP software. The results yielded by the aforementioned evolutionary algorithms were then compared with one another in a number of scenarios, using the values obtained by the waveform of reference generated by the ATP software. The comparisons were used to seek evidence of which algorithm solved the problem in a setting with limited availability of computational resources. Based on the generated results, it has been found that compact genetic algorithm satisfactorily solves the proposed problem and it is the most indicated method, when less computational effort is required.
\end{abstract}

Keywords: compact genetic algorithm, electrical power systems, harmonics, simple genetic algorithm

\section{Introduction}

Ideally, electric power systems (EPS) should operate as voltage and current waveforms the closest to a sinusoidal waveform as possible, with constant magnitude and frequency. However, this situation doesn't always happen, which implies the occurrence of disturbances in the power quality (PQ) [1]. Problems with the PQ are associated with any disturbance in the voltage, current, or frequency deviation that results in failure or defective operation of a 
consumer's equipment [2]. Studies related to the PQ are becoming increasingly important due to the characteristics of the charges and EPS, which are more sensitive to the disturbances.

Among the many disturbances in the $\mathrm{PQ}$, there is a class called harmonic distortion. Harmonic distortions are periodic distortions as voltage and current waveforms, characterized by the presence of frequencies that are integer multiples of the nominal frequency of the system and often associated to continuous operation of charges with non-linear characteristics [3]. With technological development and the development of power electronics, these disturbances became more and more relevant due to sensitive equipment in the EPS that requires electric energy of better quality [4]. Some of the problems caused by harmonic distortions are overheating of devices, activation of safety devices [3], resonance, high voltage between neutral and ground, low performance of devices and equipment, and interruption of production processes [5].

Among the methods to remedy the problems caused by harmonics are active power filters. With the identification of the harmonic components that may pollute the waveform of the voltage or current of a system, such filters can be used to properly correct the problem. AC controllers, generally present in homes or even in commercial environments are typical sources of distortions caused by harmonics [6]. In [6], a study was made to identify, with the help of artificial neural networks, the first six harmonic components of a circuit compound by a semiconductor switch (TRIAC), a sinusoidal voltage source, trip circuit, and of incandescent bulbs.

It should be stressed that non-linear charges, increasingly present in EPS, are the most sensitive to the disturbances and are also the ones that cause the greatest harmonic distortions in the EPS [7]. Therefore, the presence of the harmonics in the EPS tends to become more frequent and increases the economic losses caused by low PQ. For these reasons, many researches would like to seek methods that improve the precision and speed of the algorithms applied in the estimation of the harmonic components. Among the many techniques used, particularly noticeable are the methods based on Discrete Fourier Transform (DFT) [8], Fast Fourier Transform (FFT) [9], the Least-Squares adjustment (LS) [10], Wavelet Transform [11], and Kalman Filter [12]. The mentioned methods can be affected by the continuous current component (CCC) [9], however, methods based on computational intelligence such as Artificial Neural Networks (ANN) [13, 14], Particle Swarm Optimization (PSO) [15], and Genetic Algorithms [16] are weakly influenced by the CCC [15] and show good results for estimating harmonic components.

Considering that the proposal of using evolutionary algorithms (EA) for estimating harmonic components show good results, this work investigated the applicability and efficiency of compact genetic algorithm (CGA) [17]. For validation purposes, a comparison between CGA and SGA (simple genetic algorithm) $[18,19]$ was performed. Both algorithms were used to estimate the RMS values and the phase angles of the harmonic components of voltage electric signals. By using CGA, it is possible to get the benefits of the use of EA for estimating harmonic components with an algorithm of simple implementation that requires few computing resources [20]. 
This article was divided into six (6) additional sections, in addition to the introduction. In the second section there is a description of the problem, in which the mathematical models used are presented. The third section addresses the algorithms used, giving emphasis on descriptions related to SGA and CGA. The fourth section addresses the methodology used to get the harmonic components through two different mathematical models. In the fifth section are the results obtained through the algorithms used. In the sixth section are the discussions about the results. The seventh section presents the conclusions obtained.

\section{Problem description}

A waveform can be mathematically represented through Fourier series, in which it is possible to express a waveform in terms of its continuous, fundamental, and harmonic components. Each harmonic component of the waveform has its own amplitude, a phase angle, and a frequency, which has to be an integer multiple of the fundamental frequency [2]. Thus, a waveform as a function of time can be descripted by Eq. (1) $[15,21]$ in which $x(t)$ is the resulting value of the sum of the continuous component and the harmonic components and $x_{0}$ is the continuous component of the signal and $\lambda$ is a time constant. $A_{c, i}, A_{s, i}, \theta_{c, i}$ and $\theta_{s, i}$ are the cosine and sine amplitudes and the phase angles of the $i$ th harmonics, respectively; $\omega_{0}$ is the angular frequency; $t$ is the time the sample occurred; $i$ is the order of the harmonic; and $N$ is the number of harmonics present in the signal used to represent $x(t)$.

$$
x(t)=x_{0} e^{-\lambda t}+\sum_{i=1}^{N}\left[A_{c, i} \cos \left(i \omega_{0} t+\theta_{c, i}\right)+A_{s, i} \sin \left(i \omega_{0} t+\theta_{s, i}\right)\right]+e(t)
$$

In order to perform the estimation of the parameters, the waveform is discretized in $n$ samples, with a constant difference of time among the samples. That said, for each time $\left(t_{n}\right)$ of the function domain, there will be a corresponding $x\left(t_{n}\right)$. Thus, Eq. (1) can be re-written as pointed in Eq. (2):

$$
\left[\begin{array}{c}
x\left(t_{1}\right) \\
\vdots \\
x\left(t_{n}\right)
\end{array}\right]=\left[\begin{array}{c}
x_{0} \\
A_{c, 1} \\
A_{s, 1} \\
\vdots \\
A_{c, n} \\
A_{s, n}
\end{array}\right]+\left[\begin{array}{c}
e\left(t_{1}\right) \\
e\left(t_{2}\right) \\
\vdots \\
e\left(t_{n}\right)
\end{array}\right]
$$

with $x\left(t_{1}\right)$ being the sum of the harmonic components for time $t_{1},[M]$ being the matrix represented in Eq. (3), and $e\left(t_{n}\right)$ the error associated to each point-in-time $t_{n}$ [21]. 


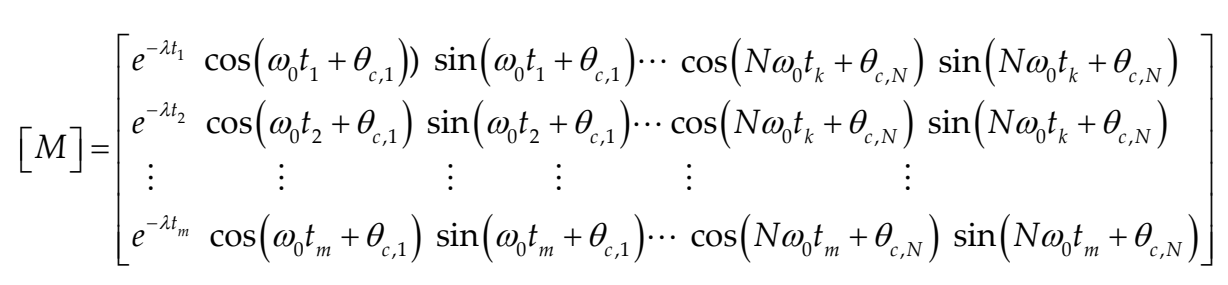

\section{Algorithms}

In this section the simple genetic algorithm (SGA) and the compact genetic algorithm (CGA) are described.

\subsection{Simple genetic algorithm}

GAs are algorithms meant for search and global optimization, based on Darwin's theory of evolution and genetics. When GAs are used, it is assumed that in a certain population, the best individuals have greater chances of survival and of generating increasingly fit individuals [19], guaranteeing that the population evolves and finds a solution for a problem.

As presented in the pseudocode in Figure 1, SGA has the following steps: initialization of the population, evaluation, selection, crossover, and mutation.

The first step is the initialization of the population. In the population evaluation step, all individuals are evaluated through the use of an evaluation function. In the selection process, an $N$ number of individuals is selected for the crossover step. After crossover, the new generated individuals undergo the mutation step. Following that, the new individuals become the new population. While the stopping criterion is not met, the algorithm will be executed from the selection step. At the end of the execution of the algorithm, the final solution will be the individual with the best evaluation grade (fitness).

\subsection{Compact genetic algorithm}

The determination itself of the necessary parameters for the functioning of the SGA, such as the crossover and mutation rates, becomes a problem of optimization inside another problem of optimization. Predicting the movement of the populations is considerably difficult [22] and because of that, new types of algorithms have been developed, such as the estimation of distribution algorithms (EDA) [22], which we can cite the CGA as one of the simplest EDA models.

CGA has a similar effectiveness as the SGA, but it consumes less computational resources as it represents the population with a vector of probability [20], which means it represents the proportion of the presence of each gene in the population. Thus, because it does not have a physical representation of the population (only the vector of probability), nor the crossover step, nor the mutation step [22], the CGA happens to be a simpler algorithm to be implemented 


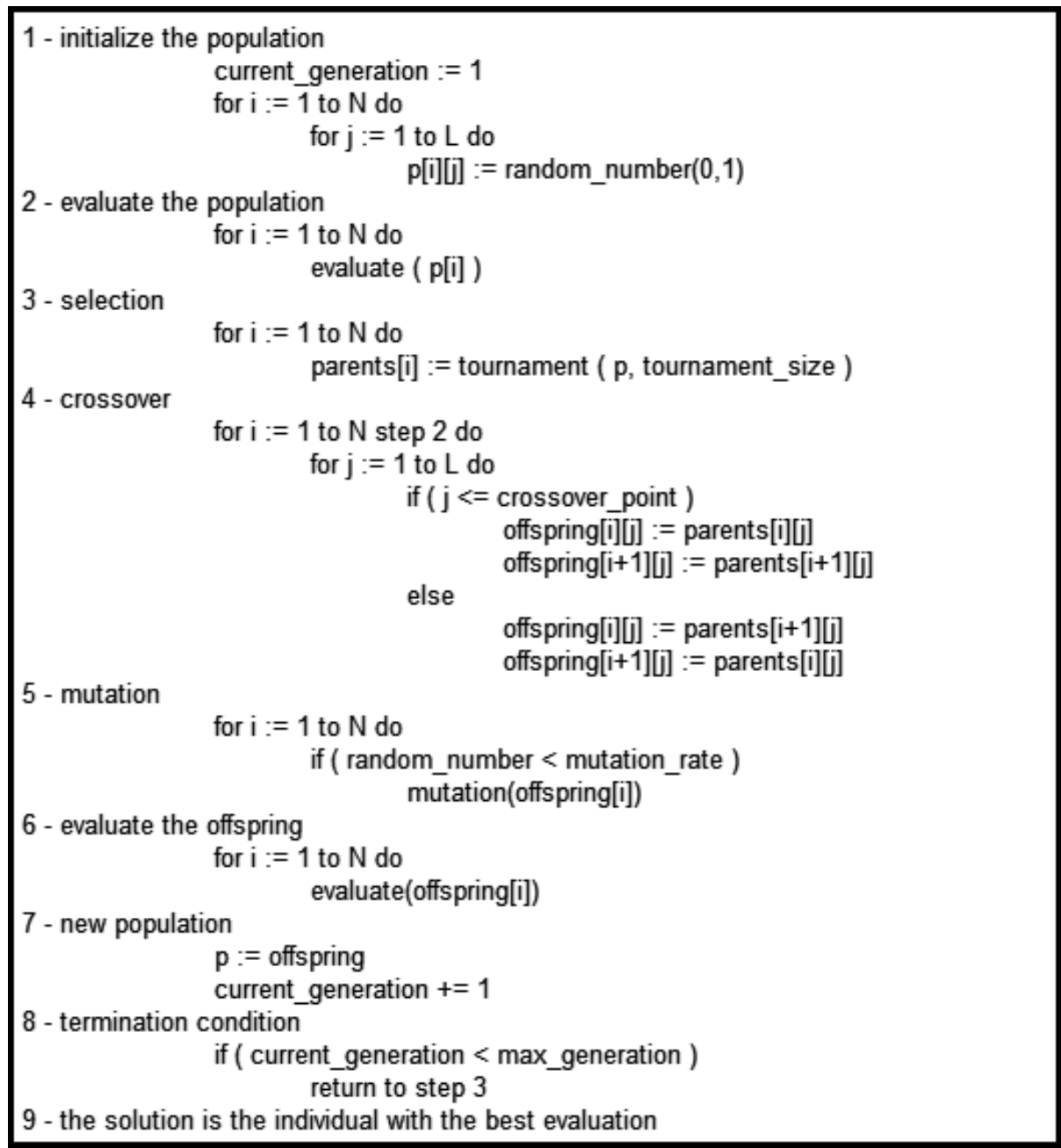

Figure 1. Pseudocode of SGA.

compared to the SGA. Figure 2 shows the pseudocode of CGA considering a tournament size equal to 2 to be the selection mechanism.

The CGA has as its first step the initialization of the vector of probability, in which for each position it is attributed the value of 0.5 , or $50 \%$ of the probability of generating 1 for that position of the individual. The second step consists of generating two individuals, taking into account the vector of probability. In the third step, the verification of the individual with the best evaluation grade is performed. Based on the comparison between the best and the worst individual, an update is performed on the vector of probability in the fifth step. While the vector of probability doesn't converge, the algorithm keeps executing from the second stage and when it converges, the algorithm stops the execution. The final solution is the vector of probability. 


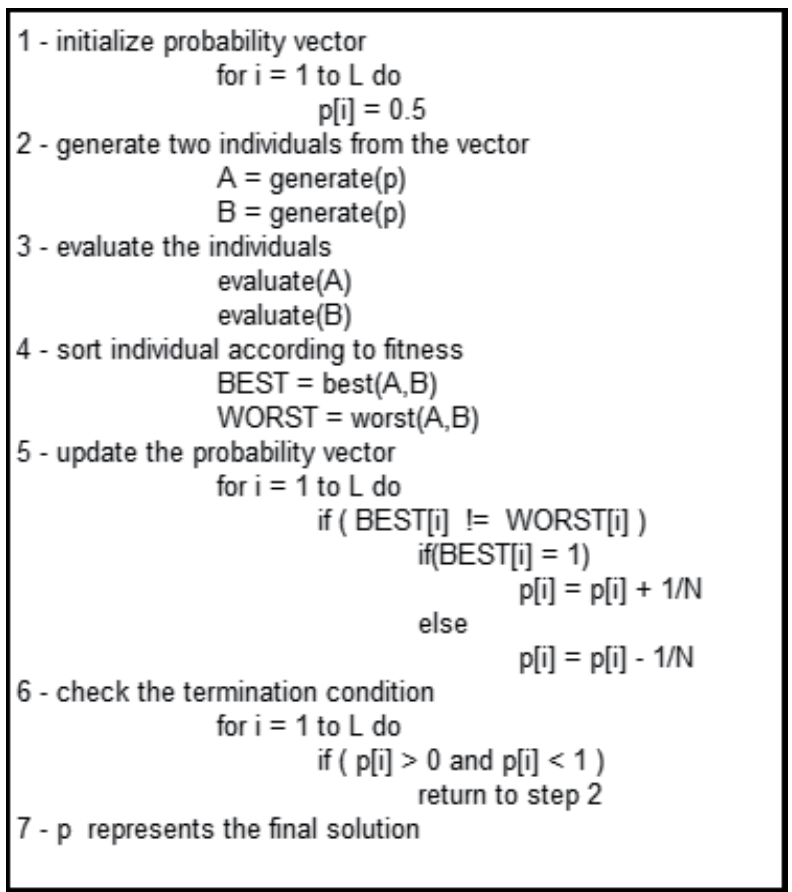

Figure 2. Pseudocode of CGA.

\section{Methodology}

In order to estimate the harmonic components, CGA and the SGA were used, both using the mathematical model to estimate the previously presented harmonic components and considering the first seven components of the Fourier series. The algorithm estimates 30 parameters, among which 28 are dedicated to the amplitude of their sins, co-sins, and phase angles, and the other two parameters are for the continuous component of the signal and for the time constant. In order to represent the parameters of the Fourier series, 8 bits were used for each parameter, as it was verified it was enough to represent the values with good precision. An individual generated is represented as shown in Figure 3.

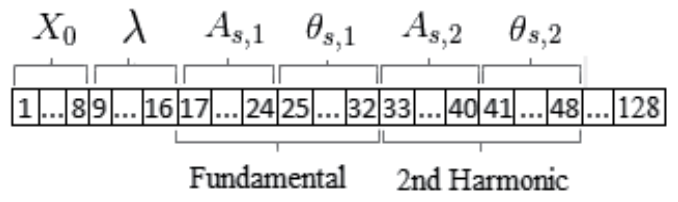

Figure 3. Representation of the individual. 
The same representation of the individuals was used in the SGA and the CGA. The SGA was implemented with a 75\% crossover rate. As there is no mutation step in the CGA, in order to perform a fairer comparison, the SGA was considered as not having a mutation step for observing its evolutionary process without this operator. The crossover rate was considered equal to $75 \%$ because no improvement was obtained or economy (saving) of computational resources.

The data used in the tests are voltage values obtained through a simulation of a power electric system using ATP software [23]. The evaluation of the individuals was performed through a comparison between the original signal and the signal generated from the estimated parameters.

Dummy Text Figure 4 shows the comparison between the waveform of a measured signal and the waveform obtained from the estimated parameters.

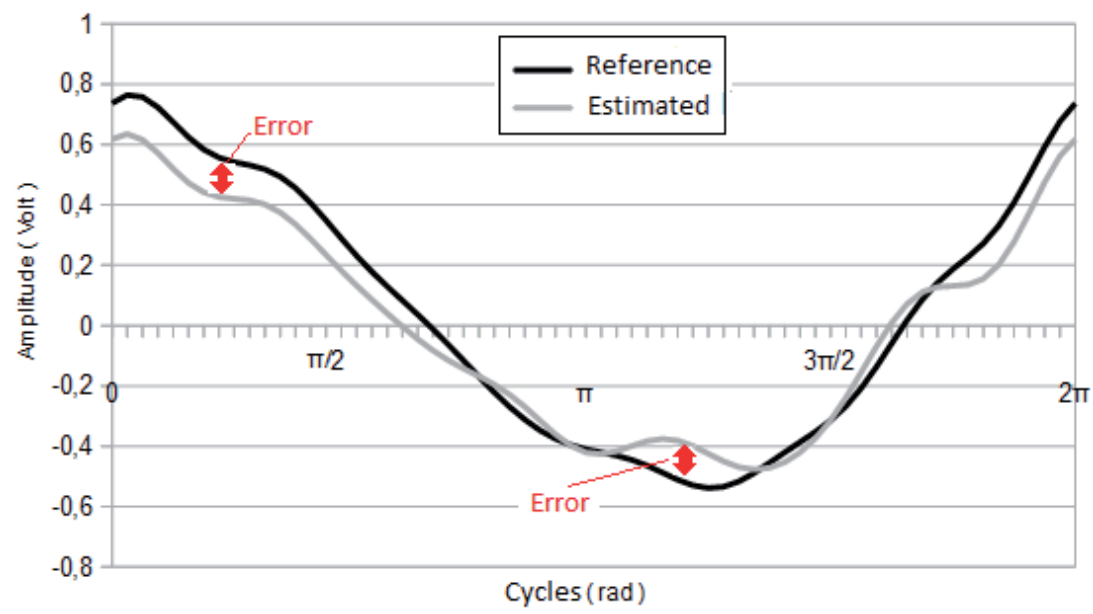

Figure 4. Error between the measured and the estimated waveform.

It is possible to observe that the smaller the error between the measured and the estimated waveforms, the better the estimation of the parameters. Therefore, the goal is to minimize the value of the evaluation function adopted that considers the errors between the signals as in Eq. (4),

$$
E=\sqrt{\sum_{k=1}^{N} \frac{\left(x_{\text {meas }}\right) t_{k}-x_{\text {est }}\left(t_{k}\right)^{2}}{N}}
$$

where $x_{\text {med }}$ is the measured signal, $x_{\text {est }}$ is the estimated signal, $N$ is the number of samples in a cycle, and $E$ is the value of the evaluation function that is intended to minimize. 
When using the binary representation of the individuals of the population, CGA adopts a stopping criterion based on the probability of each bit of the individual being 1 . So, if in all positions of the vector of probability the possibility of being 1 is less than $5 \%$ or more than $95 \%$ the algorithm should stop. It was adopted the same criterion for SGA. Considering that SGA deals with the population instead of a vector of probability, which means that when the percentage of bits that equal 1 reaches $5 \%$ or $95 \%$ for the same locus of all individuals of the population, SGA should stop. It should be pointed out that the tournament method [19] was the type of selection used.

All tests were performed with four different voltage waveforms, with population varying from 100 to 10000 and with the tournament size varying between 2,8 , and 32 . For each configuration, the average of the evaluations of the whole population corresponds to the mean error. Each configuration was executed 10 times for each of the 4 waveforms, with the purpose of obtaining the average of the mean errors, the smallest error in the 10 executions, the number of evaluations, and the standard deviation. The mean error values, the number of evaluations, and the standard deviation were obtained from the average of the 4 waveforms. The number of evaluations for the SGA was calculated as being the average of the number of generations of the 10 executions multiplied by the size of the population. For the CGA, on the other hand, it was calculated as being the size of the tournament multiplied by the average of the number of generations in the 10 executions.

\section{Results}

The algorithms applied for the estimation of harmonics were tested by means of the voltage values obtained through simulations performed with ATP software. The results obtained were compared considering the different configurations used in the algorithms.

\subsection{Estimation of the harmonic components using the proposed methodologies}

In this section, the waveform of one of the situations used is going to be presented, and this waveform is going to be compared to the waveforms generated through the harmonics estimated with different algorithm configurations.

Figure 5 presents the waveforms generated with the estimated harmonics using both SGA and CGA. In this test, the parameters in SGA and CGA were adopted as the tournament size $(\mathrm{k})$ is equal to 2 and the population size is equal to 100 individuals. As it can be observed in Figure 6 with the configuration used for the GAs, CGA showed a better answer for estimating the harmonics, as with CGA's estimation of a waveform closer to the original one simulated through ATP was generated.

Figures 6 to 9 present the parameters of reference used to obtain four different voltage waveforms. In these tables it also presented a comparison between the results obtained with CGA and SGA. Also, they show the answer gotten by DFT and PSO as presented in [15]. 


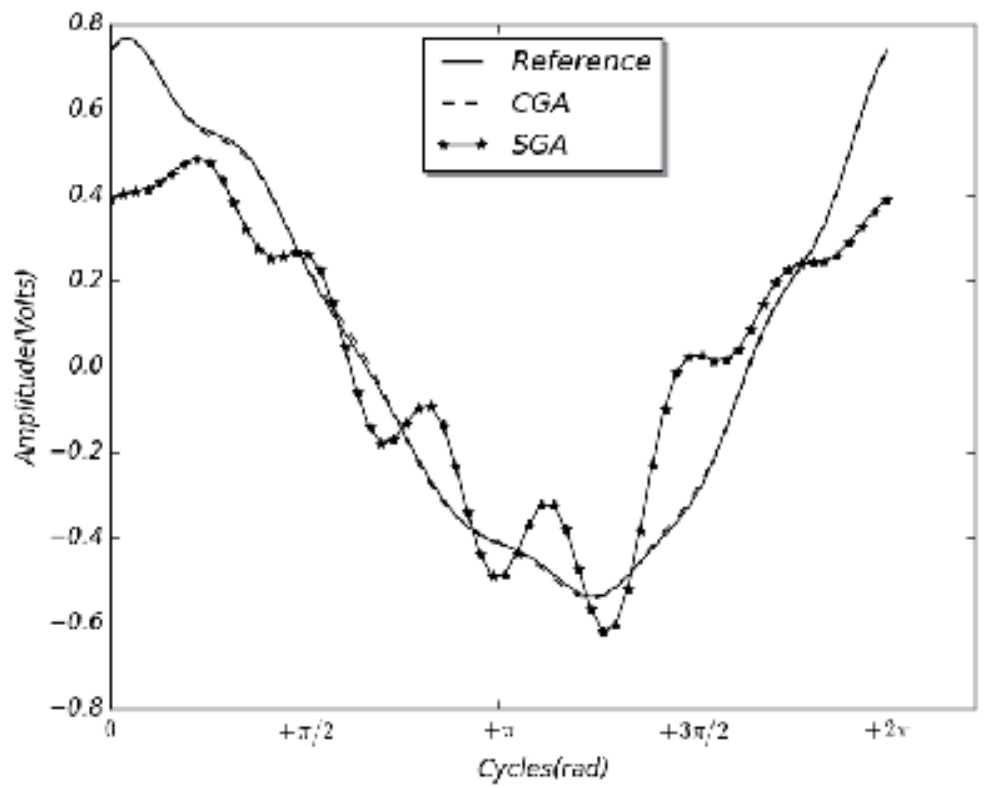

Figure 5. Waveform obtained with estimated parameters through the algorithms considering the size of the tournament (k) of 2 and size of population equal to 100.
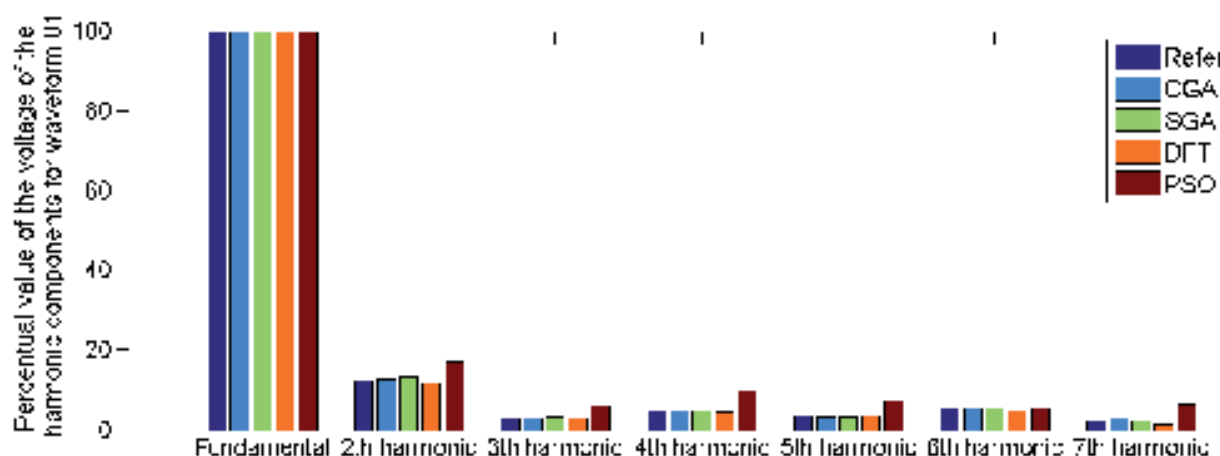

Figure 6. RMS value of the voltage of the fundamental frequency (V1) and harmonic components as percentages of the fundamental for waveform 01 .

It should be said that the results showed in Figures 6 to 9 for the CGA were obtained considering a population size of 100 individuals and a tournament size of 2 . But the results showed in both tables for SGA were obtained considering a population size of 2000 individuals and a tournament size of 8 . It should also be pointed out that the values presented are always close to the reference ones. It was observed that in some situations the estimation performed by DFT and PSO, with 30 particles, were more precise than the one obtained using the other algorithms. In the following sections the results obtained are discussed in a more general way, as well as some quality criteria of the solutions found. 


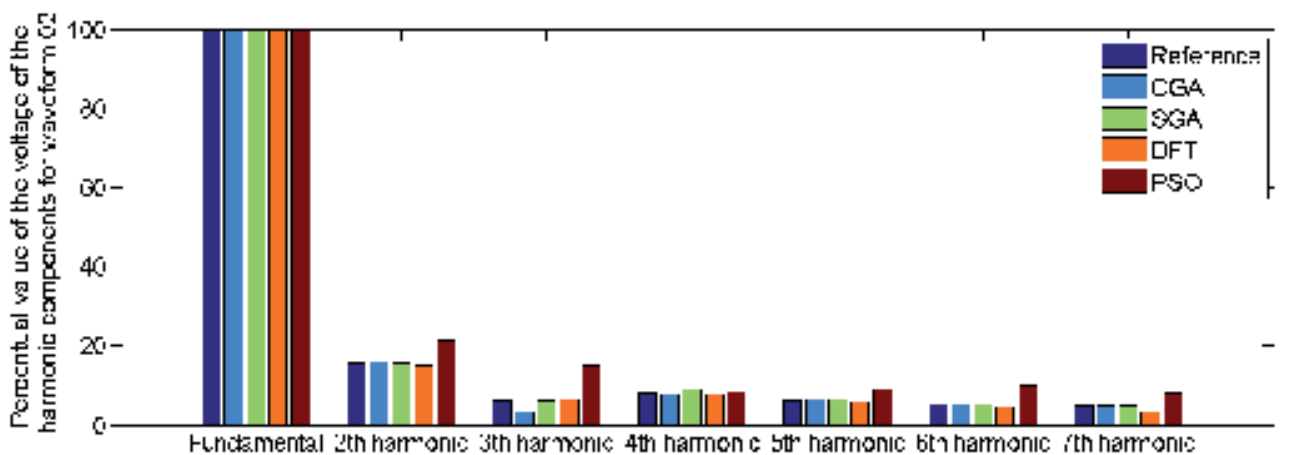

Figure 7. RMS value of the voltage of the fundamental frequency (V1) and harmonic components as percentages of the fundamental for waveform 02 .
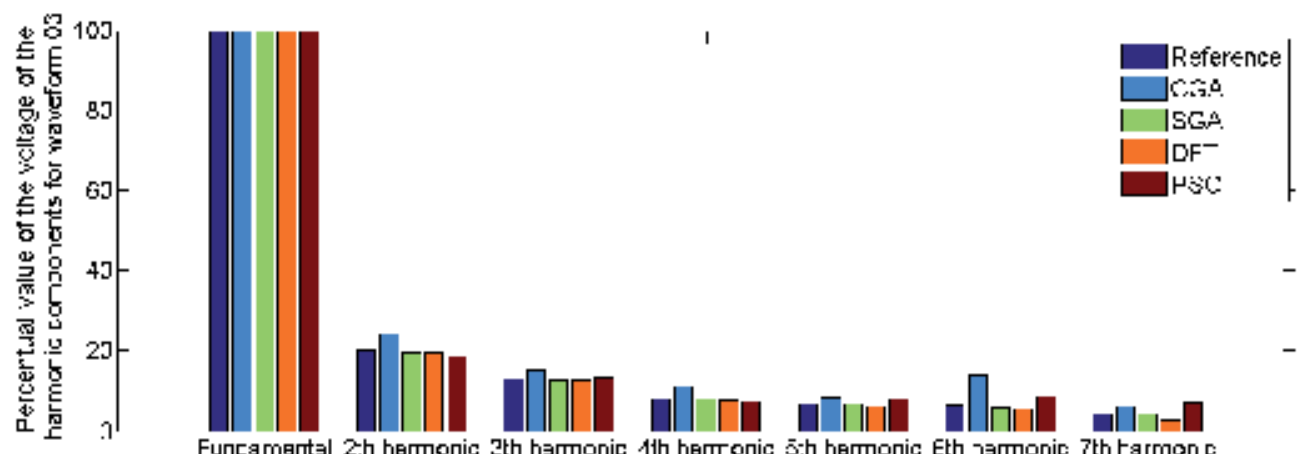

Figure 8. RMS value of the voltage of the fundamental frequency (V1) and harmonic components as percentages of the fundamental for waveform 03 .
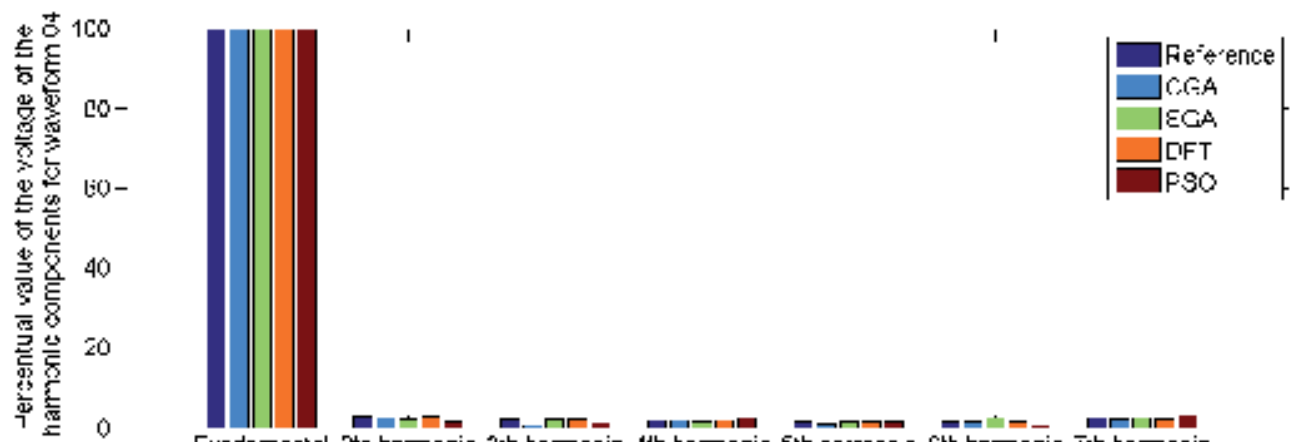

Figure 9. RMS value of the voltage of the fundamental frequency (V1) and harmonic components as percentages of the fundamental for waveform 04 . 


\subsection{Observation of the mean error}

Figures 10,11, and 12 show graphs of the mean error in the number of individuals given the tournament size of 2,8 , and 32 individuals.

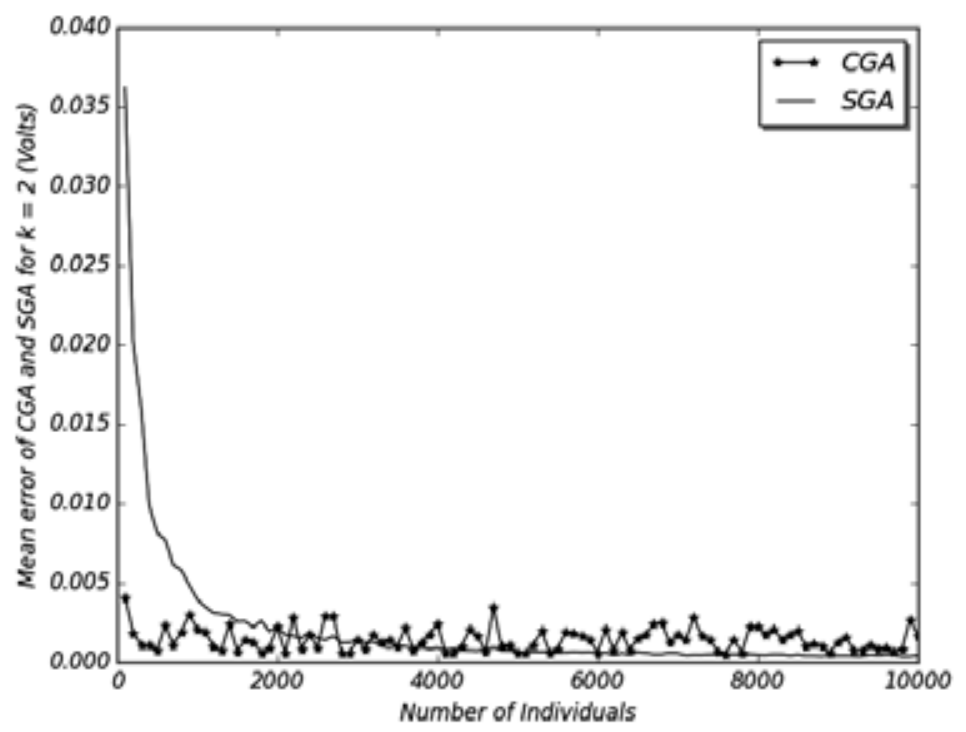

Figure 10. Results obtained with tournament size equal to 2 CGA and SGA for the average error.

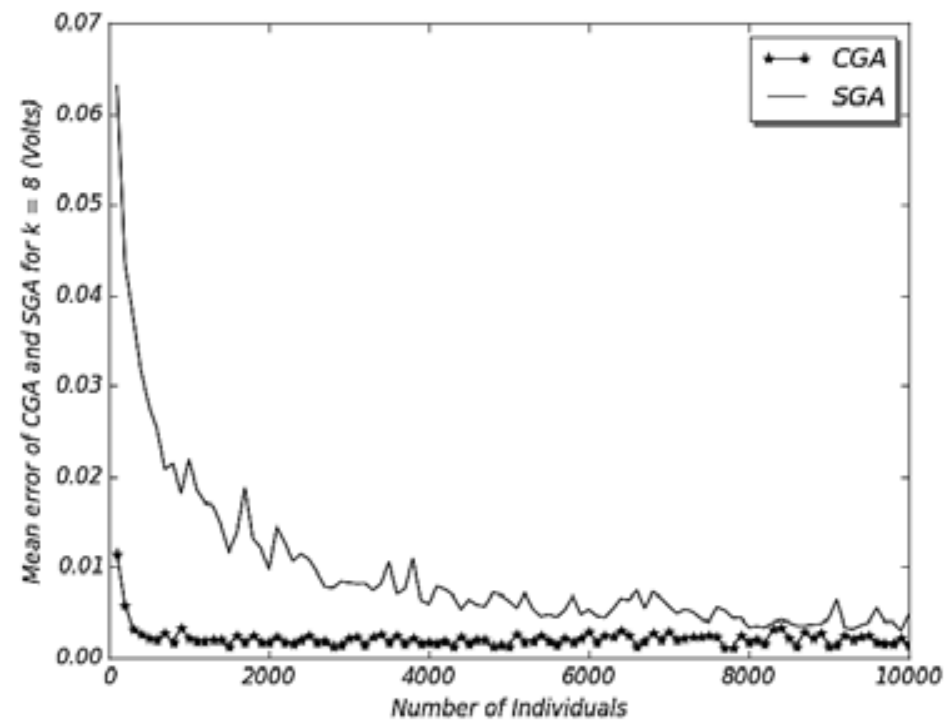

Figure 11. Results obtained with tournament size equal to 8 CGA and SGA for the average error. 


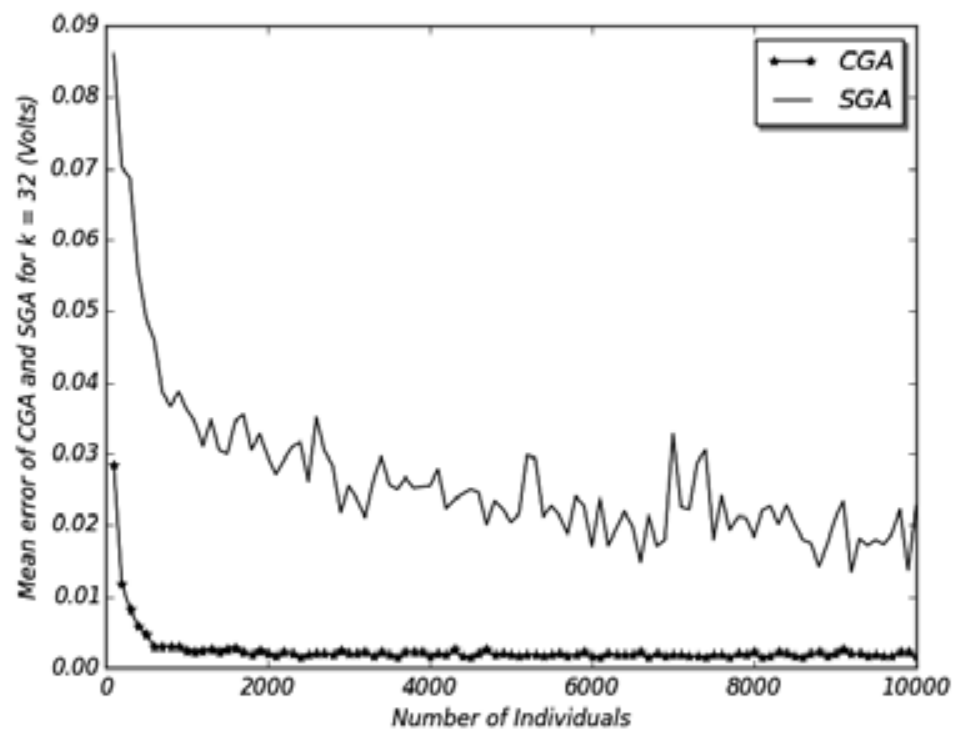

Figure 12. Results obtained with tournament size equal to 32 CGA and SGA for the average error.

\subsection{Observation of the number of evaluations}

Figures 13, 14, and 15 show graphs of the number of evaluations in the number of individuals given the tournament size of 2,8 , and 32 . Through the number of evaluations of the objective function, it is possible to evaluate the convergence time of algorithms adopted. This analysis is very important for determining their feasibility in the real world.

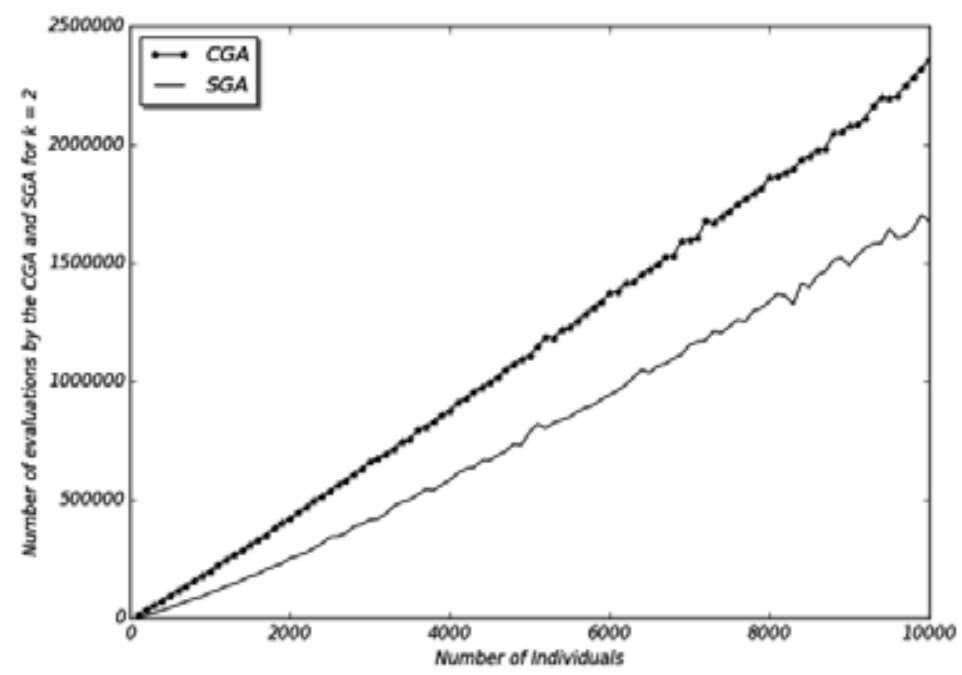

Figure 13. Results obtained with tournament size equal to 2 CGA and SGA for the number of evaluations. 


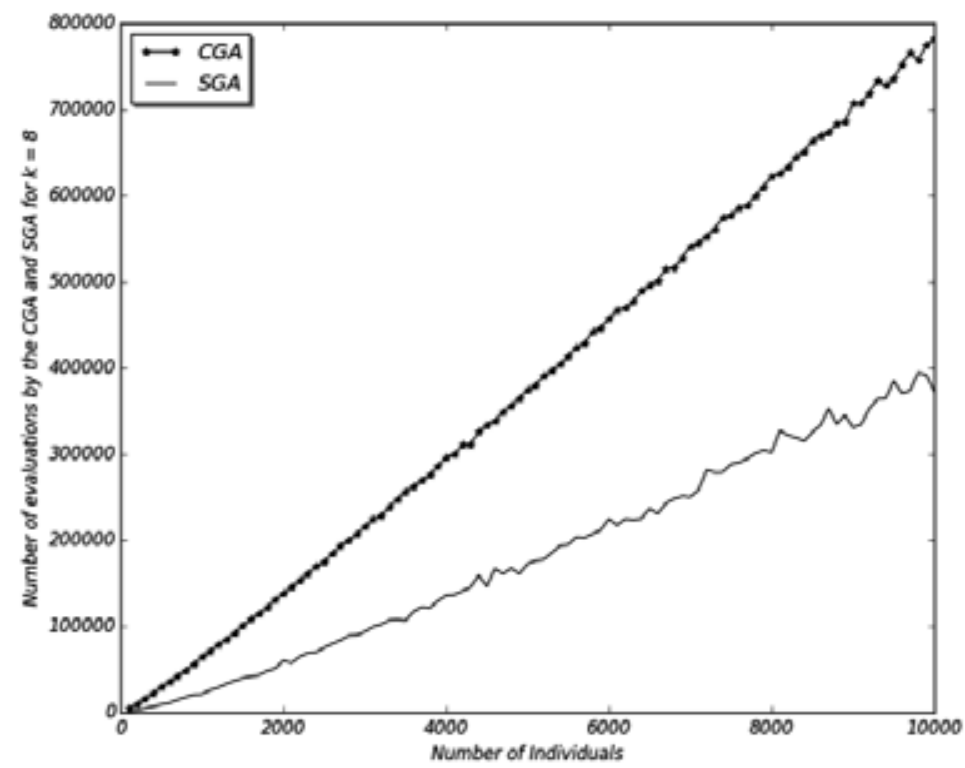

Figure 14. Results obtained with tournament size equal to 8 CGA and SGA for the number of evaluations.

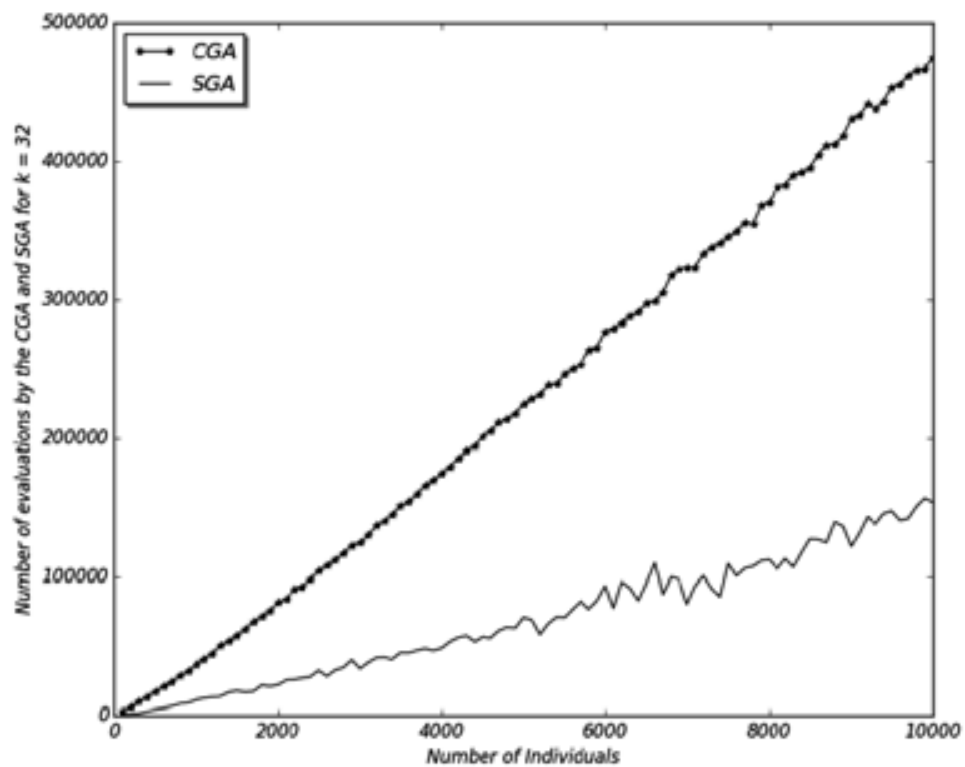

Figure 15. Results obtained with tournament size equal to 32 CGA and SGA for the number of evaluations. 


\subsection{Observation of the standard deviation}

Figures 16, 17, and 18 show graphs of the standard deviation in the number of individuals given the tournament size of 2,8 , and 32 . The standard deviation offers a way of evaluating how much the objective function is varying for all samples under analysis. A tournament size of 2 (Figure 16) SGA will show the smallest value for the standard deviation among all configurations analyzed. A tournament size of 8 CGA shows the smallest standard deviation.

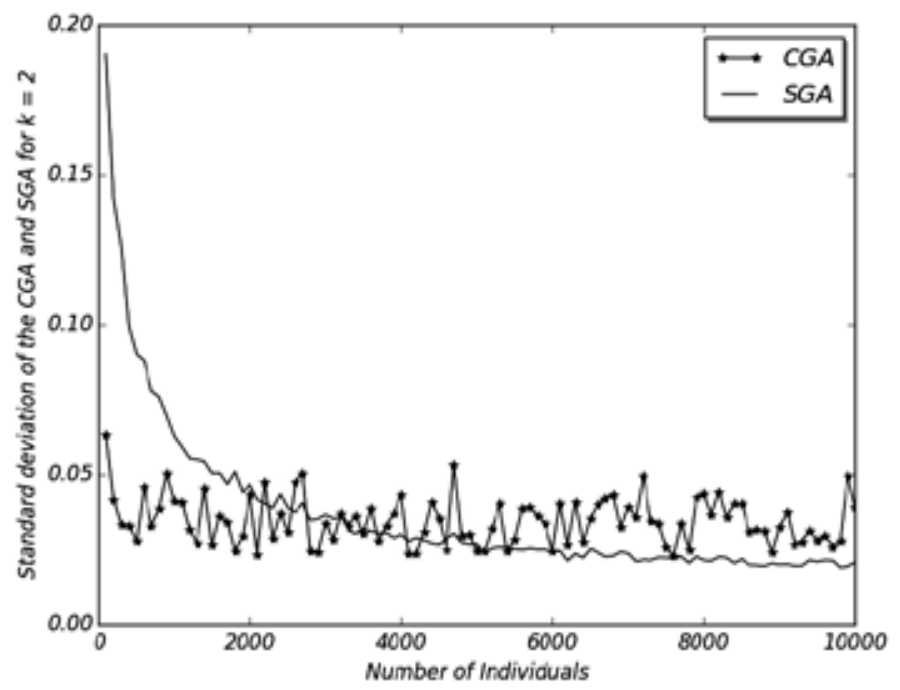

Figure 16. Results obtained with tournament size equal to 2 CGA and SGA for the standard deviation.

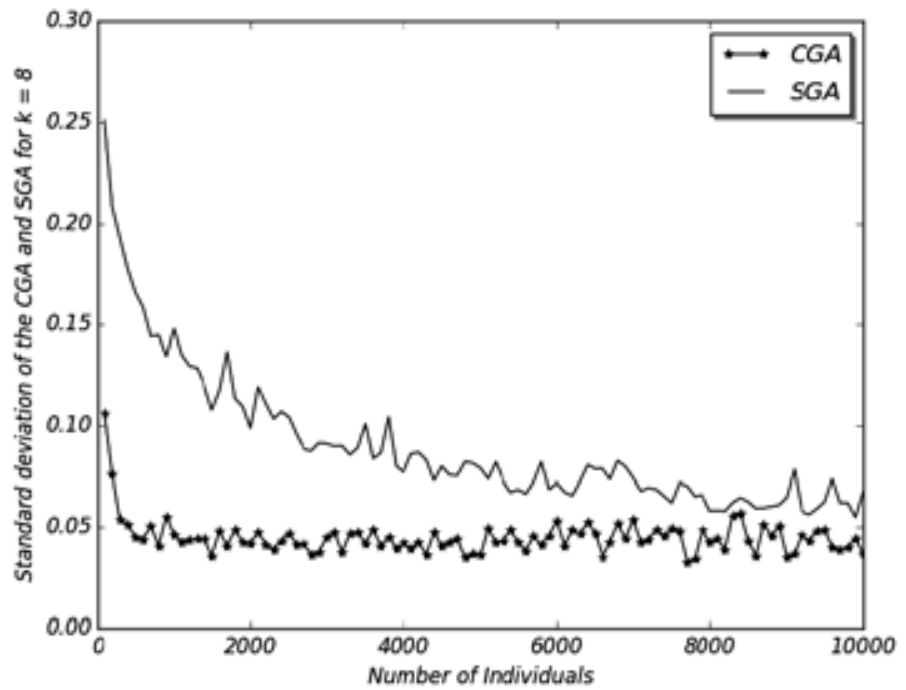

Figure 17. Results obtained with tournament size equal to 8 CGA and SGA for the standard deviation. 


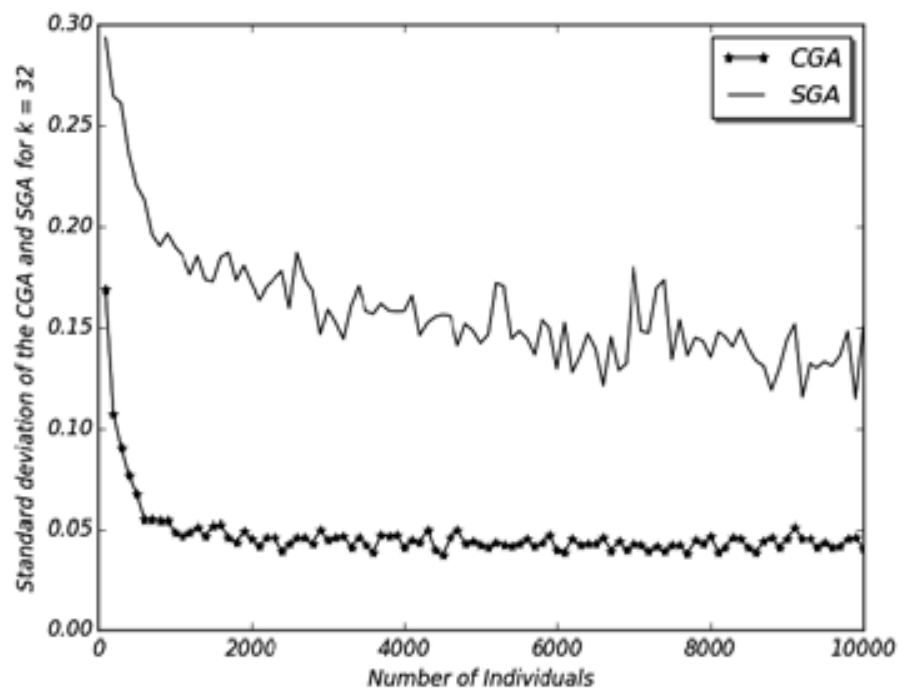

Figure 18. Results obtained with tournament size equal to 32 CGA and SGA for the standard deviation.

\section{Discussions}

a. After the presentation of the results and tests performed, a few conclusions deserve to be highlighted. Initially, concerning the mean error with tournament size of 8 , it is observed that CGA obtains better results than SGA.

b. Figure 10, with tournament size of 2 CGA to a smaller number of individuals, has a lower mean error than SGA. With the increasing number of individuals SGA tends to get a smaller mean error.

c. In Figures 11 and 12 the mean error observed with CGA tends to be smaller than with SGA. An increase in the selective pressure influenced the convergence of SGA in a negative way. On the other hand, Figures 13,14, and 15 show that CGA tends to present a number of evaluates higher than SGA with the same population size for each size tournament adopted.

d. Concerning the standard deviation, it was observed that in fact SGA is more sensitive to the selective pressure than CGA. As with a smaller number of individuals, CGA stabilizes its standard deviation while SGA needs a greater population to achieve a similar standard deviation. As a consequence, CGA gets to its global optimum value faster than SGA.

e. Considering the above observations, it is possible to affirm that the use of CGA carries in computational resources for obtaining good quality answers because for the same population size, it provides the best quality solutions (with minor mistakes and standard deviation smaller) than the SGA, even requiring a larger number of reviews to converge. 
To present solutions with the same quality as the CGA, the SGA needs to work with larger populations and consequently will require a greater number of evaluations of the objective function to obtain a solution with the same quality as the CGA. It is possible to perceive both by the results presented in Figures 6 to 9, and the graphics performance analysis of Figures 6 to 14 that the CGA with the tournament size equal to 2 and with a population of 100 individuals can provide estimates of harmonics with good accuracy. For SGA to provide solutions with the same level of accuracy requires a population of 2,000 individuals.

\section{Conclusions}

With the results found, it was verified that both algorithms present adequate solutions for the problem presented, as long as a model and convenient parameters are adopted. It is important to highlight that when a population size of 100 and a tournament size of 2 individuals are used, CGA manages to achieve a lower error than SGA with the same configuration.

The study presented showed graphs of the mean error, smallest error, number of evaluations, and standard deviation. Also, graphs comparing a waveform of reference with waveforms obtained when using CGA and SGA were presented. For the CGA, using a tournament size of 2 and population size of 100, the waveform obtained was closer to the waveform of reference than for the SGA with tournament size of 8 and population size of 500. It was also noted that for a population size of 100 and tournament size of 2, the number of evaluations of both CGA and SGA were very close. As showed in this work, CGA showed good results as that of SGA. However, by using less computational resources there is the possibility, in future works, to take advantage of the strong parallelism in the genetic algorithm to implement it in an embedded system.

\section{Acknowledgements}

The authors acknowledge the support received from UESPI, UFPI, CNPq and FAPEPI.

\section{Author details}

Andre L. S. Pessoa ${ }^{1}$, Pedro H. C. Ulisses ${ }^{1}$, Hermes M. G. C. Branco ${ }^{1}$ and Ricardo de Andrade Lira Rabêlo ${ }^{2 *}$

*Address all correspondence to: ricardalr@ufpi.edu

1 Piauı State University (UESPI), Terezina, Brazil

2 Federal University of Piauı (UFPI), Terezina, Brazil 


\section{References}

[1] M. H. Bollen and I. Gu, "Signal processing of power quality disturbances" John Wiley \& Sons, 2006, vol. 30.

[2] R. C. Dugan, M. F. McGranaghan, and H. W. Beaty, "Electrical power systems quality," New York, NY: McGraw-Hill, c1996, vol. 1, 1996.

[3] E. Fuchs and M. A. Masoum, Power quality in power systems and electrical machines. Academic press, 2011.

[4] T. A. Short, Distribution reliability and power quality. CRC Press, 2005.

[5] H. Moreno, Harmônicas nas instalações elétricas: Causas, efeitos e soluções. Procobre, 2001.

[6] C. F. Nascimento, et al. "A neural networks-based method for single-phase harmonic content identification." Proceedings-34th Annual Conference of the IEEE Industrial Electronics Society, IECON 2008. 2008.

[7] J. Arrillaga and B. C. W. N. R. W. A. R. Smith, Power system harmonic analysis. Wiley, 1997.

[8] F. Zhang, Z. Geng, and W. Yuan, "The algorithm of interpolating windowed FFT for harmonic analysis of electric power system," Power Delivery, IEEE Transactions on, vol. 16, no. 2, pp. 160-164, 2001.

[9] A. A. Girgis, W. B. Chang, and E. B. Makram, "A digital recursive measurement scheme for online tracking of power system harmonics," IEEE Transactions on Power Delivery, vol. 6, no. 3, pp. 1153-1160, 1991.

[10] I. Kamwa and R. Grondin, "Fast adaptive schemes for tracking voltage phasor and local frequency in power transmission and distribution systems," in Transmission and Distribution Conference, 1991., Proceedings of the 1991 IEEE Power Engineering Society. IEEE, pp. 930-936, 1991.

[11] W. A. Wilkinson and M. Cox, "Discrete wavelet analysis of power system transients," Power Systems, IEEE Transactions on, vol. 11, no. 4, pp. 2038-2044, 1996.

[12] C. Chen, G. Chang, R. Hong, and H. Li, “Extended real model of Kalman filter for time-varying harmonics estimation," IEEE Transactions on Power Delivery, vol. 25, no. 1, pp. 17-26, 2010.

[13] H. C. Lin, "Intelligent neural network-based fast power system harmonicection," IEEE Transactions on Industrial Electronics, vol. 54, no. 1, pp. 43-52, 2007.

[14] S. Varadan and E. Makram, "Practical considerations in the application of neural networks to the identification of harmonic loads," Electric Power Systems Research, vol. 30, no. 2, pp. 103-106, 1994. 
[15] D. A. Rabelo, M. V. Lemos, and D. Barbosa, "Power system harmonics estimation using Particle Swarm Optimization," in IEEE Evolutionary Computation (CEC), 2012 IEEE Congress on. IEEE, pp. 1-6, 2012.

[16] R. A. Macêdo, D. da Silva, D. V. Coury, and A. C. L. F. de Carvalho, "A new technique based on genetic algorithms for tracking of power system harmonics," in IEE Neural Networks, 2002. SBRN 2002.Proceedings.VII Brazilian Symposium on. IEEE, pp. 7-12, 2002.

[17] M. Pelikan, D. E. Goldberg, and F. G. Lobo, "A survey of optimization by building and using probabilistic models," Computational optimization and applications, vol. 21, no. 1, pp. 5-20, 2002.

[18] D. A. Coley, An introduction to genetic algorithms for scientists and engineers. World scientific, 1999.

[19] J. H. Holland, Adaptation in natural and artificial systems: An introductory analysis with applications to biology, control, and artificial intelligence. U Michigan Press, 1975.

[20] G. R. Harik, F. G. Lobo, and D. E. Goldberg, "The compact genetic algorithm," IEEE Transactions on Evolutionary Computation, vol. 3,no. 4, pp. 287-297, 1999.

[21] S. G. Seifossadat, M. Razzaz, M. Moghaddasian, and M. Monadi, "Harmonic estimation in power systems using adaptive perceptrons based on a genetic algorithm," WSEAS Transactions On Power Systems, no. 11, 2007.

[22] P. Larranaga, "A review on estimation of distribution algorithms," in Estimation of distribution algorithms. Springer, pp. 57-100, 2002.

[23] W. S. Meyer and T. H. Liu, "Alternative transients program (ATP) rulebook," Canadian/American EMTP User Group, vol. 2000, pp. 5-2, 1987. 
Chapter 5

\title{
A Distributed Web-Based System for Temporal and Spatial Power Quality Analysis
}

\author{
Stefano Di Pasquale, Sabino Giarnetti, Fabio Leccese, Daniele Trinca, \\ Marco Cagnetti and Maurizio Caciotta
}

Additional information is available at the end of the chapter

http://dx.doi.org/10.5772/61145

\begin{abstract}
A distributed web-based system for temporal and spatial power quality analysis has been realized and tested. Connecting by internet local instruments able to perform high accuracy measurements in real time, the Power Quality information, locally measured, can be sent to a remote central server which aim is to plot them and stored the data for future analysis. The remote instruments have been realized, tested and placed in two Italian cities, Palermo and Rome, where actually work while the server works in Rome. The web application allows to select the single instrument and to show its stored PQ information.
\end{abstract}

Keywords: Power quality, web-based instruments for power quality, power quality instruments, power quality data collection, acquisition card

\section{Introduction}

End-user equipment are increasingly getting affected by poor power quality (PQ) problems; for this reason the analysis of $P Q$ is meeting more and more the interest of the scientific community [1, 2]. Since the matter is complex, it can be faced from many different points of view. Surely, the effects on electrical devices and equipment joined with the lack of quality and the possible solutions to adopt to mitigate these effects are two aspects more and more investigated by researchers, so as the analysis of the causes that can lead to the degradation of the signal also has a big relevance within the scientific community. Each of the different aspects of this matter involve different competencies and skills: from the analysis of the physical laws, up to the study of algorithms to analyse the electrical phenomena that can happen in an electrical network that can lead to PQ phenomena; the study and realization of more accurate 
sensors able to satisfy all the needs of the normative, as well as the study and realization of more accurate input stages of the measurement instruments able to accurately reproduce the signal before its sampling; and the realization of updated hardware that mainly tries to make PQ monitoring simpler and more economical.

The PQ monitoring is a topic largely addressed in technical and scientific literature. The systems proposed differs, especially in the main aim of monitoring, acquisition, conditioning devices and platform used to transmit and store data, as reported in the following. Particular applications can be found in [3] where an industrial Programmable Logic Controller (PLC) on a web-based platform is used for transient detection of microgrid systems and in [4] where frequency fluctuations of high voltage transmission grid are monitored for the individuation of generator tripping. Some systems are designed to reach the maximum stability using commercial systems or PQ analyzers for the data acquisition $[1,5,6,7,13]$, but often this choice reduces the flexibility and increases the costs, especially in the case of a large number of measurement points (MPs).

PQ is defined by some normative terms and CEI EN 50160 [8] describes it with 13 parameters:

1. Power frequency

2. Magnitude of the supply voltage

3. Supply voltage variations

4. Rapid voltage changes

5. Supply voltage dips

6. Short interruptions of the supply voltage

7. Long interruptions of the supply voltage

8. Temporary power frequency overvoltages between live conductors and earth

9. Transient overvoltages between live conductors and earth

10. Supply voltage unbalance

11. Harmonics voltage

12. Interharmonics voltage

13. Mains signalling voltage of the supply voltage

Prompt quantification of these parameters that define the PQ is desirable as soon as a problem occurs $[2,9]$. A quick response on the measurement instrument has the advantage of monitoring in real or almost real time the electric line and allowing, as soon as possible, the activation of all the possible procedures to mitigate the effects of electric energy degradation. An instrument conceived for this aim allows punctual monitoring and control of the line, but it cannot help understand the trend of a possible problem along the electric line. Real-time PQ monitoring geographically spread on the territory could help take some corrective actions in advance. To provide customers such information, both locally and on a nationwide basis, a 
web-based near real-time PQ monitoring system is necessary [1, 9-17]. Some of the needs associated to a PQ monitoring network can be summarized as follows:

1. The increasing problems in electrical distribution system obliges to have monitoring and measurement systems of the overall electrical network [18].

2. Continuous monitoring of the current harmonics is necessary to prevent their typical negative effects such as the premature failure of reactive loads (transformers and capacitors), overheating that can lead to power losses, etc. [18-28].

3. For planning and developing a smart grid, useful data can be derived by continuously checking electrical quantities and power consumption [18].

4. The constant and continuous detection and analysis of PQ parameters can suggest the adoption of new maintenance philosophies to improve the overall efficiency of the mains.

5. For evaluating the performances of an electrical network in a deregulated electric market, the availability of a database related to PQ and reliability indices to electric regulator and customers are necessary.

6. The availability of electrical network performances on a web database will help both the electrical equipment manufacturers to redesign their equipment to meet the PQ needs present in that area and the customers to choose which apparatus buy to avoid premature breakages.

7. The availability of web-based power quality and reliability indices of various utilities will help the customer choose the electric supply and utilities that offer differentiated services for customers that have special requirements [29].

A general architecture for a distributed PQ monitoring foresees a wide network with many instruments distributed on a territory that locally sample the mains (one phase, tri-phases, and tri-phases that are more neutral) expanding the data through a series of specific algorithms to find the PQ parameters. In an architecture so conceived, the instruments should send raw data to a remote server that is able to plot the trend of the PQ parameters and able to synthesize a series of key performance indexes that allow to globally evaluate the electrical network.

A PQ monitoring network has, however, some critical elements that must be considered. First, it is necessary to consider the great number of data to manage. The normative foresees to acquire up to the $40^{\text {th }}$ harmonics of the fundamental; in case of continuous sampling, this leads a great number of samples for second of at least $4 \mathrm{kSamples} / \mathrm{s}$. A more detailed sampling, i.e., a sampling frequency of $25 \mathrm{kSamples} / \mathrm{s}$ (equals to $50 \mathrm{kbyte} / \mathrm{s}, 4,32$ Gbyte per day) is typical [2, 30-34]. To send all these information to a central remote control station could be extremely heavy. To partially solve this problem, it is possible to send to the server only the trace of the signal where the normative limit of the PQ parameter is exceeded. Another problem is the synchronization of the instruments that, for how the architecture is conceived, are distributed in a wide territory. Reference [35] proposes the synchronization of the clock of master and slave devices to permit the plotting of measured values with time. Unfortunately, this technique does not permit great time accuracy, around $10^{-6}$. A better solution is proposed by 
$[2,36,37]$ that uses the timing directly coming from National Time Metrological Institute, but this implies its availability on site. To overcome this last need, other studies try to connect the synchronization to the global positioning system (GPS) both exploiting the actual facility through the 1 Pulse Per Second synchronization signal and developing new synchronization devices able to capture the fundamental frequencies of the GPS [38-40].

The Electric and Electronic Measurement Laboratory at Roma Tre University is engaged with PQ evaluation for 10 years and this chapter wants to show the most recent novelties on PQ instruments previously realized, in particular the web architecture that allows the realization of a web PQ instrument that is geographically widespread. This architecture allows both temporal and spatial PQ analysis.

The proposed system is totally self-made. In this way, great flexibility is guaranteed from the local acquisition system to the web interface for data management, storage, analysis, and visualization.

Our current application is to monitor the quality of the electricity supplied to some central telecommunication. In these stations, the telecommunication equipments use a high-accuracy metrological clock coming from INRiM (Istituto Nazionale di Ricerca Metrologica - the National Italian Metrological Institute). We have developed an ad hoc acquisition card that, using this clock combined with the timestamp received from the GPS, can start the acquisitions with a maximum uncertainty of $244 \mathrm{~ns}$ on the sampling instant (limit due to the clock frequency of $2,048 \mathrm{kHz}$ ).

The data transmission is based on FTP protocol. In this way, by simply sending two files, each MP transmits to a remote server the computed parameters and a sample of recorded waveforms that allow us to apply for a second time a more accurate analysis or some innovative algorithm for scientific purposes.

The use of the web paradigm has the advantage to be totally OS independent: a generic web browser is sufficient to perform all the operations and it allows using the system even on mobile devices. It should be remarked as the proposed system have been designed to be easily upgraded with more performing algorithms or with more functionalities.

In the next section, the MP structure will be presented. In particular, we will describe the acquisition system composed of a self-made acquisition card and a local PC that perform the analysis and create the files to be sent to the server. Section 3 will describe the server architecture and the data management. In Section 4 , the web interface will be presented.

\section{Measurement point structure}

First, we need to describe the instrument for PQ analysis. In each measurement point (MP) localized in a territory, a PQ measurement device is present. As shown in Figure 1, it is composed of: 


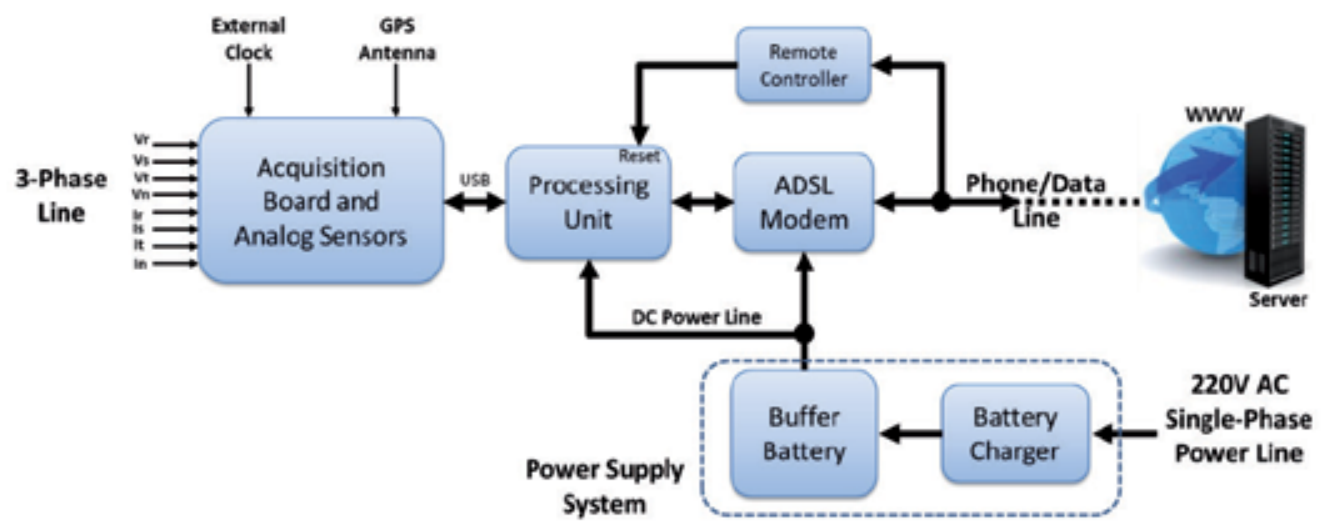

Figure 1. Block scheme of the PQ measurement device.

- A self-made acquisition card (Figure 2) able to sample both voltages and currents of a classical three-phase plus neutral electric line. Key features of this card are:

- A 14-bit, 8-channel simultaneous-sampling analog to digital converter (ADC).

- High-accuracy voltage and current sensors with flat response in the band of interest: the chosen sensors are voltage dividers for the voltages and Rogowski coils for the currents.

- GPS module to synchronize the system with the UTC time coming from satellites. This module also allows getting the timestamp of each acquisition.

- USB interface to transmit acquired data to a processing unit and to power up the acquisition card.

- High stability metrological clock (coming from INRiM, the National Italian Metrological Institute, which provides a $2048 \mathrm{kHz}$ clock signal with a stability of about $10^{-10} \mathrm{~s}$ ) and wired logic for high-accuracy acquisition timing. With this sample rate, it is possible to avoid the use of anti-aliasing filters that could distort the signal and, at the same time, it is possible to respect the maximum frequency of disturbances prescribed by the regulations. Theoretically, with the sampling frequency used by us $(25 \mathrm{kS} / \mathrm{s})$, you can calculate up to more than 200 harmonics of the fundamental, but since the regulation for instrumentation for power quality (CEI EN 61000) refers to the $40^{\text {th }}$ harmonic, we limited the estimation to the latter. Since all the data are stored on the server, it is always possible to increase the number of estimated harmonics. Moreover, with a frequency of $25 \mathrm{kS} / \mathrm{s}$ the minimum frequency specified by the regulations of $12.8 \mathrm{kS} / \mathrm{s}$ is fully respected.

- A power supply system, consisting of a buffer battery and a power supply to charge the battery, guarantees up to 3 days of autonomy in case of mains failure. In this way, it is possible to capture and analyze the trend of the power grid immediately after the return of voltages and to establish the duration of interruption.

- A remote control device is connected to the telephone line (PSTN - Public Switched Telephone Network) that provides basic information about the status of the system. This 
device also allows, in case of problems, to reboot the entire system using commands sent via the telephone keypad.

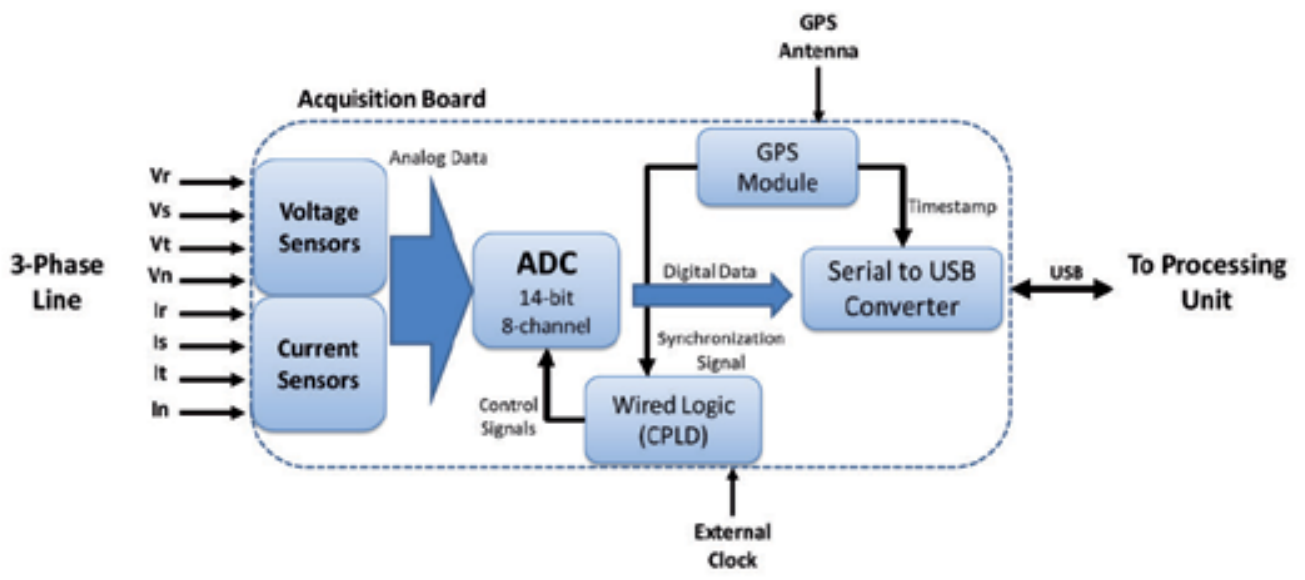

Figure 2. Acquisition board scheme.

- A processing unit (see Figure 3) that receives samples from the acquisition card and processes the acquired data to estimate various parameters (mains frequency, three-phase RMS values, magnitude and phase of each harmonic, etc.). For every acquisition, this unit generates two files, a binary file containing the raw values acquired directly from the ADC and a text file with the estimated parameters. The filename is the UTC timestamp of the acquisition. These files are regularly sent to the central server via an FTP connection but, in case of connection issues, the data is locally recorded and then it is sent as soon as the connection is again available. The processing unit is designed to operate in full autonomy, but, if necessary, the system can be accessed remotely via remote desktop software and then it is possible to check if there are anomalies, perform updates, troubleshoot malfunctions, etc. This remote connection is possible with two scripts, one that locally runs on the processing unit and the other that runs on the central server, they together allow to register the IP address of each MP. The IP address is essential to use the remote desktop software and its registration by the server is required as the measuring points have dynamic IP addresses.

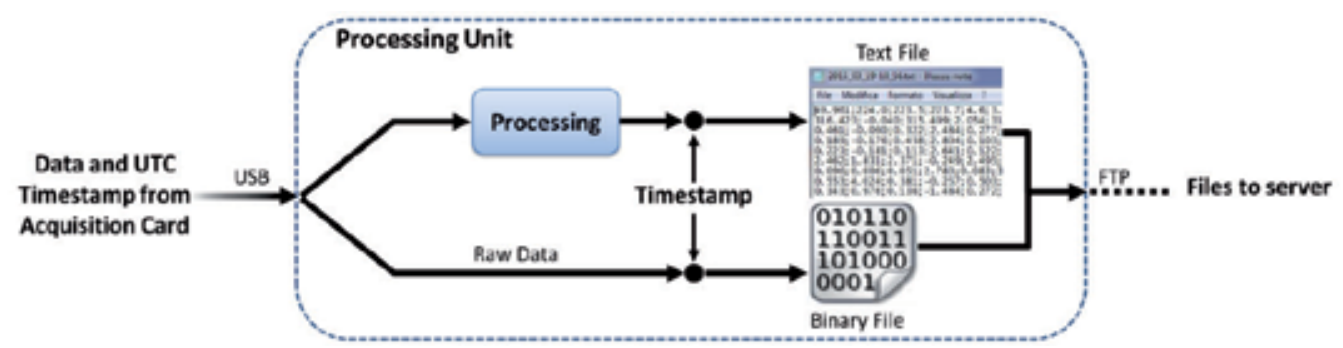

Figure 3. Processing unit functional diagram. 
The processing unit allows to locally analyze the acquired data to perform a parameters estimation and events detection. If an event is detected, the unit saves the recorded waveforms and sends them to the central server. In this way, a remote machine that has higher computing resources will perform an accurate analysis of the specific disturbance or fault. However, the system is characterized by high flexibility and it is possible to balance the computational load between the local and remote machine.

The current local processing scheme is represented in Figure 4.

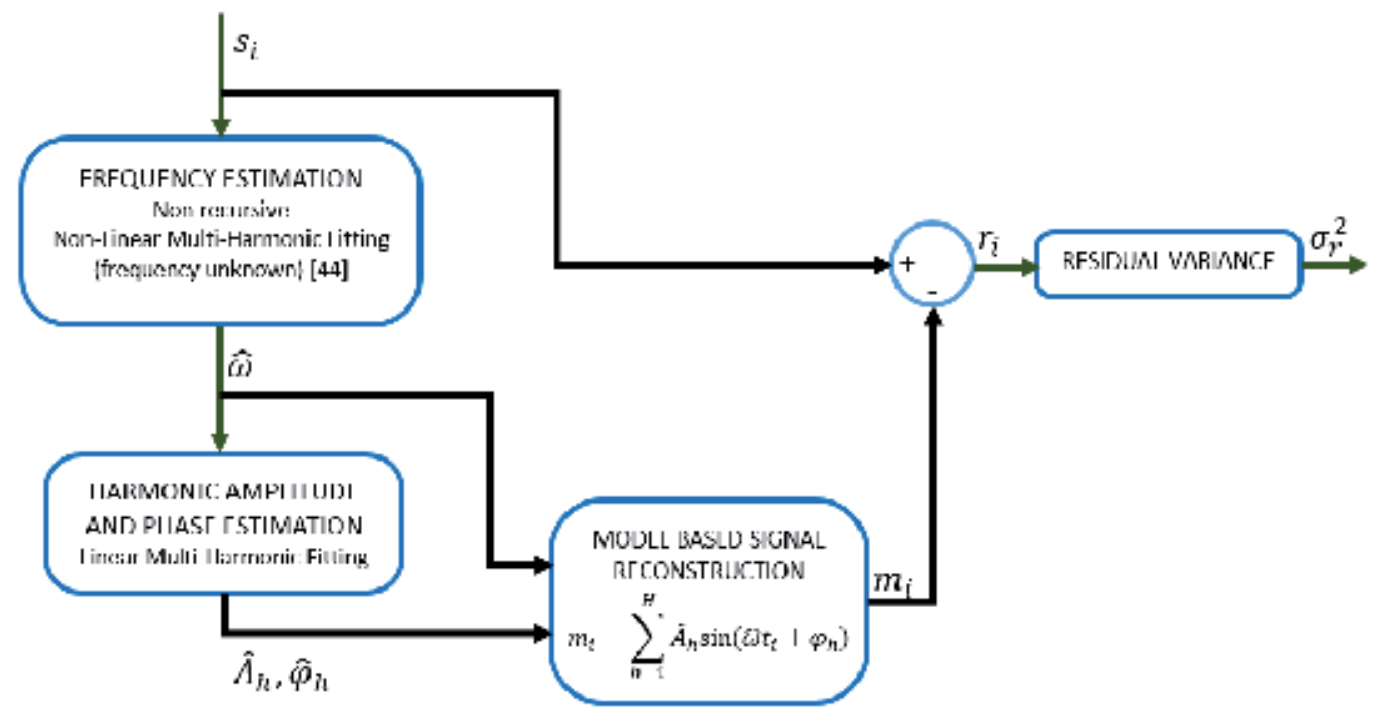

Figure 4. Calculus scheme of the processing unit. Starting from the samples of the signal $s_{i}$, a multi-harmonic least squares algorithm is performed to estimate the frequency $(\hat{\omega})$. Once known, the frequency can compute the amplitudes and phases $\left(\hat{A}_{h}, \hat{\varphi}_{h}\right)$ of the harmonics. Using these parameters it is possible to recostruct a model based signal $\mathrm{m}_{\mathrm{i}}$ and subtract it to the acquired samples. The risudals $\mathrm{r}_{\mathrm{i}}$ should contain the noise and the non-harmonic components. We use the variance $\sigma_{r}^{2}$ of the residual for the detection of the presence of interharmonics and transients. The remote server implements further analysis if $\sigma_{r}^{2}$ is higher of a threshold.

The algorithm used for the estimation of the parameters is the multi-harmonic least squares fitting. Compared with the more largely used methods such as FFT and zero crossing, this method does not require a coherent sampling and it is able to give good estimations also for short observations (few cycle of the fundamental). In the conditions of interest for the power quality analysis, this class of algorithm assures the maximum accuracy possible.

If the frequency is known, this algorithm allows estimating the amplitudes and phases of the harmonics and simply solving a linear system. This approach requires estimating the frequency in advance using some other algorithm. If the frequency is unknown, the algorithm becomes more complex and requires a recursive method. In [44] a non-recursive approach that is very useful for power quality applications was presented. This approach strongly reduces the computational load of the non-linear, multi-harmonic least square fitting, preserving at the same time its accuracy. As shown in Figure 4, in our system the method [44] has been used for 
the accurate estimation of the grid frequency. The estimated frequency is used in a second step to estimate the harmonic parameters using the linear multi-harmonic least squares. As indicator for the presence of some non-harmonic disturbances (interharmonic, subharmonic, transients, etc.), the software calculates the variance of the residuals defined as the difference between the acquired samples and the model-based reconstructed signal. If the variance is over a selected threshold determined on the basis of the SNR (signal to noise ratio) of the acquisition card the associated record will be analysed with more detail for a second time by a remote machine. The algorithms running on the remote machine can be updated in relation to the applications.

\section{Server}

The server is a LAMP (Linux - Apache - MySQL - PHP) machine (Figure 5). It is also an FTP server to allow receiving files from the MPs. The server has a modular structure; each measuring device used has a folder (with its subfolders "bin" for binary files and "txt" for text files) where it sends files. So if a monitoring point is added, a folder (and its subfolders) will be added to the server directories.

At regular and predetermined intervals, the server runs PHP scripts that acquire the parameters contained in text files and put them in the database (DB). In addition, the database is modular, so if you add a physical monitoring point you need to add a table in the DB. Each point has its own table containing all the parameters calculated.

The web server allows having a website accessible from any Internet connection. This website allows the temporal and spatial analysis of the values acquired by the monitoring system and gets information from both the DB and the binary files stored.

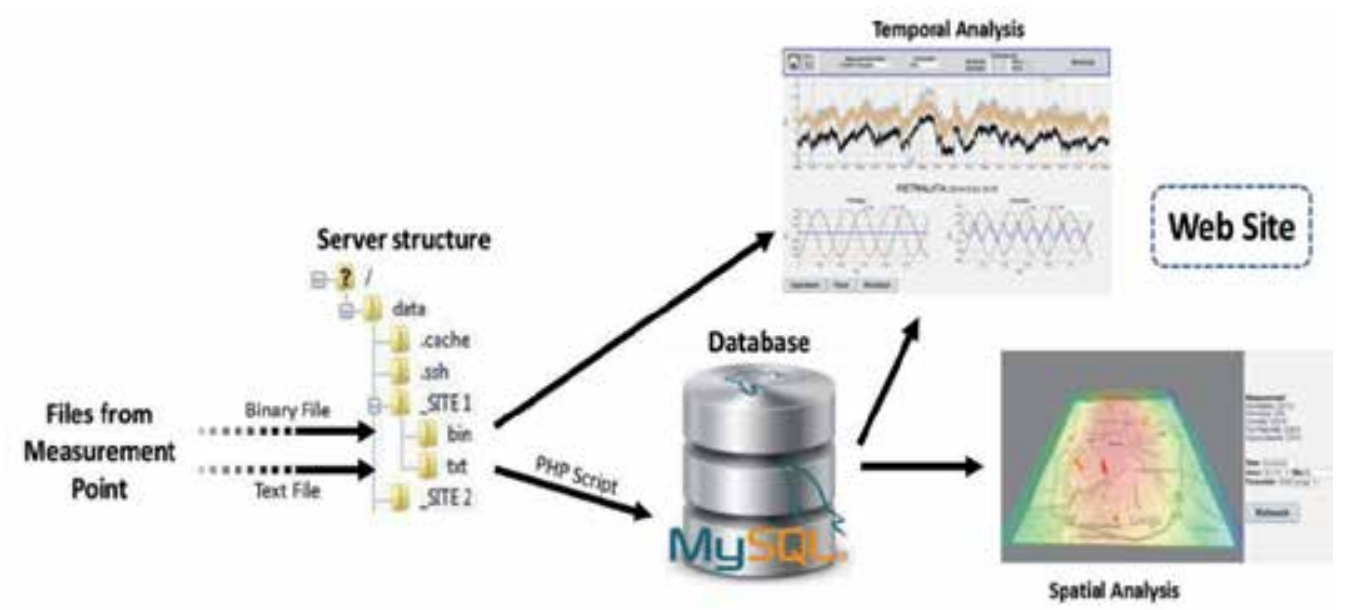

Figure 5. Structure of the server machine. 


\section{Web interface}

In this paragraph, the web user interface will be presented, highlighting data access and visualization. Exploiting a classical client-server architecture, it is possible to visualize the data using the common web browsers available for all the principal operative systems. In this way, the system has the advantage to be platform independent. At the moment, the developed web pages are the following:

- The page to visualize the temporal evolution of the calculated parameters in a selectable range of time. Each point of the graph referred to a precise timestamp is clickable allowing the visualization of the voltages and currents waveforms recorded at that timestamp;

- A page with the spectrum of the signal to analyse the harmonic content of voltages and currents;

- A dashboard for three-phase analysis with the graphical representations of the voltages and currents phasors;

- A dashboard for signal analysis to detect particular events that may be occurred;

- A page to visualize the spatial distribution between the different MPs at a precise timestamp.

The different pages are linked to each other to facilitate the analysis.

To plot the temporal data and the waveforms in the web pages the "dygraphs.js" javascript library [41] has been used. This library allows plotting time records passing a structured text dataset. The library "D3.js" [42] has been used to draw the polar plots. To draw the 3D surface in the spatial interpolation page, the javascript library "three.js" [43] has been exploited. In the following sections, the four pages will be presented and described.

\subsection{Temporal analysis web page}

This is the main page of the web site. The principal aim of this page is to visualize a temporal evolution of one of the measured parameters and to display the waveforms recorded in a given timestamp. A screenshot of this page is shown in Figure 6.

The control bar on the top of the page allows the user to select the desired MP, the parameter, and the time interval to analyse. The time interval of interest can be chosen by selecting the initial and final timestamps. Clicking the "Refresh" button, the web page performs an AJAX request to the server containing the selected choices. A specific PHP script builds the query to the SQL database on the server, eventually performs a calculation (as in the case of the powers), and finally sends back to the client the required data. After the reception, the web page displays the temporal evolution in a graph.

The quantities that can be shown are:

- Frequency;

- RMS values for voltages and currents; 


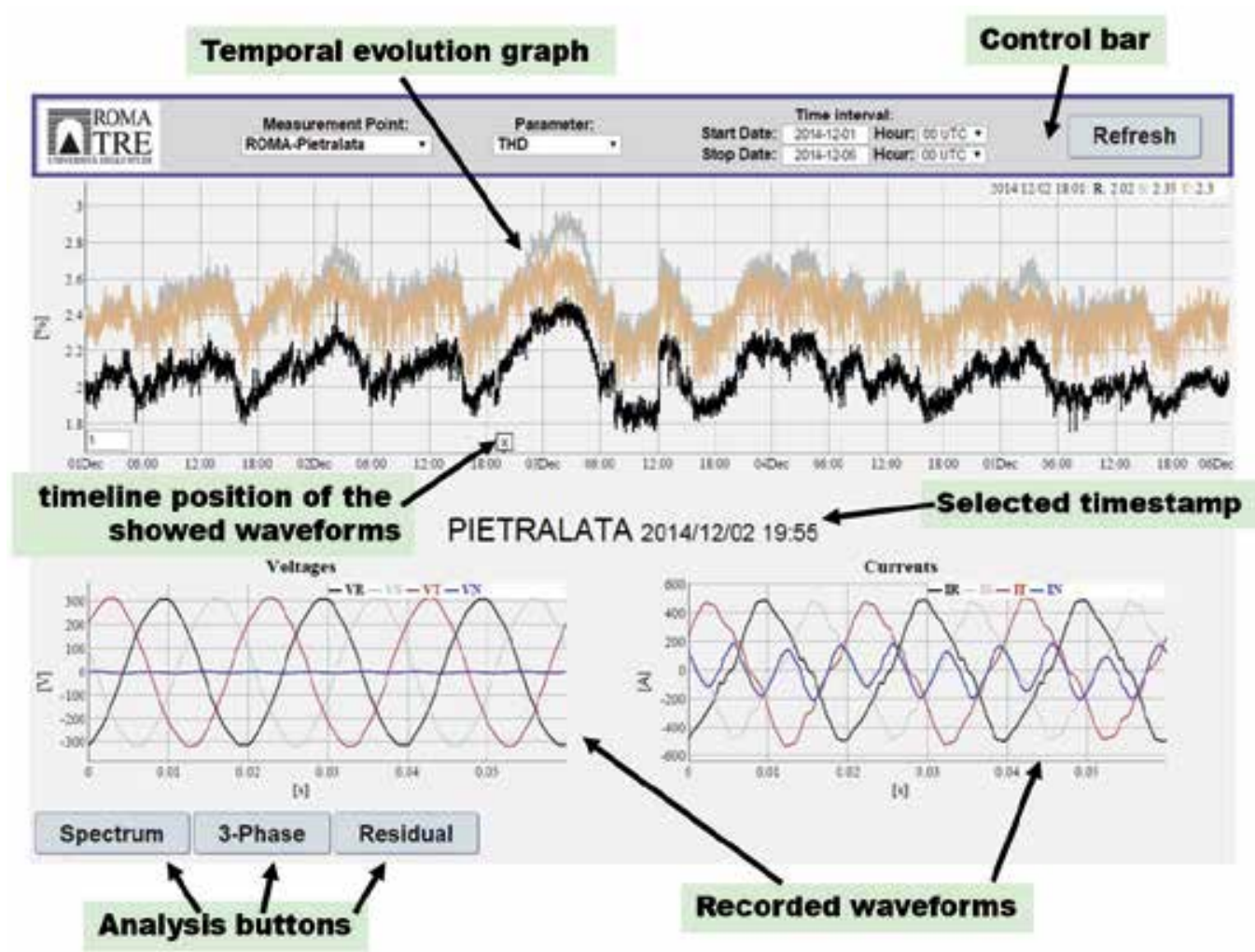

Figure 6. The figure shows the main page of the web site. The control bar on the top allows the selection of the measurement point, the parameter, and the time range to visualize on the graph. In the screenshot the time evolution of THD from $1^{\text {st }}$ to $6^{\text {th }}$ of December 2014 is displayed. Right-clicking on a point of the graph will show the voltage and current waveforms recorded in the timestamp related to the clicked point. A series of buttons allow accessing additional analysis windows.

- Harmonics up to $25^{\text {th }}$ for voltages and currents;

- Total harmonic distorsion (THD), calculated using 50 harmonics;

- Signal to noise ratio (SNR);

- Total active and reactive power and harmonic powers.

The temporal evolution highlights both short-term and long-term periodicity of the phenomena. In some cases, an anomalous behaviour can be detected simply by the presence of spikes of evident deviations of some parameters from the normal range of variation.

Another important function of this page is the possibility to display the recorded waveforms of a given timestamp simply right-clicking the related point of the graph. Under the temporal plot will appear two graphs, the one on the left containing the voltage waveforms and one on the right containing the current waveforms. After clicking, some buttons will appear at the bottom. Through these buttons, it is possible to open different windows, which allow to perform further analysis and give additional information. 


\subsection{Harmonic spectrum window}

By clicking the "Spectrum" button at the bottom of the Temporal Analysis page, a new window opens. This window shows two bar plots representing the harmonic compositions of both voltages and currents for the selected MP at a specified timestamp. Figure 7 shows the appearance of the window. Each harmonic bar contains three sub-bars indicating the harmonic level measured for each phase.

\subsection{Three-phase analysis window}

The "3-Phase" button on the main page (Figure 6) opens in a new window, a page for the threephase analysis similar to the one shown in Figure 8. The situation is referred at the same MP and at the same timestamp currently displayed on the main page.

\section{PIETRALATA 2014-12-02 19:55}

Voltages Harmonic Spectrum

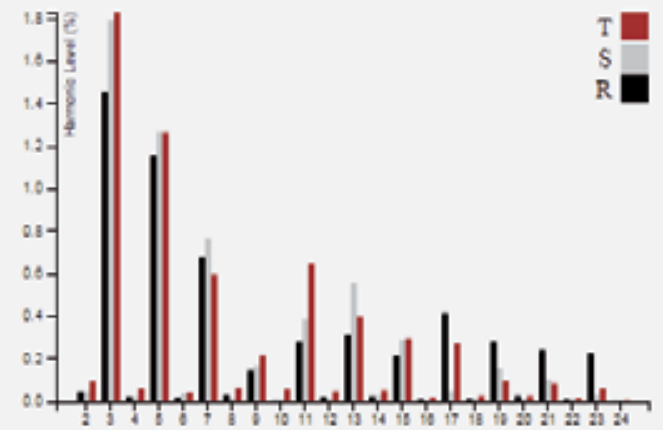

Currents Harmonic Spectrum

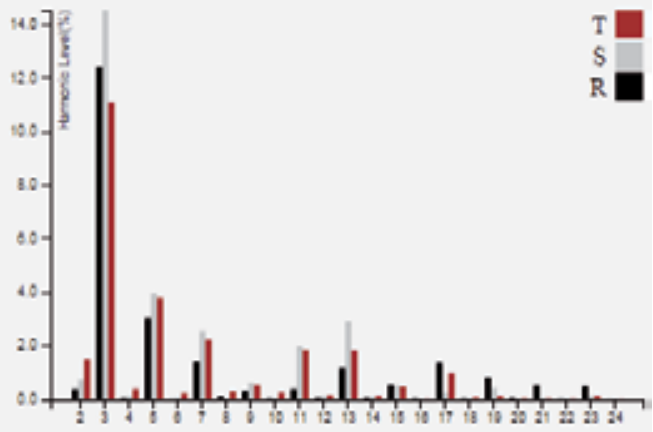

Figure 7. The figure shows the window that displays the harmonic spectrum of voltages (left bar plot) and currents (right bar plot). For each harmonic, 3 bars are represented, one for each phase.

The window is composed of four polar plots, two for the voltages (on the right side) and two for the currents (on the left side). The plots on the top show the R-S-T phasors for a specific harmonic component selectable by the dedicated control present on the control bar. The two plots at the bottom display the symmetric component (positive, negative, and zero sequences) obtained by Fortescue's transformation of the R-S-T phasors. This information allows checking the symmetry and the balancing of the three-phase system. The power factor (and then the nature of the load) is immediately visible, observing the tilt of the positive component (red vector) of the current because its phase angle is calculated with respect to the voltages positive sequence.

\subsection{Residual analysis window}

The "Residual" button on the main page (Figure 6) opens the window similar to the one in Figure 9. This page allows a residual analysis of the voltages useful for the detection of non- 


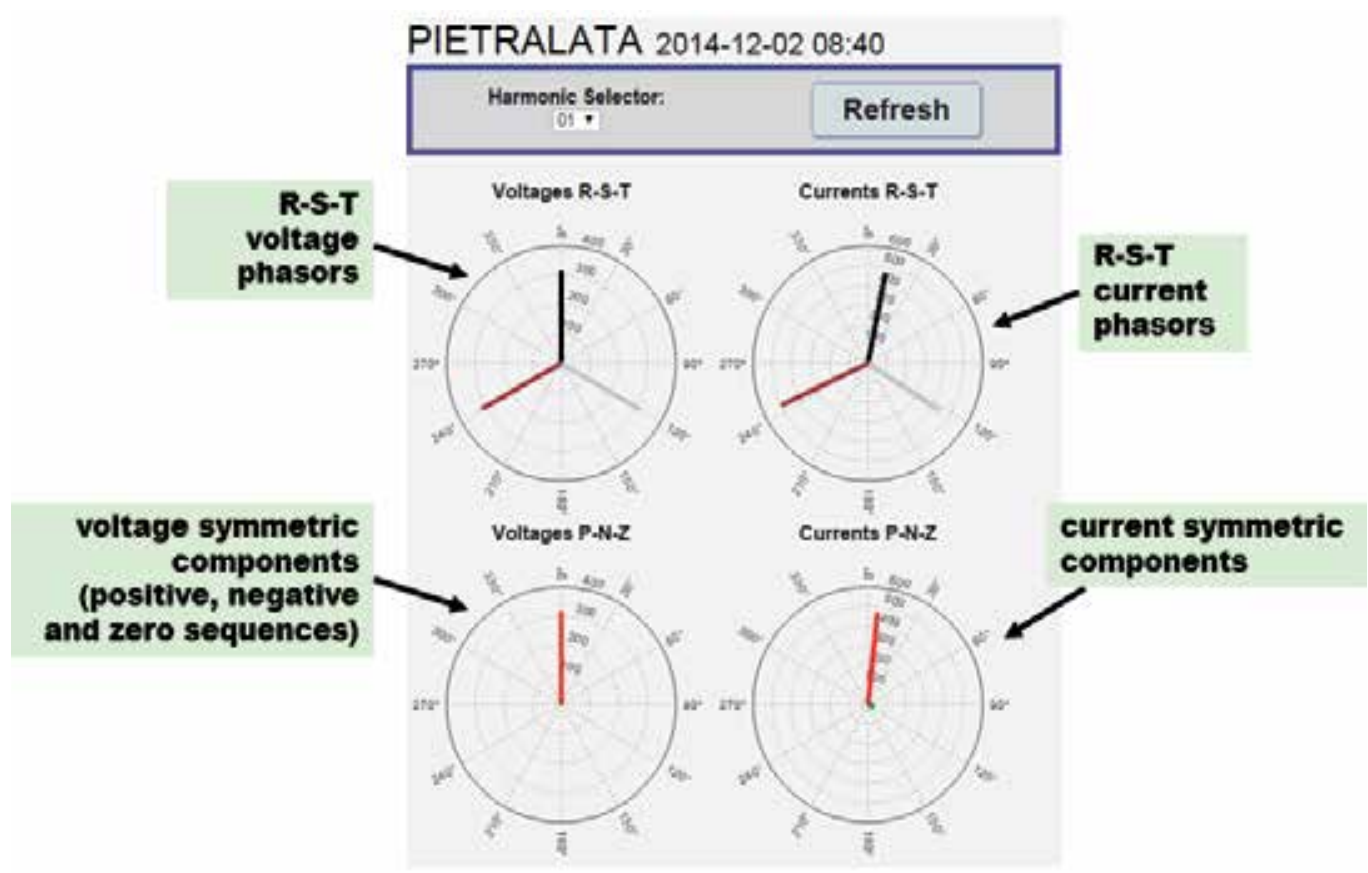

Figure 8. The figure shows the three-phase dashboard accessible through the main panel (Figure 5). The bar at the top of the window allows the selection of the harmonic order to view. The polar plots on the top represent the phasors of voltages (left) and current (right). The two polar plots on the bottom represent the symmetric components, positive (red), negative (green), and zero (blue) sequences. In this example is shown the fundamental ( $1^{\text {st }}$ harmonic). The negative and zero sequences are very small and not visible.

harmonic disturbances. Calling the page, a non-recursive multiharmonic fitting [44, 45] is performed to estimate the fundamental and the harmonic components. The residual is obtained by subtracting the estimated waveform to the measured data record. In this way, the fitting residual retains the noise and all the non-harmonic components eventually present on the voltage. The least squares multiharmonic fitting is an algorithm that allows to estimate the parameters of a periodic signal overcoming the well-known problem afflicting the Fourier Transform based algorithms (leakage and picket fence).

The histogram of the residuals is useful in knowing residual distribution. In the case of quasiGaussian distribution, the performed least squares fitting assures the best accuracy in the estimation of the signal frequency and the harmonic levels [44].

The principal non-harmonic disturbances that may affect the electric signal are sub-harmonics, inter-harmonics, flickers, and transients [2, 8, 9, 11, 21-26, 30, 32, 36, 46, 47].

In Figure 10, two representative cases are shown. The top graph highlights the presence of an interharmonic (about $670 \mathrm{~Hz}$ ) and the histogram shows a bimodal distribution typical of a sinusoidal component. In the situation represented at the bottom, the residual shows the presence of a fast transient probably due to a mechanical switching action. The bouncing effect is also visible. 


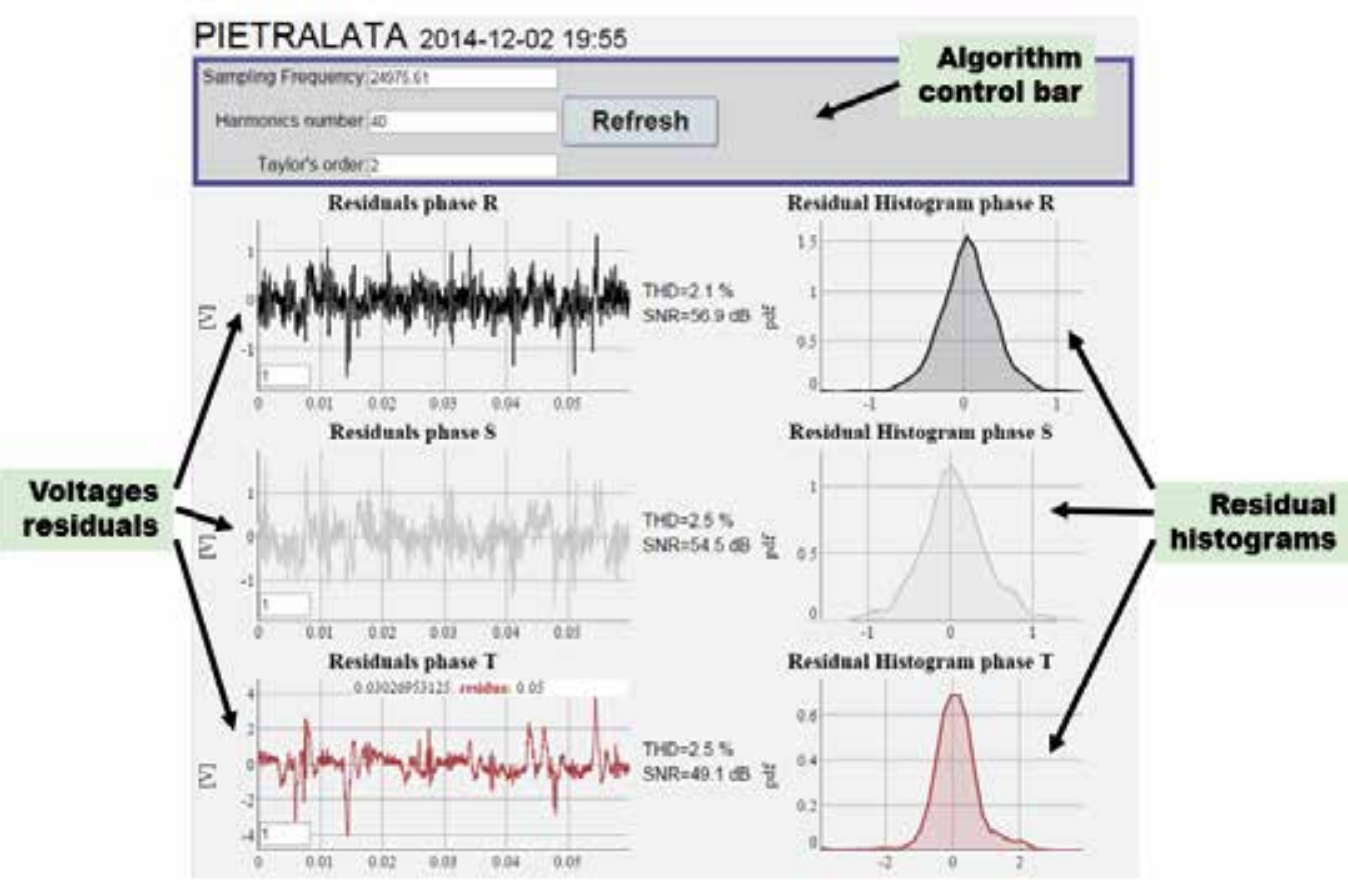

Figure 9. This figure shows the dashboard for the residual analysis. The residual is calculated as the difference between the data record and the estimated signal by multiharmonic least squares fitting. The residuals are composed of the noise and the non-harmonic components. So, the presence of some particular disturbances can be detected. On the right, the histogram of the residuals is also shown.
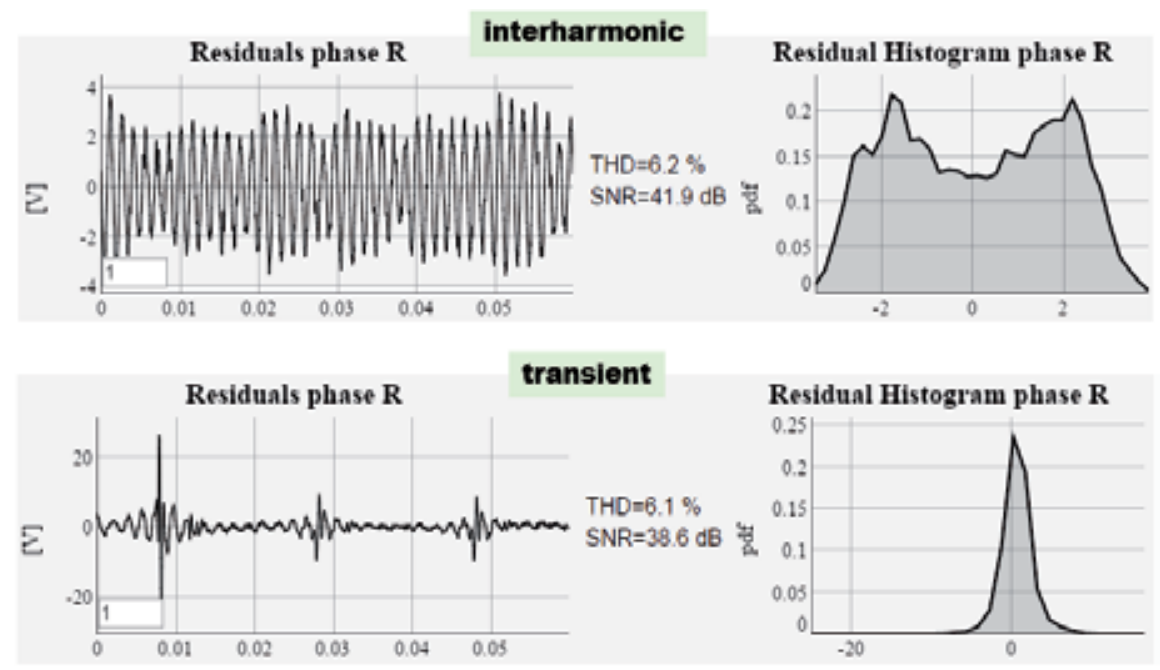

Figure 10. This figure shows two interesting cases of residuals highlighting the presences of non-harmonic disturbances. The top graph reports a real case of interharmonic of a frequency near $670 \mathrm{~Hz}$. The bottom displays a fast transient caused by a mechanical switching action. 


\subsection{Spatial analysis page}

In some cases, it can be useful to view the spatial distribution of a certain parameter at a certain timestamp. For this purpose, a dedicated web page has been developed. An example of this page is shown in Figure 11, in which is displayed the RMS measurements obtained in the city of Rome at 6:54 am on the $8^{\text {th }}$ of August, 2014. This window shows a city map on which a set of cylinders are positioned on the location of the active MPs of that city. The height of each cylinder is related to the measured value. An interpolation surface is also shown with the purpose of giving indicative information about the spatial distribution of the parameters. The geographical interface allows the individuation of local problems and eventually the propagation of large disturbances on a wide area. This tool will become more useful if the number of MPs is increased, so performing a denser spatial sampling.

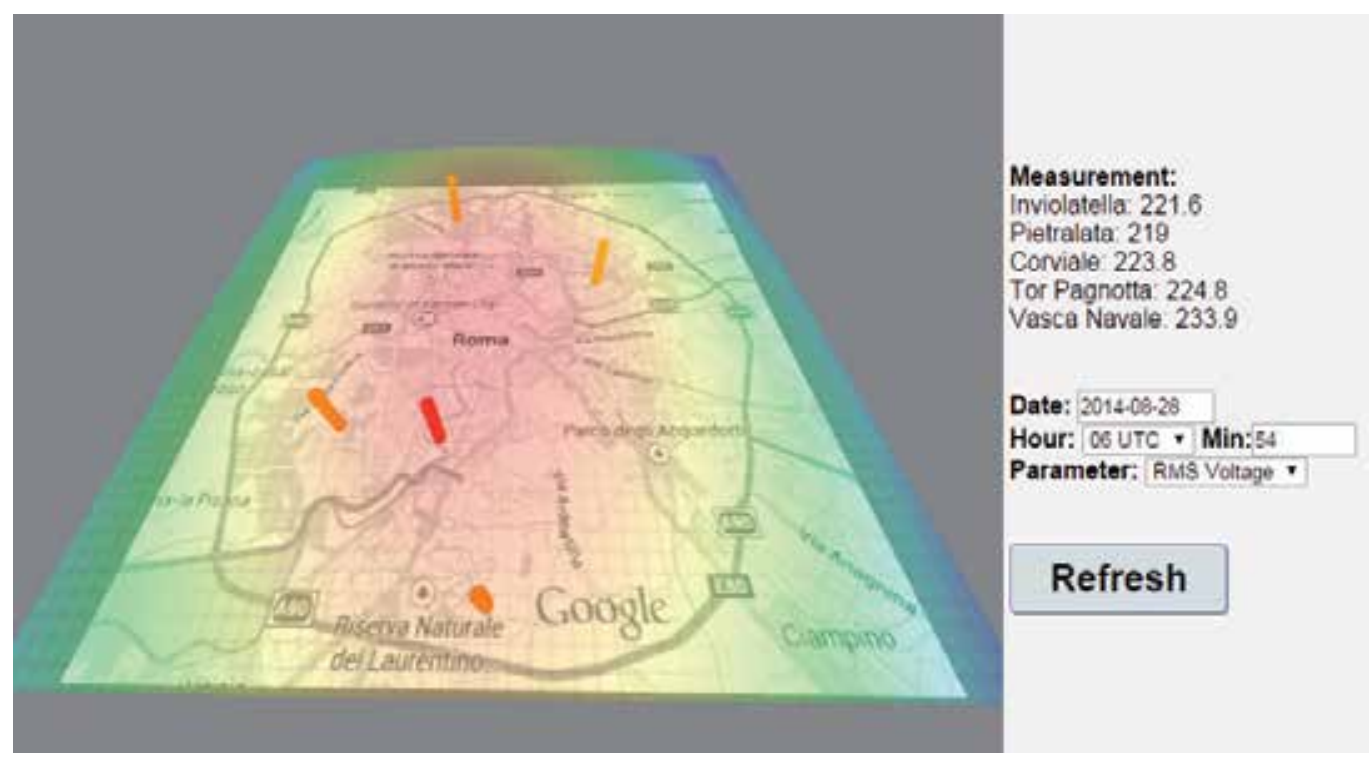

Figure 11. A dedicated page of the website allows a spatial analysis showing a 3D city map where the positions of cylinders indicate the active MPs for a specific timestamp. The height of the cylinders is proportional to the value of a recorded parameter (selectable by the form on the right). An interpolation surface is also calculated and shown. The parameter shown in this figure is the RMS of voltage.

\section{Conclusions}

The trend of the recent years highlights the importance of PQ monitoring for understanding both local and global phenomena. The former calls for an approach to induce the development of specific instrumentation with the aim of recording a series of parameters useful in solving a specific problem in a specific point of the network and to prevent damages or malfunctions in sensible devices. The latter calls for an approach that is useful in understanding the dynamics 
of the mains viewed as a largely interconnected network. In the new generation of monitoring systems, these two aspects have to coexist as useful tools to control and manage the mains especially with the large diffusion of distributed micro generation and the coming of smart grids.

In this chapter, it has been presented that the monitoring system developed in the Electric and Electronic Measurement Laboratory of Roma Tre University was built with the aim to have a monitoring system that is able to analyse the PQ both in time and space. The platform has been developed as modular as possible, not only to allow extending the monitoring network but also to add new innovative analysis tools that could be introduced in the next years. Another important aspect is the data collection. For scientific purposes, the system calculates the PQ parameters and stores the data in a database, while sampled waveforms are stored in a dedicated server. In this way, a large real data set is available as bench tests for further analysis that will be proposed in the future.

\section{Author details}

Stefano Di Pasquale, Sabino Giarnetti, Fabio Leccese, Daniele Trinca, Marco Cagnetti and Maurizio Caciotta

Electrical and Electronics Measurement Laboratory, Department of Science, Roma Tre University, Rome, Italy

\section{References}

[1] Kushare BE, Ghatol AA, Kala S. Development of web based power quality monitoring system for handling user custom power quality query and auto power quality monitoring report notification via email. In: Proceedings of IET-UK International Conference on Information and Communication Technology in Electrical Sciences (ICTES 2007); 20-22 December 2007; Chennai, Tamil Nadu, India.

[2] Caciotta M, Leccese F, Trifirò T. From power quality to perceived power quality. In: Proceedings of The IASTED International Conference on Energy and Power Systems (EPS 2006); 29-31 March 2006; Chiang Mai, Thailand, p. 94-102. ISBN CD: 0-88986-586-8.

[3] Wang L, Chang JH. A web-based real-time monitoring and control system for laboratory Microgrid systems: Part II - Transient analysis. Power and Energy Society General Meeting; 2010 IEEE; p. 1, 7; 25-29 July 2010.

[4] Demirci T, Kalaycioglu A, Kucuk D, Salor O, Guderl M, Pakhuylu S, Atalik T, Inan T, Cadirci I, Akkaya Y, Bilgen S, Ermis M. Nationwide real-time monitoring system for 
electrical quantities and power quality of the electricity transmission system. Generation, Transmission \& Distribution, IET; vol. 5; no. 5; p. 540,550, May 2011.

[5] Tsai SJS, Luo CC. Synchronized power-quality measurement network with LAMP. IEEE Transactions on Power Delivery; vol. 24; no. 1; p. 484, 485; January 2009.

[6] Eissa MM, Elmesalawy MM, Hadhoud M. Wide area monitoring system based on the third generation universal mobile telecommunication system (UMTS) for event identification. International Journal of Electrical Power \& Energy Systems; vol. 69; July 2015; p. 34-47; ISSN 0142-0615.

[7] Music M, Bosovic A, Hasanspahic N, Avdakovic S, Becirovic E. Integrated power quality monitoring systems in smart distribution grids. Energy Conference and Exhibition (ENERGYCON) 2012 IEEE International; p. 501, 506; 9-12 September 2012.

[8] EN 50160 (CEI 110-22) Voltages Characteristics of electricity supplied by public distribution systems edited by CEI (Comitato Elettrotecnico Italiano).

[9] Leccese F. Analysis of power quality data on some telecommunication sites in Rome. In: Proceedings of The Eight IASTED International Conference on Power and Energy Systems (EuroPES 2008), 23-25 June 2008; Corfù, Greece. p. 62-67, ISBN CD: 978-0-88986-729-1.

[10] Yingkayun K, Premrudeepreechacharn S. A power quality monitoring system via the ethernet network based on the embedded system, electrical generation and distribution systems and power quality disturbances. Shangai, China: InTech; 2011.

[11] Smith JC, et al.. IEEE Recommended Practice for Monitoring Electric Power Quality. IEEE, USA, 1995.

[12] Zhu C, Hu M, Wu Z, Dou X, Zhao S. Design and realization of regional power quality monitoring system. In: Proceedings of The Third International Conference on Electric Utility Deregulation and Restructuring and Power Technologies (DRPT2008); 6-9 April 2008; Nanjing, China.

[13] Zhang M, Li K. A power quality monitoring system over the internet. In: Proceedings of The 1st International Conference on Information Science and Engineering (ICISE2009); 26-28 December 2009; Nanjing, China.

[14] Meyer J, Kilter J, Howe B, Zavoda F, Tenti L, Romero Gordon JM, Milanovi JV. Contemporary and future aspects of cost effective power quality monitoring - Position Paper of CIGRE WG C4.112, IEEE, 2012.

[15] Kilter J, Meyer J, Howe B, Zavoda F, Tenti L, Milanovic JV, Bollen M, Ribeiro PF, Doyle P, Romero Gordon JM. Current practice and future challenges for power quality monitoring - ClGRE WO C4.112 Perspective, IEEE, 2012.

[16] Romero Gordon JM, Meyer J, Schegner P. Design aspects for large pq monitoring systems in future smart grids. In: Proceedings of Power and Energy Society General 
Meeting 2011; 24-29 July 2011; Detroit, Michigan, USA. p. 1-8. DOI: 10.1109/PES. 2011.6039296.

[17] Leccese F. Electrical energy measurements for rome lv customers by distributed webserver instruments. In: Proceedings of $8^{\text {th }}$ EEEIC International Conference on Environment and Electrical Engineering 2009; 10-13 May 2009; Wroclaw, Poland. ISBN: 978-3-940471-10-9.

[18] Lee RPK, Lai LL, Tse N. A web based with multi-channel power quality monitoring system for a large network, power system management and control. In: Proceedings of Power System Management and Control, IEE Conference Publication on, no. 482; 17-19 April 2002; London, UK.

[19] Leccese F. Subharmonics Determination method based on binary successive approximation feed forward artificial neural network: A preliminary study. In: Proceedings of $9^{\text {th }}$ International Conference on Environment and Electrical Engineering (IEEE sponsored); May 16-19 2010; Prague, Czech Republic. ISBN: 978-1-4244-5371-9.

[20] Leccese F: Subharmonics determination method based on binary successive approximation feed forward artificial neural network: A first improvement. Przeglad Elektrotechniczny (Electrical Review) - Oldest magazine of Polish electrician. 2010, R.86 NR 11a/2010, p. 18-22. ISSN: 0033-2097.

[21] Fuchs EF. Power quality in power systems and electric machines, ECEN 5787 Course Notes, Department of Electrical and Computer Engineering. University of Colorado at Boulder, Fall 2005.

[22] Fuchs EF, Roesler DJ, Masoum MAS. Are harmonic recommendations according to IEEE and IEC too restrictive? IEEE Transactions on Power Delivery. vol. 19, no. 4, October 2004, p. 1775-1786.

[23] Fuchs EF, Roesler DJ, Alashhab FS. Sensitivity of electrical appliances to harmonics and fractional harmonics of the power system's voltage, part I. IEEE Transactions on Power Delivery. April 1987, vol. TPWRD-2, no. 2, p. 437-444.

[24] Fuchs EF, Roesler DJ, Kovacs KP. Sensitivity of electrical appliances to harmonics and fractional harmonics of the power system's voltage, part II. IEEE Transactions on Power Delivery. April 1987, vol. TPWRD-2, no. 2, p. 445-453.

[25] Fuller JF, Fuchs EF, Roesler DJ. Influence of harmonics on power system distribution protection, IEEE Transactions on Power Delivery. April 1988, vol. TPWRD-3, no. 2, p. 546-554.

[26] Fuchs EF, Masoum MAS. Power quality in power systems and electric machines. Elsevier; 2008. ISBN: 978-0-12-369536-9.

[27] Barros J, de Apraiz M, Diego RI. Measurement of subharmonics in power voltages. In: Proceedings of Power Tech 2007; 1-7 July 2007; Lausanne, Switzerland; 2007. 
[28] de Abreu JPG, Emanuel AE. The need to limit subharmonic injection. In: Proceedings of the $9^{\text {th }}$ International Conference on Harmonics and Quality of Power, vol. I; 1-4 October 2000; Orlando, Florida, USA; p. 251-253.

[29] Brooks DL, Dugan RC, Waclawiak M, Sundaram A. Indices for assessing utility distribution system RMS variation performance. IEEE transactions on power delivery. 1998; vol. 13, no.1, pp 245-259.

[30] Leccese F. Rome, a first example of Perceived Power Quality of electrical energy: The telecommunication point of view. In: Proceedings of International Telecommunications Energy Conference (INTELEC 2007); September 30-October 4 2007; Rome, Italy, DOI: 10.1109/INTLEC.2007.4448800.

[31] Leccese F. The perceived power quality way as new frontiers of relationship between customers and producers. In: Proceedings of $7^{\text {th }}$ EEEIC International Workshop on Environment and Electrical Engineering; 5-11 May 2008, Wroclaw-Cottbus, Poland. p. 55-58. ISBN: 978-3-940471-07-9.

[32] Caciotta M, Giarnetti S, Lattanzi Cinquegrani G, Leccese F, Trinca D. Development and characterization of a multi-platform data acquisition system for power quality metrological certification. In: Proceedings of International Conference on Renewable Energies and Power Quality (ICREPQ'11); 13-15 April 2011; Las Palmas de Gran Canaria, Spain. ISBN: 978-84-614-7527-8.

[33] Caciotta M, Giarnetti S, Leccese F, Trinca D. Development of an USB data acquisition system for power quality and smart metering applications. In: Proceedings of $11^{\text {th }} \mathrm{In}$ ternational Conference on Environment and Electrical Engineering (EEEIC2012); 18-25 May 2012; Venice, Italy. ISBN: 978-1-4577-1828-1.

[34] Caciotta M, Giarnetti S, Leccese F, Pedruzzi E. Curve fitting algorithm fpga implementation. In: Proceedings of $10^{\text {th }}$ International Conference on Environment and Electrical Engineering (EEEIC2011); 8-11 May 2011; Rome, Italy. ISBN: 978-1-4244-8781-3.

[35] Cristaldi L, Ferrero A, Salicone S. A distributed system for electric power quality measurement. IEEE Transactions on Instrumentation and Measurements. 2002; vol. 51, no. 4, p. 776-781. DOI: 10.1109/TIM.2002.803300.

[36] Caciotta M, Leccese F, Trifirò T. Curve-fitting-algorithm (CFA) as power quality basic algorithm. In: Proceedings of XVIII IMEKO WORLD CONGRESS, Metrology for a Sustainable Development September; 17-22 September 2006; Rio de Janeiro, Brazil.

[37] Caciotta M, Leccese F, Giarnetti S, Di Pasquale S. Geographical monitoring of Electrical Energy Quality determination: the problems of the sensors. In: Proceedings of 2013 Seventh International Conference on Sensing Technology (ICST 2013); 3-5 December 2013; Wellington, New Zealand.

[38] Caciotta M, Leccese F, Piuzzi E. Study of a new gps-carriers based time reference with high instantaneous accuracy. In: Proceedings of International Conference on 
Electronic Measurement \& Instruments (ICEMI'2007); 16-18 August 2007; Xi'An, China. Vol.I, p. 1-4.

[39] Caciotta M, Leccese F, Pisa S, Piuzzi E. A voltage controlled oscillator for obtaining a frequency reference constantly locked to L1 GPS carrier for Power Quality assessment applications." In: Proceedings of $16^{\text {th }}$ IMEKO TC4 Symposium Exploring New Frontiers of Instrumentation and Methods for Electrical and Electronic Measurements; 22-24 September 2008; Florence, Italy. ISBN CD: 978-88-903149-3-3.

[40] Caciotta M, Di Liberto A, Leccese F, Pisa S, Piuzzi E. A system for obtaining a frequency reference constantly locked to 11 gps carrier for distributed power quality assessment. In: Proceedings of International Conference on Electronic Measurement \& Instruments (ICEMI'2009); 16-18 August 2009; Beijing, China, ISBN: 978-1-4244-3864-8/09.

[41] Vanderkam D, et. al. Dygraphs. Available on: http://dygraphs.com/ [Accessed: 2015-03-22].

[42] Bostock M, et. al. D3 Data Driven Documents. Available on: http://d3js.org/ [Accessed: 2015-03-22].

[43] Cabello R, et. al. Three.js. Available on: http://threejs.org/ [Accessed: 2015-03-22].

[44] Giarnetti S, Leccese F, Caciotta M. Non recursive multi-harmonic least squares fitting for grid frequency estimation. Measurement. 2015; vol. 66, p. 229-237. ISSN: 0263-2241. http://dx.doi.org/10.1016/j.measurement.2015.02.021.

[45] Ramos PM, Janeiro FM, Radil T. On the use of multi-harmonic least-squares fitting for THD estimation in power quality analysis. Metrology and Measurement Systems. 2012; vol. 19, issue 2, p. 295-306. ISSN (Print): 0860-8229, DOI: 10.2478/ v10178-012-0025-8.

[46] Leccese F. Rome: A first example of perceived power quality of electrical energy. In: Proceedings of The Seventh IASTED International Conference on Power and Energy Systems (EuroPES 2007); 29-31 August 2007; Palma de Mallorca, Spain. p. 169-176.

[47] Leccese F. A first analysis of Perceived Power Quality for domestic customers. In: Proceedings of $12^{\text {th }}$ IMEKO TC1 \& TC7 Joint Symposium on Man Science \& Measurement; 3-5 September 2008; Annecy, France. ISBN: 2-9516453-8-4. 




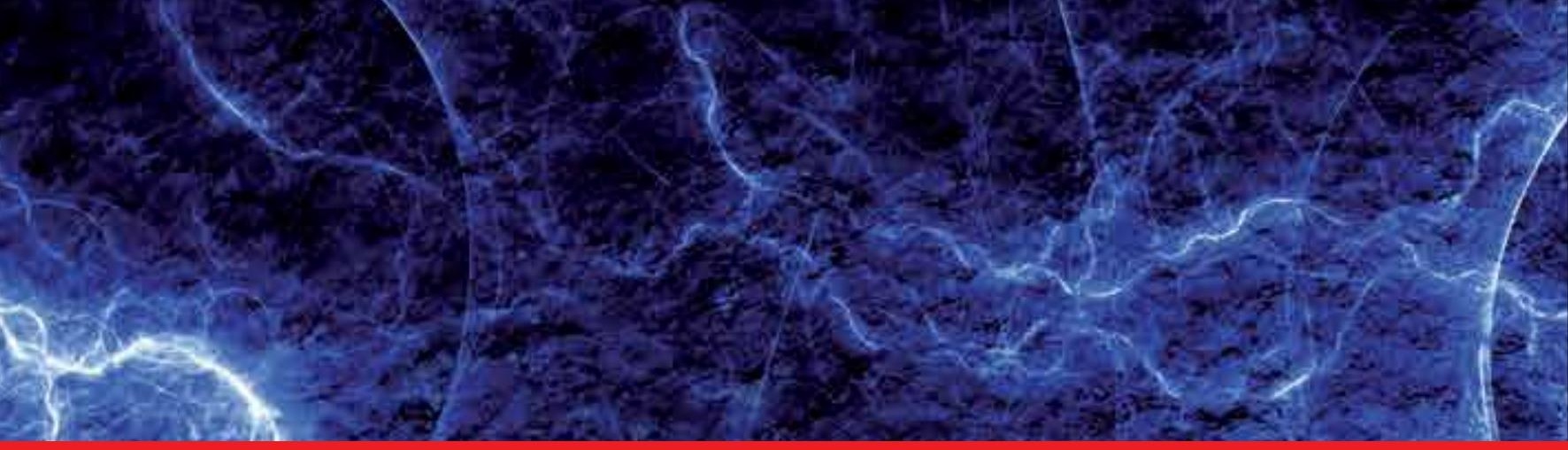

\section{Edited by Jaroslaw Luszcz}

This book deals with several selected aspects of electric power quality issues typically faced during grid integration processes of contemporary renewable energy sources. In subsequent chapters of this book the reader will be familiarized with the issues related

to voltage and current harmonics and inter-harmonics generation and elimination,

harmonic emission of switch-mode rectifiers, reactive power flow control in power system with non-linear loads, modeling and simulation of power quality issues in power grid, advanced algorithms used for estimating harmonic components, and new methods of measurement and analysis of real time accessible power quality related data.

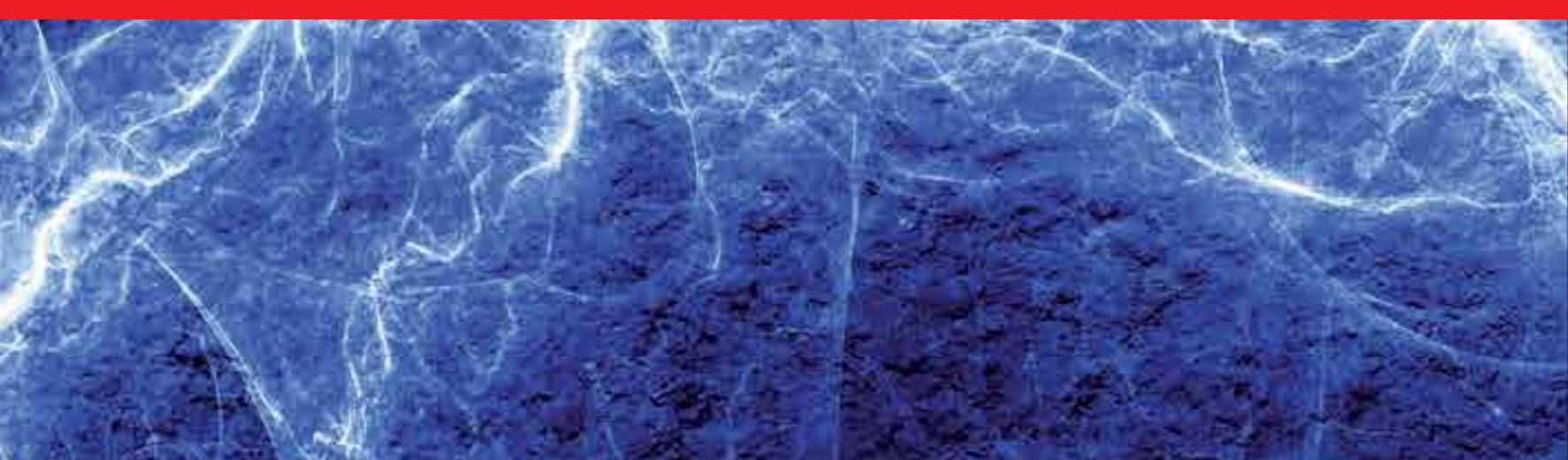

